University of Massachusetts Amherst

ScholarWorks@UMass Amherst

November 2015

\title{
New Wenzhou: Migration, Metropolitan Spatial Development and Modernity in a Third-tier Chinese Model City
}

sainan lin

University of Massachusetts Amherst

Follow this and additional works at: https://scholarworks.umass.edu/dissertations_2

Part of the Human Geography Commons

\section{Recommended Citation}

lin, sainan, "New Wenzhou: Migration, Metropolitan Spatial Development and Modernity in a Third-tier Chinese Model City" (2015). Doctoral Dissertations. 522.

https://doi.org/10.7275/7532154.0 https://scholarworks.umass.edu/dissertations_2/522

This Open Access Dissertation is brought to you for free and open access by the Dissertations and Theses at ScholarWorks@UMass Amherst. It has been accepted for inclusion in Doctoral Dissertations by an authorized administrator of ScholarWorks@UMass Amherst. For more information, please contact scholarworks@library.umass.edu. 
New Wenzhou: Migration, Metropolitan Spatial Development and Modernity in a Third-tier Chinese Model City

A Dissertation Presented

by

SAINAN LIN

Submitted to the Graduate School of the University of Massachusetts Amherst in partial fulfillment of the requirements for the degree of

\section{DOCTOR OF PHILOSOPHY}

September 2015

Department of Geosciences 
(C) Copyright by Sainan Lin 2015

All Rights Reserved 
New Wenzhou: Migration, Metropolitan Spatial Development and

Modernity in a Third-tier Chinese Model City

A Dissertation Presented

By

SAINAN LIN

Approved as to style and content by:

Piper R. Gaubatz, Chair

Stan Stevens, Member

Mark Hamin, Member

Julie Brigham-Grette, Department Head Department of Geosciences 


\section{DEDICATION}

To my parents and loving husband 


\section{ACKNOWLEDGEMENTS}

First and foremost I would like to thank my advisor, Professor Piper Gaubatz, who has consistently guided and supported me throughout my stay at UMass Amherst. Piper has patiently provided insightful comments and constructive suggestions for my doctoral project and dissertation. I would also like to thank the other members of my committee, Stan Stevens and Mark Hamin, for their helpful comments and suggestions on all stages of the project.

Special thanks to those who have participated in the survey research in Wenzhou, without your voices, my dissertation would not be possible. I thank China scholarship Council and the Department of Geosciences at UMass provide me funding. I also would like to thank my Chinese fellow colleagues and friends--Weining, Xin, Changjiang, Jiwei and Liang, who have supported and encouraged me through the life at UMass.

Behind this successful women is a great man. Yanzhuo has given me persistent encouragement and support. I'm deeply sorry for being years of long-distance situation, and can't wait to start the new life with you soon in China. Last but not the least, I would like to thank my parents and brother for their unconditional love and support. 


\author{
ABSTRACT \\ NEW WENZHOU: MIGRATION, METROPOLITAN SPATIAL DEVELOPMENT AND MODERNITY IN A \\ THIRD-TIER CHINESE MODEL CITY \\ SEPTEMBER 2015 \\ SAINAN LIN B.A., NORTHEAST NORMAL UNIVERSITY, CHINA \\ M.A., SUN YAT-SEN UNIVERSITY, CHINA \\ Ph.D., UNIVERSITY OF MASSACHUSETTS AMHERST \\ Directed by: Professor Piper Gaubatz
}

Migration has asserted great influence on urban spatial structure, especially during China's recent waves of rural-to-urban migration. This dissertation focuses on Wenzhou, a third-tier Chinese city that served as a national model for the re-introduction of small-scale private enterprise in the 1990s. Wenzhou's economic success generated migration that has served as a catalyst for new forms of urbanization in which migrants play a central role. I aim to examine and understand the distribution patterns of migrant settlements, their changes over time and the ways that the formation of these settlements has impacted emerging urban form. There are two primary components in this study: a broad-scale comparative study of the formation and location of migrant settlements based on census data and existing studies of Beijing and Guangzhou, and a fine-scale, survey- and interview-based analysis of a case-study migrant settlement.

Using data drawn from the 2000 and 2010 population censuses, the city-scale analysis finds that Wenzhou's migrant settlements, which are dominated by manufacturing workers, are spatially linked to patterns of industrial development. Thus the city's industrial development 
strategies have had a direct influence on the location, formation, and characteristics of migrant settlements. This is a direct contrast to the spatial formation of migrant settlements in Beijing and Guangzhou, where factors such as the location of village-held land and place-of-origin linked migrant settlements have been more important. Further analysis uses the classic "concentric zone model" as a baseline for understanding the differing dynamics of migrant settlements in contemporary Chinese cities.

Drawing from a survey of 435 migrants and 20 in-depth interviews in Shuangyu, Wenzhou, this dissertation further reveals the residential and activity space in migrant settlements, the daily life of migrants and how they connect with the other parts of the city. The findings address the social and spatial isolation of migrant settlements from the other parts of the city, contributing to the formation of "city within a city". This new kind of urban space constitutes a significant new "assemblage" in Wenzhou's evolving urban form, and challenges the generalizations often made on the basis of the experience of migration in Beijing and Guangzhou. 
TABLE OF CONTENTS

Page

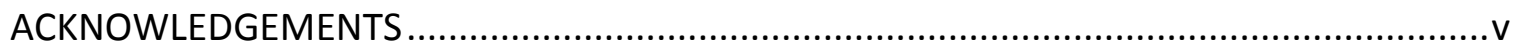

ABSTRACT ........................................................................................................

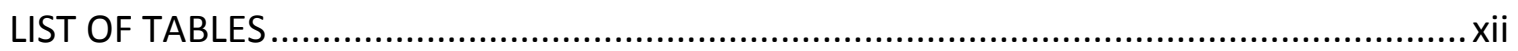

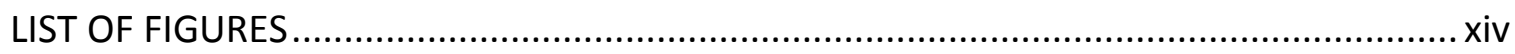

CHAPTER

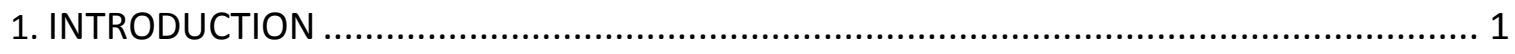

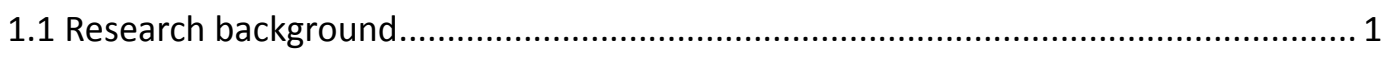

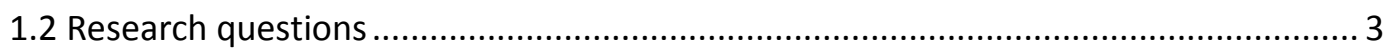

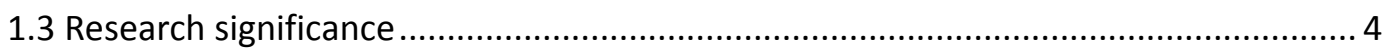

1.4 Organization of the dissertation and framework ............................................... 7

1.4.1 Organization of the dissertation ............................................................ 7

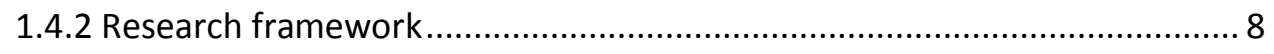

2. MIGRATION AND SPATIAL DEVELOPMENT IN CHINA ................................................ 9

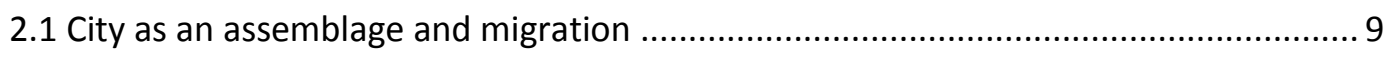

2.2 Studies of migrant settlements and urban morphology in Western countries.......... 13

2.2.1 Early theory on migrant settlements and urban form............................. 13

2.2.2 Social assimilation/segregation ......................................................... 14

2.3 Understanding migrant settlement and spatial distribution in developing

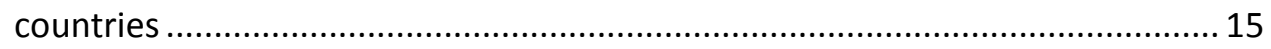

2.4 Migrant settlement and urban spatial development in Chinese cities...................... 18

2.4.1 Major migrant settlements: village in the city ......................................... 18

2.4.2 Research on the types of migrant settlements ...................................... 19 
2.4.2 Research on migrant settlement and urban spatial development in

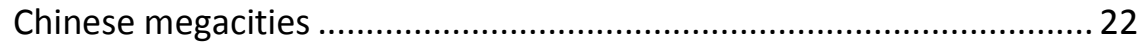

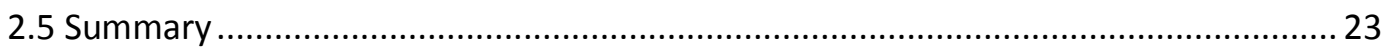

3. WENZHOU'S HISTORICAL DEVELOPMENT, URBAN FORM AND MIGRATION ............... 25

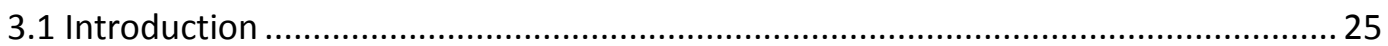

3.2 Historical development, urban form and migration ............................................... 27

3.2.1 Trading port era (Pre-1949): commerce, specialized production

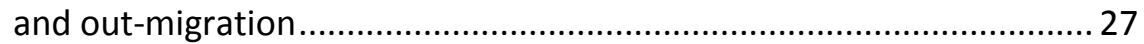

3.2.2 Maoist Wenzhou (1949-1978): isolation and out-migration ...................... 32

3.2.3 Post-reform era (1978-2000): economic model, spatial expansion

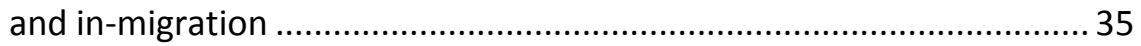

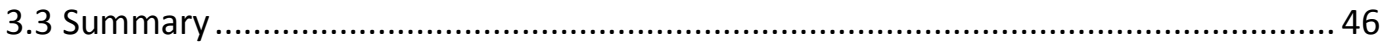

4. MIGRATION, METROPOLITAN SPATIAL DEVELOPMENT AND MODERNITY IN

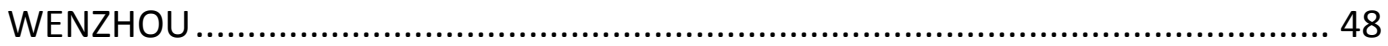

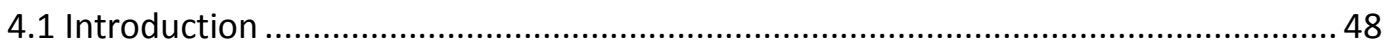

4.2 Locating Wenzhou's migrant settlements: data and methodology ......................... 49

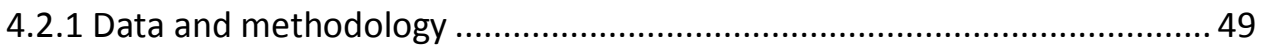

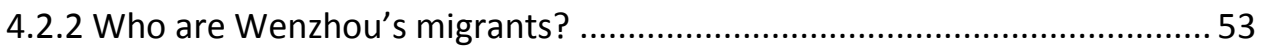

4.3 Changing spatial patterns in Wenzhou ................................................................. 55

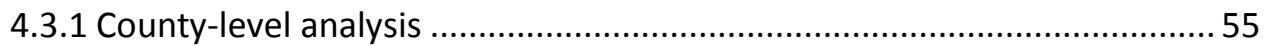

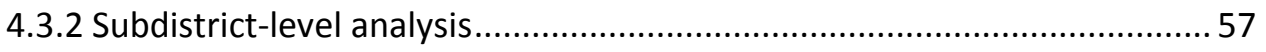

4.4.3 In comparison with Beijing and Guangzhou ...........................................67

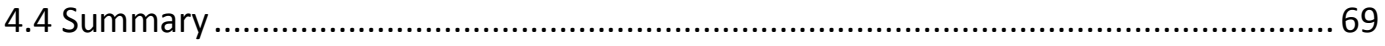

5. A SURVEY OF MIGRANT SETTLEMENT IN SHUANGYU, WENZHOU ............................. 72

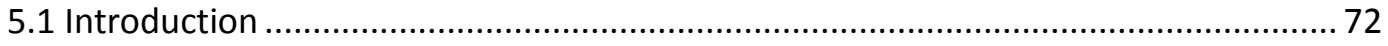

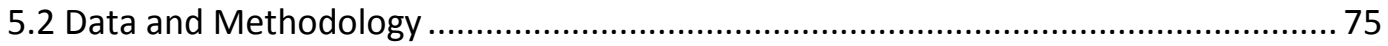


5.3 Demographic and economic characteristics of migrants in Shuangyu

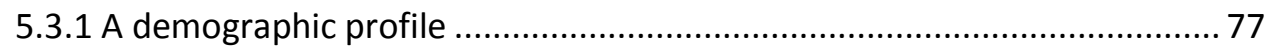

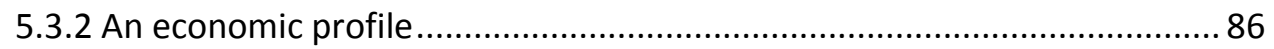

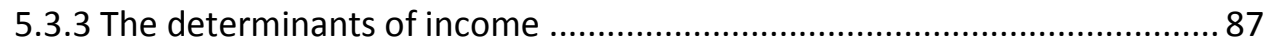

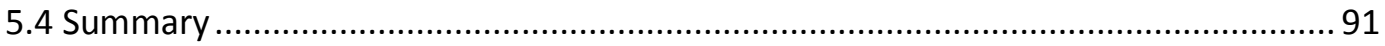

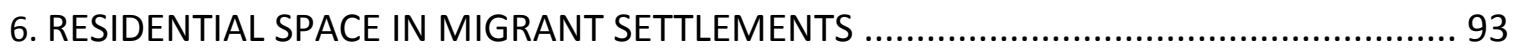

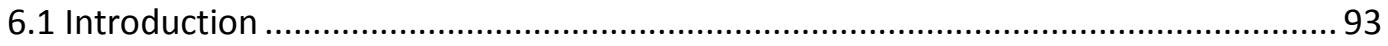

6.2 Housing and living environment in migrant settlements .................................... 94

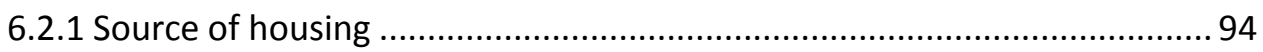

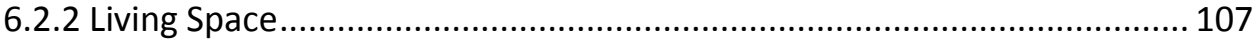

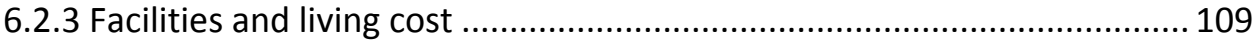

6.2.4 Satisfaction with living conditions .................................................... 113

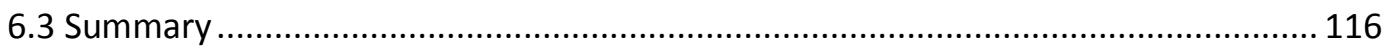

7. LEISURE TIME AND ACTIVITY SPACE IN MIGRANT SETTLEMENTS ........................... 117

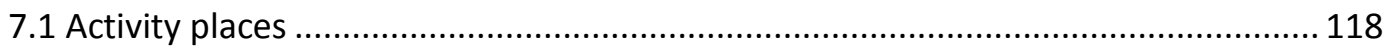

7.1.1 Street as activity place ......................................................................... 118

7.1.2 Semi-public space in VICs................................................................. 131

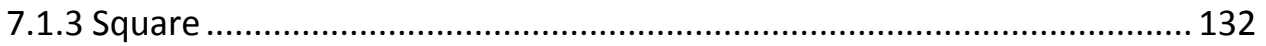

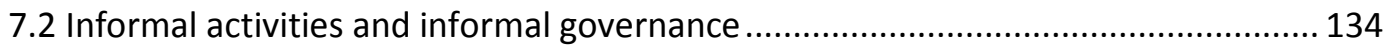

7.2.1 Motorcycles with umbrellas ................................................................. 134

7.2.2 Street vendors and peddlers............................................................. 136

7.2.3 One day off: informal practices of the "holiday" .................................... 138

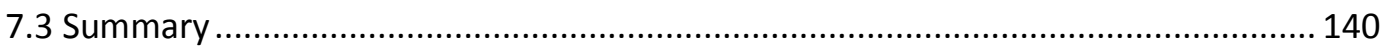

8. SOCIAL AND SPATIAL IMPACT OF MIGRANT SETTLEMENTS ON URBAN SPATIAL

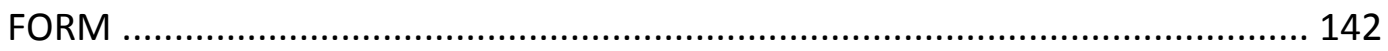

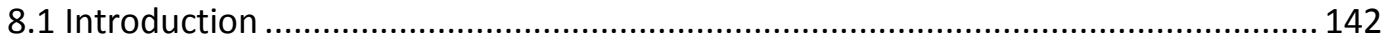


8.2 Spatial and social connections of migrant settlement with other parts of the city. 144

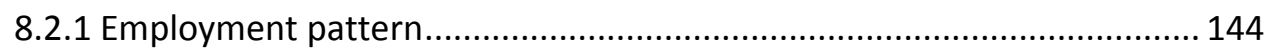

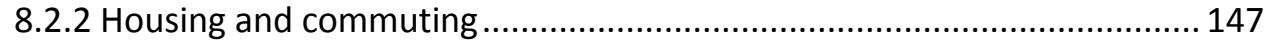

8.2.3 Consumption patterns .................................................................... 150

8.2.4 Leisure pattern and social network ................................................... 154

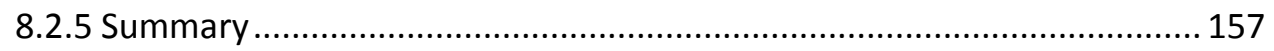

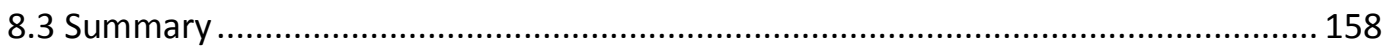

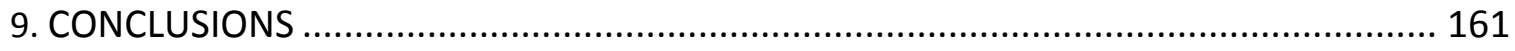

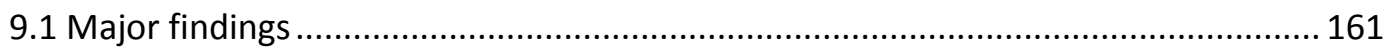

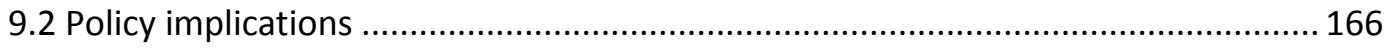

9.3 Limitations of the study and suggestions for future research ............................... 168

\section{APPENDICES}

I: QUESTIONNAIRE SURVEY IN MIGRANT SETTLEMENTS IN SHUANGYU,

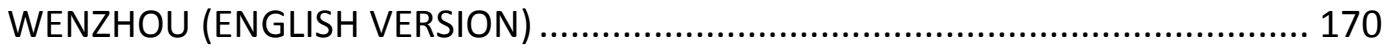

II: QUESTIONNAIRE SURVEY IN MIGRANT SETTLEMENTS IN SHUANGYU,

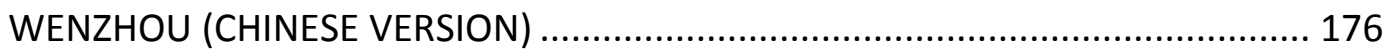

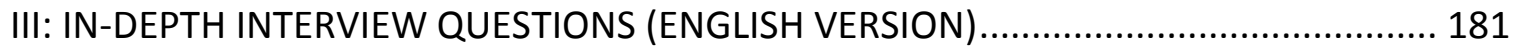

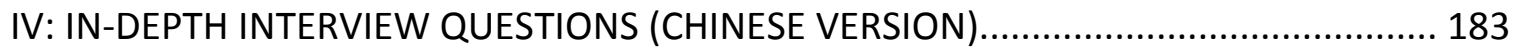

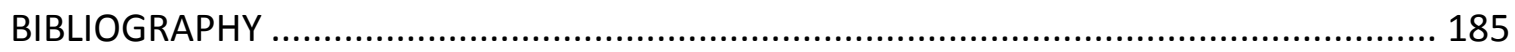




\section{LIST OF TABLES}

Table

Page

Table 3.1 Household Industries in Wenzhou, 1979-1988 39

Table 4.1 Concentration of industrial enterprises above designated size in urban districts, 2013

Table 5.1 Characteristics of migrants in the survey .80

Table 5.2 Did you bring your children to Wenzhou?

Table 5.3 Years in Wenzhou 83

Table 5.4 Migrants' intention of stay. 84

Table 5.5 Migrants' concerns about Wenzhou 85

Table 5.6 Industrial (occupational) distributions of migrants, Wenzhou 87

Table 5.7 Income and work hours per day of migrants in the survey ...... 88

Table 5.8 Linear regression for the determinants of a migrant's income (Enter) ...... .89

Table 5.9 Linear regression for the determinants of a migrant's income (Forward) ....................90

Table 6.1 Housing tenure (\%) from author's Survey of 435 migrants .......................................96

Table 6.2 Number of migrants and local residents in Shuangyu, 2013 ................................... 101

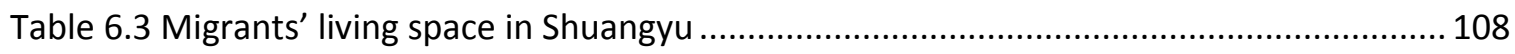

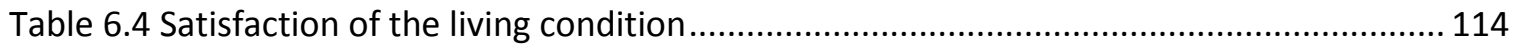

Table 6.5 Reasons that migrants unsatisfied with the living environment .............................. 114

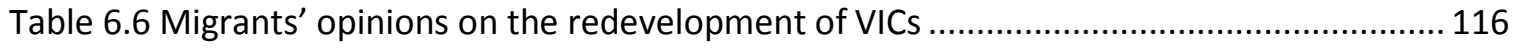

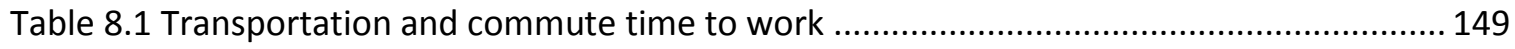

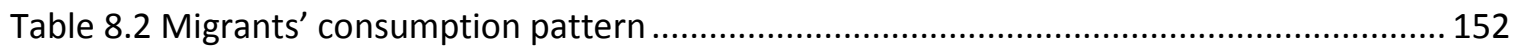

Table 8.3 Popular shopping malls and commercial streets in Wenzhou .................................. 153

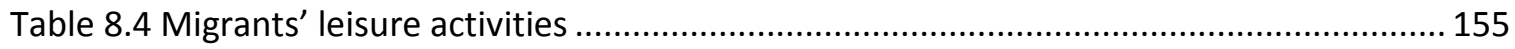




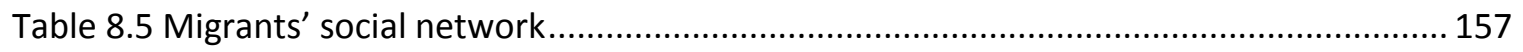




\section{LIST OF FIGURES}

Figure

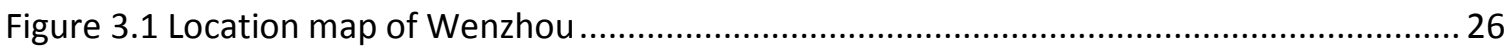

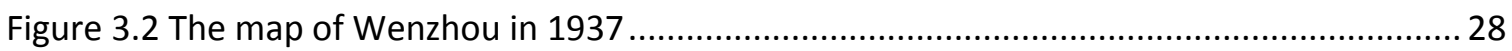

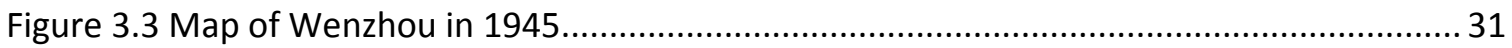

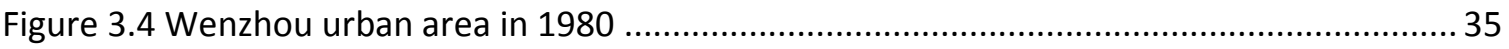

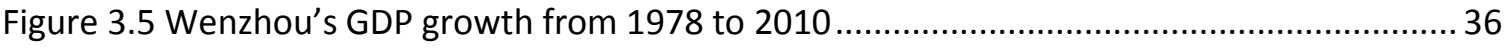

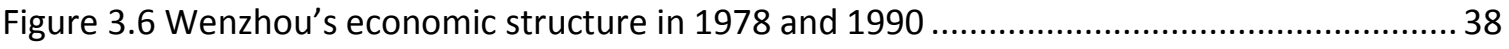

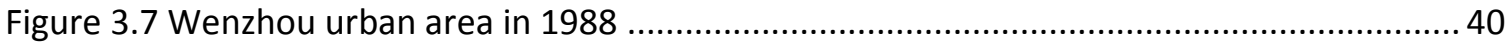

Figure 3.8 Industrial parks in Wenzhou's Three Urban Districts ............................................... 43

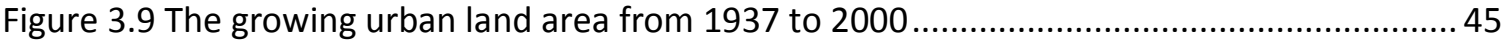

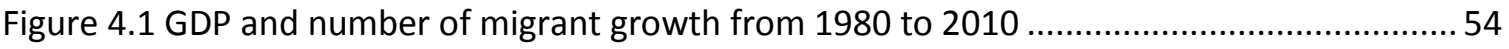

Figure 4.2 Educational attainment of migrants in 2010, Beijing, Guangzhou and

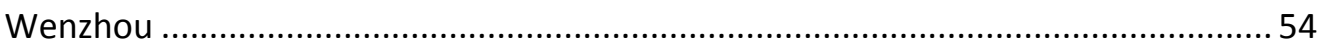

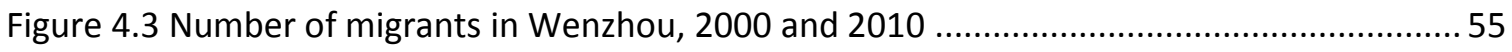

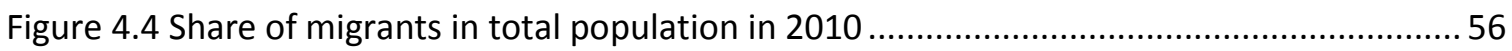

Figure 4.5 Location quotient (LQ) of migrant population in metropolitan Wenzhou in

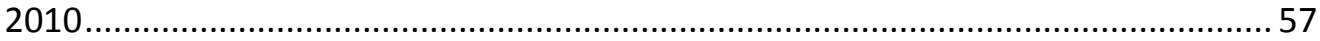

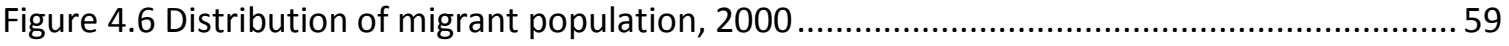

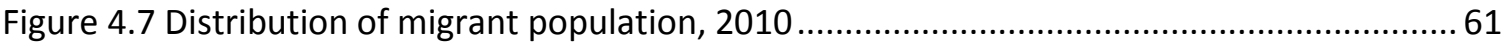

Figure 4.8 One core and two sub-centers structure of Metropolitan Wenzhou..........................62

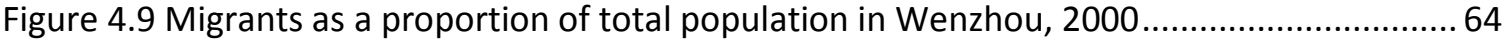

Figure 4.10 Migrants as a proportion of total population in Wenzhou, 2010.............................65

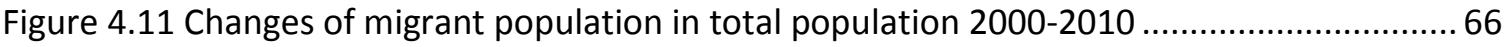


Figure 4.12 The spatial distribution of migrant settlements in Beijing, Guangzhou and Wenzhou, 2010

Figure 5.1 Location map of Shuangyu

Figure 5.2 Shoe capital of China Industrial Park and Lucheng Light Manufacturing Industrial Garden.

Figure 5.3 Major survey sites in Shuangyu sub-district ...................................................... 76

Figure 5.4 Age and sex compositions of the migrants in the survey ........................................ 78

Figure 5.5 Origins of the migrants in Wenzhou in general (A), and in the Shuangyu survey sample (B).

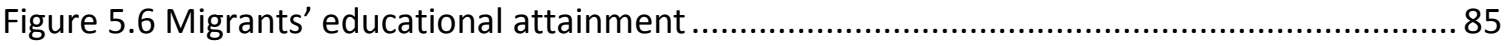

Figure 6.1 Dorm for single workers and public bathroom in a floor ....................................... 97

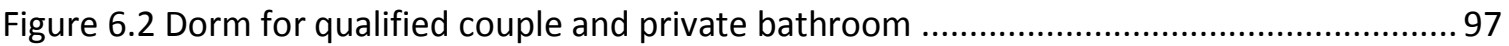

Figure 6.3 Contract situation of migrants live in factory dormitory and rented housing..............98

Figure 6.4 Number of jobs had before of migrants live in the rented housing and factory dormitory 99

Figure 6.5 Ratio of migrants to local resident in Shuangyu sub-district .................................. 102

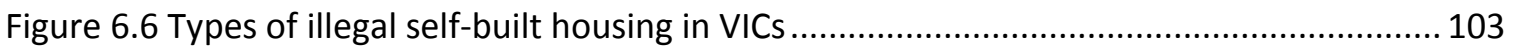

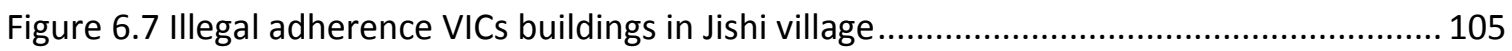

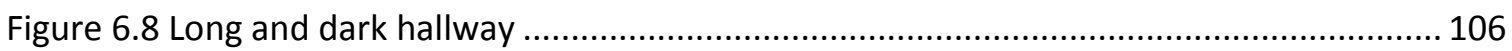

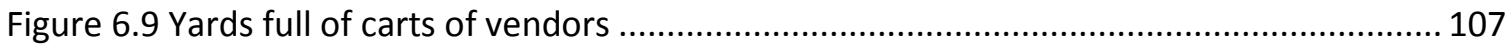

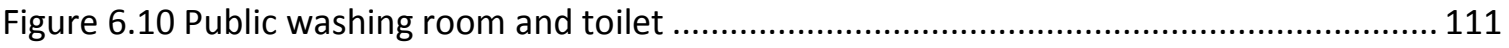

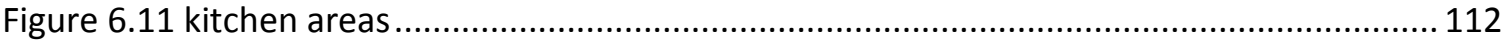

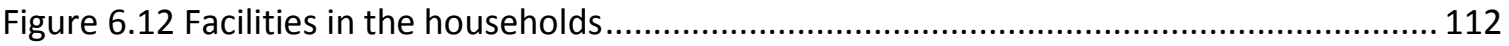

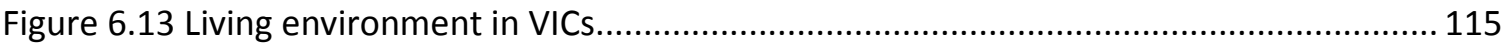

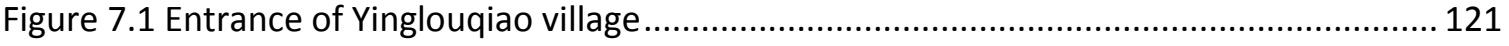

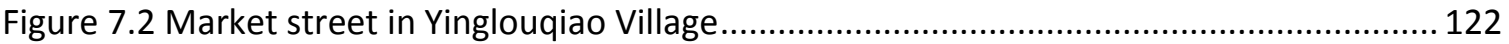




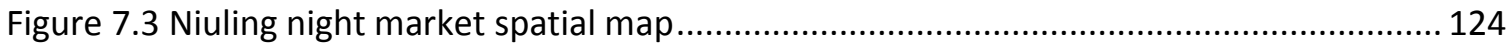

Figure 7.4 Indoor farmers' market and temporary market ................................................... 125

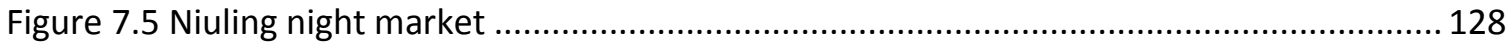

Figure 7.6 City polices are patrolling in Niuling night market............................................... 129

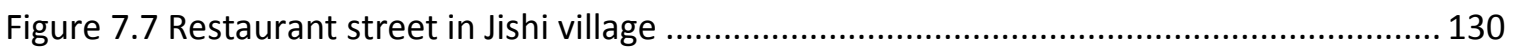

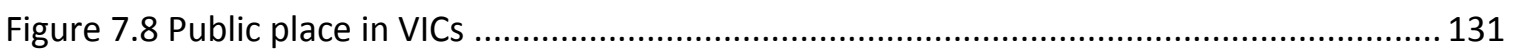

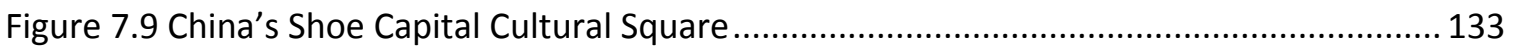

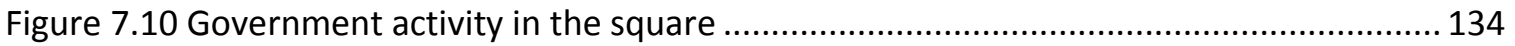

Figure 7.11 Motorcycle drivers waiting in the entrance of VIC ............................................. 136

Figure 7.12 China Telecom is holding a lottery activity ....................................................... 139

Figure 7.13 Merchants display the products outside the stores and migrants rest on the

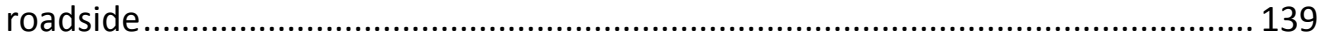

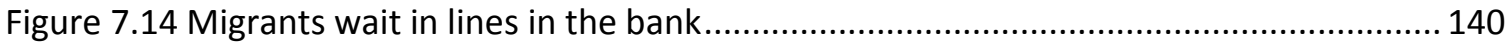

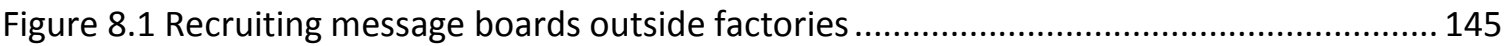

Figure 8.2 Local residents' workplace and living, shopping center ........................................ 148

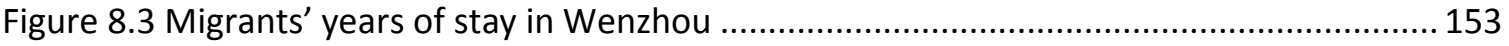




\section{CHAPTER 1}

\section{INTRODUCTION}

\subsection{Research background}

Internal migration is transforming Chinese cities in unprecedented ways. According to the National Bureau of Statistics of China, there were 245 million temporary migrants in the city as of 2014, which account for 18 percent of China's total population (NBSC, 2013). With 80 percent migrating from rural areas, this demographic movement has contributed to the rapid urbanization and economic growth of Chinese cities. The large cities, in particular, attract the most migrants due to a perception of more job opportunities and better-paid salaries. Despite the State Council's efforts to redistribute migration flows, such as loosening the limitations on migration to small and medium-sized cities, and allowing migrants who satisfy certain criteria to obtain local hukou ${ }^{1}$ (household registration), internal migration towards the larger cities is unabated in recent years (UNDP, 2013). The top one percent of cities, in terms of population, receive nearly half the country's rural to urban migrants (Liu, et al, 2015). As a result, extensive studies on migrants and migration have been done in the first-tier megacities such as Beijing, Shanghai and Guangzhou (Liao \& Wong, 2014; Lin, De Meulder, Cai, Hu, \& Lai, 2014; Yuting Liu, He, Wu, \& Webster, 2010; W. Wu, 2008; Siqu Zheng, Fenjie Long, C.Cindy Fan, \& Yizhen Gu,

${ }^{1}$ Hukou: is a record in the system of household registration in China. Introduced in 1950s, the hukou system divided people into two categories: those who hold urban hukou enjoy relatively generous urban social services; and those with rural hukou have less access to social services. 
2009). Yet, despite these growing numbers of migrants in third-tier cities ${ }^{2}$, the impact of temporary labor migrants on urban form and development is not well understood.

Most studies place the formation and spatiality of migrant settlements within the frameworks established in the megacities - especially Beijing's peripheral migrant settlements (Xiang, 2005), Guangzhou's “village in the city" model (Yuting Liu et al., 2010), or Shanghai's concentrations of migrants in inner-city and suburban private housing (W. Wu, 2008; Liao and Wong, 2014). Recent scholarship has added an element of process with analyses of how the distribution, concentration, and characteristics of migrant settlements in Beijing, Shanghai and Guangzhou have changed over time (Liao and Wong, 2014; Liu, et. al., 2015). Do the migrant settlements in third-tier Chinese cities follow any of the patterns established in the first-tier cities? Or, as Liao and Wong suggest, does “...the persistence of significant urban and regional contrasts ensure that certain phenomena [such as migrant settlements] are not generalizable across cities" in China? A key objective of this dissertation is to understand how migrant settlement patterns in a third-tier city might be distinct from those in megacities such as Beijing and Guangzhou. I use a case study of Wenzhou, a large third-tier city of more than 9 million people on China's southeast coast, to analyze how the process of migration and settlement has changed the spatial structure of a less well-known city.

Migration has been a significant factor in the recent development of Wenzhou, one of China's model cities for reform-era (post-1980) economic growth. Wenzhou has experienced rapid economic growth since the 1980s, which is often analyzed in terms of the role it has

${ }^{2}$ China's City Tier System is widely used in the public and media. It divides cities into different tiers by their political status, economic strength, population size and regional influence. "Third-tier cities" in China refer to these fast-growing small and medium-sized cities, which are usually sub-regional centers, such as Wenzhou, Zhuhai and Jilin. 
played as a model for the privatization and entrepreneurialization of China's economy. Since 1985, China has used Wenzhou as a model for the development of private enterprise. The essence of the "Wenzhou model" is a system of production that is centered on family enterprises and embedded in thick local institutions (Forster, 1990; A. P. L. Liu, 1992; Kristen Parris, 1993; Wei, 2007). These local economic, social and cultural institutions were forged in Wenzhou's historical success as a trading center. This local economic culture, deeply-rooted in family-run enterprises and trade networks, appealed to the 1980 's reform-era efforts to reestablish entrepreneurialism in Chinese cities. In turn, the national attention brought to Wenzhou by its elevation as a "model" for economic reform, led to an economic boom from 1985 to 2000, with an annual growth rate of 23 percent (WMBS, 2011). Wenzhou has developed from a small, quiet village to a thriving city.

Paradoxically, this economic success, while deeply embedded within Wenzhou's cultural traditions, may well be generating fundamental changes in that local culture. Today, recent migrants make up more than 35 percent of Wenzhou's population and migrants are the majority in several districts. In this context, I reexamine the Wenzhou model not as an economic development strategy, but rather as a catalyst for new forms of urbanization in which migrants play a central role. I aim to understand the ways in which migration contributes to Wenzhou's emerging urban form in comparison with those already identified patterns in the megacities.

\subsection{Research questions}

The main objective of this dissertation is to examine and understand the distribution patterns of migrant settlements in a third-tier city, their changes over time and how has migrant 
settlements impacted on the emerging urban form. Specifically, this dissertation addresses the following five research questions:

(1) What are the distinctive characteristics of migrants and the process of migrant settlement formation in Wenzhou in comparison to Beijing and Guangzhou?

(2) How are migrants spatially distributed in the city? In particular, how has the metropolitan form/spatial pattern changed from 2000 to 2010 ?

(3) How is the spatial distribution of migrant settlements in the city similar to or different from the patterns in Beijing and Guangzhou?

(4) What are the distinctive features of migrant settlements in terms of migrant housing, living environment, activity places, as well as governance?

(5) What is the spatial and social relationship of migrant settlements to the city center? Are they strongly connected to other parts of the city, or do they generate distinct urban spaces such as "cities within the city" or "two parallel cities"?

\subsection{Research significance}

This dissertation contributes to a more nuanced understanding of migrant settlements in China, and generate a multi-dimensional framework for analysis of current Chinese urban form and urban image in the context of rapid migration and development. The current phase of globalization has seen a massive displacement and movement of migrants, both at the transnational and the national levels, mostly to urban spaces throughout the world (Venn, 2006). Social, economic, and political issues of major significance raised by the huge migration in cities have been gaining importance since mid-1970s. Migration-related issues such as rates of internal labor mobility and urban economic growth, high levels of unemployment, huge growth 
of urban slums and shantytowns, limited access to health care, and impact on self-identity have captured the greatest attention worldwide and have become important topics of study across disciplines such as geography, sociology, urban planning, anthropology, and economics (Bhattachary, 1993; C.Beauchemin \& P.Bocquier, 2004; Meyerson, Merino, \& Durand, 2007; R.Skeldon, 1990). China is no doubt a valuable exemplar for study of internal migration in transitional economies. But while there are many studies of migrants, migrant settlements, and migration process (Chan \& Zhang, 1999; C. Fan, 2008; Roberts, 2007), less attention has been paid to the transformative influence of migration on overall urban form, function and structure. Migration, as the dominant driver of dramatic urbanization in China, and in most developing countries as well, creates distinctive emergent features of urban space.

This dissertation develops both a theoretical and an empirical understanding of how migrants' residence and mobility in the city produce and re-produce urban form in terms of social relations, economy, culture, and built environment. This discussion enriches urban studies in the field of urban morphology by interpreting the impacts of migration and the formation of migrant settlements on the form and function of a dynamic Chinese city. The fluid processes of migration and settlement territorialize parts of the city and create distinctive features of urban space, while also following patterns of deterritorialization and reterritorialization. The dissertation will examine these processes to understand the recent debates about urban assemblage theory (Brenner, Madden, \& Wachsmuth, 2011; McFarlane, 2011a; Swanton, 2011). According to urban assemblage theory, the city is a fluid assemblage, with different parts or sublevel assemblages that work independently but are also interconnected. My dissertation research will examine how migration has influenced urban form by closely exploring migrants' perspectives on their interaction with the other parts of the city. 
By analyzing a Chinese city less well-known than Beijing, Shanghai and Guangzhou, but nevertheless a major destination for labor migrants, this research has the potential to shift the current thinking about migrant settlements in China to a more multi-dimension framework and to further explain the rapid changes in the urban form of contemporary Chinese cities. This study also contributes to the evolving understanding and typology of migrant settlements in urban China. The results of my project have the potential to enrich the understanding of the different ways in which migrant villages are integrated with overall urban form beyond the often-cited "migrant villages on the periphery of Beijing" and "villages in the city of Guangzhou".

Methodologically, this dissertation approaches the empirical study in two distinct geographical scales - the city as a whole and a micro-analysis of selected migrant settlements. Based on the census data, the city-level analysis shows the overall distribution pattern of migrant settlements in Wenzhou and how it has impacted Wenzhou's emerging urban form. Through discussing the ways that migrants use/interact with the city, the micro-analysis addresses how the presence of the migrants, using the city in the way that they do, has impacted on the city as a whole, based on the fieldwork data primary from questionnaire survey and in-depth interview.

In summary, this dissertation examines the ways in which the mobile migrant population has contributed to the city's emerging urban form. By using Wenzhou as a case study, this study analyzes how the process of migration and settlement changes the spatial character and form of less well-known Chinese cities. 


\subsection{Organization of the dissertation and framework}

\subsubsection{Organization of the dissertation}

The dissertation is structured in nine chapters. The first two chapters provide a detailed account of the research background, research questions, research framework, and research methodology.

Chapter 2 reviews the existing literature on migration and urban form from the perspectives of cities in western countries, developing countries, and China.

Chapter 3 introduces Wenzhou's urban development, morphological change and migration in a historical context (before 2000), which is important to better understand Wenzhou's current development and make differentiations to the first-tier megacities.

By comparing the 2000 and 2010 census data, chapter 4 reveals the changing distribution patterns of migrant settlements in Wenzhou, and how they are related to Wenzhou's emerging form. It further addresses how the spatial distribution of migrant settlements in the city is similar to or different from the patterns in Beijing and Guangzhou.

Chapters 5, 6, 7 and 8 focus on micro-level analysis of survey research carried out in Shuangyu, which is a subdistrict in the inner ring with great number of migrants. Specifically, Chapter 5 introduces the survey area, and provide an overview of the characteristics of migrants in the survey. Chapter 6 and 7 analyzes the features of migrant settlements, particularly the housing and living space, activity space and urban governance. Chapter 8 reveals the daily life of migrants in the city and how they connect with the other parts of the city, and further addresses the social and spatial implication of this connection pattern to Wenzhou's urban form. 
of study, and provides suggestions for future research.

\subsubsection{Research framework}

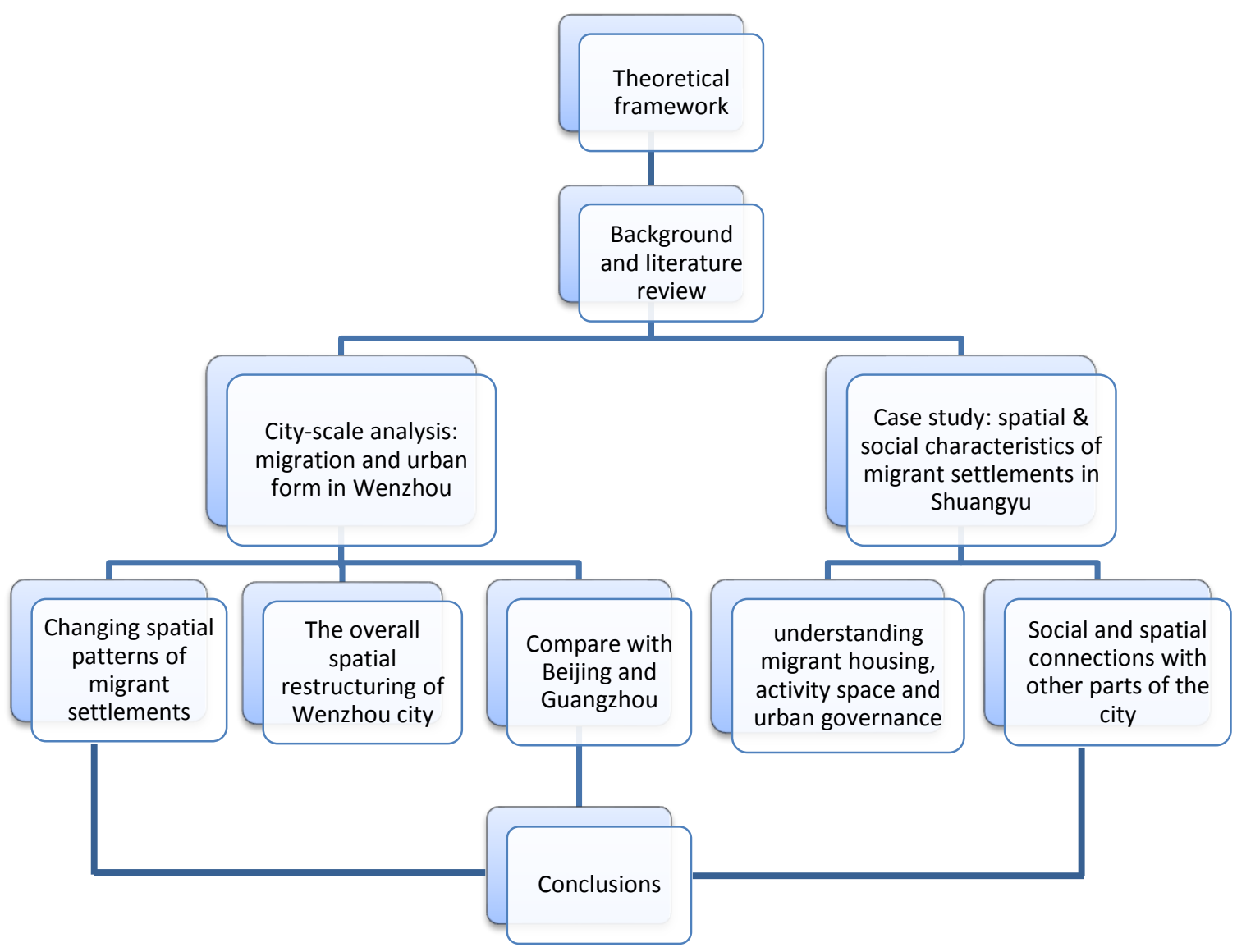




\section{CHAPTER 2}

\section{MIGRATION AND SPATIAL DEVELOPMENT IN CHINA}

This chapter reviews migration and spatial development around the globe and China. Starting with the discussion about the spatial order of the city, it analyzes recent discussions of "city as assemblage" as a theoretical background for this study. Secondly, it also reviews the research on migration and spatial development in western countries and developing countries. Last but not the least, based on a review of current studies migration and spatial development in China, this chapter reveals the research gaps in relevant fields in the Chinese context.

\subsection{City as an assemblage and migration}

The spatial order of cities today is dramatically different from that of previous eras. Nowhere is this more true than in China, where the pace of urban change is so fast that the spatial and social landscapes has changed dramatically and spatial order has been in nearconstant flux since the $1980 \mathrm{~s}$. In the early 20th century, Burgess's concentric zone model suggested that urban space could be perceived as concentric rings, where different social groups were distributed (Burgess, 1924); by the mid-20th century, due to increased car ownership and greater mobility, urban spatial models were reconFigured to see urban space as polynucleated with a more dispersed multi-centered metropolitan form;. More recently, the information and communication revolution, intertwined with the globalization, turned urban space into "annihilated space" (Harvey, 1990; Kirsch, 1995; Marx, 1973). As Lefebvre anticipated in 1970s, society is transforming to an urban world-with the development of processes of urban concentration, rural exodus, extension of the urban fabric, and, eventually, the complete subordination of the agrarian to the urban (Lefebvre, 2003 [1970]).Urbanization has astonished 
us by its scale (Lefebvre, 2003 [1970]). The urban is a place of encounter, assembly, and simultaneity (Lefebvre, 2003 [1970]). Urban space becomes ever complex, and is occupied by interrelated networks, power relationships, human and non-human actors. As Manuel Castells suggests, the spatial organization of this "network society" is a change from a 'space of places' to a 'space of flows' (Castells, 1996). With this has come a more fluid interpretation of urban space, with the contention that "city" is everywhere and anything (Amin \& Thrift, 2002); or that "city" has become geographically and socially permeable and incomplete, and is turning into a place of intermingling and improvisation (Edensor \& Jayne, 2011).

The recent assemblage theory, which provides a new understanding of cities as emergent and fluid concatenations of multiple elements, has gained important attention in urban studies (Ureta, 2013). Deriving from Giles Deleuze and Felix Guattari, assemblage, like the rhizome, has no beginning or end. It is always processual, mobile, temporal and multiple (Deleuze \& Guattari, 1987). Since its usage by DeLanda (2006), assemblage theory has reemerged in urban studies and has been incorporated into studies of cities by scholars such as Farias and Bender (2009), McFarlane and Anderson (2011) and McFarlane (2011a). However, considering the conceptual and theoretical components of "assemblage theory" in its current uses, scholars often partially adhere to the original philosophy of Gliles Deleuze and Felix Guattari. One of the well-known examples is the "actor-network theory' (ANT). Developed by shcolars such as Bruno Latour, Michel Callon, John Law and their followers, ANT is originally derived from an "actant-rhizome ontology, it arguably departs significantly from the philosophical-political project of Deleuze and Guattari (Brenner et al., 2011). More recently, McFarlane (2011a, 2011b) and Brenner, Madden, \& Wachsmuth (2011) have debated on what assemblage thinking could offer to urban critical theory in the special issues of City (Vol 15, 
2011). Colin McFarlane uses the Deleuze-Guattarian conception of "assemblage" (agencement), arguing that assemblage is "expansive terms of an orientation, a concept, and an imaginary" that it might both connect with and differ from critical urbanism. They emphasize the heterogeneous parts of the whole and are "interested in emergence and process, and in multiple temporalities and possibilities, rather than focusing on cities as resultant formations". (McFarlane, 2011a, p2056. On the other hand, Brenner et al, agree that assemblage thinking opens up the prospect for thinking space as relationally, indeterminacy, emergence, becoming, processuality and turbulence. (Brenner et al., 2011). However, they question the concept of assemblage could be used as a new theory (supersede for the urban critical theory) to explain the new forms of urbanization and world-making process. They suggest to the most effective way to apply assemblage thinking is when it is linked systematically to the intellectual tools and political orientations of critical geopolitical economy (Brenner et al., 2011).

Departs from the current debate, this dissertation seeks to link assemblage theory to the contemporary dynamics of cities, and how it might inform and guide empirical research in urban studies. Specifically, the urban assemblage approach inspired me to think of the spatiality of the city as processual, relational, mobile, and unequal. An assemblage is a whole that is formed from the interconnectivity and flows between constituent parts-a social-spatial cluster of interconnections between parts wherein the identities and functions of parts and wholes emerge from the flows among them (Dovey, 2012). The process of migration and settlement has been one of the flows and place making factors in the globalizing world. Based on this theory, this study aims to understand how different parts of cities, especially migrant settlements compare to the other parts, interconnect with each other but change unevenly with different pace in terms of socio-spatial aspects. 
Contemporary rural to urban migration in China-history's ever largest migration--is creating new urban spaces and refiguring economies (C. Fan, 2008; Sauners, 2011; W. Wu \& Gaubatz, 2012). Such movements appear as events, that is, as irruptions to the original urban system, which go through adaptation, invention and further generates new combination and changes in configuration. Chinese cities serve one of the best examples with flux of huge mobile migrants (W. Wu \& Gaubatz, 2012). Rural-urban migrants, usually regarded as marginal urban population, work, live, and spend their leisure time in ways that all together form an interwoven system of urban life, and create distinctive spatial imprints in the city (Venn, 2006). Studies of current migration in China are mostly done by sociologist, economists, and geographers, who tend to focus on the general patterns, structural causes, policy effects, and economic consequences based on quantitative survey data (Chan, 2011; Chan \& Zhang, 1999; C. Fan, 2003, 2008; Mobrand, 2006; Roberts, 2007; Y. Zhao, 1999). Their research draws largely on three theoretical frameworks that seek to understand why people move: the push-pull model, macroanalysis of structural and historical processes, spatial distribution and social networks theory (Knight, Deng, \& Li, 2011; Portes \& Bach, 1985; Teng, 2012; Willmore, Cao, \& Xin, 2012; L. Zhang, 2001; Zhu, Luo, \& Zou, 2012). Although these studies provide a valuable picture of rural urban migration movement, rural-urban migration as a component of the place-making process has been neglected. We know little about how migrants influence the city both consciously and unconsciously, where they follow a pattern of deterritorialization and reterritorialization (Venn, 2006) and changes the spatial image of cities. 


\subsection{Studies of migrant settlements and urban morphology in Western countries}

\subsubsection{Early theory on migrant settlements and urban form}

Migrants have long held a contested, tenuous and fluid place in analysis of urban spatial patterns in Western countries. Studies on migration in Western countries (Western Europe and North America) are often carried out on the international migrants. Since 1990, North America and Europe have the largest gain in the absolute number of international migrants, 25 million for North America and 23 million for Europe between 1990 and 2013 (UNDEA, 2013). Today, about six out of every ten international migrants in the world reside in the developed regions (UNDEA \& OECD, 2013). In the early 20th century, Ernest Burgess may have been the first scholar to consider the dynamic spatial relationship between migrants and cities. In his classic analysis of Chicago's urban form, he depicts waves of migrants who settle first in the urban core, then move outward as successive generations become more economically successful, leaving vacancies for new migrants behind them (Burgess, 1924). In cities like Chicago, migrants were fundamental in shaping the city form. Many of the subsequent well-known refinements of the Burgess model (such as Hoyt's sectoral zone model or Harris and Ullman's multiple nuclei model in North America) drop the cultural identifiers (such as "Little Sicily" or "Deutschland") which identified migrant neighborhoods, preferring functional or economic classifications.

Although the Chicago school has been criticized as outdated model which developed when American cities were growing very fast in demographic term and when motorized transportation was still uncommon as most people used public transit. But it did describe the succession and invasion of different ethnic groups into suburban zone, as migrants firstly settled 
in the notorious city center close to employment locations and subsequently moved out to places with better amenities when their economic status improved.

\subsubsection{Social assimilation/segregation}

Migrants' initial settlement in the city is often based on cultural and economic similarity. They mostly reside closely to their same ethnic groups for mutual support and close to where they work to reduce living cost. However, these are often transitional neighborhoods - they represent a practical and temporary phase in the incorporation of new groups into society. As soon as their socioeconomic situations improve, their residents and next generations seek to improve their spatial position in urban society, which typically means moving into neighborhoods with more amenities, safer streets, better schools, and they learn to navigate daily life in a more mainstream setting. This is the process of migrants' spatial assimilation into the local society (Massey, 1985). Nonetheless, even with integration/assimilation of some welloff migrants into the mainstream society, social and spatial segregation created by these immigration in western countries still has become one of the key forces of social transformation, creating so-called "divided cities". Since postwar period, large number of guest workers (temporary labor migrants) were recruited from less developed countries to Western countries, playing a crucial role in the growth and restructuring of industrial economies (Castles and Miller, 1998). Even the recruitment of guest-workers ended in the 1970s, many of those migrants became permanent ethnic minorities, contributing to spatial segregation, social polarization and social exclusion of these cities. Western cities, especially those well-known global cities, have variously been described as divided cities (Fainstein \& Gorden, 1992), dual cities (Mollenkopf \& 
Castells, 1992), partitioned cities (Marcuse \& Kempen, 2002), mostly as a consequences of socioeconomic status of different ethnic groups.

Early research tends to emphasize the negative effects of spatial segregation. They believe that concentration of low-income groups might lead to fewer job opportunities, high rate of crime, less amenities such as schools and other public services (Bolt, Burgers, \& Kempen,

1998). However, the very recent research, mainly under the EU project of "Divercities: governing urban diversity" led by a group of scholars from Europe examines how Europe can be benefit from diversity, seeing urban diversity is an asset and proposed the idea of hyper-diversified cities (Tasan-Kok, Kempen, Raco, \& Bolt, 2014).

\subsection{Understanding migrant settlement and spatial distribution in developing countries}

Unlike the Western countries, the most influential type of migrants in developing countries is internal migrants, who are primarily rural to urban migrants. Analyses of the numerous post World War II spatial reconfigurations of settlement in Asia, Africa, and Latin America often have acknowledged urban migrant spaces (usually as "squatter settlements" or the equivalent). Especially in some Asian and African countries, internal migration has become the major source of urbanization. Although they work and live in the urban area, many of those migrants are never fully integrated and have been unable to become permanent urban dwellers. The settlements where migrants concentrate, also called slums, squatter camps, favelas, shantytowns in some countries, create distinctive and informal urban spaces on the one hand, but also challenge urban governance on the other hand (Holm \& Kuhn, 2011; Huchzermeyer, 2003; T. McGee, 1979; Minnery et al., 2013). Slums and squatter settlements have particularly formed around large cities in the developing countries since the end of World War II. In contrast 
to models of "industrial cities" where low-income immigrants reside in the city center and the rich in spacious accommodation in the suburbs, as in Burgess' concentric zone model I have mentioned above, for example, the process of migrants' spatial location has been found different. At the beginning, Turner (1968)'s empirical research on the urban settlement patterns of low-income migrants has gained general acceptance (Conway \& Brown, 1980). Based on his empirical research on Peru, he suggests that a two-stage process of settlement just like cities in the developed world--initial settlement of migrants in the city center as "port of entry" and outward relocation to a peripheral residential environment (Turner, 1968). However, followed by several empirical studies, such as in Mexico City (Brown, 1972), inner-city areas are no longer found to be the major initial destination for new migrants. The expansion and redevelopment of the city center to commercial center has led to a great rise in land costs. To avoid higher rents within the city, migrants are attracted to settlements in intermediate or peripheral zones, and recent arrivals tend to locate more on the urban fringe (W. Wu, 2005).

The location of migrant settlements in different developing countries also have been reflected in some well-known urban form models. For example, the updated Ford's model of the Latin American city (1996) found most recent migrants live in a zone of periphery that made up of squatter settlements. Migrants usually commute a long way to work. And many of these squatter settlements are transformed through time into permanent neighborhoods. In T. G. McGee (1967)'s model of the South East Asian city, he featured a high-class residential sector extends outwards from the government zone in the center, and squatter settlements in the urban periphery where usually poor rural-to-urban migrants reside, along with more recent suburbs. What is common to all of these analyses of migration and its impacts is that the migrants must settle in marginal, unregulated, or ambiguous areas, with informal housing and 
land use arrangements. The location of such space vis a vis the "formal," regulated areas of the city is contingent upon many location-specific factors such as political economy, land tenure policies and practices, regulatory environment, social and cultural landscapes, and topography. This common theme is consistent with China's recent experience, in which migrants have settled in places and situations outside the highly-regulated realm of registered Chinese urban space.

Due to its unregulated, crowded, unsanitary and possibly unsafe nature, as well as different situation in different countries, government policy towards and groups/agencies that are involved to such settlements has varied both in time and place. One of the often approach to such settlements is attempt to clearance/eradication and relocation. This approach was particularly used in the 1950s and 1960s when many Latin American and Asian cities were growing rapidly, slums and squatter settlements were often consider by governments and other urban residents as great problems. This approach may achieve certain success in some Asia countries, such as Hong Kong and Singapore, but in general failed (Willis, 2009). It either failed to provide affordable housing, or destroyed the economic opportunities for the low-income migrants who may rely on the informal sectors in the slums and squatters or have to move far away from their employment. In the late 1960 s and 1970s, upgrading and administrative incorporation has been gradually introduced as a new approach the slums and squatter settlements. Governments and international agencies such as the World Bank and the United Nations, increasingly sought to provide support to the self-build process. Some are involved with the regularization of land tenure and secure the tenureship for the dwellers to improve their houses without fear of eviction. Other support include providing better services and subsidized building materials for home improvements. 


\subsection{Migrant settlement and urban spatial development in Chinese cities}

China's internal migration is one of the most striking examples in the world today, and contributed 38 per cent of the world's total internal migration in 2012. There are two types of rural-to-urban migrants in China: permanent migrants who formally transferred their hukou to the destination city (qianyi) and temporary migrants (officially called "floating population" or liudong renkou nationwide) without official changes of hukou from the origin to the destination. The latter group, which makes up the bulk of total migrants, is our focus in this dissertation. Studies of current migration in China are mostly done by geographers, sociologists, and economists, who tend to focus on the general patterns, structural causes, policy effects, and economic consequences based on quantitative survey data (Chan, 2011; Chan \& Zhang, 1999; C. Fan, 2003, 2008; Mobrand, 2006; Roberts, 2007; Y. Zhao, 1999). Their research draws largely on three theoretical frameworks that seek to understand why people move: the push-pull model, the macro-analysis of structural and historical processes, and the spatial distribution and social networks theory (Knight et al., 2011; Portes \& Bach, 1985; Teng, 2012; Willmore et al., 2012; L. Zhang, 2001; Zhu et al., 2012). Despite the extensive studies of China's migration, only recently have there been substantial published case studies of migrant settlements (Ye Liu, Li, \& Breitung, 2012; F. Wu, Zhang, \& Webster, 2012; X. Wu, 2003; Xiang, 2005; Siqu Zheng et al., 2009).

\subsubsection{Major migrant settlements: village in the city}

In contrast to the rural migrants who are often living in the slum and squatter housing built by themselves, migrants in China are not allowed to build their own housing in the city due 
to the land rights. The housing available for migrants are mainly constructed by the indigenous peasants living in the VICs. As a product of rapid industrialization and urbanization in the postreform era, VIC refers to settlements that are designated as rural areas but are located within the jurisdictional boundaries of the city. Because of their low-cost housing and loose residency requirements, they became the major habitats of a large number of low-income rural migrants. VICs, by having the characteristics of a juridical ambiguity regarding housing, lack of settlement planning control, and an unregulated rental market, are also regarded as informal settlements that manifest a new dimension of spatial transformation in post-socialist Chinese cities (L.

Zhang, 2011). They are products of dual urban-rural hukou and land management systems and an underprovision of migrant demands for housing and living (F. Wu et al., 2012). Due to the concentration of low-income residents, a lack of basic facilities and infrastructure, unsanitary environments, and high rates of crime, city managers and planners perceive VIC as an eyesore or nuisance. They attempt to eliminate this informality or "non-state space" to create more governable spaces through formal land and infrastructure development (F. Wu et al., 2012). Therefore, the 'demolish and redevelop' approach to VIC has become a common strategy to build a so-called 'civilized and harmonized' urban space in Chinese cities.

\subsubsection{Research on the types of migrant settlements}

\subsubsection{Homogeneous migrant settlements}

Migrants who have kinship and come from the same place of origin, or similar group of people, or work in the same industry are more likely to settle in one place. And these migrant settlements can be generalized as homogeneous migrant settlements (X. Wu, 2003). One of the 
most well-studied types of homogeneous migrant enclaves are mainly based on kinship and same area of origin, which are usually named after the sending province, such as "Zhejiang village", "Xinjiang village" and "Anhui village" in Beijing. "Zhejiang village" is the most famous and well-studied such migrant "village" in Beijing. "Zhejiang Village" is neither the name of a natural village nor of a municipal district, but rather a nickname for a residential colony occupied by rural migrants primarily from the rural area of Wenzhou district (Yueqing and Yongjia Counties) in Zhejiang province. It is located in a transitional area between city and countryside and that it straddles several street committee areas and the rural township of Nanyuan. After a period of contestation over local government, Zhejiang village gained its economic power by having an important garment industry and the largest market for garments and cloth in Beijing (X. Liu \& Liang, 1997). Migrants are not eligible for many municipal services, such as education and health care. Over a decade (1984-1995), Zhejiang village matured into a largely self-sufficient community to the extent that the residents provide urban services themselves, such as dispensaries, schools, nursery schools, doctors, kindergartens, clinics, etc., in the context of well-established social, economic and spatial networks (Qian \& Chen, 2003; Xiang, 2005). Many scholars have analyzed its development history, formation mechanism, spatial pattern, and the social networks among the migrants (Qian \& Chen, 2003; Xiang, 2005). The other type of homogeneous migrant settlements that have been well studied are primarily composed of young university graduates in large cities especially Beijing, Shanghai, and Guangzhou (Bei-shang-guang). These homogeneous migrant settlements have been widely referred by the social media as "Ant Tribe" (Yizu). This term describes the settlement of China's post-'80s generation--university graduates from rural China who dream of a better life but struggle with low-paying jobs and poor living standards in large cities (Lian, 2009). Located in the 
transition areas between city and rural areas, ant tribe enclaves are composed of those university graduates who share rented rooms with others in cramped places just like ants. They usually commute to work in the city. They are intelligent and hardworking, yet anonymous and underpaid. Major concerns have been given to them in terms of unemployment situation and living condition of them in the large cities (A. Jacobs, 2010). More recently, some scholars have also pointed out that the concentration of students (including newly graduates) in certain urban areas has resulted in significant neighborhood change, which they call studentification (Smith, 2002). Based on the investigation in the student villages in Guangzhou, He (2014) addresses studentification as a process of re-urbanizing the 'village in the city' through bringing in urban living/urban consumptions. She argues that studentification has the potential to become a solution to sustain and upgrade the villages in the city. Students/new graduates might be a great proportion of migrants in many first-tier cities which impose great impact on the city structure, however, they might less important in the third-tier cities which are usually less attractive to young graduates.

\subsubsection{Heterogeneous migrant settlements}

In other cities such as Guangzhou and Shenzhen, migrants are concentrated in the villages (VICs) in the city center (F. Wu et al., 2012). These migrants are usually from a wide range of origins and occupations, and their concentration in one place are mainly due to housing availability. Those heterogeneous migrant settlements usually do not have strong ties in culture, social connection and economy. 


\subsubsection{Research on migrant settlement and urban spatial development in Chinese megacities}

The large cities, in particular, attract the most migrants due to a perception of more job opportunities and better-paid salaries. Despite the State Council's efforts to one redistribute migration flows, such as loosening the limitations on migration to small and medium-sized cities, and allowing migrants who satisfy certain criteria to obtain local hukou, rural-urban migration towards the larger cities has continued unabated in recent years (UNDP, 2013). The top one percent of cities, in terms of population, receive nearly half the country's temporary migrants (T. Liu, Qi, Cao, \& Liu, 2015). As a result, extensive studies on migrants and migration have been done in the first-tier megacities such as Beijing, Shanghai and Guangzhou (Liao \& Wong, 2014; Lin et al., 2014; Yuting Liu et al., 2010; W. Wu, 2008; Siqu Zheng et al., 2009). They have analyzed the general pattern of migrant settlements, the settlement formation mechanisms and the general impact on urban development. Due to a shortage of affordable housing inside central Chinese cities and limitations on where people without urban hukou are permitted to live (Wang et al 2010; W. Wu, 2002), migrant settlements are often located on land officially classified as rural (typically referred to as "village" land), and thus outside the system of urban land regulation. Studies of migrant settlements in Beijing and Guangzhou identify two different types of migrant settlements in contemporary China: "migrant villages on the city periphery" and "villages in the city" (Gu \& Shen, 2003a; Xue \& Huang, 2008). "Migrant villages on the city periphery" describes the spatial location of migrant settlement areas within village land in the city periphery. The spatial structure of migrant settlements in Guangzhou has evolved differently in village enclaves within the municipal center known as "villages in the city' rather than in the city periphery (P. Li, 2002; Ye Liu, Li, Liu, \& Chen, 2014; F. Wu et al., 2012). As such, 
according to Beijing and Guangzhou, we know that the location of village-held land and the emergence of place-of-origin linked migrant settlements have been important.

However, despite many third-tier cities ${ }^{3}$ which comprise the overwhelming majority of migrant settlements, the impact of migrants on urban form and development in such cities is not well understood. Paradoxically, urbanization of those cities especially shows a dual-process development, which is driven by both the growth of township enterprises-bottom-up and spontaneous growth, and by the central city's expansion-top-down and metropolitan-based growth. Along with the growth of township and village enterprises (TVEs) and the thriving private economy, the massive number of rural migrants who flood to cities end up working in informal sectors such as construction and manufacturing without contracts, and live in low-cost but crowded and unsanitary informal housing. Therefore, studies on those fast-growing secondtier cities are important and have the potential to enrich studies of migrant settlement and urban form for different scales of cities.

\subsection{Summary}

The process of migration and settlement has been one of the defining features of urban development and place making in the globalizing world. Early studies in Western countries and the developing countries have considered migration and migrant settlements as an important feature and have placed great impacts on the spatial structure of cities. Although there have

${ }^{3}$ China's City Tier System is widely used in the public and media. It divides cities into different tiers by their political status, economic strength, population size and regional influence. "Third-tier cities" in China refer to these fast-growing small and medium-sized cities, which are usually sub-regional centers, such as Wenzhou, Zhuhai and Jilin. 
been many studies of the migration process and the lives of migrants in China, there has been less attention to the impact of this migration on urban form. As China's mobile migrants, who lie between traditional urban and rural sectors, go through processes of territorialization, deterritorialization and reterritorialization in the urban area, they contribute to the development of hybrid urbanisms and new types of conjoined city regions. Based on the urban assemblage theory, this dissertation examines the ways in which the mobile migrant population-as "an irruption", has contributed to city's emerging urban form.

Furthermore, extensive studies on migrants and migration have been done in the firsttier megacities such as Beijing, Shanghai and Guangzhou. Despite the growing numbers of migrants in third-tier cities, the impact of temporary labor migrants on urban form and development is not well understood. Most studies place the formation and spatiality of migrant settlements within the frameworks established in the megacities - especially Beijing's peripheral migrant settlements, and Guangzhou's "village in the city" model. As such, this study challenges the existing literature on Chinese city that overemphasizes a few well-known mega cities and calls for attention to those less studied but important to theorize in urban form. The results have the potential to enrich the understanding of the different ways in which migrant villages are integrated with overall urban form other than those two well-known models. 


\section{CHAPTER 3}

\section{WENZHOU'S HISTORICAL DEVELOPMENT, URBAN FORM AND MIGRATION}

\subsection{Introduction}

Wenzhou, one of the 14 coastal cities that opened to foreign investment in 1984 , is situated in the southwest corner of Zhejiang Province. With jurisdiction over three districts, two county-level cities and six counties, it covers a land area of 11,784 square kilometers, with a total population of 9.12 million in 2012 (Fig. 3.1). As one of China's model cities for reform-era (post-1980) economic growth, Wenzhou has experienced rapid development and is often analyzed in terms of the role it has played as a model for the privatization and entrepreneurialization of China's economy. Since 1985, China has used Wenzhou as one of three models ${ }^{4}$ for the development of private enterprises. The essence of the "Wenzhou model" (Wenzhou moshi) is a system of production that is centered on family enterprises and embedded in thick local institutions (Forster, 1990; A. P. L. Liu, 1992; Kristen Parris, 1993; Wei, 2007). These local institutions were integral to Wenzhou's historical and cultural traditions that had long contributed to the city's success as a trading center. This local economic culture, deeply-rooted in family-run enterprises and trade networks, appealed to the 1980's reform-era efforts to reestablish entrepreneurialism in Chinese cities which had been dominated by staterun enterprises. The national attention brought to Wenzhou by its elevation to a "model" for

\footnotetext{
${ }^{4}$ The Wenzhou model along with the Sunan model, the Pearl River Delta model have been used as economic development models in the beginning of China's reform era. The Sunan model attributes the development of Sunan (Southern Jiangsu) to local state-directed townships and village enterprises (TVES). The Pearl River Delta model refers to the foreign direct investment (FDI) development, due to their close location to Hong Kong and Macau.
} 
economic reform, led to an economic boom from 1985 to 2000, with an annual growth rate of 23 percent (WMBS, 2011). Wenzhou has developed from a quiet small village to a thriving city. This economic success, while deeply embedded within Wenzhou's cultural traditions, has also brought fundamental changes to Wenzhou's local culture and urban spatial structure. This chapter introduces the processes of Wenzhou's urban development and analyzes how the region changed from an out-migration region to an in-migration region since1980s.

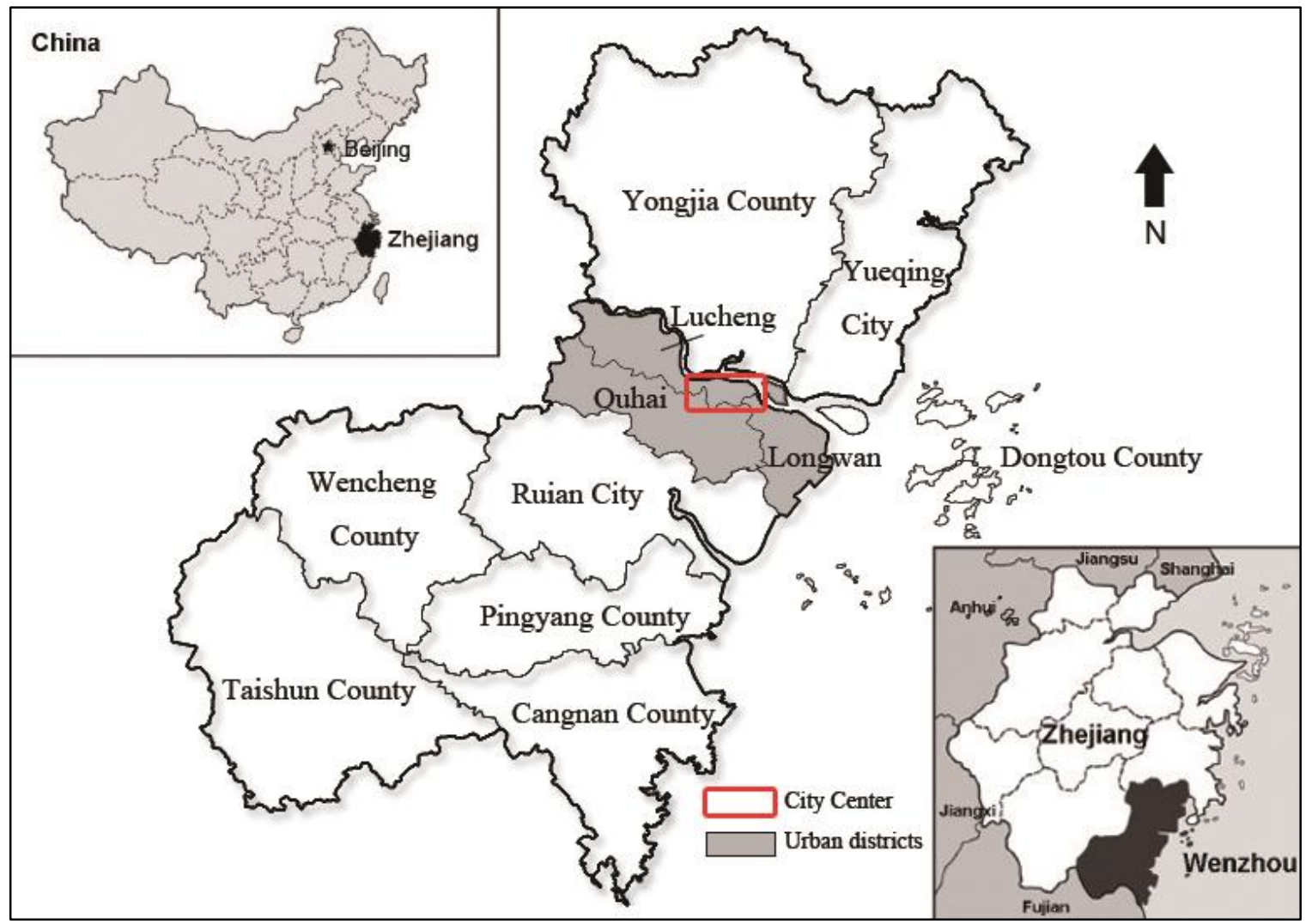

Figure 3.1 Location map of Wenzhou

Source: Basemap adapted from: Wei, Y. (2009). China's Shoe Manufacturing and the Wenzhou Model: Perspectives on the World's Leading Producer and Exporter of Footwear. Eurasian Geography and Economics, 50(6), 720-739. 


\subsection{Historical development, urban form and migration}

\subsubsection{Trading port era (Pre-1949): commerce, specialized production and out-migration}

Wenzhou's traditional role has been as a trading port with flourishing commercial activities. Located in the mountainous southeast of Zhejiang province, Wenzhou has a very limited amount of arable land and poor ground transportation connections with the interior. However, the people of Wenzhou have turned this disadvantaged natural condition into comparative advantage by using its coastal location and riverine topography. During the Song Dynasty (A.D. 960-1279), the people of Wenzhou made good use of the market demand engaging in specialized craft productions, such as textiles and clothing, paper and printing. These products were mostly traded to neighboring countries by sea, such as Japan, Korea and Cambodia. Moreover, Wenzhounese became highly mobile and skilled in long-distance trade, which enabled Wenzhou to sustain larger population than its geography and natural situation would have allowed (A. P. L. Liu, 1992). However, in the later Ming and Qing Dynasties, due to fear of foreign invasion, the Wenzhou port was closed to foreign trade according to the jinghai (closing the sea) policy. Although sea trade and commodity production were seriously hampered by this new policy, some Wenzhou traders emigrated overseas to pursue their business at the turn of $20^{\text {th }}$ century (L. Zhang, 2001).

The urban morphology of old Wenzhou city is similar to other ancient cities. It was a walled city with major streets and architecture oriented on the cardinal directions, conforming to a grid pattern (Gaubatz and Wu, 2012, p50). The whole city was composed of nine towns with five of them located inside the walls and four of them outside. The five towns inside the walls held most of the population - two thirds of the population lived inside the walls in 1937. The 
nature-based layout and appearance of old Wenzhou city had several remarkable features: with the main administrative compound in the geometric center of the whole city, the city had two major streets -Nanbei street and Xinhe Street came from North to South and four much shorter streets-Baili, Kangyue, Mochi, and Wuma street from west to east (Fig. 3.2). Other streets which ran either from north to south or west to east divided the whole city into different squares which were called fang at that time. In addition to the Ou River in the north and moat outside the city wall, Wenzhou was also known as a water town due to its well-developed water system. The old streets are paved with brick and stone, and many run alongside small canals. "One fang, one canal, one bridge" was the basic feature of the old city during the Qing dynasty.

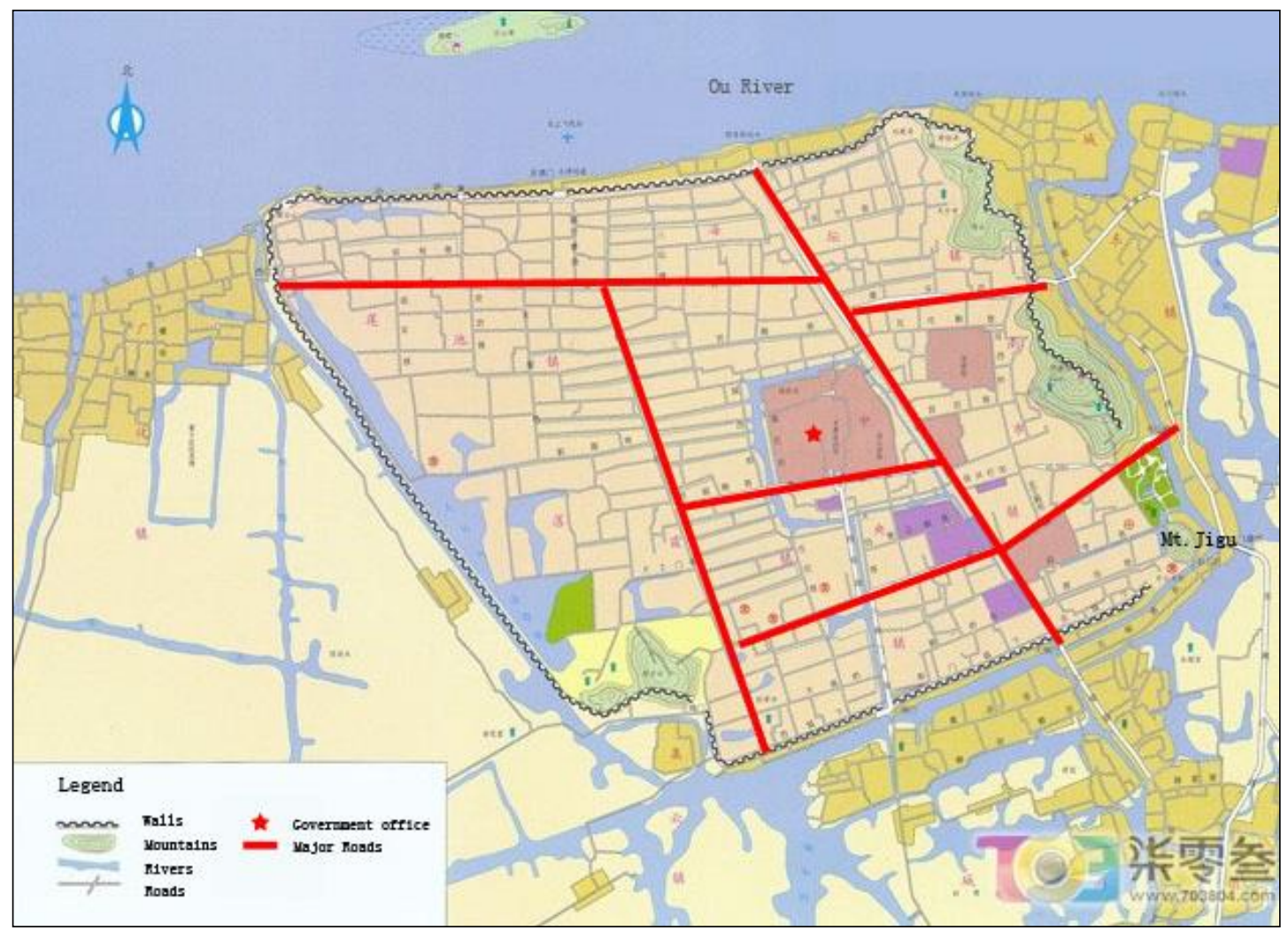

Figure 3.2 The map of Wenzhou in 1937

Map source: Adapted from map found online, http://www.wzu.edu.cn/Art/Art_6/Art_6_60579.aspx 
After the Sino British treaty of Yantai in 1877, Wenzhou was opened to foreign trades and became one of the foreign treaty ports. With the establishment of the consulate general of Britain on Jiangxin Island, European style churches, schools, hospitals appeared in the old city center. Wuma street (the walled city region), is a landmark of Wenzhou's traditional shopping street, which retains many European-style structures. Wenzhou's commercial and handicraft industry developed quite fast during this period. The development of the shipping lines between Wenzhou and other port cities such as Shanghai boosted foreign trade. During this period, it was common for Wenzhou's businessman to travel abroad to sell commercial goods. However, due to its remote location and poor transportation connect to inland China, as well as unique topology that trapped by three sides of mountains, Wenzhou was less impacted by the foreign countries than other port cities such as Shanghai, Guangzhou. The spatial structure of traditional Wenzhou city remained quite the same until the Republican era. As it was recorded in British Admiralty handbook for China, some of the streets in Wenzhou "have been widened and modernized and new buildings erected, but the town still remains essentially Chinese." The report continues, "There is no foreign settlement and the foreign residents have been limited to a few missionaries and trade officials... There has been no industrial development." (The Great Mirror, 2007)

During the Republican era, there was a significant decline in traditional urban structures and landscapes. Starting from 1927 when the walls around the Jigu Mountain was firstly destroyed to make way for the construction of Zhongshan park, the old city walls were destroyed and torn down piece by piece. In 1945, almost all of the old city walls were torn down except few ruins left in Huagai Mountain (M. Zhao, 2009). The canals used to be the major transportation, were gradually filled up and reclaimed to meet the need for the growing 
population from the republican era to $1970 \mathrm{~s}$. In addition, with the development of commercial streets, the function of the city center transferred from single political function to a more diverse one.

Wenzhou in the treaty port and republican era although expanded in terms of population, trade, and industry production, the physical extent of which was still limited to the "walled area" - despite the real walls had already been destroyed (Fig. 3.3). One of the determining reasons of this is that located in such a mountainous and remote area, Wenzhou was still quite isolated from outside without any outward roads at this time. The main connections to the outside was by sea or using waterways. Therefore, there was only a little expansion to the west and south of the old city because of the well-developed waterways. 


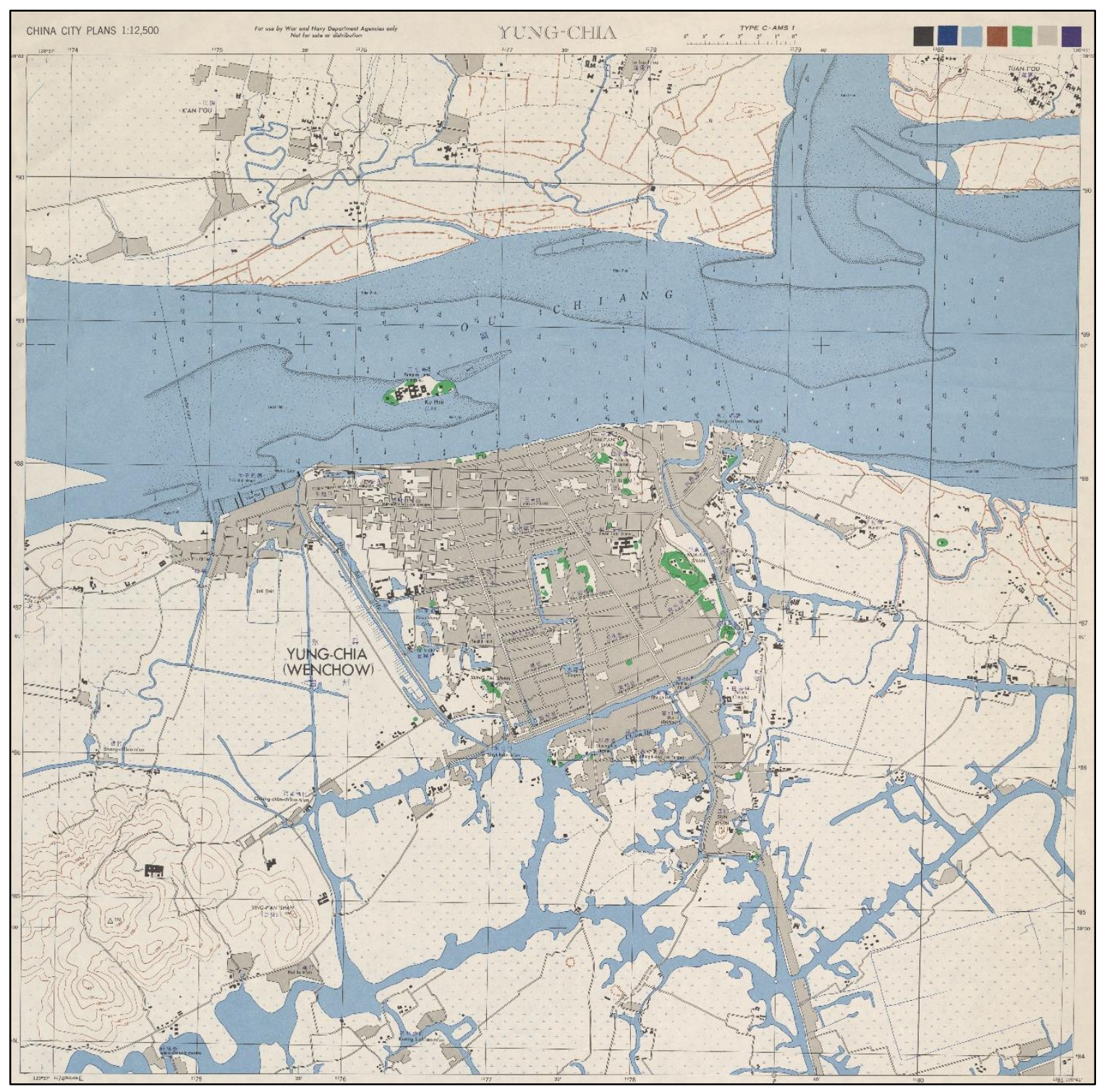

Figure 3.3 Map of Wenzhou in 1945

Map source:http://www.lib.utexas.edu/maps/ams/china_city_plans/txu-oclc-6567068.jpg [Wenzhou] Yung-Chia 1945,U.S. Army Map Service, 1:12,500. Courtesy of the University of Texas Libraries, The University of Texas at Austin. 
Wenzhou's population has increased tremendously in the beginning of $20^{\text {th }}$ century, with the rising manufacturing industries and an influx of refugees escaping from civil wars and the Japanese invasion. However, the land of Wenzhou was not able to sustain the growing population. Gradually, out-migration to seek better living and long-distance trade grew to be another of Wenzhou's traditions. The emigration trend continued unabated (A. P. L. Liu, 1992). These Wenzhou migrants played a determining role in Wenzhou's economic success, by providing the initial capital for the industrial enterprises and acting as "sales agents" for Wenzhou (Liu, 1992).

\subsubsection{Maoist Wenzhou (1949-1978): isolation and out-migration}

After 1949, Wenzhou and the entire Zhejiang province, suffered from serious political discrimination under Mao and were generally ignored by the central government. This was partly due to Zhejiang's being the home province of Chiang Kai-shek, who was the leader of the Nationalist Party, and partly due to its proximity to Taiwan which makes it vulnerable to war damage (A. P. L. Liu, 1992; Kristen Parris, 1993). It was among the cities that received the least amount of national investment. From 1950 to 1978, the average per capita investment from the central government was 600 CNY nationwide, 240 CNY in Zhejiang Province and only 88 CNY in Wenzhou. The per capita investment in Wenzhou was only one seventh of the national level (Hu, 1987). As such, while State owned enterprises (SOEs) dominated the industrial production in most of the cities and provided most of the jobs during Mao's era, the scale of SOEs in Wenzhou was small. Only seven SOEs had over 1,000 employees. Another twenty SOEs had 500 to 1,000 employees (Chen \& Ma, 2007). At the same time, Mao's preference for collectivization and socialist enterprises required Wenzhounese to stay put and farm. However, arable land in 
the mountainous Wenzhou region is scarce, with only 17 percent of the total territory in plains; per capita arable land is 0.02 ha which is one third of national average (Wei, 2007). Wenzhou was not able to sustain its growing population. The situation was even worse after the Great Leap Forward (1958-1960) and the Cultural Revolution (1966-1976), Wenzhou's economy declined rapidly. Private businesses were suppressed by the state because they were seen as "the tail of capitalism" which would erode socialism and restore capitalism (L. Zhang, 2001). While the population more than doubled from 2.76 million in 1949 to 5.61 million in 1978, Wenzhou was burdened with a deepening demographic crisis in the 1970s.

On the one hand, the poor situation forced Wenzhounese turn to overseas for commercial trade and continue migrating to particularly European countries. On the other hand, "illegal" private industry was emerging underground. "Weaving one night rather than farming one year" (Zhongtian yinian buru fangzhi yiye) was a popular old saying among Wenzhounese. Developing industry was the only way for Wenzhounese to conquer the poverty. Thus, even under the harsh political circumstances, a number of peasants created and managed to run small private businesses under the name of branches of SOEs, which was known as the "guahu" or "hang-on household". Those guahu companies attached themselves to an established collective or state owned enterprise, paying a fee for the use of its name, stationery, letters of introduction and, most important, bank account numbers and receipt books, as well as taxes paid on its income (Parris, 1993). They were private businesses but under the disguise of SOEs, which was also known as "wearing a red hat" (dai hongmaozi). In this way, Wenzhou's private economy was already quite active even before the Economic Reform began in 1978.

During this period, Wenzhou city's total built-up area expanded from 6.3 sq.km in 1949 to $8.92 \mathrm{sq} . \mathrm{km}$ in 1988 (M. Zhao, 2009). With the lack of investment and the constraints of 
mountains and the East China Sea, Wenzhou's urban development was mostly limited within the old wall, which is mostly inside the range of Wuma Street in current administrative boundary (the old Lucheng district). Wenzhou was one of only two cities in China with more than 400,000 population without a railway connection. The only two roads that connect the suburbs were built between 1956 and1959, which are Xishan road to the west and Wenzhuang road to the east (indicated red on the map) (Fig. 3.4). As the old saying in China goes-"Building the road is the first step to becoming rich," without railways and expressways to connect it to the outside world, Wenzhou was one of the most economically-backward cities in eastern China (Forster, 1990). The urban structure of Wenzhou city remained a single center with gradual expansion in three directions from the old city center to the west, south and east. 


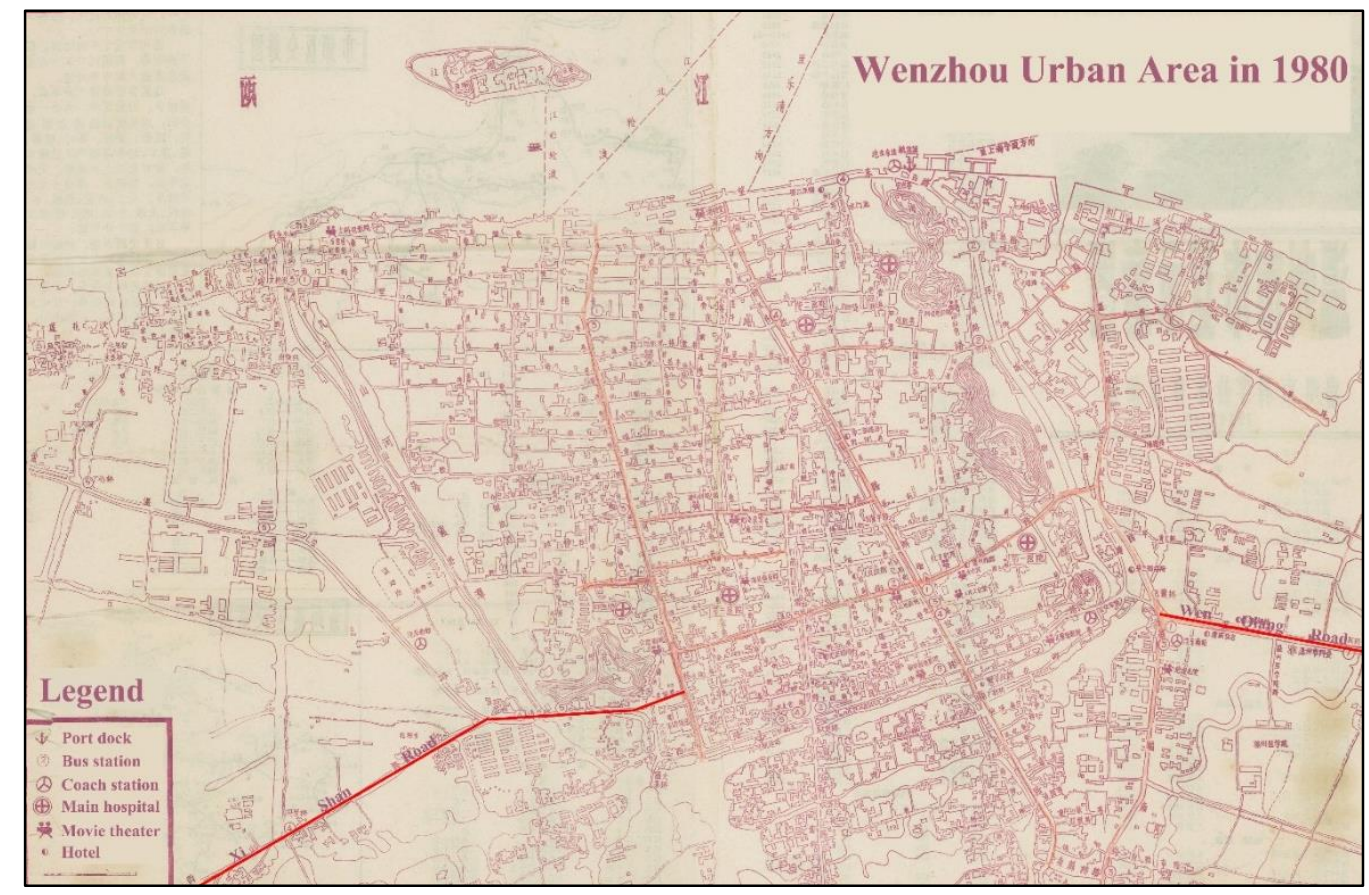

Figure 3.4 Wenzhou urban area in $\mathbf{1 9 8 0}$

Map source: Wenzhou Science and Technology Association (1980). Wenzhou Urban District. The original map is collected by the author from Wenzhou Urban Construction Archives during the fieldwork in Wenzhou. Adaptation is made by the author.

\subsubsection{Post-reform era (1978-2000): economic model, spatial expansion and in-migration}

After the Reform Era began in the late 1970s, Wenzhou was the first city to set up individual and private enterprises as well as a shareholding cooperative economy. This economic reform, based on Wenzhou's traditional local institutions, became one of the most prominent influences on urban and regional development patterns in China (Tomba, 1999; Wei, 2007, 2009, 2011; R. Zhang, 1994; Z. Zhang, 1989). At the very beginning of China's economic reform in the 1980s, Wenzhou's "quasi-capitalism" led to nationwide criticism, skepticism and heated debate (R. Zhang, 1994; Zheng, 2007). Critics who held conservative views of the reform commented "if one wants to see the restoration of capitalism in China today, go to Wenzhou" (Z. Zhang, 1989). It was not until the late 1980 s that the Wenzhou model finally secured a 
legitimate position and was widely publicized as a model for economic reform. The successful economic reform had lifted Wenzhou from obscurity to national and international prominence, and received worldwide attention (Nolan \& Dong, 1989; K. Parris, 1993; Sonobe, Hu, \& Otsuka, 2004; Ye \& Wei, 2005). Wenzhou became a major source of "Made in China" goods such as shoes, clothes, and cigarette lighters, and a leader in the world's light manufacturing sector with its success riding on the export-oriented.

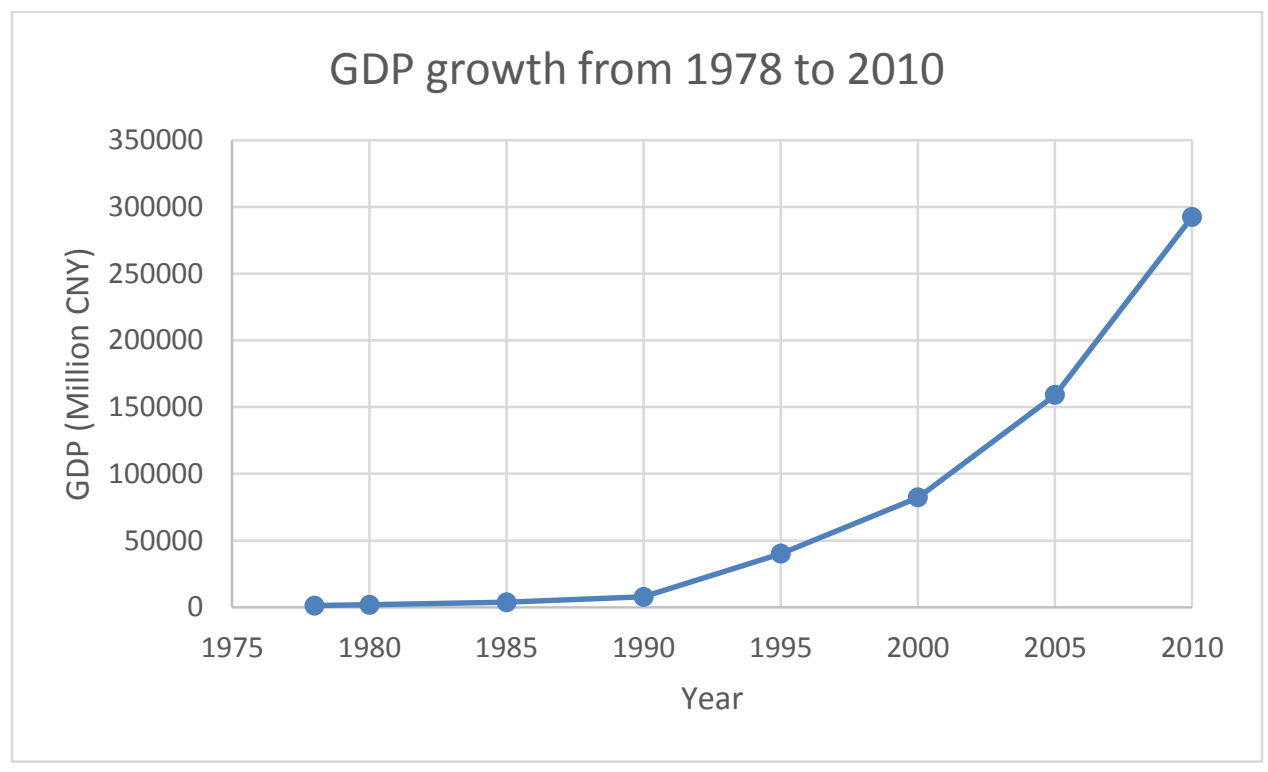

Figure 3.5 Wenzhou's GDP growth from 1978 to 2010

Data source: Wenzhou Municipal Bureau of Statistics (Ed.). (2011). Wenzhou tongji nianjian [Wenzhou Statistical Yearbook]: China Statistics Press.

Not surprisingly, along with the rapid economic development, the spatial structure of Wenzhou changed tremendously. Firstly, one of the principle features of Wenzhou's new urban landscape is the formation and transformation of the inner ring and the urban fringe with the newly established industrial development zones. Secondly, Wenzhou's city center has grown substantially with both expansion of the old city center and the construction of a new 
administrative center on the east of the old city center. Last but not the least, migrant settlements have gradually emerged mainly around the industrial parks in the urban fringe, which represent a new type of urban low-class clusters contributing to Wenzhou's emerging urban form.

\subsubsection{1978-1990}

After inspection by leaders at both the provincial and national level, the Wenzhou model (Wenzhou moshi) for economic reform was finalized and received great publicity throughout the whole country. Wenzhou was appointed as one of the 14 coastal cities that opened to foreign investment in 1984. In the same year, Longwan, which was a suburban town east of traditional Wenzhou city, became a new urban district of Wenzhou (the other one is Lucheng district). The urban built-up area expanded from 13 sq.km in 1985 to 27 sq. km in 1990. Wenzhou's economy developed rapidly with the GDP of 7.79 billion in 1990, which is about 6 times the city's GDP in 1978 (WMBS, 2011). The economic structure of Wenzhou changed substantially from an agriculture-based one to a secondary industry based economic system (Fig. 3.6).

During this period, the most dramatic change occurred in the rural area, where the household industries contributed to the largest proportion of the product output. The number of household industries rose from 1,844 in 1979 to 150,000 in 1988 (Table 3.1). Rural private and family owned enterprises made up 81 percent of the total number of licensed firms in mid1984, compared with 52 per cent the previous year. Townships developed rapidly by engaging in specialized manufacturing products, such as Qiaotou's button industry in Yongjia County, Liushi's low-voltage equipment product (e.g., switches) in Yueqing County, Jinxiang's aluminum 
badges, and plastic film products in Cangnan County. Moreover, not only the surplus labor from the farms, but also the farmers became self-employed salesman, factory owners, and employees. The average income of Wenzhou peasants was 50 percent above the national average in 1989 (924 yuan in Wenzhou as compared to 601 yuan for the nation), which had been among the lowest in the nation before 1980 (A. P. L. Liu, 1992).

"Qiaotou button market in Yongjia county which developed from a small, "spontaneous", plastic flower market in the 1970s to nation's largest button market in 1991, with over 1,900 wholesale vendors and a daily turnover of over 500,000 yuan. Initially most of the buttons were brought in from other areas but soon household industries began producing them and in the early 1990 s the county was providing 80 percent of China's buttons." (Parris, 1993)

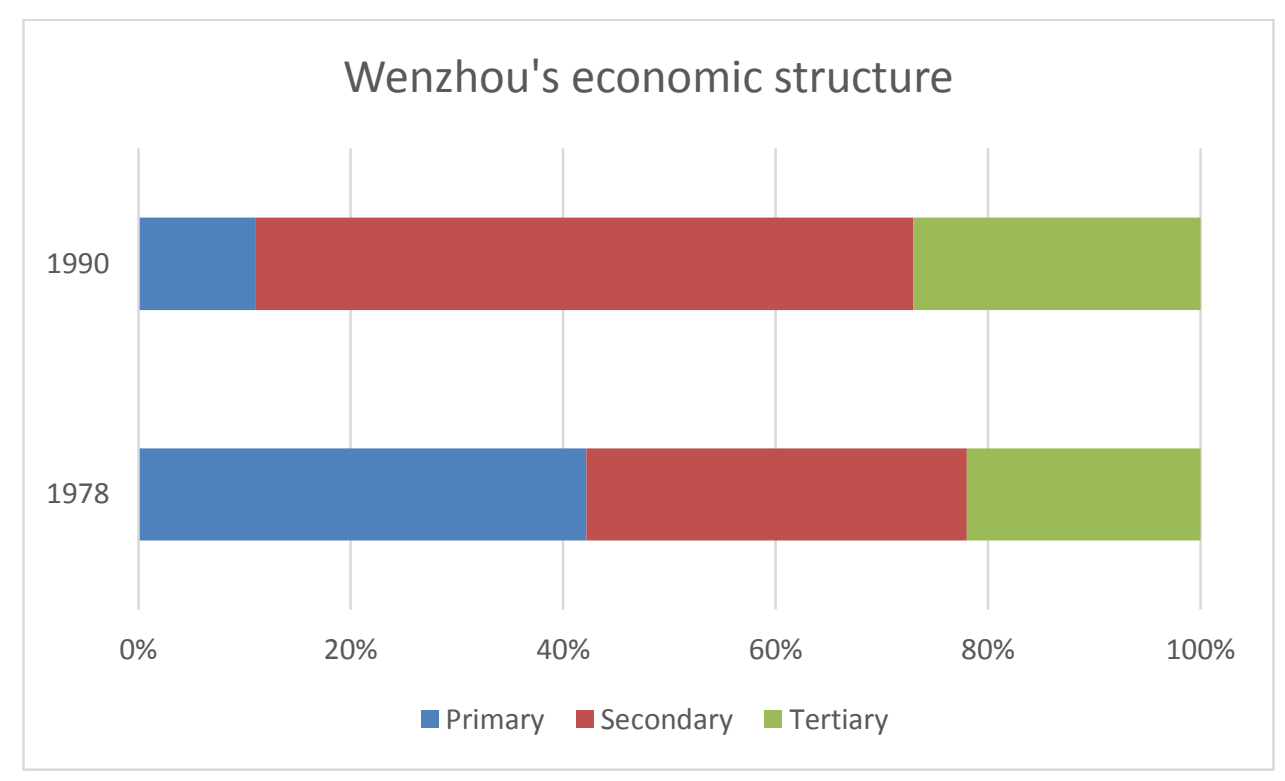

Figure 3.6 Wenzhou's economic structure in 1978 and 1990 
Table 3.1 Household Industries in Wenzhou, 1979-1988

\begin{tabular}{lr}
\hline Year & Number \\
\hline 1979 & 1,844 \\
1981 & 13,231 \\
1982 & 20,363 \\
1983 & 39,698 \\
1984 & 100,286 \\
1985 & 130,407 \\
1988 & 150,000 \\
\hline
\end{tabular}

Sources: Liu, A. P. L. (1992). The "Wenzhou Model" of Development and China's Modernization. Asian Survey, 32(8), 696-711; He Rongfei, Zheng Dajiong, and Majinlong, eds., Wenzhou jingji Geju [General pattern of Wenzhou economy]. Wenzhou: Zhejiang Renmin Chubanshe, 1987, pp. 133-35; 1989 Zhongguo Jingji Nianjian, part iv, p. 105.

However, compared to the rapid rural industrialization, the development of Wenzhou's urban districts were quite slow. After thirty years of neglect from both national and provincial level, investment in infrastructure has failed to keep up with the rapid economic growth in Wenzhou city. Although Wenzhou was listed as one of 14 coastal cities that opened to foreign trade since 1984, it was the only one of those cities without any railway or airport. Even with the newly constructed roads in the old city center, it was still hard to support the increasing population as well as the traffic growth. The per capita service infrastructures and amenities such as schools, hospitals were far below the national level. Communications, even with the provincial capital city-Hangzhou, are difficult and inconvenient. The steep mountain road and bumpy roads terrified lots of leaders who came from other provinces to investigate Wenzhou's economic development, complaining that Wenzhou is a place that you must come, but never come again. 


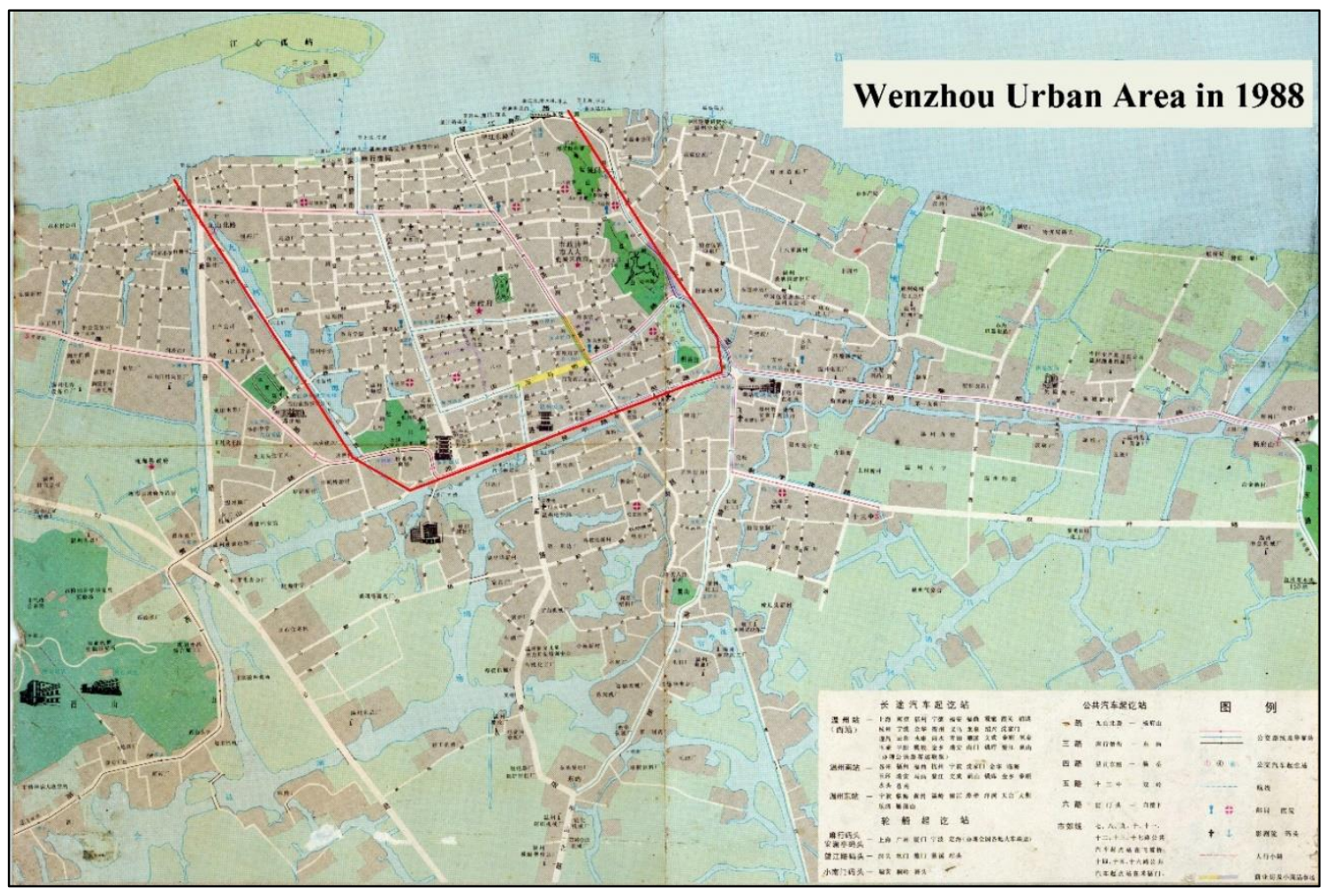

Figure 3.7 Wenzhou urban area in 1988

Map source: Surveying and Mapping Bureau of Zhejiang Province \& Office of Weznhou's Local Chronicles (1988). Transportation Map of Wenzhou Urban Districts. The original map is collected by the author from Wenzhou Urban Construction Archives during the fieldwork in Wenzhou. Adaptation is made by the author.

The total investment in fixed assets has increased from 37.62 million CNY to 1.76 billion CNY during this period. Twelve new residential communities have been developed either in the inner ring or new urban districts. The basic layout and design of a new residential community is no more than five-floor apartments lining in parallels. The design of new public architectures are more diverse. In 1985, the first high-rising public building-Dong'ou hotel was built. In the next couple decades, various high-rise buildings were built which expanded the city structure in the vertical direction. Meanwhile, due to lack of proper urban planning, the city center was characterized by a mixed pattern of land use and industrial fragmentation. Family workshops or 
small factories were everywhere in the city, including some of which are encircled by the residential area.

Wenzhou only started to attract migrants in the mid-1980s. Many of these migrants came from nearby inland provinces, such as Jiangxi Province, which had not been part of the "open cities" program. The number was about 97,400 in 1990. Most of them worked for the small family workshops that spread all over the city and the rural areas.

\subsubsection{1990-2000}

After Deng Xiaoping's visit to the southern parts of China in 1992, China's economic reform changed from skepticism about the private (siying) economy to welcoming the development of diverse economies. Wenzhou's economy developed substantially in this period with GDP growth more than 10 times of 1990. In 1992, Ouhai became the third urban district of Wenzhou. The total urban built-up land expanded tremendously, from 27 sq.km in 1990 to 108 sq. $\mathrm{km}$ in 2000 with an annual growth rate of approximately 15 percent. This is one of the most important decades for Wenzhou's urban spatial development with the major focuses on the old city redevelopment, infrastructure improvement and industrial relocation. The whole city's structure has changed fundamentally.

For many Chinese cities, one of the structural changes from Maoist cities to Post-reform cities was the establishment of industrial development zones, which were designed to attract foreign and extra-regional investment (Gaubatz, 1998). When Wenzhou first proposed to establish such a special zone in 1984, it was rejected by the state government for its lack of skilled employers and basic infrastructure and services. In 1987, Wenzhou established its own export processing zone-Longwan Export Industry Zone-without any funds from the central 
government. It was about 0.88 sq.km when it was firstly established. In1992, Longwan Export Zone was upgraded to "Wenzhou Economic and Technological Development Zone" (WETDZ) with the approval of the State Council. The establishment of WETDZ not only accelerated Wenzhou's economic development, but also reoriented development priorities from the old city core to Longwan district. As such the urban form majorly expanded along the Ou River from the old city center to the east.

Since then, a number of new economic and technology development zones, simply called industrial parks, have been gradually established in the inner ring as well as in the counties, including Wenzhou Poverty Relief Program Development Zone (1992), Yueqing Economic Development Zone (1993), Ouhai Economic Development Zone (1994), Rui'an Economic Development Zone (1994), Pingyang Economic Development Zone (1994), Wenzhou High-tech Development Zone (1998), China Shoe Capital Industrial Park (1999), Wenzhou Economic and Technology Development Zone (2000), and Wenzhou Lucheng Light Industrial Garden (2002) (Fig. 3.8). These industrial parks were not established from nowhere or randomly, mostly were according to their original economic base. China Shoes Capital Industrial Park, for example, is located in Shuangyu which already has a cluster of many shoe manufacturing factories. Since the establishment of the industrial park, Shuangyu has attracted many more similar industries to relocate. As such, a new trend in this period was the relocation of industries from the city center to these industrial parks which mainly located in urban fringe belt and counties.

This process of industrial relocation has freed up a significant amount of space in the city center and led to an industrial concentration in the inner suburb and county towns. Various development zones also changed the urban structure from compact to a more dispersed one. 


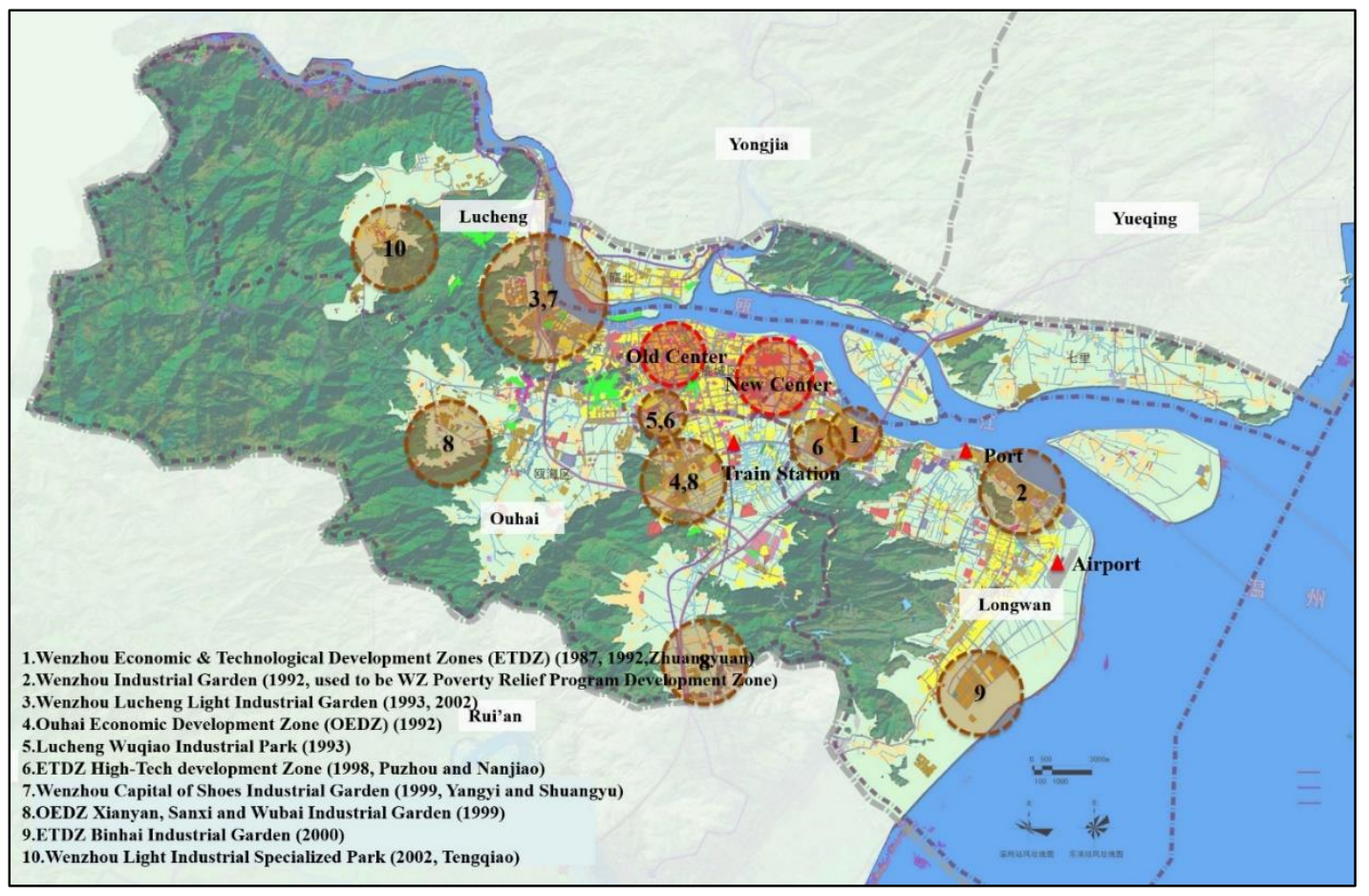

Figure 3.8 Industrial parks in Wenzhou's Three Urban Districts

Note: This map only shows the industrial parks in three urban districts.

Basemap: Land use of Wenzhou's urban districts in 2010

The inner ring of Wenzhou developed at a fast pace during this period. The newly

formed industrial parks in Wenzhou, which are mainly labor-intensive based light manufacturing industries, started to attract significant amount of migrants from bordered provinces such as Jiangxi, Anhui, came to Wenzhou to make a living. The number reached 1.35 million in 2000, from fewer than 100,000 in the 1980 s. When they first came to Wenzhou during the 1990 s, most of them worked in family workshops which were sporadic in the city centers, and later moved to the inner suburb followed the job diffusion. As a migrant who came from Jiujiang, Jiangxi province recalled, he was working in a family workshop in the city center when he first time came to Wenzhou in 1991, and moved to Shuangyu due to the fast development of the China shoe capital industrial park. 
Meanwhile, the city center of Wenzhou also experienced substantial redevelopment. With the deepening population crisis, redevelopment of the city center was urgent. Starting with the reconstruction of the Renmin Road at the end of 1980s, Wenzhou carried out a redevelopment plan for the city center including reconstruction of 16 major roads and development new residential area. The plan dismantled housing designated as "dangerous and old" along the major streets and built up new high-rise buildings instead, which was about 23 percent of total building area. The redevelopment area covered 37.9 percent of the old city range. The reconstruction of the buildings along the major streets not only changed the city's image but also generated large amount of profits. The newly built high rise buildings which are usually well designed with good facilities and service attracted more people from other parts of Wenzhou to come to live in the city center. In order to ease the housing pressure in the city core, most newly built residential areas were located in the inner suburbs, such as Shuixin residential community, Nanpu residential community. However, the high plot ratio increased the population density to 35,000 people per sq.km in the city center.

The fast development of the urban transportation system also contributed to Wenzhou's urban transformation. Realizing the importance of outside connections, Wenzhou invested more capital to develop the transportation system. The two most significant projects are construction of the first railway-Jinhua to Wenzhou railway (Jinwen railway) and the airport in Longwan district. Jinwen railway, constructed since 1992, was opened for operation in 1998. It starts from Jinhua city, crosses the western side of Lucheng district, and ends in Longwan district, Wenzhou. It was the first shareholding railway in China, funded by a Hong Kong company, Zhejiang provincial government and State Ministry of Railways. Its operation connected Wenzhou to other parts of Zhejiang Province, and further improved its economic 
development. Meanwhile, the connection with outside also stimulates the industrial development of the western part of Wenzhou. The other important project is Wenzhou Yongqiang Airport (now called Wenzhou Longwan International airport, 2013), which was put into operation in 1990. The central government contributed only 20 million of the total 130 million yuan in construction costs (Lu, 2008). Its completion offers a quicker and alternative ns of transport to outside. It is located in the east part of Wenzhou's new urban district-Longwan. Along with the establishment of Wenzhou Poverty Relief Program Development Zone in Longwan at the same time, Wenzhou city expanded mainly toward east to the East Sea (Fig. 3.9)., Thus the spatial structure of Wenzhou city was expanding along the Ou River to the west, and more importantly, to the east.

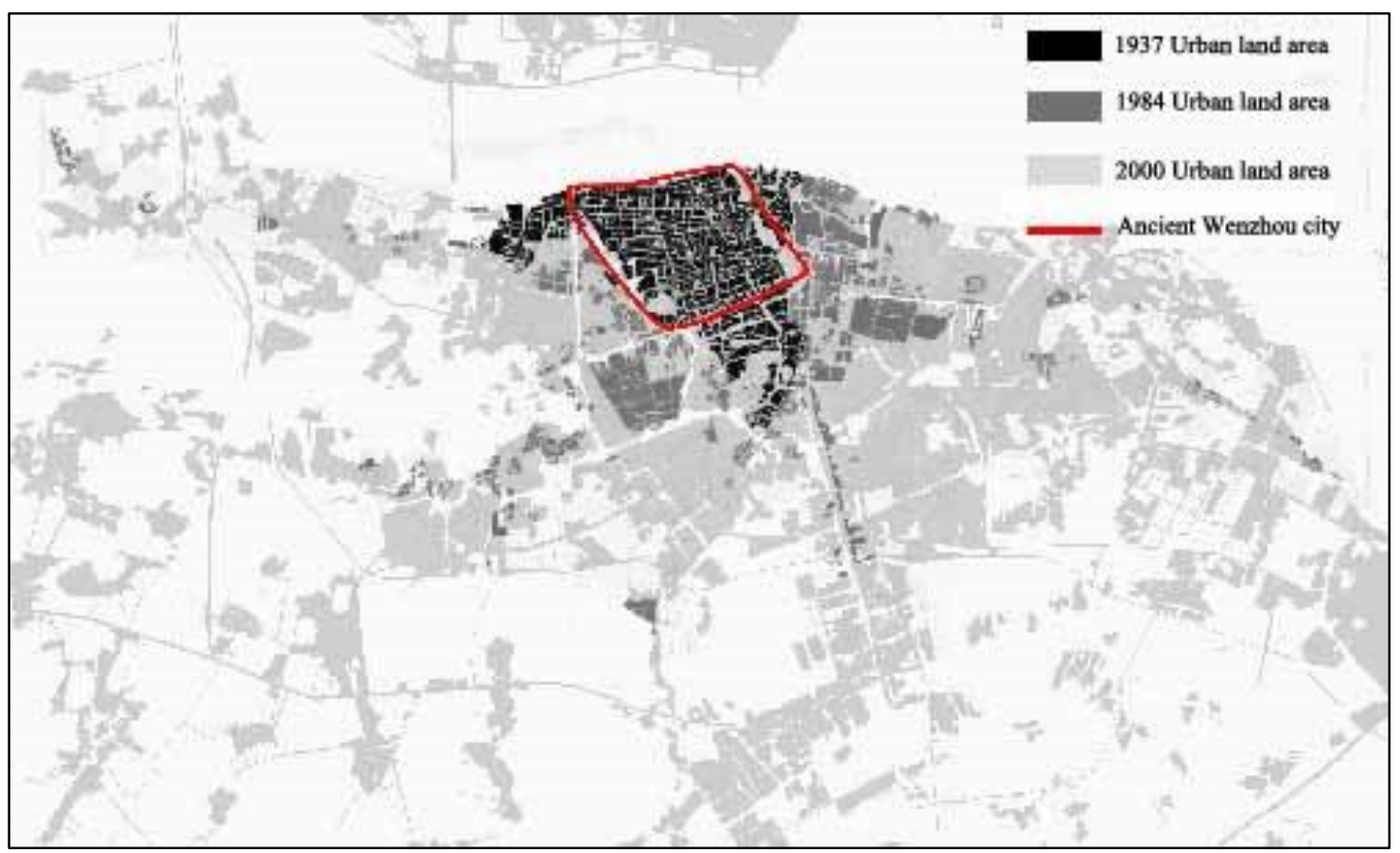

Figure 3.9 The growing urban land area from 1937 to 2000 Map source: The Special Issue Five-Research on the Urban Spatial Structure Planning in Wenzhou City Master Plan (2003-2020). (2004). China Academy of Urban Planning \& Design. P 51. Adaptation is made by the author. 
Following the fast industrial development and city expansion, one of the striking changes was the influx of a great number of migrants, which increased from 97,400 in 1990 to 1.35 million in 2000. Wenzhou was ranked the seventh among all the cities in China in terms of the number of migrants in 2000.

\subsection{Summary}

Exploring the historical development is important to understand the current development of Wenzhou. This chapter introduced the processes of Wenzhou's economic and urban spatial development and analyzed how it has changed from an out-migration region to an immigration region before 2000. Lacking of state investment and poor natural endowment, Wenzhou's initial economic success owes to its Wenzhou migrant and rural industrialization. Even before the Reform Era, Wenzhou migrants either acted as sales agents or businessmen who, while living overseas provided the initial capital for the development of industrial enterprises. Meanwhile, the limited arable land made it possible for many surplus laborers to engage in specialized goods production in the rural areas. Thus, unlike many other cities whose development mainly started in the city center, the fast development of Wenzhou was primarily initiated from the towns and villages, where massive household and family-run industrial enterprises had been established.

Due to a lack of urban planning, the urban development (including the infrastructure, amenities) relatively lagged behind the economic development. The spatial structure of Wenzhou was not significantly changed until 1990s. One of the principle features of Wenzhou's new urban landscape after 1990s was the formation and transformation of the inner ring and 
the urban fringe with the newly established industrial development zones. Secondly, Wenzhou's city center has grown substantially with both expansion of the old city center and the construction of new administrative center on the east of the old city center.

This chapter also reviews that Wenzhou has changed from an out-migration region to a major destination for in-migration. These migrants, usually from poor inland provinces, came to Wenzhou and worked in the manufacturing industries. 


\section{CHAPTER 4}

\section{MIGRATION, METROPOLITAN SPATIAL DEVELOPMENT AND MODERNITY IN WENZHOU}

\subsection{Introduction}

From 2000 to 2010, Wenzhou's economy continue to grow rapidly, with a 13.53 percent annual percentage growth rate. Along with this fast economic development, the spatial structure has changed substantially in both urban districts and the whole Wenzhou city. In the urban districts, the changes can be described as redevelopment of the old city center and construction of specialized zones. The primary spatial structural change of Wenzhou city as a whole is the emerging multiple-centered metropolitan form. More importantly, Wenzhou, which used to be seen primarily as an out-migration place, now has become one of the major destinations for migrants. As one of the early "opened-up" model cities, Wenzhou has attracted a large number of migrants from some poor inland provinces. In particular, the number of migrants has grown since mid-1990s ${ }^{5}$, when a large number of factories were moved to the industrial development zones and grew in size. They contribute to the formation of Wenzhou's current urban structure and are the majority in several districts. This chapter focuses on an analysis of the post-1995 development of migrant settlements, using census data from 2000 and 2010.

${ }^{5}$ Since the mid-1990s, Wenzhou has experienced both economic and spatial restructuring. The economic restructuring mainly refers to the transformation from relative small size share-holding cooperatives to shareholding enterprises and limited liability corporations, as well as conglomerations. Driven by both market forces and government-led industrial park construction, many enterprises have relocated to the inner ring areas to enjoy the larger industrial land and better infrastructure, as well as benefiting from industrial agglomerations. 
Specifically, this chapter reexamines the "Wenzhou model" not as an economic development strategy, but rather as a catalyst for new forms of urbanization in which migrants play a central role. It aims to understand the ways in which migration contributes to Wenzhou's emerging urban form in comparison with those already identified patterns in the megacities. In particular, I consider:

(1) What are the distinctive characteristics of migrants and the process of migrant settlement formation in Wenzhou in comparison to Beijing and Guangzhou?

(2) How are migrants spatially distributed in the city? In particular, how has the metropolitan form/spatial pattern changed from 2000 to 2010 ?

(3) How is the spatial distribution of migrant settlements in the city similar to or different from the patterns in Beijing and Guangzhou?

\subsection{Locating Wenzhou's migrant settlements: data and methodology}

\subsubsection{Data and methodology}

Compared to the population of permanent migrants, the "floating population", who reside away from the location of their official hukou, is difficult to identify and enumerate. Duration is one of the key factors--how long does one need to be away from one's original household registration location to be considered part of the floating population (Goodkind, 2002). The definitions of floating population used by the Ministry of Public Security in different cities throughout China vary. Beijing, for example, only counts those migrants who plan to stay in the city for more than one month for work or business purposes as floating population. Wenzhou considers those who plan to stay for more than three days in the city as floating 
population and requires them to get temporary registration within the first three days. As such, the total number of floating population varies not only in absolute terms, but also according to different ways of counting.

Generally, the National Population Censuses in China which are taken every ten years provide the most comprehensive and authoritative data on floating population. However, the standard definition of floating migrants also has changed through different censuses. To be counted as floating population in the fourth (1990) population census data, either one had to have resided somewhere for one year or more with a hukou elsewhere, or have resided somewhere for less than one year but have been away from the original hukou location for more than one year. In the fifth (2000) and the sixth (2010) population census, the standard duration was reduced from one year to sixth months. As such, to make it comparable, this chapter uses the fifth and the sixth population censuses to explore the changing patterns of migrant settlement in Wenzhou. In addition, only the fifth and sixth population census data of Wenzhou are detailed at the street (Jiedao) and township level. The other key factor is the distance that migrants need to be away from their official hukou to be considered as floating population - this varies from away from the hukou registered town but within the same city, to outside the city of registration, or outside the province of registration. For consistency and also based on the availability of the data, this chapter defines the floating population as those who are originally from outside the city where they currently reside, without further regard to distance.

Wenzhou city comprises three urban districts, two county-level cities and six counties with 132 township-level units (based on the new administrative adjustment in 2011), including streets for urban areas and towns (zhen) for rural areas (referred to in this dissertation as 
subdistricts). There were 267 subdistricts in 2000. Since 2000, Wenzhou has experienced two major rounds of administrative division adjustment--one in 2001 and the other in 2011. The first round of adjustment basically adjusted the areas within the three urban districts including Lucheng, Ouhai and Longwan. The second round of adjustment could be summarized as amalgamation of villages and towns (Xiangzhen hebing), and upgrading of some of the towns to urban streets. As mentioned above, this chapter mainly uses two sets of data, the Fifth Population Census (2000) and the Sixth Population Census (2010). The Sixth Population Census data (WZMPCO, 2013), was already adjusted to match the 2011 new administrative division. For better comparison, I then adjusted the 2000 census data to match the new administrative units in $2011^{6}$. Due to a lack of detailed georeferenced shapefile data for the township-level, the basemap used in this chapter is re-drawn by the author from the most recent map available (2011).

This chapter approaches the analysis at two different geographic scales--county-level analysis and subdistrict-level analysis. The county-level analysis first explores the general distribution pattern of migrant settlement in Wenzhou, then uses Location Quotient (LQ) as an indicator showing the spatial concentration degree of migrants in county-level in contemporary Wenzhou. LQ is commonly used as a way of quantifying how concentrated a particular industry,

${ }^{6}$ Basically, I traced those towns and streets back to 2000 which were combined or divided through the two rounds of adjustment, and added or subtracted the number accordingly. Most of the changes simply combined different towns and streets together, however, certain towns were divided into several street units, or have had parts taken out and added to other units, which are almost impossible to get the exact number. Therefore, the final numbers of migrants and permanent population are approximate or show as data unavailable on the map. 
cluster, occupation, or demographic group is in a region as compared to the nation. It can reveal what makes a particular region "distinctive" in comparison to the national average.

$$
L Q_{i}=\frac{M_{i}}{P_{i}} / \frac{M_{t}}{P_{t}}
$$

$L Q_{i}$ shows the concentration of migrant population in different districts as compared to Wenzhou city as a whole; $M_{i}$ means the migrant population in district $I ; P_{i}$ means the number of total permanent (long-term) residents ${ }^{7}$ in district $\mathrm{I} ; \mathrm{M}_{\mathrm{t}}$ indicates the total migrant population in the city; $\mathrm{P}_{\mathrm{t}}$ is the total permanent population in city. $L Q_{i}=1$ means equal migrant concentration degree in this district with the whole city; $L Q_{i}>1$ indicates a higher concentration rate of migrants in this district than the whole city; $L Q_{i}<1$ indicates a lower concentration rate of migrants in this district than the average.

In the subdistrict-level analysis, I then visualize the spatial distribution of migrants in Wenzhou. By using both indicators--number of migrants and proportion of migrants in total permanent population, I analyze the distribution pattern of migrant settlements in Wenzhou, and further discuss its relation to urban structural change. Finally, this chapter compares the influence of migrants on Wenzhou's spatial with Beijing and Guangzhou.

\footnotetext{
${ }^{7}$ Permanent (Long-term) population (changzhu renkou): according to the People
} Republic of China's Sixth Population Census, permanent population includes residents who have local hukou and currently reside in the city (town), registered migrant population who have been in the city (town) for more than six months, and residents who have local hukou and currently out of the city (town) for less than six months. 


\subsubsection{Who are Wenzhou's migrants?}

The number of temporary migrants in Wenzhou skyrocketed with the tremendous economic growth from 97,400 in 1990 to 2.84 million in 2010, with an average annual growth rate of 18.37 percent (Fig. 4.1). In many Chinese cities, particularly first-tier cities, where the economic structure is undergoing transformation from a secondary industry-based to a tertiary industry-based structure, migrants mainly work in the tertiary industry. In Beijing, for example, only 27.51 percent of total migrants work in the secondary industry while 71.02 percent of total migrants work in the tertiary industry (BJMBS, 2011). However, most Wenzhou migrants--about 78.8 per cent of the total-- work in secondary industry, primarily in light manufacturing factories, rather than the in service sector jobs such as hotel, restaurant, retail and wholesale work (20.5 percent). Meanwhile, since most of the enterprises in Wenzhou are labor-intensive and focus on light manufacturing, they have very little requirement for skilled labor. The average education attainment of migrants in Wenzhou is lower than the other large cities (Fig. 4.2). More than 87 percent of total migrants have an education level of middle school or lower. Only 2.44 percent of them obtained post-secondary school or college degree and up, compares to 24.35 percent in Beijing, and 15.81 percent in Guangzhou. The basic differences in the characteristics of migrants in Wenzhou influences their choice of housing and living in the city, and further shapes the spatial characteristics of migrant settlements. 


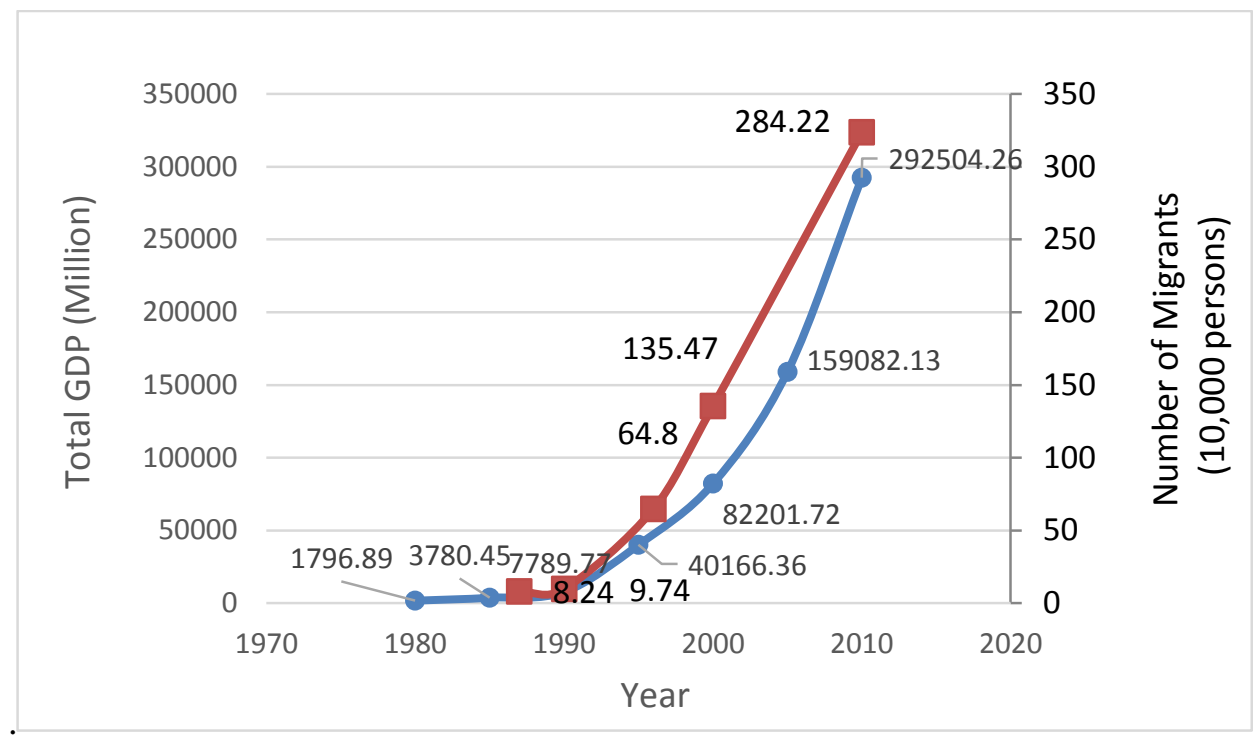

Figure 4.1 GDP and number of migrant growth from 1980 to 2010 Data sources: Wenzhou Municipal Bureau of Statistics (Ed.). (2011). Wenzhou Statistical Yearbook: China Statistics Press.

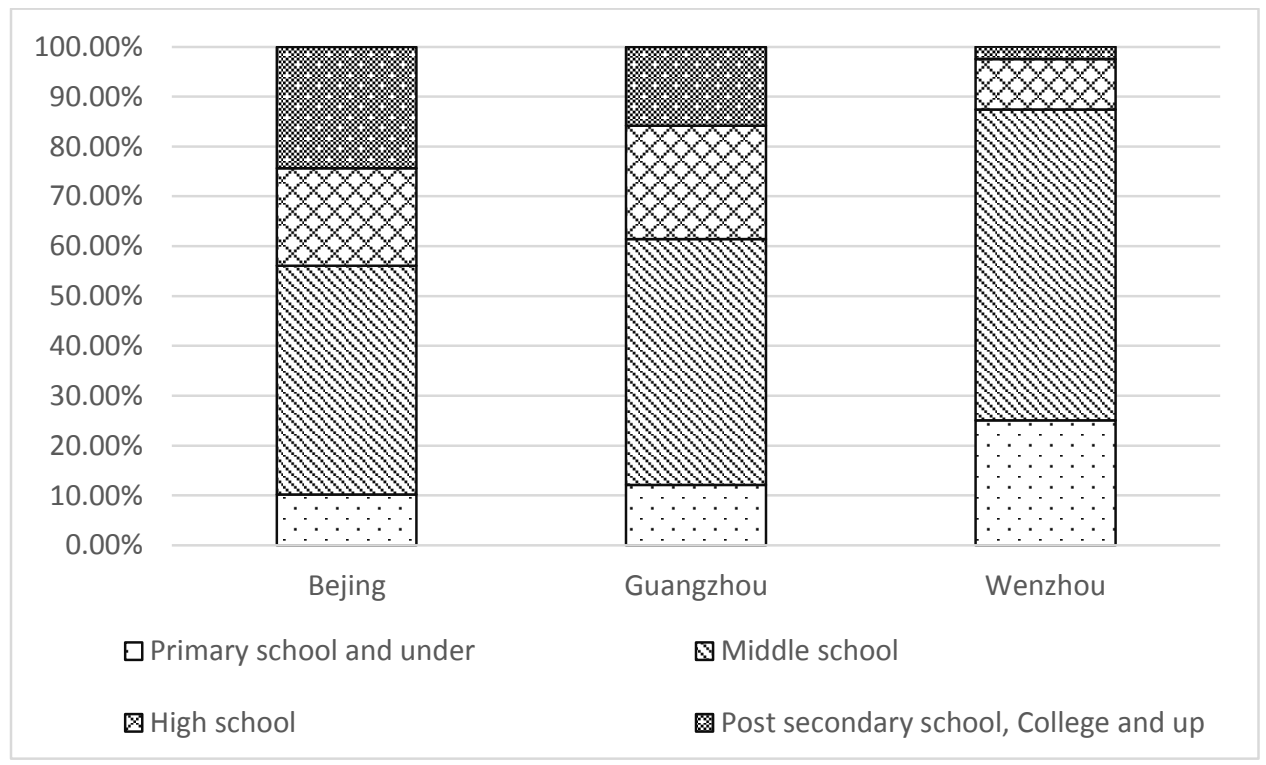

Figure 4.2 Educational attainment of migrants in 2010, Beijing, Guangzhou and Wenzhou Data source: the 2010 Sixth population census data of Beijing, Shanghai, Guangzhou and Wenzhou. 


\subsection{Changing spatial patterns in Wenzhou}

\subsubsection{County-level analysis}

From 2000 to 2010, the number of migrants increased substantially in Wenzhou, particularly in the three urban districts-Lucheng, Longwan, Ouhai and two county-level citiesRui'an and Yueqing (Fig. 4.3).

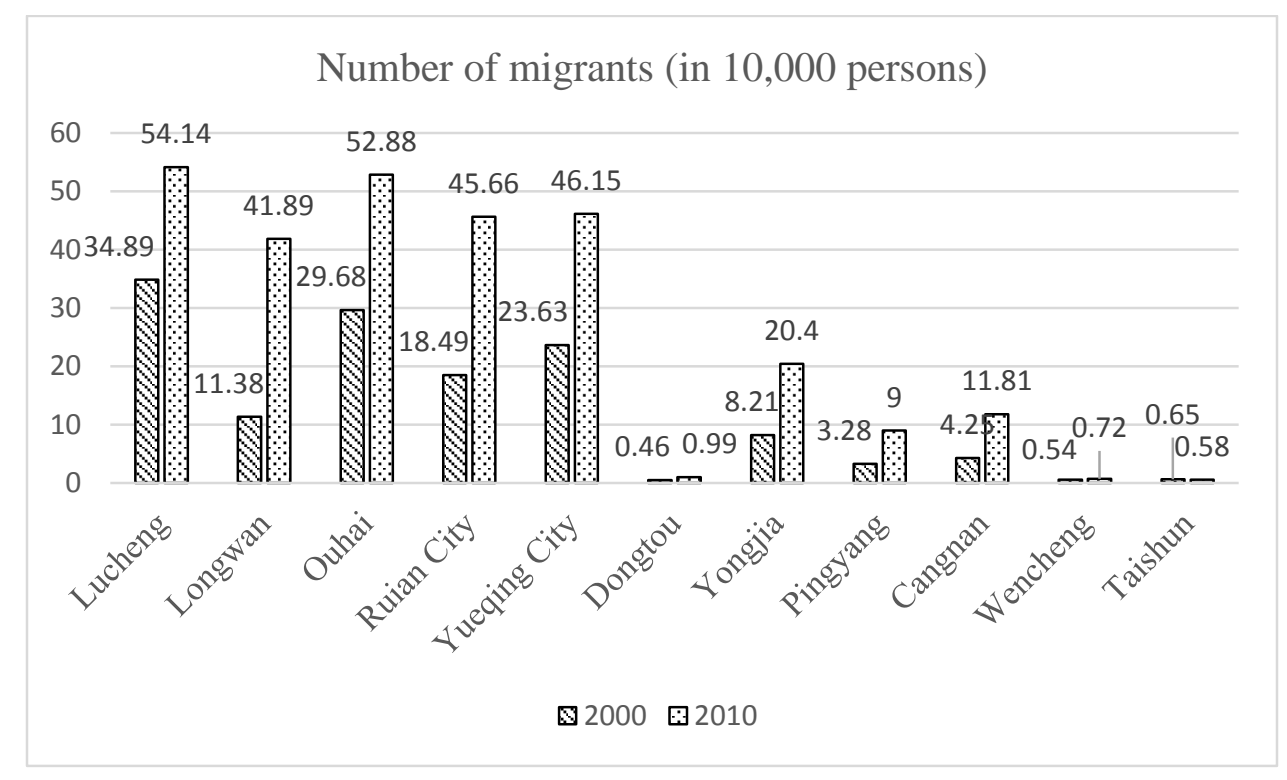

Figure 4.3 Number of migrants in Wenzhou, 2000 and 2010

Migrants in Wenzhou are highly concentrated in the traditional central district--Lucheng and two other urban districts--Ouhai and Longwan. In all three districts, migrants account for more than 50 percent of the total permanent population. Figure 4.4 demonstrates a decreasing significant proportion of migrants in population from the three urban districts, to two countylevel cities and then to six counties. This reflects the economic development of Wenzhou, with 70 percent of total GDP contributed by the three urban districts and two county-level cities (WMBS, 2011). Figure 4.5 shows a spatial concentration pattern of migrants in Wenzhou 
identified by LQ calculations. Similar to the result of the proportion of migrants in the population, three urban districts and two county-level cities have more significant concentration rates than the average in total Wenzhou city. Yongjia County, as home to several manufacturing clusters such as rubber and leather shoes, valves, and buttons, also has a relatively significant concentration of migrants.

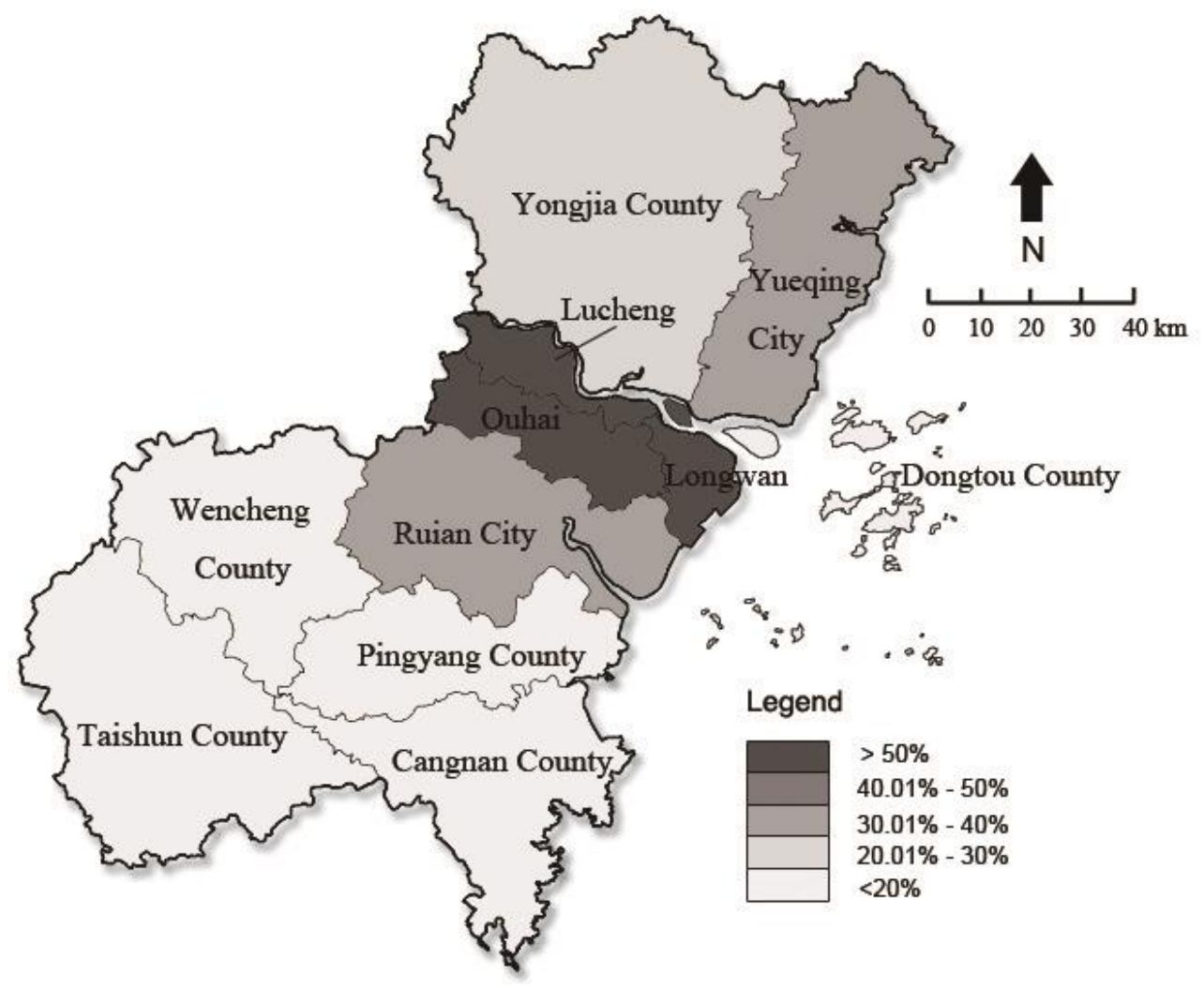

Figure 4.4 Share of migrants in total population in 2010 


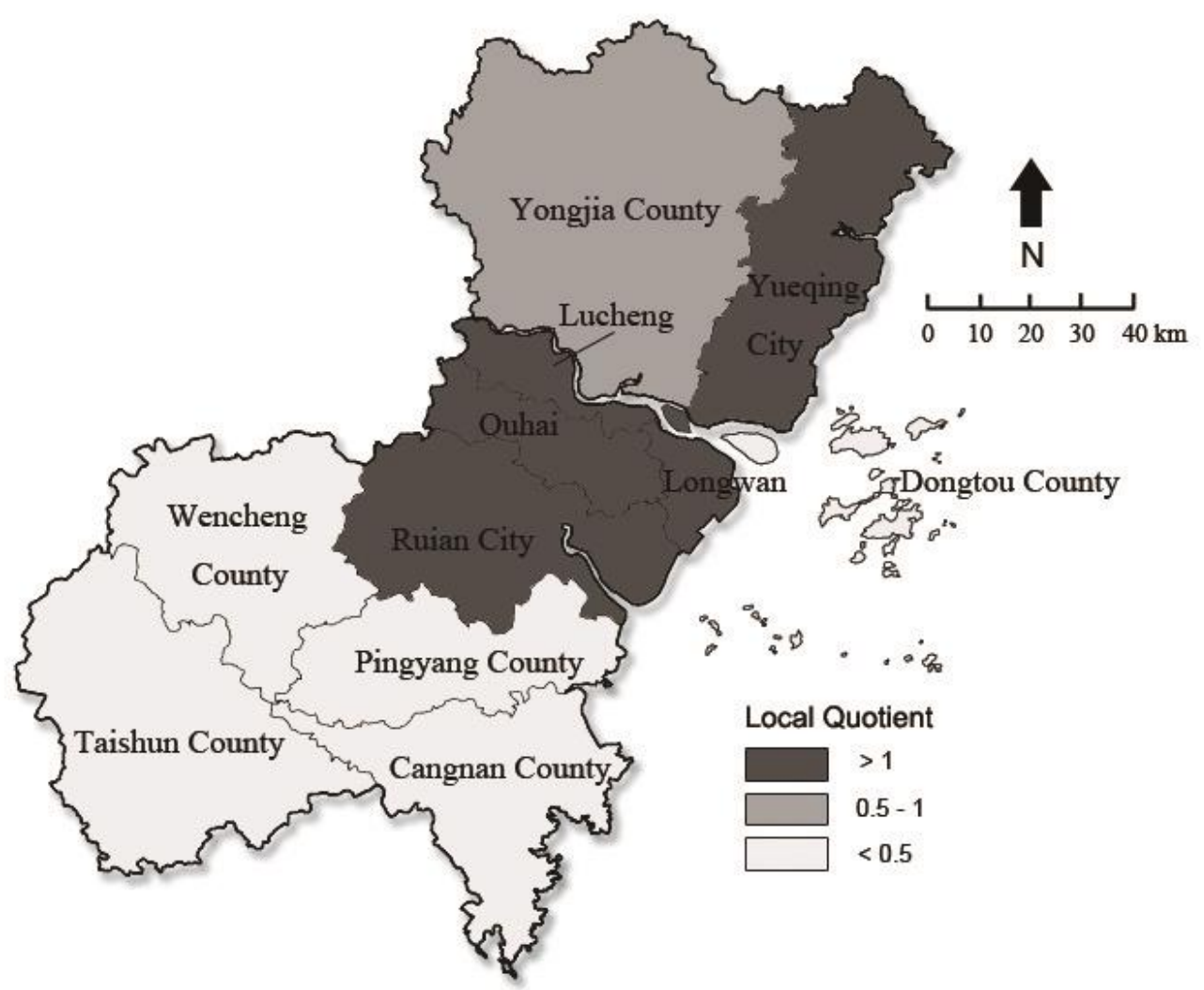

Figure 4.5 Location quotient (LQ) of migrant population in metropolitan Wenzhou in 2010

\subsubsection{Subdistrict-level analysis}

\subsubsection{Distribution of migrant population}

At the beginning of the Reform Era, Wenzhou experienced a unique bottom-up urbanization pattern, which was driven by the growth of individual/household enterprises. Manufacturing industry not only developed in the urban districts, but also in many villages and towns in the rural areas. This spatial distribution pattern of industrial enterprises differs from Beijing and Guangzhou, where most industries are located in the urban districts rather than in the rural regions (Table 4.1). According to Marukawa (2009), there were a total of 153 industrial 
clusters in Wenzhou in 2001. 56 out of 283 townships $^{8}$ had one cluster or more, and most of them were located in the coastal and riverside townships.

Table 4.1 Concentration of industrial enterprises above designated size in urban

districts, 2013

\begin{tabular}{lrrr}
\hline City & Whole city & Urban districts & $\%$ \\
\hline Beijing & 3641 & 3473 & 95.39 \\
Guangzhou & 4812 & 3550 & 73.77 \\
Wenzhou & 4521 & 1621 & 35.85 \\
\hline
\end{tabular}

Data Source: Department of Urban Socio-economic Surveys and NBSC (2014). China City

Statistical Yearbook. Beijing: China Statistics Press.

${ }^{8}$ In 2001, Wenzhou had 11 county-level regions and 299 township-level regions. Among the latter group, Marukawagrouped together the 17 subdistricts (jiedao) into one region as the city center. This generated an urban structure defined by one city center and 282 townships (xiang and zhen). 


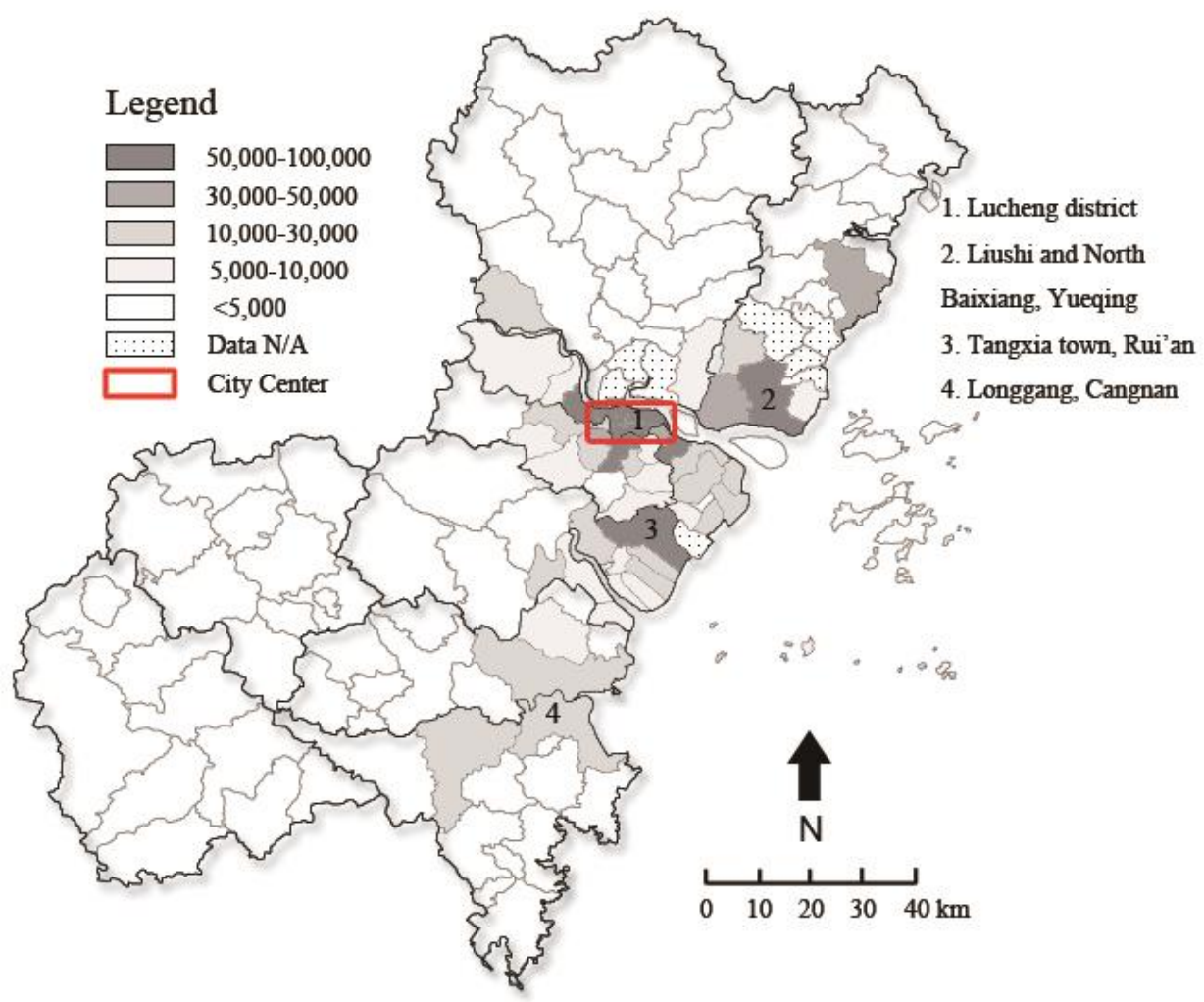

Figure 4.6 Distribution of migrant population, 2000

Figure 4.6 shows that in 2000 migrants mainly concentrated in the city center and parts of Yueqing, Rui'an and Cangnan County. This distribution pattern of migrant settlements follows the distribution of major industrial clusters. There were three major migrant settlement concentrations: (1) the traditional urban district--Lucheng district (indicated 1 on the map), which has the largest industrial clusters of leather shoes and apparel industry. (2) Liushi-North Baixiang region in Yueqing city (indicated 2 on the map) and (3) Tangxia town in Rui'an city (indicated 3 on the map). These three areas were regarded as the birthplace of the "Wenzhou model" in the beginning of Reform Era. Liushi town is known as "China electric city", has the 
largest cluster of electric equipment. It had more than 600 firms that engaged in productions of switches, electric parts and other power control machinery in 2001 (Marukawa, 2009). Tangxia town is known for its thousands of automobile and motorcycle parts manufacturing factories. These factories provide a large number of jobs for migrant workers. In addition to these three regions, Longgang town in Cangnan County (indicated 4 on the map) also houses a quite significant number of rural migrants. Longgang town used to have the largest cluster in terms of number of firms located within a single township, in which 345 corporations were engaged in printing packages and labels in 2001 (Marukawa, 2009). It was also called "the first farmer's city" in China during 1980s. The residents of the city are ex-farmers who made money from the printing business and transformed their village into a city. Longgang farmers are the people who built the city and also labor force for the industries. As such, the number of rural migrants who came from outside Longgan is significant, but not as many as other industrial clusters in Wenzhou. 


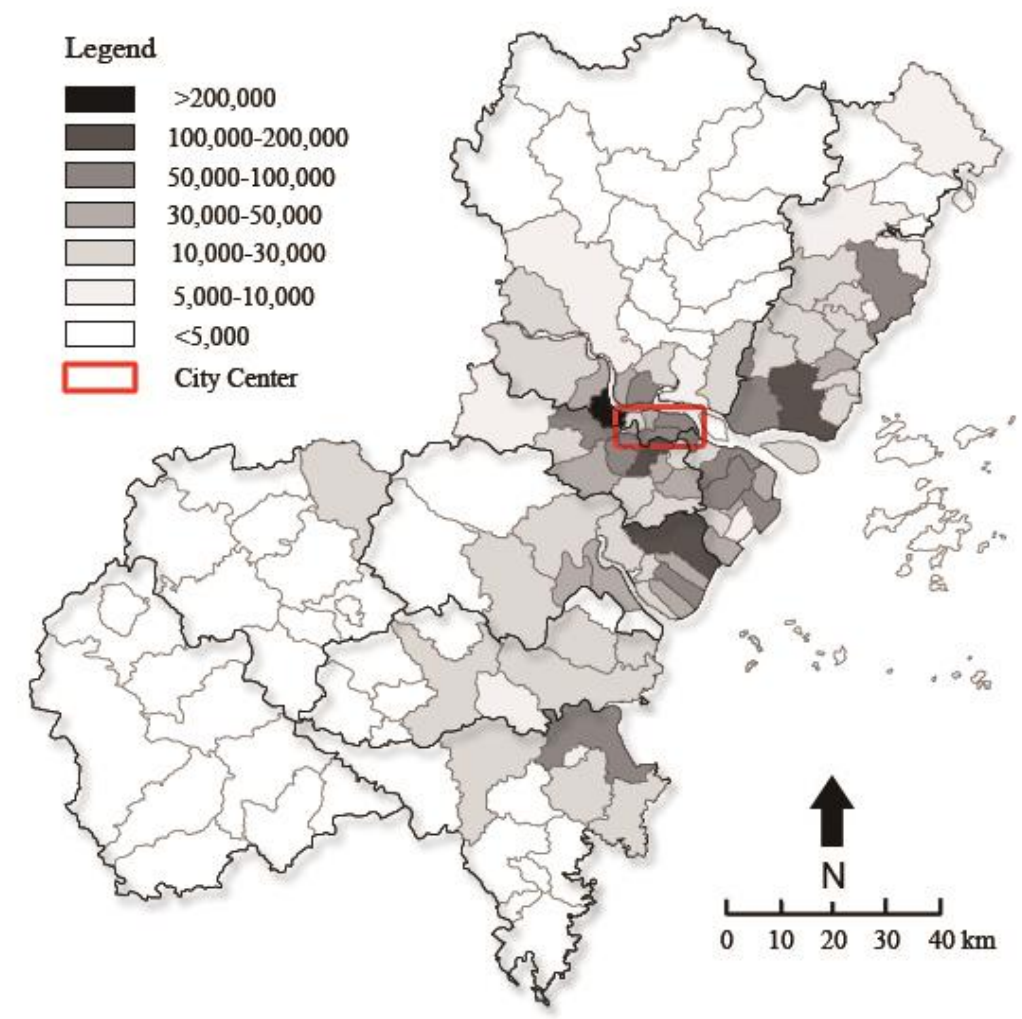

Figure 4.7 Distribution of migrant population, 2010

Figure 4.7 shows the distribution of migrant population in 2010. Compared with 2000, there is a general growing number of migrants in many street communities and townships, especially in the urban districts, Yueqing city, Rui'an City and Longgang region in Cangnan County. In 2000, there were approximately 40 percent of total number of street communities and townships have more than 5,000 migrants, which are 60 percent of them in 2010 . By and large, the distribution of migrant settlement is consistent with the spatial and economic structure of Wenzhou. The number of migrants in these four regions that pointed out in 2000 continues to grow in size (Fig. 4.7). This distribution pattern is inconsistent with the forming 
metropolitan Wenzhou. In 2003, the Wenzhou Master Plan (2003-2020) firstly put forward the goal of building "metropolitan Wenzhou", trying to break the boundaries between the three districts, two county-level cities and six counties and considering them as a whole. In 2013, the newly revised Wenzhou City Master Plan (2003-2020) proposed Wenzhou's new spatial structure as "one core region and two sub-centers" (Fig. 4.8). The core region mainly include the east part of urban districts and the east part of Rui'an City. The two sub-centers are Yueqing City in the north and Pingyang-Cangnan region in the south.

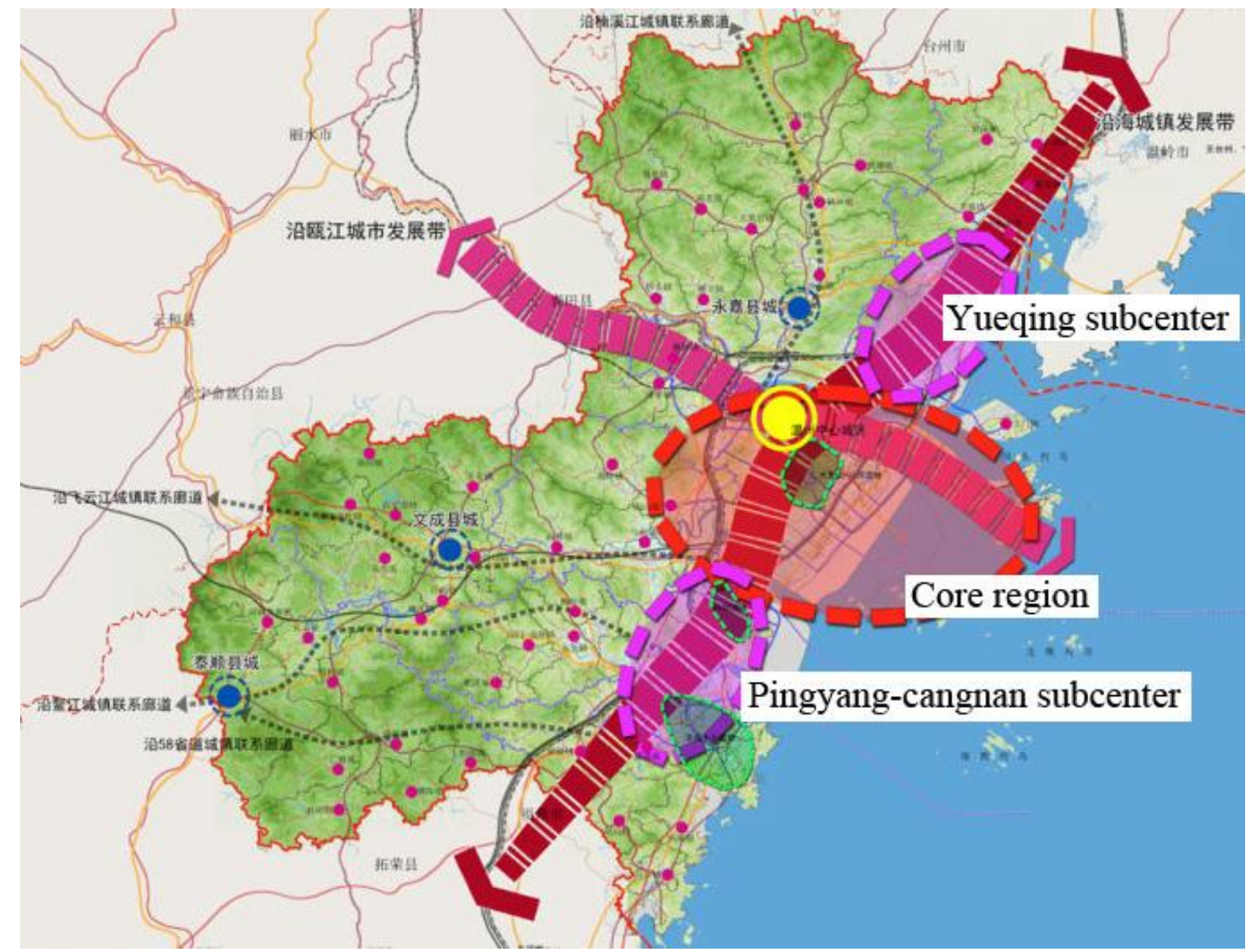

Figure 4.8 One core and two sub-centers structure of Metropolitan Wenzhou Source: revised Wenzhou Master Plan (2003-2020), 2013. 


\subsubsection{Migrants as a proportion of total population}

Figure 4.9 and Figure 4.10 show the proportion of migrants in total population in 2000 and 2010. In 2000, there were only 5 streets and townships with more than 50 percent of migrant population. By 2010, this had risen to 19 streets. In an analysis of Wenzhou's spatial structure as concentric zones, migrants tended to concentrate in the city center and inner ring in 2000, account for 33.72 and 42.14 percent of total population in urban districts, respectively. In 2010, Particularly, there is a significant concentration of migrants in the inner ring (indicated as \#2 in fig. 10), such as Shuangyu, Yangyi, South Baixiang, Puzhou, Louqiao, and Wutian have more than 65 percent of total population who are migrants. 


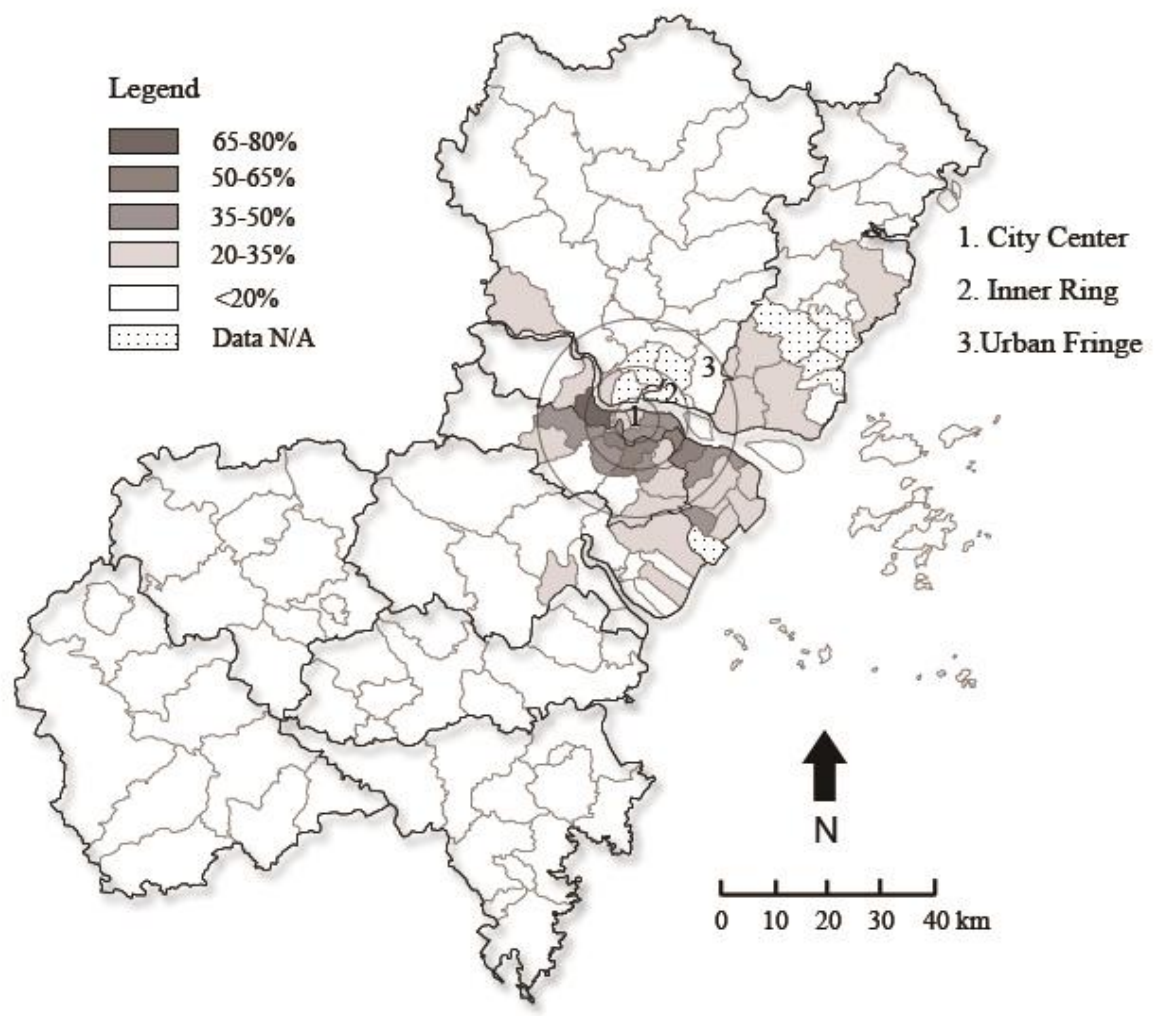

Figure 4.9 Migrants as a proportion of total population in Wenzhou, 2000 


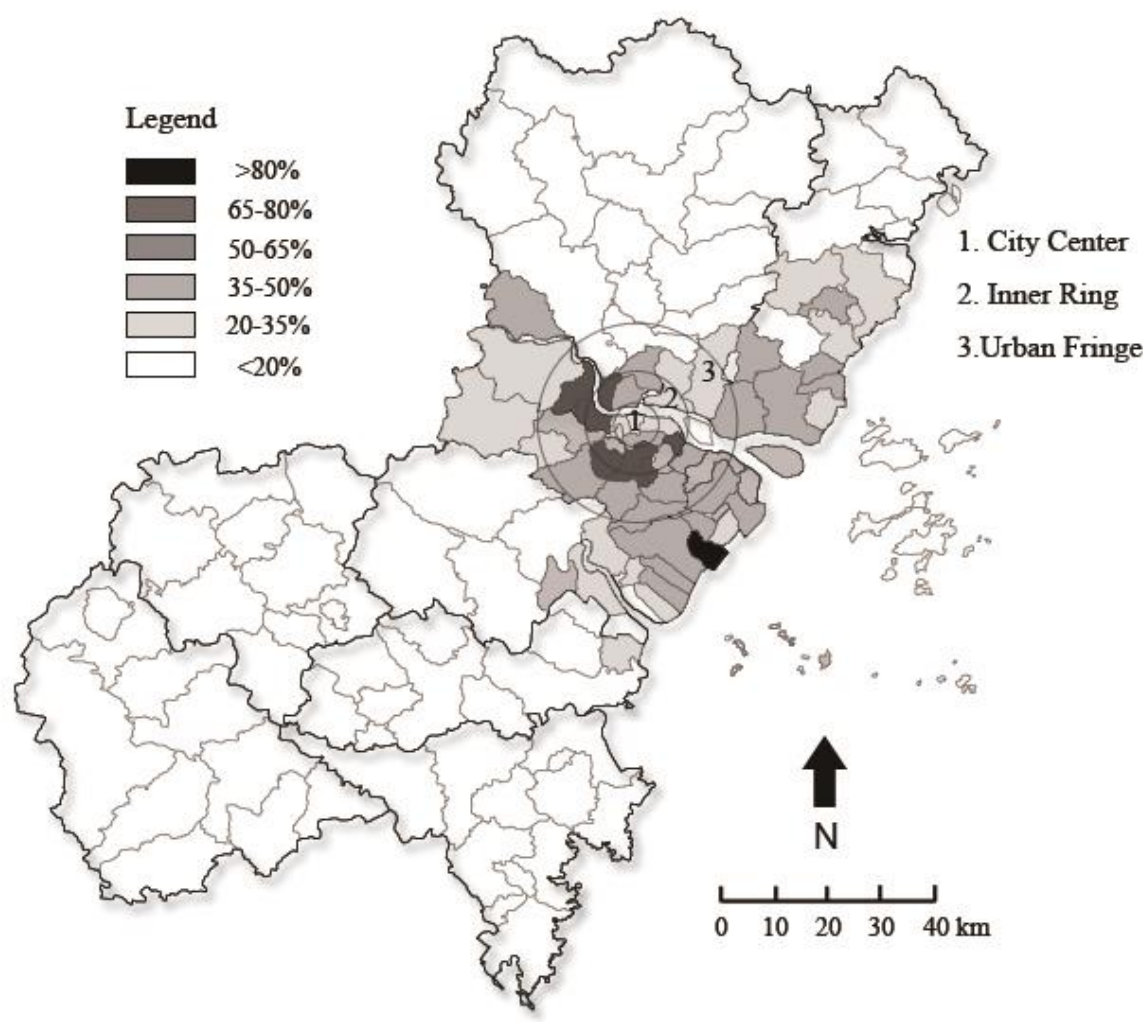

Figure 4.10 Migrants as a proportion of total population in Wenzhou, 2010

Furthering the analysis by looking at the changes from 2000 to 2010, I found different changes have occurred in different zones (Fig. 4.11). The proportion of migrants in total population in the city center experienced significant decrease during the 10 years. The subdistricts in the inner ring and particularly in the urban fringe demonstrate a substantial gain in the number of migrants in total population. The decreasing proportion of migrant population in total population in the city center is in accord with the redevelopment of the city core as commercial and administrative center. This redevelopment has involved major changes in industrial location. The first round of industrial park construction was started in early 1990s - 
these early industrial parks were located mainly in the inner ring. Since the end of the 1990s, more industrial parks have been established in the subdistricts of the urban fringe where there was an ample supply of cheaper land available. Following the industrial park construction, many factories have gradually relocated to the industrial parks in the inner suburbs or urban fringe. Undoubtedly, Wenzhou's industrial development strategies have had a direct influence on the location and formation of migrant settlements, which resulted in the concentration of migrant settlements in the inner ring and urban fringe.

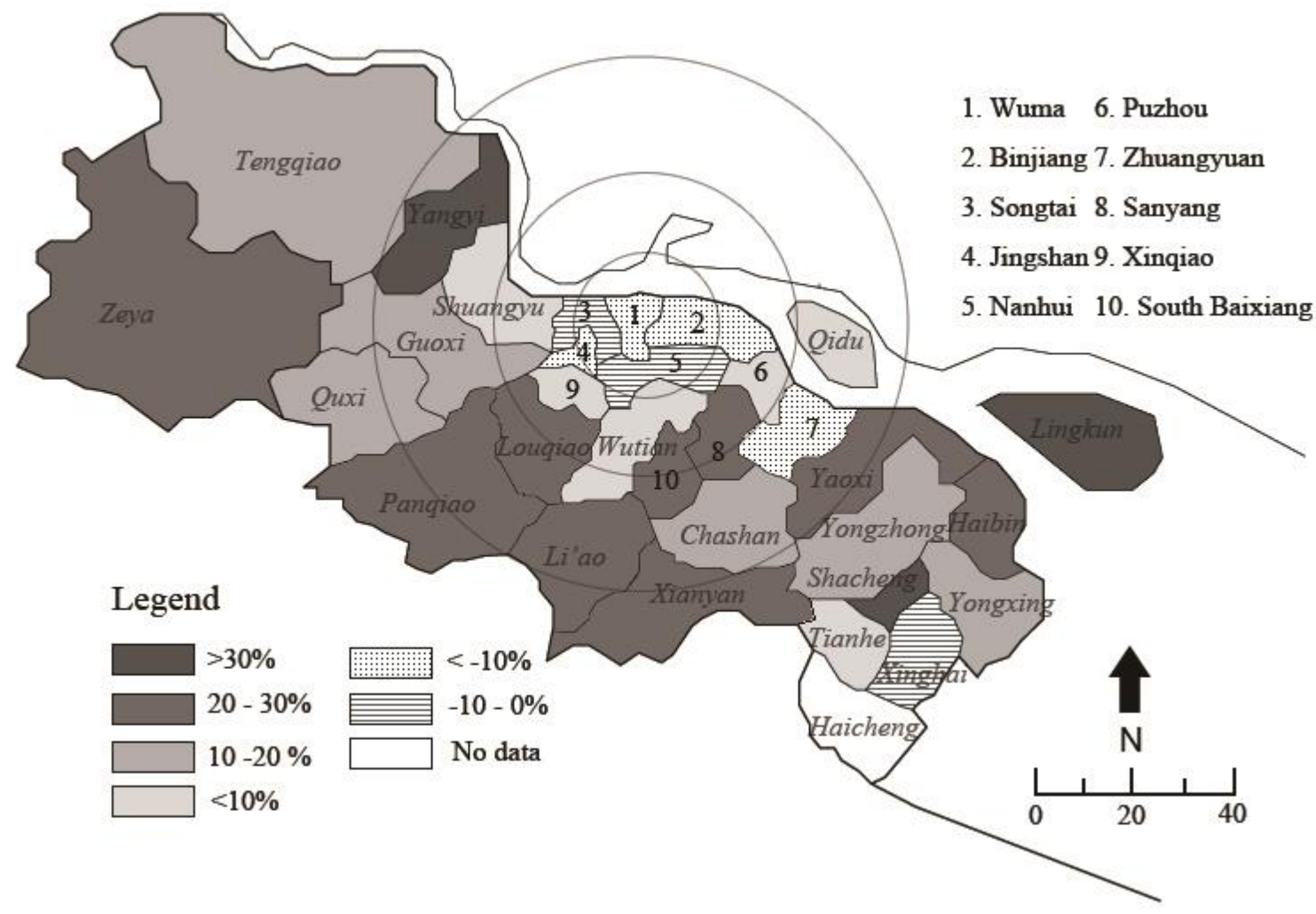

Figure 4.11 Changes of migrant population in total population 2000-2010 


\subsubsection{In comparison with Beijing and Guangzhou}

Beijing has attracted a great number of migrants, which make up about 36 percent of its total population (BJMBS, 2011). Since the end of the 1980s, scholars have identified the growing number of migrant settlements in the transition areas between city and countryside as "migrant villages on the city periphery". These settlements usually comprise migrants with common places of origin and economic roles, such as "Zhejiang village" (garment industry), "Henan Village" (waste collection and recycling), and "Xinjiang Village" (restaurant) in Beijing (Ma \& Xiang, 1998). With the rapid expansion of Beijing's urban area and its changing spatial structure since the 1990s, these migrant settlements are no longer located in the urban periphery as they have been engulfed in Beijing's outward growth. The majority of migrant settlements formed between the Third and Sixth Ring Road since 1985s (Y. Fan, Allen, \& Sun, 2014; Gu \& Shen, 2003b) (Fig. 4.12). While these villages were once well outside the urbanized area, today urban development is encroaching upon and surrounding them. The relative location of the villages within the city's urban structure is thus transitioning from the urban periphery to a ring surrounding the urban core.

Guangzhou, traditionally the largest mainland city in the Pearl River Delta adjacent to Hong Kong, has attracted 4.76 million migrants, accounting for more than 37 percent of its total population by 2010 (GZMBS, 2011). Although also having a high percentage of migrant population live in the urban fringe as Beijing, it is noteworthy to pointing out that a significant proportion of migrant population live in the city center, which is about 30 percent (Fig. 4.12). These migrant settlements have evolved differently in village enclaves within the city. Yuan and $\mathrm{Xu}(2008)$ affirmed that there is a strong correlation between the location quotient of migrants and the spatial distribution of VICs. Meanwhile, Jiang and Wu (2014)'s research concluded that 
the spatial distribution of migrants contributes to the formation of Guangzhou's polycentric spatial structure. Guangzhou is in the process of forming a one center and four sub-center structure. In the four growing centers, Tongde street, Fengyang street, Tangxia Street and Shahe Street, migrants compose 84 percent, 74 percent, 68 percent and 38 percent of the total population, respectively (Jiang \& Wu, 2014). Migrants in Guangzhou are the main driving force for the formation of these growing sub-centers. Many of them engage in similar business, such as fabric and accessory wholesale and retail business in Fengyang Street. The agglomeration of a great number of these businesses contributed to the formation of global market place, and continues to attract more migrants.

Compared to Beijing and Guangzhou, one of the most obvious differences is that migrant settlements in Wenzhou have not only evolved in the inner ring and urban fringe, but also in the counties, townships and villages, which account for almost 50 percent of the migrant population. The concentration of Wenzhou's migrants in certain regions of the city is a result of co-location with the industrial clusters or specific job opportunities, rather than the influence of the location of village-held land and the emergence of place-of-origin linked migrant settlements. As such, migrant settlements emerge primarily around the industrial parks in the inner ring, urban fringe and industrial townships, contribute to Wenzhou's emerging urban form. They represent a new type of urban low-class clusters, which have great impacts on the urban spatial structure. 


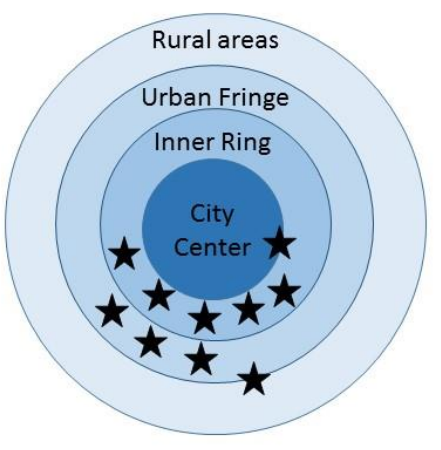

Beijing

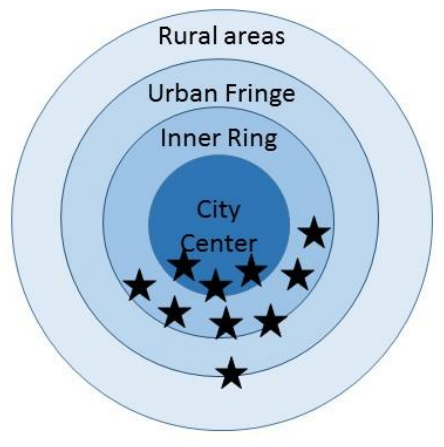

Guangzhou

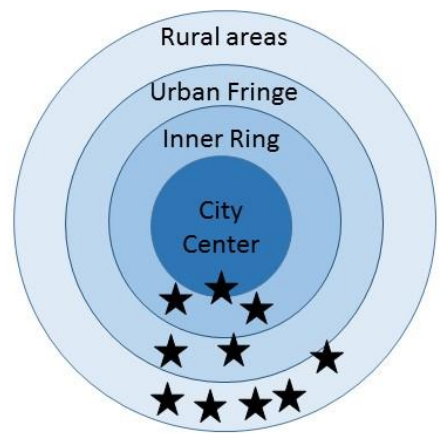

Wenzhou

Migrant settlement (stars represent proportion of settlement in different spatial locations), One star $=10 \%$

Figure 4.12 The spatial distribution of migrant settlements in Beijing, Guangzhou and Wenzhou, 2010

Data sources: 2010 (the sixth) National population Census of Beijing, Guangzhou and Wenzhou

\subsection{Summary}

Migrants are 35.5 percent of Wenzhou's total population, compared to 36 percent in Beijing and 37 percent in Guangzhou. Unlike Beijing and Guangzhou's migrants, however, many of whom are successful migrant businessman, or well-educated college graduates, the majority of the migrants in Wenzhou are laborers with low educational attainment. The long working hours and low income jobs require them to live close to the factories. As such, their housing of choice is usually a shared room in villages around the factories, or factory dormitories.

The concentration of migrant settlements in different parts of a city may derive from a variety of different factors. Housing availability (concentrate in the village-held land) or social network (concentrate in the places where already have many migrants come from the same 
place of origin) are important factors that influence the formation of migrant comminutes in Beijing and Guangzhou. In contrast, Wenzhou's migrant settlements, which are dominated by manufacturing workers, are spatially linked to patterns of industrial development. Thus the city's industrial development strategies have had a direct influence on the location, formation, and characteristics of migrant settlements. The county-level analysis indicates that the majority of the migrants concentrate in the urban districts and two county-level cities, which also account for the determinant portion of industrial product output. By looking at the urban districts alone, we can see that with the manufacturing industries' successive movement from the city center to the inner ring, and to the urban fringe, the migrant settlements also relocated with the industries.

Furthermore, I also make use of the classic "concentric zone model" of urban spatial organization as a baseline for understanding the differing dynamics of migrant settlements in contemporary Chinese cities. Migrant settlements in Beijing, which were first primarily located in the urban periphery, have become an inner ring zone surrounding the city center as the city has expanded. Migrants who live this zone either travel to the city center for service jobs, or travel to urban fringe for construction and secondary industry work. Meanwhile, a wealthy people's zone has been gradually developed in the urban fringe. Unlike Beijing, Guangzhou's migrant settlements have a significant concentration in the city center. These migrant settlements have evolved around the villages in the city center, and have gradually become subcenters of Guangzhou city. In comparison with the patterns of "migrant settlements in the city periphery" in Beijing and "villages in the city" in Guangzhou, migration and migrant settlements contribute to Wenzhou's emerging urban form in a manner which diverges from the two models. The migrant settlement in Wenzhou represents a third type, that is - migrant 
settlements are not only located in inner ring and urban fringe zone, but also in the rural regions which have evolved around "single-industry clusters". 


\section{CHAPTER 5}

\section{A SURVEY OF MIGRANT SETTLEMENT IN SHUANGYU, WENZHOU}

\subsection{Introduction}

From the previous chapters we know that migrant settlements evolved around manufacturing industries in different subdistricts have contributed to Wenzhou's emerging metropolitan form. This chapter introduces a case study-Shuangyu-an inner ring subdistrict with great number of migrants, to better understand the major morphologies and spatialities of migrant settlement in Wenzhou - the ways in which migrants flourish in the spatial interstices of the city and produce urban phenomena with a potent impact on the streetscape and urban image.

Located about five kilometers west of the old city center, Shuangyu is a subdistrict in the inner ring of Wenzhou city (Fig. 5.1). It used to be part of Yongjia County and later became administered by Wenzhou city after 1958 . Similar to the other townships, family-owned private enterprises mushroomed in Shuangyu since 1984. With its fast economic development, it was one of Wenzhou's top 30 economically successful towns in 1995 and Zhejiang's top 100 economically successful towns in 1996. Due to urban expansion of Wenzhou city during the past two decades, Shuangyu has changed from a countryside town to an inner ring urban subdistrict with a mixed landscape of villages and modern communities. Fast industrialization and increasing value of the land in Wenzhou's city center have caused the city to relocate manufacturing factories and housing in the inner ring and urban fringe. As an inner ring subdistrict with strong industrial base, as well as convenient location in the intersection of the 
national road 104, Jinhua-Wenzhou railway and Jinhua-Lishui-Wenzhou highway, Shuangyu has gradually developed into an industrial center.

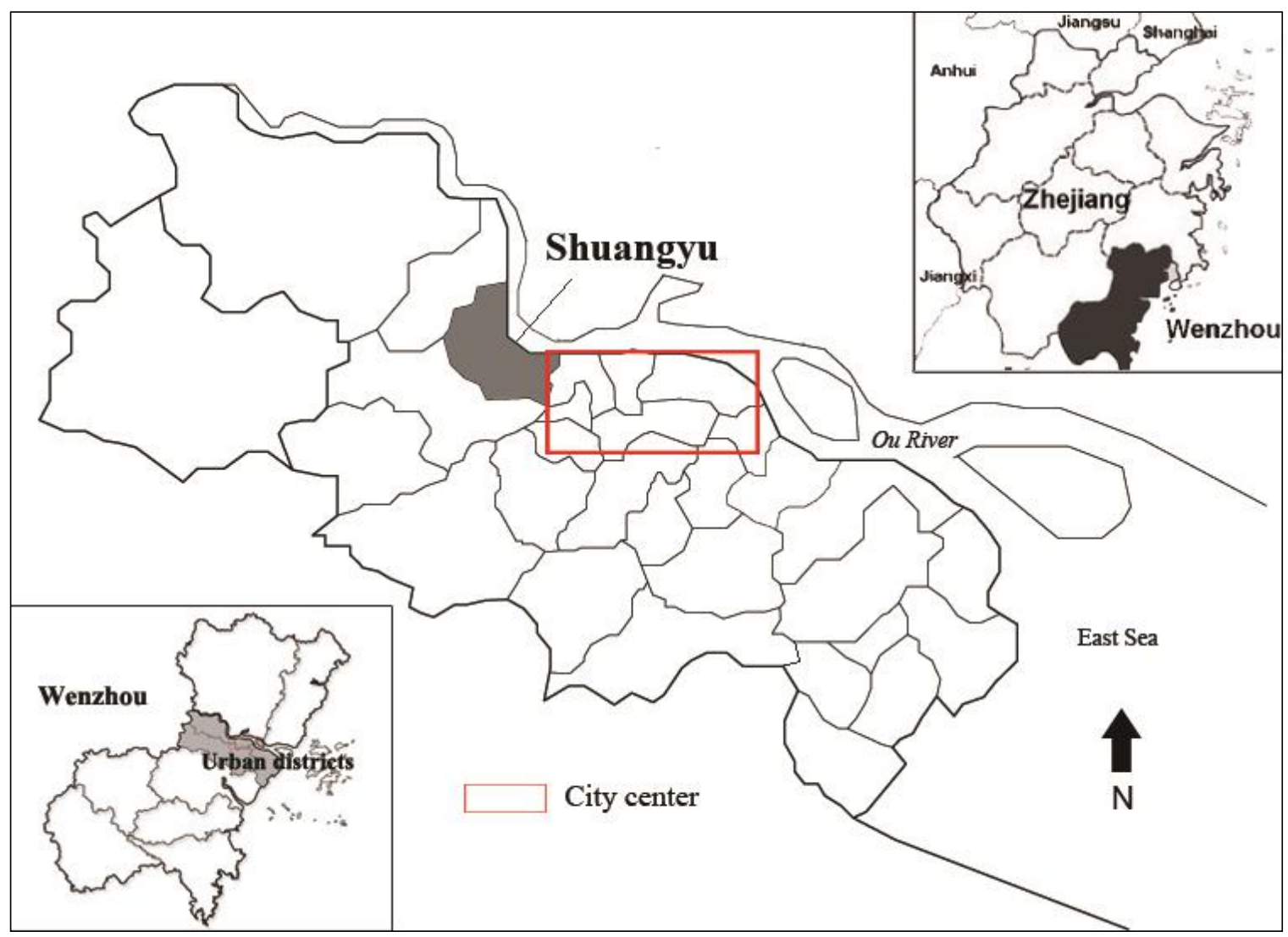

Figure 5.1 Location map of Shuangyu

If Wenzhou is known as "China's shoe capital", then Shuangyu is worthy of the name: “Wenzhou's shoe capital." In 2010, it had about 3,300 industrial enterprises, in which 133 are designated large industrial enterprises. Among those 133 enterprises, 112 are leather shoe manufacturing enterprises, and another 11 are shoe-related manufacturing enterprises (LCECO, 2011) They are mainly located inside two industrial parks-China's Shoe Capital Industrial Park (Zhongguo xiedu gongye yuanqu; 2.6 sq.km) and Wenzhou Lucheng Light Manufacturing 
Industrial Garden (Wenzhou lucheng qing gongye yuanqu; $0.68 \mathrm{sq} . \mathrm{km}$ ) which were established in 1999 and 2002, respectively (Fig. 5.2). With the concentration of manufacturing industries, Shuangyu attracted more than 231,068 migrants, which is about 6 times the total local population $(39,461)$ by 2010 . It is becoming a typical migrant enclave housing migrant workers of both high mobility and socioeconomic diversity. With a mix of traditional industry clusters and migrant neighborhoods, Shuangyu offers a rich environment for this micro-analysis.

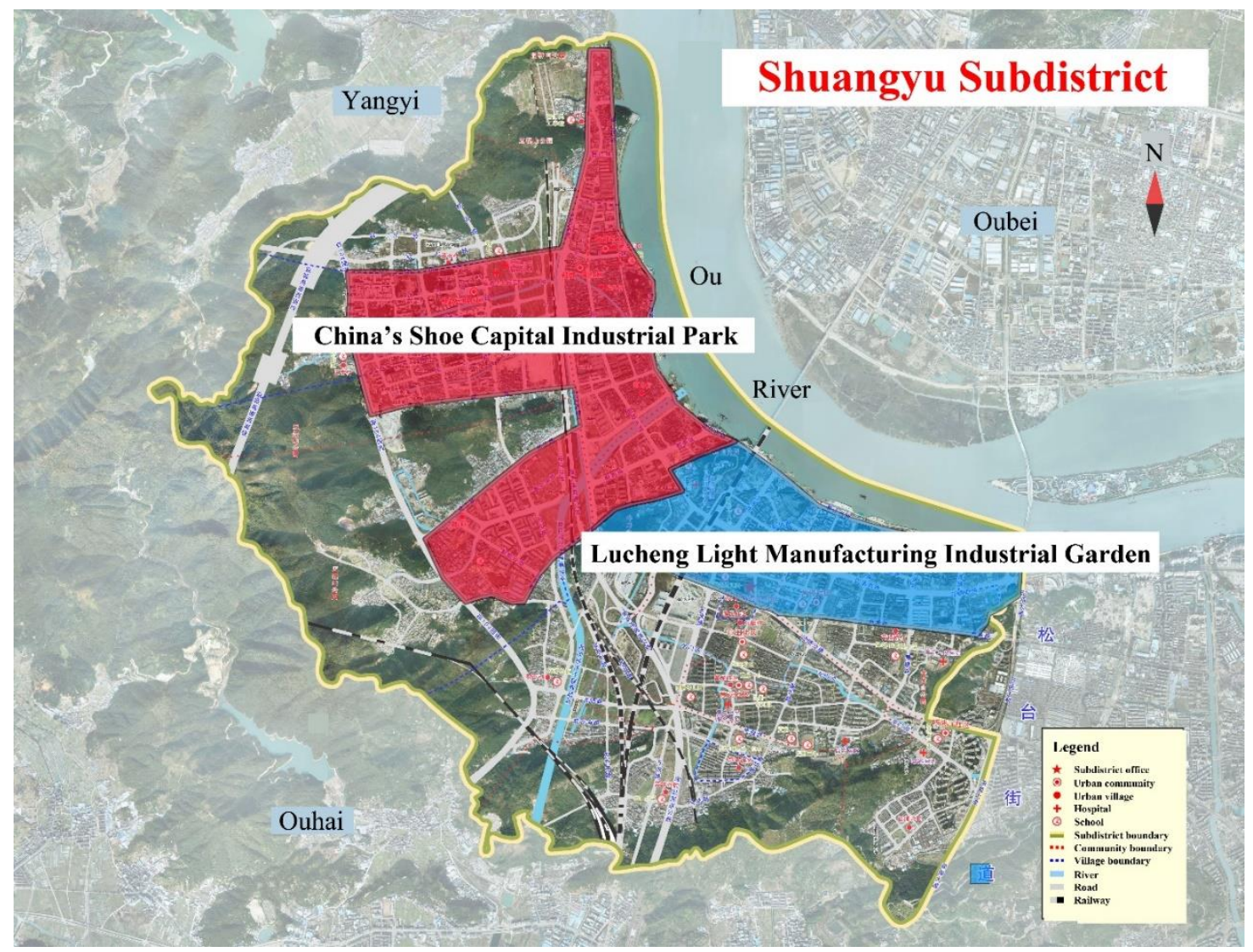

Figure 5.2 Shoe capital of China Industrial Park and Lucheng Light Manufacturing Industrial Garden

Map source: basemap provided by Shuangyu Street Committee Main Office. 


\subsection{Data and Methodology}

In this micro-analysis, methods such as site observation, questionnaires, and semistructured interview are used to help gaining a better sense of the distinctive features of migrant settlement, the socio-spatial relationship between migration settlements and the other parts of the city. Before carrying out the survey in Shuangyu, a site analysis/observation has been firstly carried out. On-site observation is one of the most effective tools for geographical fieldwork in which the researcher personally goes to the site and discovers the functioning of the system (Hay, 2010). As an observer, I can gain first-hand knowledge of the activities, operations, processes of the system on-site, hence here my role is that of an information seeker. Based on the observation in the summer of 2012 and 2013, five types of places where migrants have interactions with urban space were chosen for the survey (Fig. 5.3):

(1) Migrants' residential areas: Several dormitories inside the factories and seven villages including Shangyi, Jishi, Niuling, Yinglou qiao, Yangtian, Qianchen and Yutou.

(2) Migrants' workplaces including four questionnaire collective points inside four factories (three shoe manufacturing factories and one paper mill) and points outside several other factories.

(3) Shopping areas including commercial streets and temporary markets.

(4) Public space: the major public spaces in Shuangyu that migrants use, including Shoe Capital Cultural Square, Binjiang Road, Lucheng Library and some public space inside villages.

(5) Transportation area: the square in front of Shuangyu Passenger Transport Center and bus stations. 


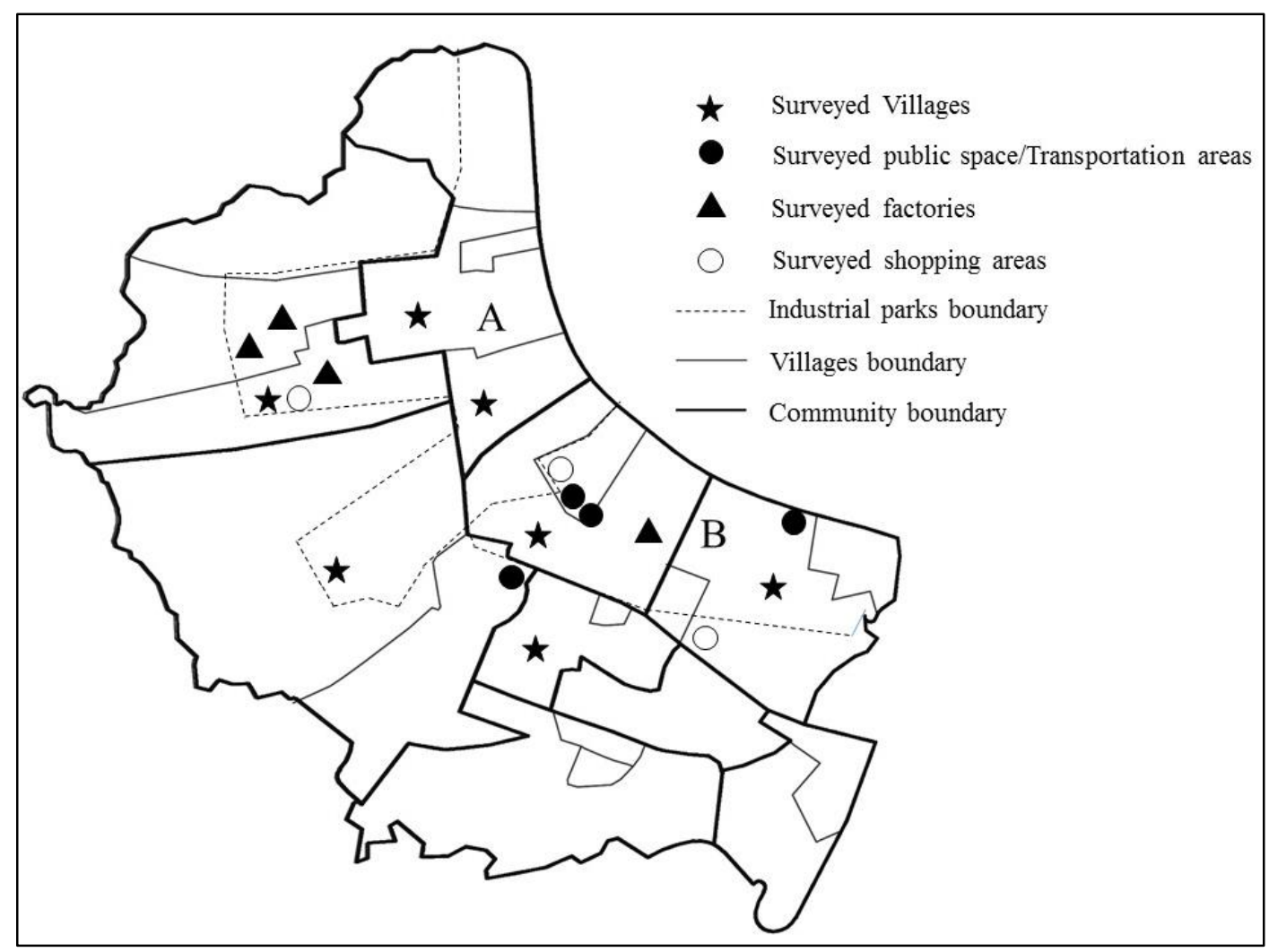

Figure 5.3 Major survey sites in Shuangyu sub-district

After the sites been chosen, a survey has been carried out in the summer of 2013. A survey is a good means of collecting detailed and important data on migrants and their characteristics. I planned to use snowball sampling to recruit more subjects based on the connections I have with the first, randomly recruited subjects, however, the majority of the migrants refused to help introduce friends to fill out the questionnaire, which to them is more like a trouble. Therefore, I have just randomly surveyed a diverse sample of migrants in the Shuangyu area who originally came from different provinces, and work in various fields. The survey yielded 435 completed and valid questionnaires. This sampling method, not entirely random, ensured that the sample was as systematically drawn as possible to give a good representation of the migrant population living in Shuangyu. Considering that most migrants 
have low levels of educational attainment, surveys were typically administered orally (usually take more than 20 minutes for one questionnaire), with the surveyors (including myself and two-hired college students) writing down the answers.

Moreover, realizing the sample size in the survey is relatively small for the purpose of statistical analysis, and to gather more specific, in-depth information, I conducted in-depth interviews (20 of them) with migrants and other people whose work related to migrants and migrant settlement from government officers to enterprise managers to village head ${ }^{9}$. This indepth interview methods, sometimes referred to as informal, conversational or "soft" interview, involves talking directly with people but in ways that are self-conscious, orderly and partially structured (Longhurst, 2010). I planned to offer some drinks to the migrants who I chose to interview, but none of them had accepted my offer and prefer to sit down in a park or public square to conduct the interview. Most of the interviews were carried out more than half an hour.

\subsection{Demographic and economic characteristics of migrants in Shuangyu}

\subsubsection{A demographic profile}

A large number of migrants in Shuangyu are young people from rural areas who have a low educational attainment (most typically, they have completed only 8 years of formal education). In this survey, 59 percent of the migrants are male, which is consistent with the 2010 Census, which reports the migrant population as 57 percent male. Approximately 92

\footnotetext{
${ }^{9}$ Village head is the person that elected by the villagers to administer a village.
} 
percent of the surveyed migrants are from age 18 to age 45 . They are working-age and their primary reason of being in the city is to work. Figure 5.4 shows the age and sex pyramids of the migrants in the survey. More than 76 percent of total migrants are born after 1980s and with a domination of post-80s generation from age 26 to 35 . Unlike the first generation rural migrants, these new generation migrants usually have looser ties to their villages. They often know little about the farm work such as when the planting season begins. As such, their trips home are no longer dictated by the farming calendar. Instead, younger migrants come and go during special holidays such as Chinese New Year, or according to their personal schedules of switching jobs and obtaining leaves, and these are often tied to the demands of the production cycle (Chang, 2009) . 67.59 percent of the total number of the migrants in the survey return home every year during the Chinese New Year. 25.52 percent of them visit home quite often when the work is not busy.

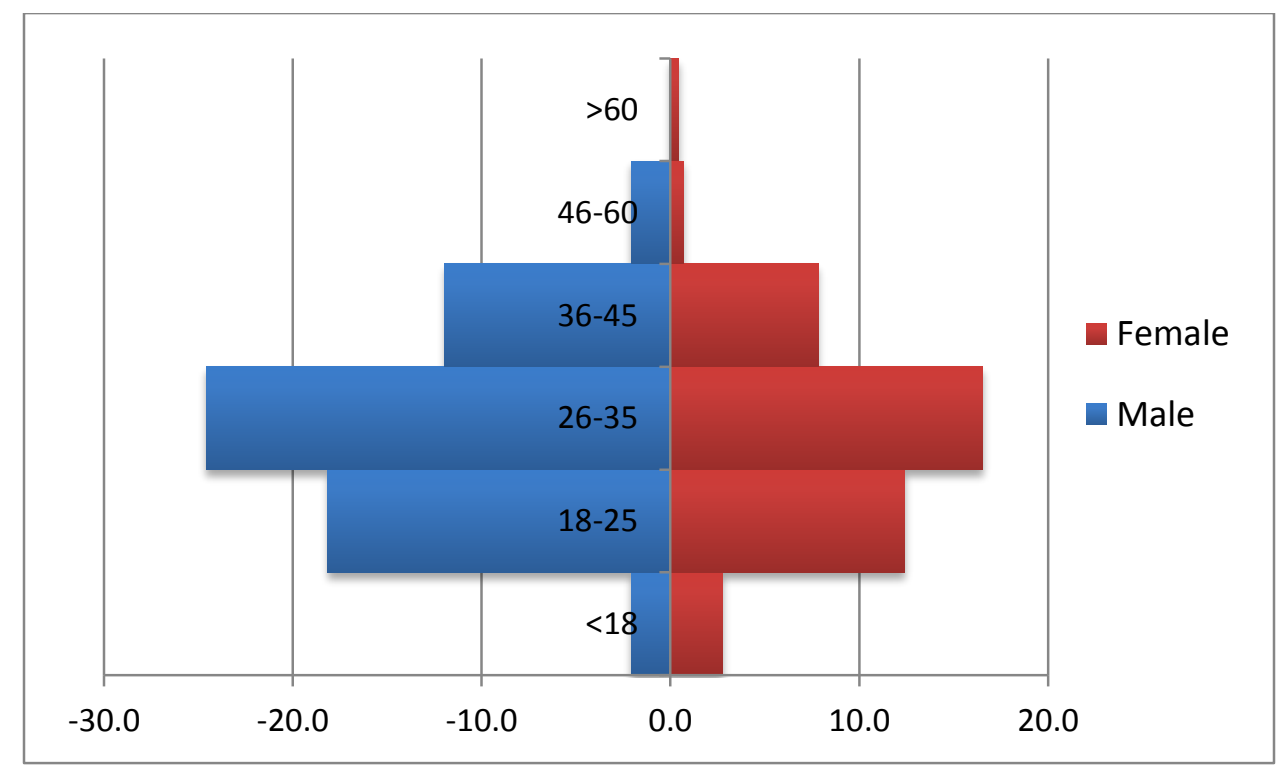

Figure 5.4 Age and sex compositions of the migrants in the survey 
There is a dominant number of the migrants with rural hukou in the survey, accounts for 90 percent (Table 5.1). They are from more than ten different provinces. Specifically, 85.22 percent of the migrants in the survey are from China's top six out-migrant provinces-Jiangxi, Anhui, Guizhou, Hubei, Hunan, and Sichuan provinces, which are relatively poor and have long histories of out-migration. This is consistent with the entire city of Wenzhou, where 73 percent of migrants are from these six provinces (Fig. 5.5). Only a small number of the migrants are from the neighboring provinces-Zhejiang (Where Wenzhou is located), Fujian (on the south) and Jiangsu (on the north), which have relatively advanced economies. It differs with Beijing and Guangzhou's situation which both have the majority of migrants from nearby - from Hebei, in the case of Beijing, which is adjacent to that province, and Guangdong province, in the case of Guangzhou. It demonstrates that Wenzhou is more attractive to migrants who came from more economically disadvantaged regions. 
Table 5.1 Characteristics of migrants in the survey

\begin{tabular}{|c|c|c|}
\hline & No. of Migrants & $\%$ \\
\hline \multicolumn{3}{|l|}{ Origins of residence registration } \\
\hline Rural Hukou & 391 & 89.89 \\
\hline Urban Hukou & 44 & 10.11 \\
\hline \multicolumn{3}{|l|}{ Origins of province } \\
\hline Jiangxi & 84 & 19.31 \\
\hline Anhui & 80 & 18.39 \\
\hline Guizhou & 58 & 13.33 \\
\hline Hubei & 47 & 10.80 \\
\hline Hunan & 40 & 9.20 \\
\hline Sichuan & 31 & 7.13 \\
\hline Henan & 29 & 6.67 \\
\hline Zhejiang & 18 & 4.14 \\
\hline Jiangsu & 11 & 2.53 \\
\hline Others & 37 & 8.51 \\
\hline \multicolumn{3}{|l|}{ Age } \\
\hline$<18$ & 21 & 4.83 \\
\hline $18-25$ & 133 & 30.57 \\
\hline $26-35$ & 181 & 41.61 \\
\hline $36-45$ & 86 & 19.77 \\
\hline $46-60$ & 12 & 2.76 \\
\hline$>60$ & 2 & 0.46 \\
\hline \multicolumn{3}{|l|}{ Gender } \\
\hline Male & 257 & 59.08 \\
\hline Female & 178 & 40.92 \\
\hline \multicolumn{3}{|l|}{ Marital status } \\
\hline Single & 143 & 32.87 \\
\hline Married & 283 & 65.06 \\
\hline Divorced, widow or widower & 7 & 1.61 \\
\hline No response & 2 & 0.46 \\
\hline
\end{tabular}


A: The Sixth Census of Wenzhou (2010)

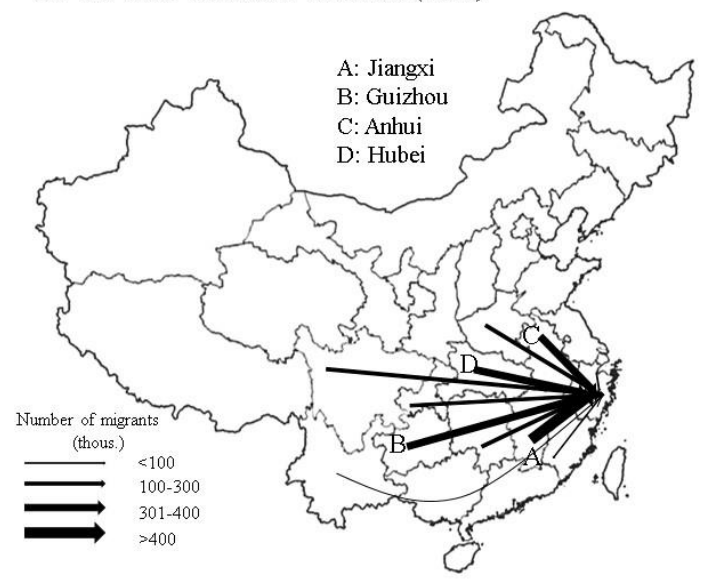

B: 2013 Survey

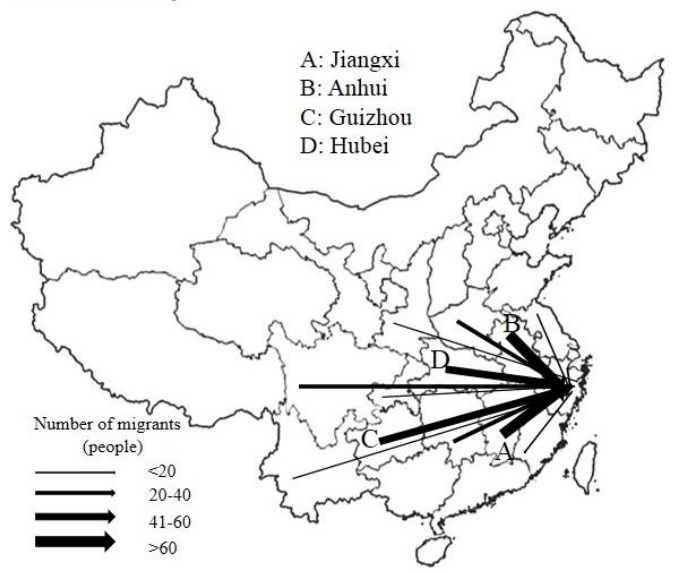

Figure 5.5 Origins of the migrants in Wenzhou in general (A), and in the Shuangyu survey sample (B).

The majority of migrants are married and reported living together with their spouse in Wenzhou. The trend of family migration is significant. Among the 435 migrants in the survey, 65 percent of the migrants are currently married, among whom 77 percent reported living with a spouse in Wenzhou. This is partly due to the fact that that long-term family separation has become less acceptable as the period of urban employment has lengthened. This is partly due to the fact that increased urban wages are much more desirable than farming in the villages.

However, even with 96 percent of those couples having at least have one child, many of them left children at home in the village, to be minded by the grandparents (Table 5.2). Only about 35 percent of these migrants who have children together in Wenzhou ${ }^{10}$.

${ }^{10}$ The plight of such "left behind" children is a growing concern in rural China. Biao, X. (2007). How far are the left-behind left behind? A preliminary study in rural China. Population, Space and Place, 13(3), 179-191. Chang, H., Dong, X.-y., \& MacPhail, F. (2011). Labor Migration 
Table 5.2 Did you bring your children to Wenzhou?

\begin{tabular}{lrr}
\hline & No. of Migrants & $\%$ \\
\hline Yes, they go to school/stay in Wenzhou & 64 & 30.99 \\
Yes, they are working in Wenzhou & 13 & 4.58 \\
No, they go to school/stay in hometown & 150 & 52.82 \\
No, they go to work in hometown & 13 & 4.58 \\
No, they go to work in other cities & 8 & 2.82 \\
N/A & 12 & 4.23 \\
\hline
\end{tabular}

In the survey, I also noticed the trend of long-term residence is significant. In spite of their temporary status, migrants stayed longer than before in the city. About 54.71 percent of the migrants in the survey have been staying in Wenzhou for more than 5 years, among which quite a large number of them have been staying in Wenzhou for more than 10 years (Table 5.3). 19.31 percent of them have been in Wenzhou for about two to five years. Further analysis shows a clear stratification between married and single migrants. Married migrants in general have stayed in Wenzhou for longer periods of time than single migrants. Compared to 36.36 percent of single migrants, there are 64.08 percent of total married migrants have stayed in Wenzhou for more than five years.

and Time Use Patterns of the Left-behind Children and Elderly in Rural China. World Development, 39(12), 2199-2210. He, C., \& Ye, J. (2014). Lonely Sunsets: Impacts of Rural-urban Migration on the Left-behind Elderly in Rural China. Population, Space and Place, 20(4), 352-369. 
Table 5.3 Years in Wenzhou

\begin{tabular}{|c|c|c|c|}
\hline Years in Wenzhou & Total (\%) & Single (\%) & Married (\%) \\
\hline Less than half a year & 5.52 & 10.49 & 3.17 \\
\hline Half to one year & 7.82 & 10.49 & 5.99 \\
\hline One to two years & 12.64 & 18.88 & 9.51 \\
\hline Two to five years & 19.31 & 23.78 & 17.25 \\
\hline More than five years & 54.71 & 36.36 & 64.08 \\
\hline
\end{tabular}

However, most migrants who come to Wenzhou in search of employment opportunities show little interest in becoming permanent residents (Table 5.4). Only 19.31 percent of them intend to stay in Wenzhou in the future; 52.18 percent of them would leave if there are better opportunities in their hometown or other cities; and 28.51 percent have no idea. It suggests that the majority of migrant workers come to Wenzhou primarily to earn money rather than to reside in Wenzhou permanently.

Although in general the majority of migrants are willing to leave Wenzhou if there are better working opportunities in their hometown or other cities, there are different choices between married migrants with, or without spouse in Wenzhou and single migrants. Married migrants with a spouse in Wenzhou are more willing to stay in Wenzhou than the other two types of migrants. Married migrants without spouse in Wenzhou (most of which have spouse at their hometown) tend to move back to their hometown. Single migrants are inclined to find jobs in other cities compare to the married migrants. In short, family is a very important factor that constrains the mobility of migration. 
Table 5.4 Migrants' intention of stay

\begin{tabular}{lrrr}
\hline & $\begin{array}{c}\text { Married with } \\
\text { spouse in Wenzhou } \\
(\%)\end{array}$ & $\begin{array}{c}\text { Married without spouse in } \\
\text { Wenzhou (\%) }\end{array}$ & Single (\%) \\
\hline Yes & 26.03 & 15.38 & 11.19 \\
$\begin{array}{l}\text { No, if there is any good job } \\
\text { opportunity, I'll move back } \\
\text { to my hometown }\end{array}$ & 35.16 & 47.69 & 36.36 \\
$\begin{array}{l}\text { No, I plan to find a job in } \\
\text { other cities } \\
\text { Haven't thought about it }\end{array}$ & 10.96 & & \\
\hline
\end{tabular}

Compared to the other metropolises such as Beijing, Guangzhou, obtaining a local hukou in Wenzhou is not desirable for migrants. In fact, whether or not they can obtain a local hukou is the least important thing that migrants to Wenzhou are concerned about. Instead, salary and living cost are the two most important things that migrants care about (Table 5.5). As one of the migrants replied: "Why would I want to become a Wenzhounese? I was born in Zhuzhou (Hunan Province), and my family root is there too. I'd rather choose to get a Henan hukou (where her husband came from) but not Wenzhou. This is only a place to get job and earn money. I'll leave if there is better opportunity in my hometown. 
Table 5.5 Migrants' concerns about Wenzhou

\begin{tabular}{lrr}
\hline & No. of migrants & \multicolumn{2}{c}{$\%$} \\
\hline Salary & 306 & 70.34 \\
Living cost & 90 & 20.69 \\
Safety & 81 & 18.62 \\
Health and social welfare & 80 & 18.39 \\
Living environment & 78 & 17.93 \\
Children's education & 71 & 16.32 \\
Job opportunities & 69 & 15.86 \\
Leisure & 41 & 9.43 \\
Wenzhou hukou & 16 & 3.68 \\
\hline
\end{tabular}

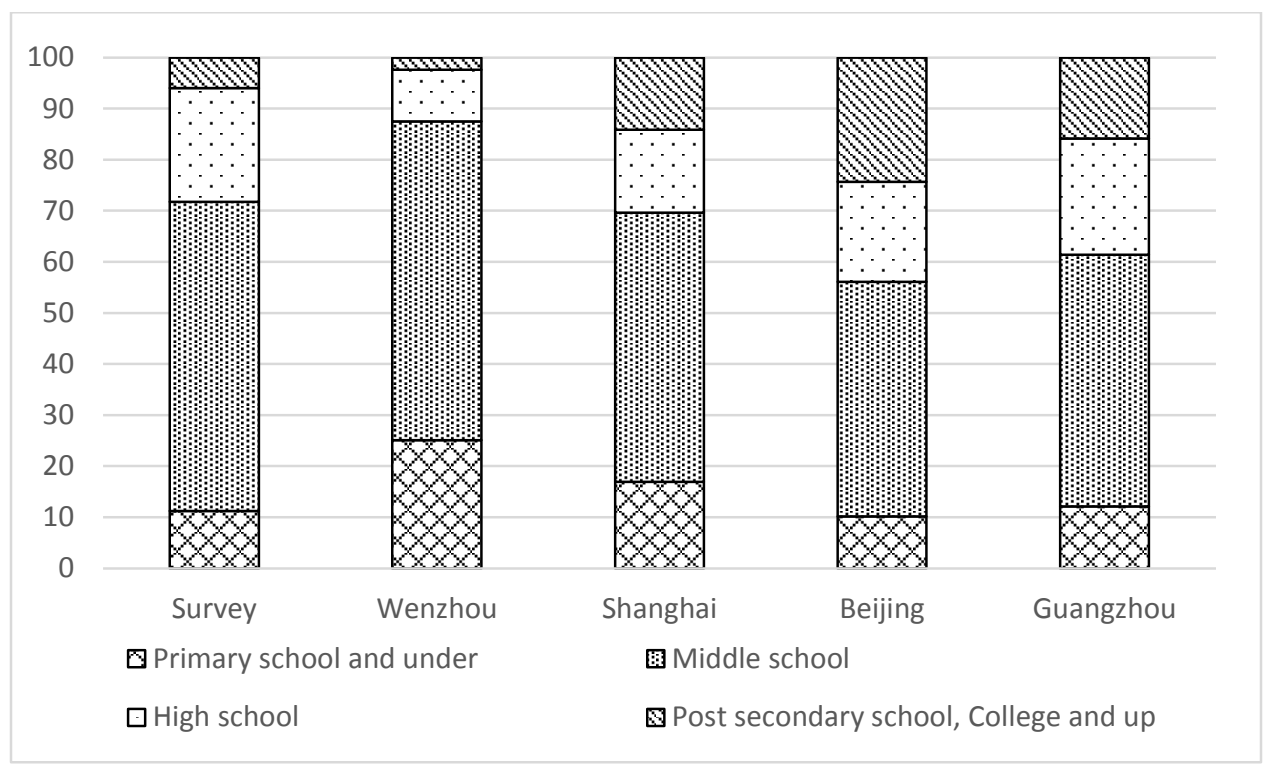

Figure 5.6 Migrants' educational attainment

Data source: the Sixth (2010) Population Census of Wenzhou, Shanghai, Beijing and Guangzhou.

Figure 5.6 compares the educational attainment of migrants in the survey with Wenzhou and megacities. Although migrants in general have low educational attainment, the migrants in Wenzhou are even less well educated than the migrants in other large cities in China. 


\subsubsection{An economic profile}

The relative ease of migrants' entry into the urban labor market seems to reflect a demand for labor in sectors unfilled by urban residents. Secondary industry, especially laborintensive manufacturing, has contributed to the major portion of GDP in Wenzhou. There is a large demand for laborers. However, because of the deeply rooted mercantile ideology, Wenzhounese prefer either to be entrepreneurs who work for themselves or civil servants who are considered as insiders of the government, and look down on people who work for others (dagong)(Yanlu Wang, 2009). Therefore, the flood of rural migrants filled up the gap. As shown in Table 5.6, migrants mainly work in the manufacturing sectors. As expected, the majority of migrants work in the lower ranks of the manufacturing industries-as manual laborers. Overall, fewer than 10 percent of migrant workers are in pink or white-collar positions, such as office clerks, secretaries, and line supervisors. Among migrants' industrial (occupational) distributions, there is not a clear stratification by gender due to the dominant number of manufacturing workers. But it is worth pointing out that males are almost twice likely to be in the manager level positions, such as line supervisors. Females are more widely represented in self-employed and business sectors, such as restaurant owners, grocery shops, and salons. 
Table 5.6 Industrial (occupational) distributions of migrants, Wenzhou

\begin{tabular}{lrrr}
\hline Industry & Total (\%) & Female (\%) & \multicolumn{2}{c}{ Male (\%) } \\
\hline Manufacturing & 80.40 & 83.71 & 80.93 \\
(Manager level) & $(9.35)$ & $(6.74)$ & $(11.74)$ \\
Self-employed and business & 6.46 & 7.3 & 4.67 \\
Construction and transport & 3.34 & 0.56 & 2.33 \\
Services & 2.00 & 1.12 & 2.33 \\
Vendors & 2.90 & 1.12 & 3.11 \\
Unemployed & 3.34 & 3.37 & 3.5 \\
Others & 1.56 & 2.81 & 3.11 \\
\hline
\end{tabular}

Note: total number of the sample migrants here is 449 , due to 14 migrants in the survey reported to have two jobs.

\subsubsection{The determinants of income}

As mentioned before, working or earning money is the primary reason that migrants report for having come to Wenzhou. How much they can earn is the most important thing that concerns them about living in Wenzhou. The survey shows that many migrant workers earn a wage that falls into the categories of $2,000-3,000$ or 3,000-5,000 Yuan. Compared to Wenzhou's average wage $-3,528$ Yuan/month in 2011, the average wage for migrant workers seems comparable. However, migrants work longer than Wenzhou's average population's work time8 hours per day. 87.31 percent of the migrants in the survey work more than 8 hours per day, among whom, 60.80 percent of them work more than 10 hours a day (Table 5.7). 
Table 5.7 Income and work hours per day of migrants in the survey

\begin{tabular}{lrr}
\hline & No. of migrants & $\%$ \\
\hline Income & & \\
$<1,000$ & 11 & 2.58 \\
$1,000-2,000$ & 30 & 7.04 \\
$2,000-3,000$ & 181 & 42.49 \\
$3,000-5,000$ & 53 & 35.45 \\
$>5,000$ & 9 & 12.44 \\
Work hours per day & & \\
Less than six hours & 9 & 2.07 \\
six-eight hours & 42 & 9.66 \\
eight-ten hours & 116 & 26.67 \\
More than ten hours & 259 & 59.54 \\
No response & 9 & 2.07 \\
\hline
\end{tabular}

What are the factors that determine migrants' income? Many studies, such as Feng, Zuo, and Ruan (2002), have researched the determinants of migrants' income in the city. Are the factors that influence migrants' income in Wenzhou similar or different from the other cities? Based on the survey data, I specifically examine the roles of five categories of variables. The first category includes two demographic variables-age and gender-which are often believed to influence the income of migrants. The second category of variables is the migrants' original registration status-hukou. The third category of variables includes education and years of stay in Wenzhou which indicate their work ability and experience. Generally, these two variables are recorded to have a positive effect on income, that is, migrants with a higher educational attainment and longer years of stay usually attain higher income. The fourth category is a migrant's occupation. Although the majority of migrants in Wenzhou work in the manufacturing industry, it is also interesting to know whether manufacturing jobs brought them higher pay. The last category is working hours. 
Table 5.8 Linear regression for the determinants of a migrant's income (Enter)

\begin{tabular}{|c|c|c|c|c|}
\hline \multirow[t]{2}{*}{ Model } & \multicolumn{2}{|c|}{$\begin{array}{l}\text { Unstandardized } \\
\text { Coefficients }\end{array}$} & \multirow{2}{*}{$\begin{array}{c}\text { Standardized } \\
\text { Coefficients } \\
\text { Beta } \\
\end{array}$} & \multirow[t]{2}{*}{ Sig. } \\
\hline & $\mathrm{B}$ & Std. Error & & \\
\hline (Constant) & 1.652 & 0.891 & & .065 \\
\hline Sex $($ Female $=0$, male $=1)$ & 0.415 & 0.083 & 0.228 & .000 \\
\hline Hukou (Urban=0, rural=1) & -0.077 & 0.138 & -0.026 & .579 \\
\hline \multicolumn{5}{|l|}{ Age } \\
\hline \multicolumn{5}{|l|}{$<18$ (as reference) } \\
\hline $18-25$ & 0.376 & 0.831 & 0.195 & .651 \\
\hline $26-35$ & 0.331 & 0.827 & 0.183 & .689 \\
\hline $36-45$ & 0.274 & 0.827 & 0.122 & .741 \\
\hline $46-60$ & 0.267 & 0.856 & 0.048 & .755 \\
\hline$>60$ & 0.19 & 0.847 & 0.046 & .823 \\
\hline \multicolumn{5}{|l|}{$\begin{array}{l}\text { Education } \\
\text { Primary and under (as } \\
\text { reference) }\end{array}$} \\
\hline Middle school & 0.073 & 0.139 & 0.04 & .602 \\
\hline High school and technical school & 0.157 & 0.158 & 0.074 & .322 \\
\hline Post-secondary & 0.113 & 0.252 & 0.024 & .654 \\
\hline College and up & 0.157 & 0.352 & 0.022 & .656 \\
\hline \multicolumn{5}{|l|}{ Years of stay } \\
\hline \multicolumn{5}{|l|}{$<$ Half year (as reference) } \\
\hline Half to one & 0.207 & 0.223 & 0.061 & .354 \\
\hline One to two & 0.464 & 0.204 & 0.173 & .024 \\
\hline Two to five & 0.327 & 0.194 & 0.146 & .093 \\
\hline More than five & 0.581 & 0.185 & 0.324 & .002 \\
\hline \multicolumn{5}{|l|}{ Occupation } \\
\hline \multicolumn{5}{|l|}{ Manufacturing (as reference) } \\
\hline Business owners & 0.801 & 0.183 & 0.203 & .000 \\
\hline Transport and construct & 0.413 & 0.319 & 0.059 & .196 \\
\hline Services & -0.58 & 0.3 & -0.088 & .054 \\
\hline Vendors & -0.372 & 0.265 & -0.063 & .161 \\
\hline Unemployed & 0.196 & 0.277 & 0.033 & .480 \\
\hline Other & -1.163 & 0.342 & -0.154 & .001 \\
\hline \multicolumn{5}{|l|}{ Work hours per day } \\
\hline \multicolumn{5}{|l|}{$<6$ (as reference) } \\
\hline 6 to 8 & 0.688 & 0.304 & 0.23 & .024 \\
\hline 8 to 10 & 0.696 & 0.284 & 0.347 & .015 \\
\hline$>10$ & 0.845 & 0.278 & 0.463 & .003 \\
\hline
\end{tabular}


Note: $R^{2}=0.217$, Adjusted $R^{2}=0.170$, Sig. $F$ Change $=0.000$, Durbin-Watson $=1.959$. Number of cases $=426$, is smaller than the total surveyed number of migrants because the migrants who with two jobs at one time have been excluded.

Table 5.9 Linear regression for the determinants of a migrant's income (Forward)

\begin{tabular}{|c|c|c|c|c|}
\hline \multirow[t]{2}{*}{ Model 2} & \multicolumn{2}{|c|}{ Unstandardized Coefficients } & \multirow{2}{*}{$\begin{array}{c}\begin{array}{c}\text { Standardized } \\
\text { Coefficients }\end{array} \\
\text { Beta }\end{array}$} & \multirow{2}{*}{ Sig. } \\
\hline & B & Std. Error & & \\
\hline (Constant) & 2.981 & 0.086 & & .000 \\
\hline Gender & 0.442 & 0.081 & 0.244 & .000 \\
\hline \multicolumn{5}{|l|}{ Hukou } \\
\hline \multicolumn{5}{|l|}{ Age } \\
\hline \multicolumn{5}{|l|}{ Education } \\
\hline \multicolumn{5}{|l|}{ Years of stay } \\
\hline More than five years & 0.237 & 0.08 & 0.133 & .003 \\
\hline \multicolumn{5}{|l|}{ Occupation } \\
\hline Business owners & 0.71 & 0.175 & 0.18 & .000 \\
\hline Services & -0.589 & 0.292 & -0.09 & .045 \\
\hline Others & -1.376 & 0.336 & -0.182 & .000 \\
\hline \multicolumn{5}{|l|}{ Work hours per day } \\
\hline More than 10 hours & 0.166 & 0.081 & 0.091 & .042 \\
\hline
\end{tabular}

Note: $\mathrm{R}^{2}=0.177$, Adjusted $\mathrm{R}^{2}=0.166$, Sig. $\mathrm{F}$ Change $=0.45$. Durbin-Watson $=2.000$. Variables without data indicate that these variables have been excluded from the models during the regression process.

Table 5.8 reveals the result of linear regressions for all the determinants of migrant's income. A migrant's gender play an important role. A male migrant $(B=0.415)$ has higher income than a female migrant if controlling for the hukou status, age, education, years of stay, occupation and work hours per day. A migrant's occupation clearly has affected their income level. Their longer years of stay in Wenzhou and longer work hours per day also contribute to their income level. Surprisingly, however, a migrant's original hukou status, age and education are usually reported to have positive effect on a migrant's income in some megacities such as 
Shanghai (Feng et al., 2002), Beijing (Siqu Zheng et al., 2009), are not significantly related to the income in Wenzhou's case.

Moreover, to best explain the relations between factors and income level, the regression approach of "forward" in SPSS has been chosen (Table 5.9). Only a few variables are found to be associated with a migrant's income level, such as gender, years of stay (more than five years), occupation (business owner, services, and others), work hours per day (more than 10 hours). The results from this model generally follow the first model, while providing more details in each category. In years of stay and working hours per day for example, only a migrant who has stayed Wenzhou for more than five years $(B=0.237)$ or worked more than 10 hours a day $(B=0.166)$ see a difference in their income level. It indicates that migrants who are new to the city need to work extreme long hours to earn more money. Moreover, different occupations may have an opposite influence on the income level. Compared to those who work in the manufacturing industries, migrants who are business owners have higher income; while those who work in the service sectors such as babysitters, waiters and others who work as teachers, for example, earn less. Although running a business is desirable to meet their goals of earning money in the city, it is not always easy to start. As such, manufacturing work in Wenzhou seems to be the best choice for migrants.

\subsection{Summary}

The different characteristics of migrants may result in different impacts on the city or have connections with other parts of the city. In this chapter, using quantitative and qualitative data derived from a questionnaire survey and in-depth interviews carried out in Shuangyu, Wenzhou, I have reviewed some distinctive demographic and economic characteristics of 
migrants in Wenzhou, and then furthered the analysis by evaluating the determining factors of migrants' income in Wenzhou.

The majority of migrants, who are from the rural regions in the inland poor provinces, come to Wenzhou in search of employment opportunities. They mostly work in the manufacturing factories. Although they may have stayed many years in Wenzhou, few intend to stay in Wenzhou in the future and most have little interest in becoming permanent residents. It indicates their living in the city is more for working rather than becoming involved with the city life. Meanwhile, long working hours (more than 10 hours per day) may have limited their chances for exploring, experiencing and changing the city. Also, the majority of the migrants left their children behind, minding by their parents in the rural hometown. It indicates the children are usually not living in Wenzhou and become a second generation migrants as what we have learned in early Chicago and other Western cities. It further indicates that migrants in Wenzhou have less impact on the urban form as in Chicago and other Western cities.

The regression analysis shows that the determining factors of migrants' income level have been different from what has been mentioned in the existing literature for the megacities. Surprisingly, how much migrants could earn is not decided by the educational level, but rather is influenced by the sex, length of stay (work experience), and work hours. The findings have also pointed out that manufacturing work has been the most desirable to migrants due to their economic purpose in the city. 


\section{CHAPTER 6}

\section{RESIDENTIAL SPACE IN MIGRANT SETTLEMENTS}

\subsection{Introduction}

On the bus \#80 from Yongjia industrial park to Shuangyu, I started to hear people speak different dialects or mandarins with strong accents. Males with dyed and stylish hairs are usually slim, wearing casual T-shirt and tight pants;

Girls who are often young wear garish and bright colored clothes. On a regular day, unlike the busy bus lines in the city center, this bus route is quite empty. Streets, villages, shops and public spaces are often very quiet before $4 \mathrm{pm}$ in the daytime. Also, distinctive dialect and local character that value

appearance of Wenzhounese could easily differentiate from migrants.

--the Author

The fluid processes of migration and settlement territorialize parts of the city and create distinctive features of urban space, while also following patterns of deterritorialization and reterritorialization. Considering migrant settlement as a deeper layer of the whole urban assemblage, this chapter aims to better understand the major morphologies and spatialities of migrant settlement-the ways in which migrants flourish in the spatial interstices of the city and produce urban phenomena with a potent impact on the streetscape and urban image. By exploring the residential space of Shuangyu's migrant settlement, this chapter also analyzes how the formal/informal processes involved in the development of migrant settlements.

The informality of the migrant settlements is often perceived as an eyesore or nuisance by city managers and planners. They attempt to eliminate this informality or "non-state space" to create more governable spaces through formal land and infrastructure development (F. Wu et al., 2012). However, as Dovey (2012) argues “...There is nothing essentially good or bad about urban informality...". Both formal and informal processes represent constituent aspects of urbanization in China. In this chapter, the concept of 'urban assemblage' helps to re-think the 
formal/informal framework, searching for what is the best possible means to incorporate the informal settlements into overall urban planning and management.

The analysis in this chapter is primarily based on the data collected in the summer of 2012 and 2013, as well as the author's observations and fieldwork. In the analysis of the housing and living environment in migrant settlements, I particularly evaluate the housing and living conditions of migrants by discussing the housing sources, residential patterns, living space, living cost and facilities, and migrants' evaluation of their the living conditions.

\subsection{Housing and living environment in migrant settlements}

Many scholars have discussed that close location to work place and affordability are two of most important factors that influencing migrants' decision making on housing (Conway \& Brown, 1980; Turner, 1968; W. P. Wu, 2002a) . A large number of migrants in Shuangyu have a low level of educational attainment and improve their income in a way that requires devoting extremely long time and intensive labor. They have to maximize their savings by minimizing their living costs, in which housing costs contribute to a significant portion. In this section, I will evaluate the housing and living conditions of migrants by discussing the housing sources, residential patterns, living space, living cost and facilities, and migrants' evaluation of their living conditions.

\subsubsection{Source of housing}

Migrants' temporary status and economic purpose in the city suggests that accommodations are mainly places to sleep and rest. So proximity to the workplace and low cost are higher priorities than comfortable living environment and space. Wenzhou is not only 
well-known as an entrepreneurial hub that breeds wealthy businessmen but also is famous for property speculation. In fact, Wenzhounese have been blamed for inflating mainland property prices. For a long time, Wenzhou's housing price ranked among of the highest in the 70 large and medium sized cities. Even after it dropped substantially after 2011, Wenzhou's housing price ranked second only after Beijing in Feb 2012 with an average of 23,130 yuan/sq. meter (about $\$ 40,156 \mathrm{sq} \mathrm{ft}$ ) and ranked fourth place in Aug. 2013 (CITYRE, 2013). Many wellestablished local residents cannot afford such high housing prices, let alone rural migrant workers. Therefore, owning an apartment in Wenzhou is impossible for most of the migrants (less than 1 percent out of total surveyed migrants). In addition, as Wu (2002) explained in regard to migrants in Shanghai and Beijing, economic and comfortable housing ${ }^{11}$, municipal public housing and work-unit public housing are all not accessible to migrants (W. Wu, 2002). Similarly in Wenzhou, dormitories provided by the employers and cheaper rented housing from private parties are the major accommodation for migrants. In the survey, 36 percent of the total number of migrants live in the dormitories that provided by their employers and about 62 percent of migrants rent room from private party. This was consistent with other cities and nationwide.

${ }^{11}$ Economic and comfortable housing (jingji shiyong fang): is a type of affordable housing for low-or middle-income local urban residents to purchase, which is built by for-profit real estate developers while subsidized by government to maintain the relative low price. It is important to point out that all affordable units are developed for sale, not for rent and are only accessible to eligible urban residents. 
Table 6.1 Housing tenure (\%) from author's Survey of 435 migrants

\begin{tabular}{lrr}
\hline Housing sources & Single (\%) & Married (\%) \\
\hline Apartment I bought & 2.1 & 0.35 \\
A rented apartment, alone & 40.56 & 54.93 \\
Sharing a rented apartment with others & 14.69 & 9.86 \\
Company dormitory & 39.16 & 33.8 \\
Others & 1.4 & 0.35 \\
No response & 2.1 & 0.7 \\
Total & 100 & 100 \\
\hline
\end{tabular}

\subsubsection{Factory dormitory}

It is common for factories to provide free dormitories for their workers in Shuangyu. There are usually two types of dorms-one for single workers and the other for qualified couples. The standard room for single workers is usually equipped with four bunk beds or tribeds which can accommodate a maximum of eight or twelve people. The rooms usually are provided with air conditioners and sometimes better ones have a private balcony. They share one public bathroom and one public toilet in each floor (Fig. 6.1). The dorm rooms can be very crowded if they accommodate 8 people or more. Or if the room is not full, workers will take the space of the empty beds for storage. The dorm for qualified couples is much more spacious than single workers' dorm, and is usually equipped with air conditioner, private bathroom and water heater (Fig. 6.2). Because of the limited number of rooms, these private dorms are only for couples with at least one of them whose occupation is equal or higher than line leaders (such as workshop managers, managers). Those who are qualified for this housing but choose not to live 
in the dorm, can get a certain amount of compensation in some factories. For both type of the rooms, the workers only have to pay for utilities such as electricity and water.
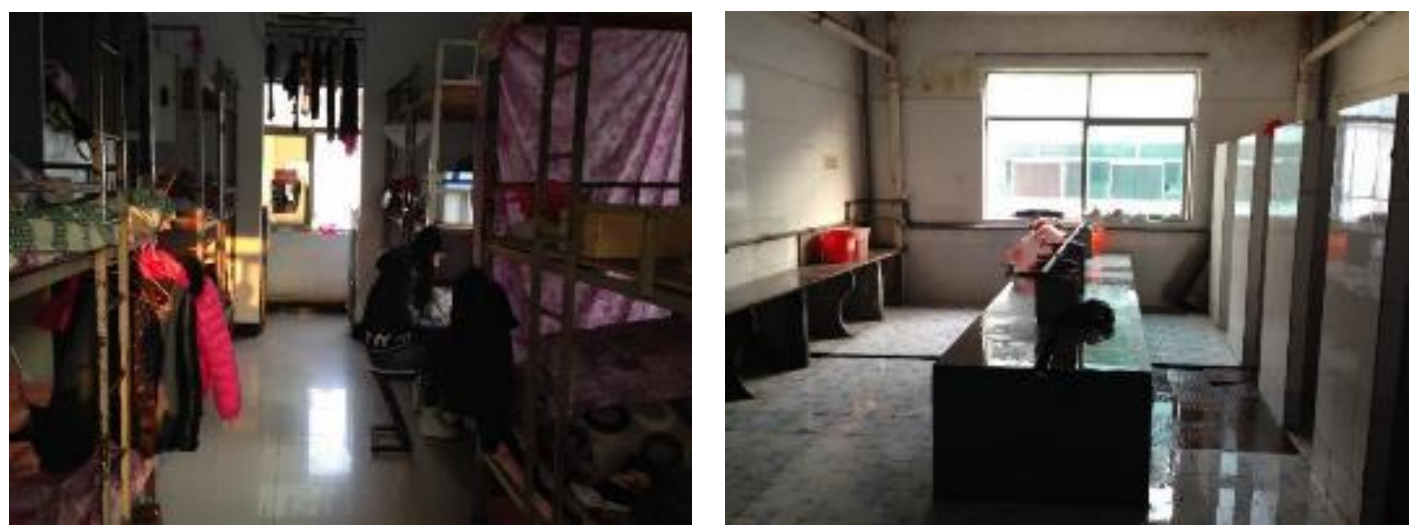

Figure 6.1 Dorm for single workers and public bathroom in a floor
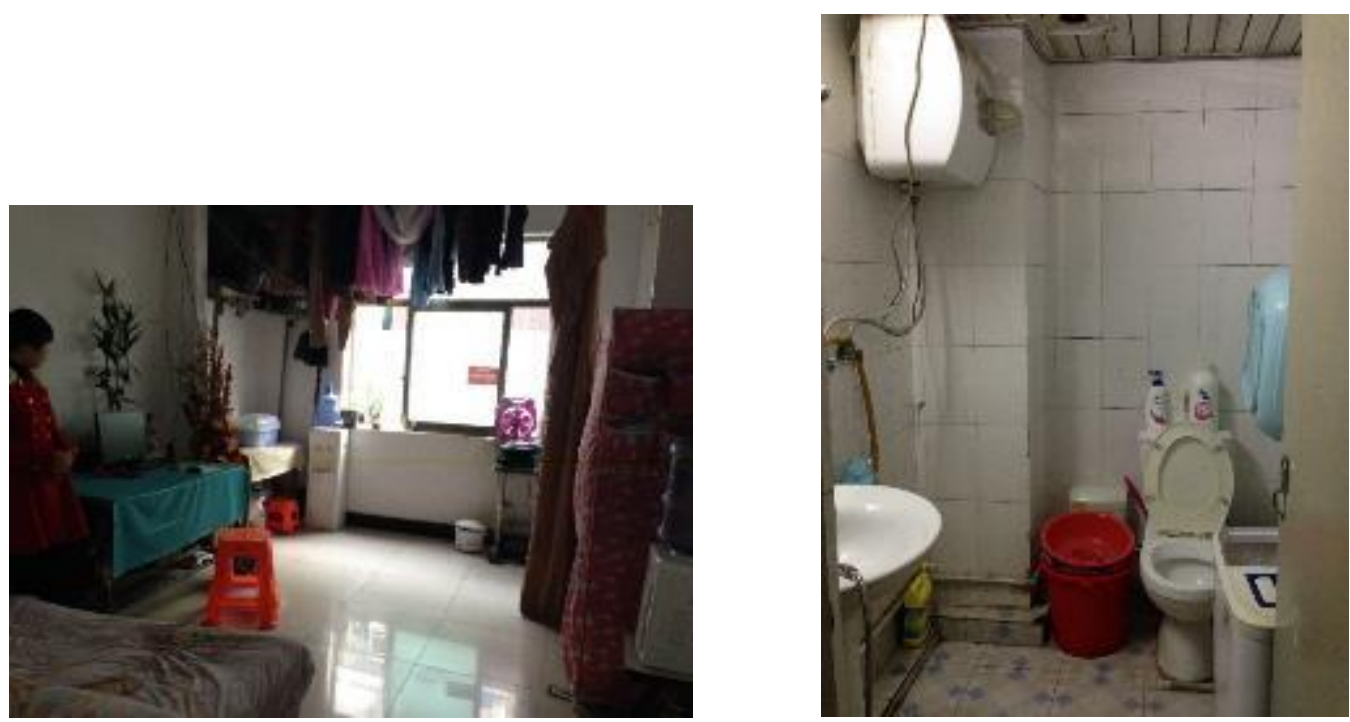

Figure 6.2 Dorm for qualified couple and private bathroom

Approximately 36 percent of the migrants in the survey live in such employer-run dormitories. There are more single migrants (39.16 percent) who live in the factory dorms than married ones ( 33.80 percent). Also, migrants who choose to live in the factory dorms tend to have relative stable relationships with the factories. 60.9 percent of migrants who live in the dormitory have signed a work contract with the factories, compare to 28.15 percent of migrants 
who live in rented housing outside the factories, who mostly work on task-basis or daily basis.

This also can be seen from the frequency with which migrants change jobs. More than 53 percent of migrants who live in the dormitories never changed jobs (e.g., they have stayed with a single employer since arriving in Wenzhou). In comparison, only 24 percent of migrants who live in rented housing have remained with a single employer throughout their stay in Wenzhou. In short, migrants who live in the dormitories are tend to be single and have relatively stable jobs in the factories.

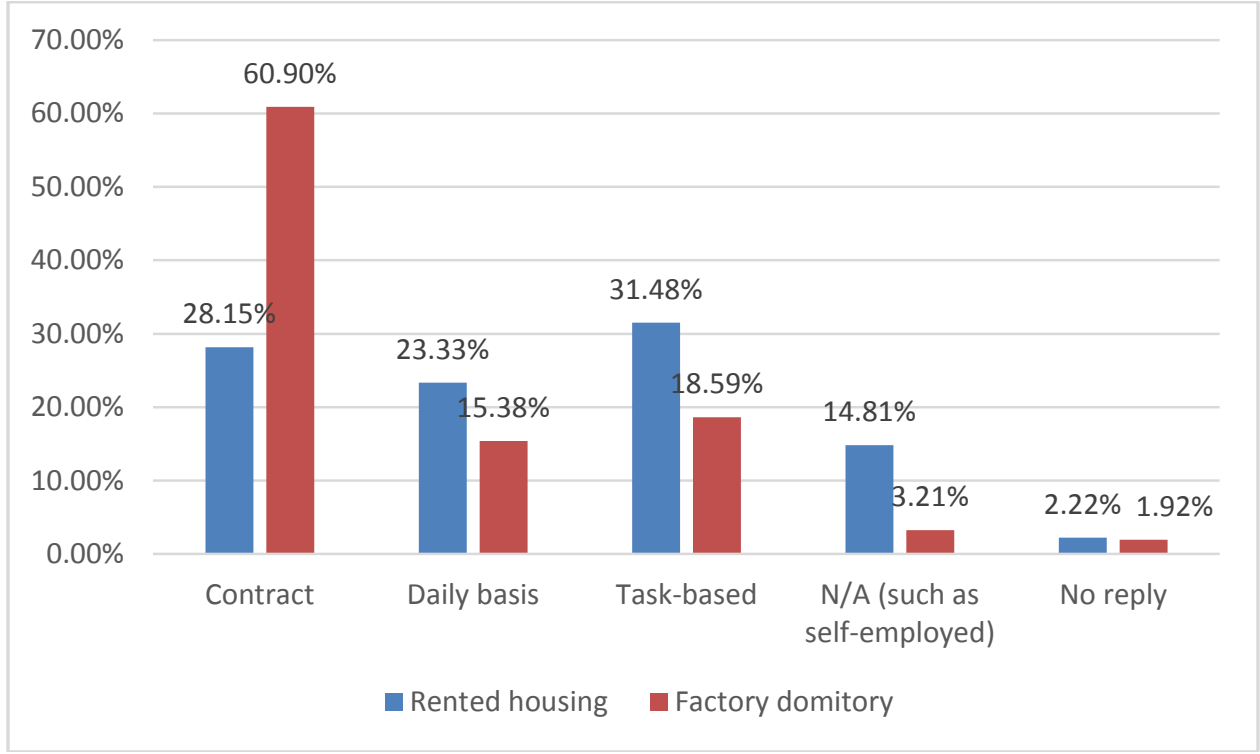

Figure 6.3 Contract situation of migrants live in factory dormitory and rented housing 


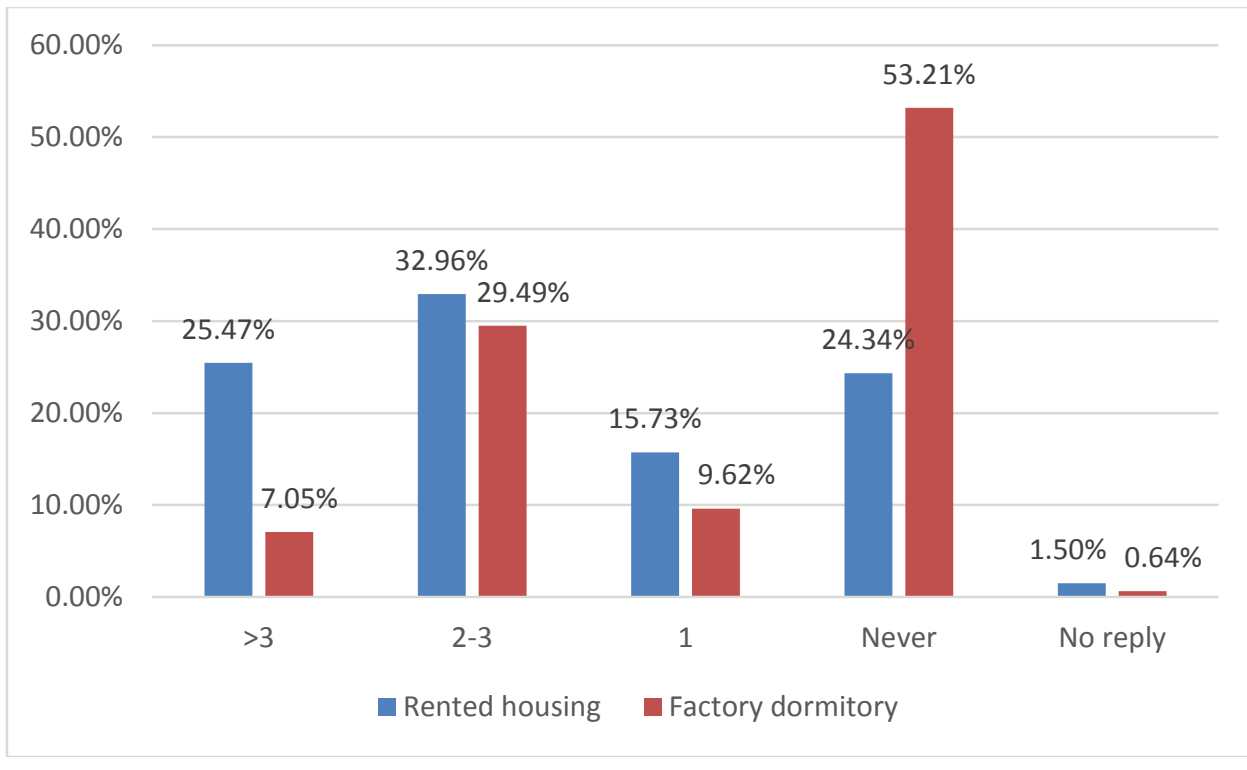

Figure 6.4 Number of jobs had before of migrants live in the rented housing and factory dormitory

Although living in a dormitory is free, this is not the major housing choice for the migrant workers. More migrant workers choose to rent rooms from private party. There are three reasons: (1) a large number of migrants come to Wenzhou with their families. Although some of the factories provide private rooms for couples, only a small portion of them are qualified to enjoy the privileges. (2) many migrant workers change jobs quite often, which means they have to move frequently if they live in the factory dormitory. (3) dormitories are noisy and unsafe. Living in a dormitory means that you have to share a room with a lot of strangers. Sometimes roommates change quite frequently. It is unsafe and lack of privacy.

\subsubsection{Rented housing in villages: formal/informal}

The largest proportion of migrants (62 percent in the survey) live in rented housing from private parties in Shuangyu, particularly housing in the villages. After administrative adjustment in 2011, Shuangyu has become a sub-district of Wenzhou's urban district. 13 villages inside 
Shuangyu then became VICs. These VICs were originally rural settlements, but due to rapid industrialization and urbanization, the agricultural land owned by these villages was gradually transferred to urban built-up area. Six of them are located within the two industrial parks, which are Niuling, Yutou, Zheng'ao, Shangyi, Qianchen and Jishi village. The others are located close to the two industrial parks. On the one hand, compare to housing in the newly build-up communities with high rise buildings and modern design of gated communities, cheaper housing from VICs is more popular among migrants. On the other hand, renting out housing to migrants at affordable rates is also quite a common income-generating business for local villagers.

According to data obtained from Shuangyu Sub-district Office in the summer of 2013, VICs accommodate 78 percent of total migrants in Shuangyu (Table 6.2). In most of the villages, the migrants substantially outnumber the local residents (Fig. 6.5). Niuling village due to its special location half inside the Lucheng Light Manufacturing Industrial Garden and half inside the Shoe Capital of China Industrial Park, has the highest ratio of migrants to local residents, which is 23.22:1. I was informed by the village head in Niuling village that almost every local resident has rented out all or a portion of their housing to migrants and many of them rely on the income from rental fees for making a living. The villagers/landlords themselves usually move out the village and live in the modern apartment community which are usually nearby in the same subdistrict. Jishi, Shangyi and Qianchen village, as three villages that are located inside the shoe capital of China industrial park also attract large number of migrants which is all more than 10 times of local residents. 
Table 6.2 Number of migrants and local residents in Shuangyu, 2013

\begin{tabular}{|c|c|c|c|}
\hline Community (Village) & $\begin{array}{l}\text { No. of Migrants* } \\
\text { (Person) }\end{array}$ & $\begin{array}{l}\text { No. of Local residents } \\
\text { (Person) }\end{array}$ & $\begin{array}{l}\text { Ratio (Local } \\
\text { residents as } 1 \text { ) }\end{array}$ \\
\hline Niuling village & 34,503 & 1,486 & $23.22: 1$ \\
\hline Jishi village & 39,298 & 2,662 & 14.76:1 \\
\hline Shangyi village & 17,954 & 1,539 & $11.67: 1$ \\
\hline Qianchen village & 12,803 & 1,196 & 10.70:1 \\
\hline Zheng'ao village & 9,407 & 969 & $9.71: 1$ \\
\hline Yinglouqiao village & 41,533 & 4,454 & $9.32: 1$ \\
\hline Yutou village & 15,256 & 1,768 & $8.63: 1$ \\
\hline Oupuyang village & 10,145 & 1,193 & $8.50: 1$ \\
\hline Shuang'ao village & 18,986 & 2,560 & $7.42: 1$ \\
\hline Pan'ao village & 8,451 & 1,227 & 6.89:1 \\
\hline Yangtian village & 17,331 & 2,585 & $6.70: 1$ \\
\hline Yanmen village & 8,477 & 1,317 & $6.44: 1$ \\
\hline Ruoli'ao village & 12,542 & 2,007 & $6.25: 1$ \\
\hline Kangcheng community & 6,524 & 633 & 10.31:1 \\
\hline Zhongyangtu community & 11,596 & 1,167 & 9.94:1 \\
\hline Qishan community & 4,324 & 545 & 7.93:1 \\
\hline Xinyu community & 6,071 & 1,261 & 4.81:1 \\
\hline $\begin{array}{l}\text { Huanglong Community: } \\
\text { 1st, 2nd, 3rd, } \\
\text { 4th districts, Zonglv wan }\end{array}$ & 15,007 & 3,488 & 4.30:1 \\
\hline Xinze Community & 8,354 & 2,576 & $3.24: 1$ \\
\hline $\begin{array}{l}\text { Huanglong Community: } \\
\text { 5th,6th, 7th, } \\
\text { 8th, 9th districts }\end{array}$ & 12,209 & 4,265 & $2.86: 1$ \\
\hline Wenhua comminity & 1,979 & 1,091 & $1.81: 1$ \\
\hline Yinglou Community & 4,280 & 2,493 & $1.72: 1$ \\
\hline
\end{tabular}

Source: Data were collected from Shuangyu sub-district office by the author during the fieldwork in the summer of 2013. *"Migrants" in this table only counts those migrants who stayed in Wenzhou for more than half a year. 


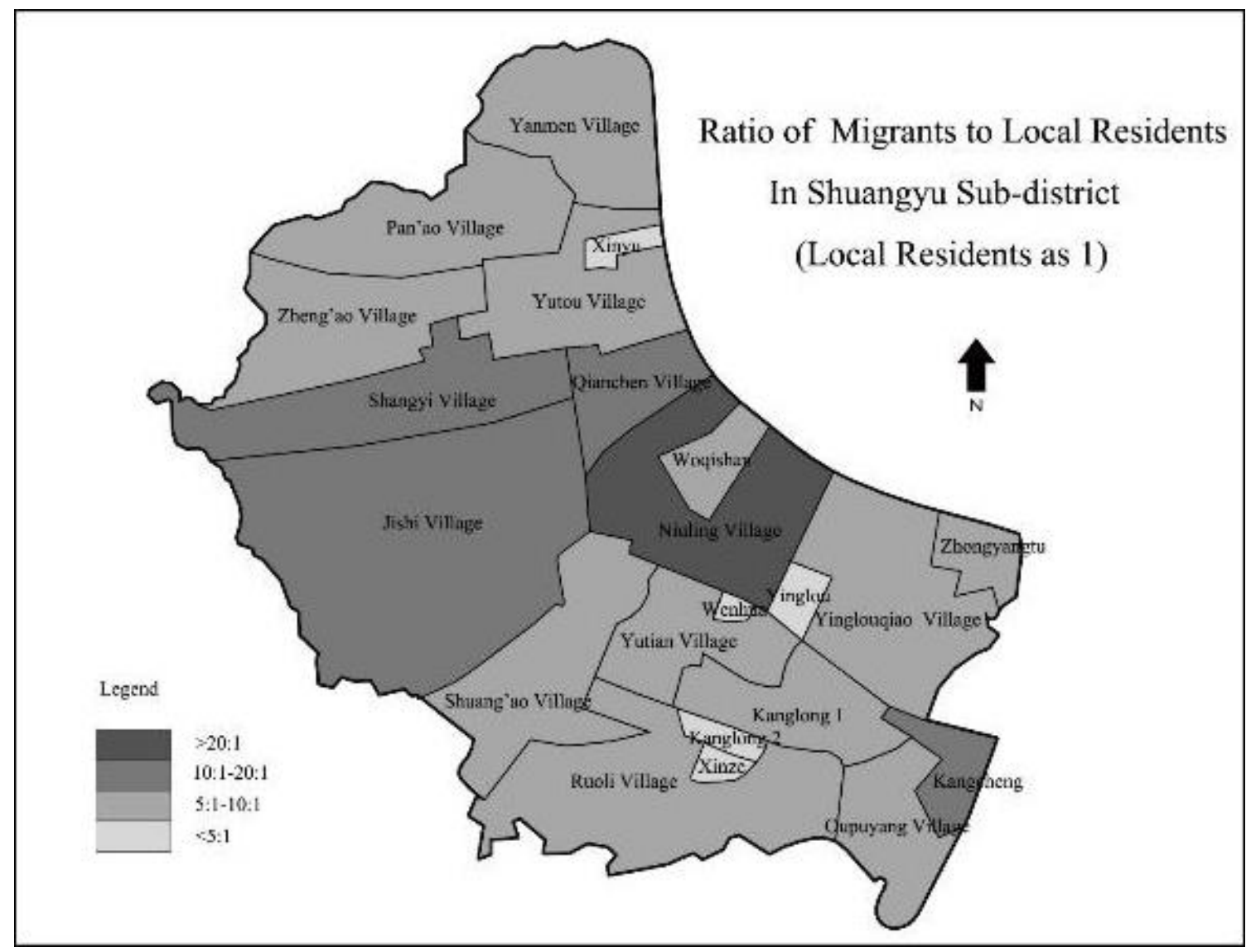

Figure 6.5 Ratio of migrants to local resident in Shuangyu sub-district

Due to their ambiguous juridical situation, VICs lack planning control and have formed an unregulated and informal rental market. The high demand of low-cost rental housing stimulates speculation illegal self-built housing. In order to increase their profits by renting out more rooms for migrants, the villagers tried every trick to maximize building areas on their land and create as many single rooms as possible. Original rooms were divided into many tiny single rooms for rent. More importantly, many local residents rebuilt their houses into multi-story buildings, attaching new construction to their original buildings, inserting parts into urban space area to create more rooms for rent, which are mostly illegal. Because of the collectively-owned nature of the land, the state government failed to halt the massive construction of illegal 
buildings. To indigenous villagers, the houses not only function to generate rents in the short term but also serve as a bargaining tool for higher compensation in case built land is requisitioned in future for urban development (L. Zhang, Zhao, \& Tian, 2003)

Based on my fieldwork in Wenzhou, I classified all illegal/informal self-built housing in VICs to three major types: Multi-story, accretion and infilling yards (Fig. 6.6).

(1)

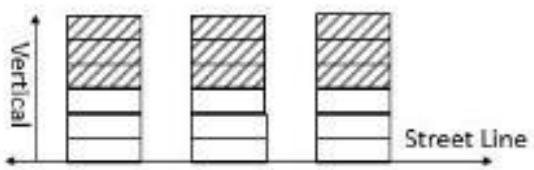

(2)

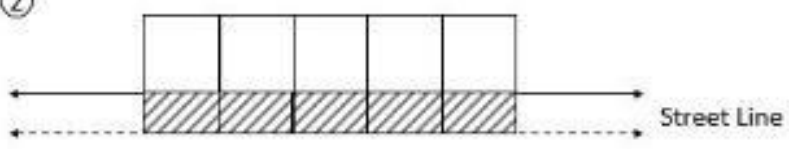

(3)

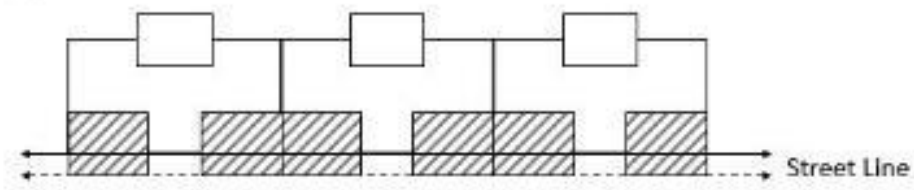

(4)

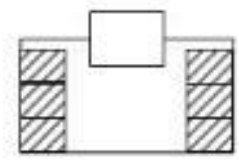

(5)

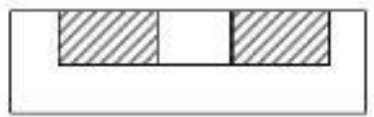

Figure 6.6 Types of illegal self-built housing in VICs

Source: Draw by author based on the fieldwork during the summer, 2013

1) Multi-story: extend vertically (1))

Multi-story buildings and narrow alleys are features that people often use to describe

VICs. Based on the pre-existing formal framework, villagers illegally add couple more floors (usually from one to three floors) to extend their building vertically. This is the most common way that villagers often use to expand their housing areas. Those added floors are usually simply built by using materials such as steel and concrete. Each floor is divided to several rooms and rented out to migrants. These "tall" buildings make the narrow alley look even narrower. Those 
narrow alleys are dark even during the day time due to lack of sunshine come through. They are also called "hand-shaking buildings" (woshoulou) or "a gleam of sky buildings (yixiantian)" in China-one can shake hands with neighbors in the next house or can only see a gleam of sky when you standing in the alley.

2) Accretion: extend horizontally (2) (3))

This type is that informal parts attach to the formal existing framework and burst through a formal public facade. Generally in the public street, the informal part, usually one floor will be attached to the formal building at the ground level to create shop fronts for migrants who want to run small businesses. In some semi-private alleys, villagers usually expand their house toward the alley and create more space for rooms. Figure 6.7 (left) shows a relatively formal three-story streetscape in Jishi village with informal protrusions at ground level. Figure 6.7 (right) shows a narrow semi-private alley after both sides of the houses expanded and occupied the alley space. 

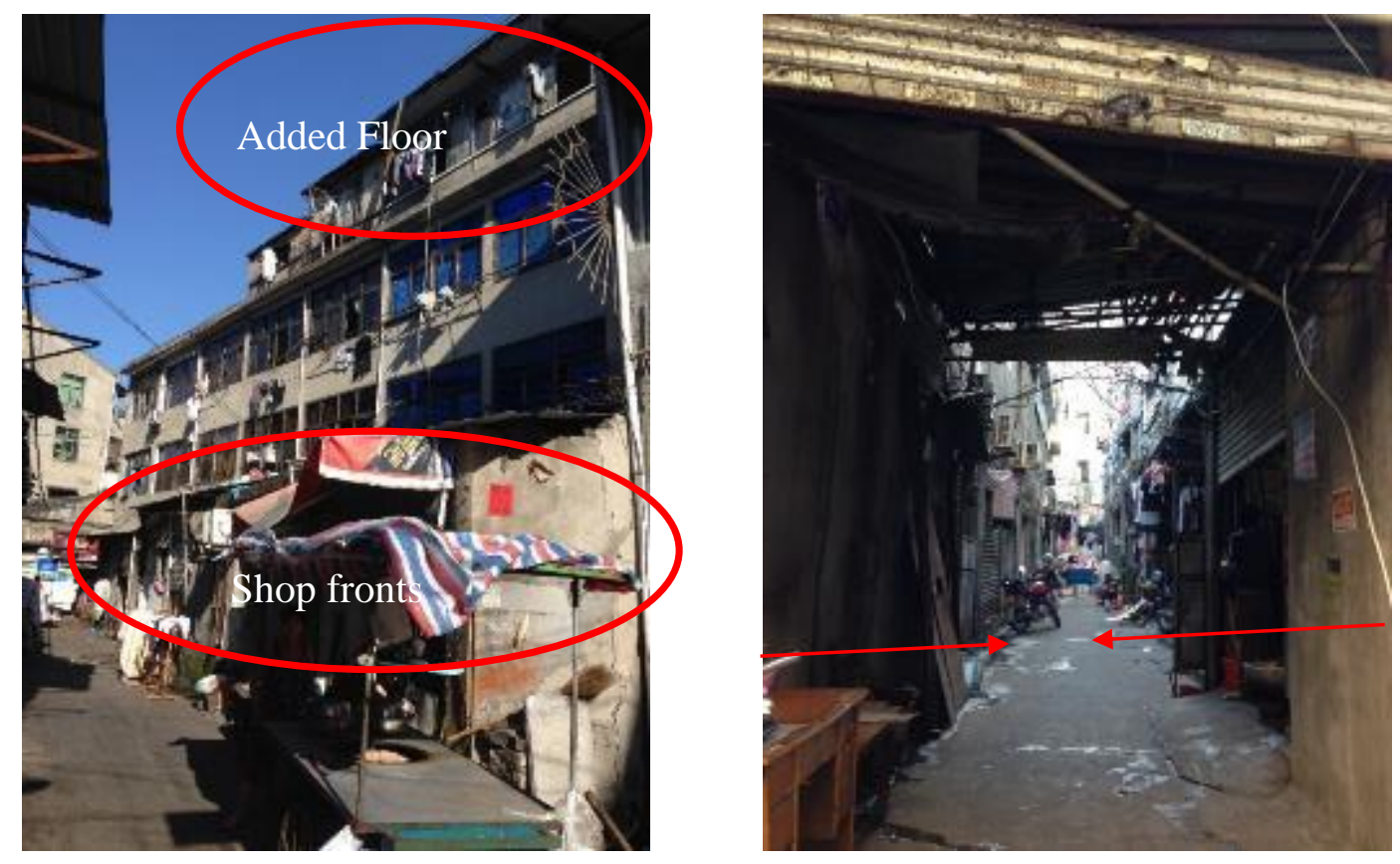

Figure 6.7 Illegal adherence VICs buildings in Jishi village

Note: photos are taken by the author in the summer of 2013

3) Infilling yard (4)(5))

Infilling the courtyard is the third type that is commonly seen in VICs. Housing with courtyards, as the traditional morphology of the villages, made this possible for this informal development. Meanwhile, it is the type that can be largely hidden from the public gaze. Villagers either extend their existing building or build new ones inside their yards. The former ones create extremely long buildings. Figure 6.8 shows an example of this. Original rooms are divided to tiny rooms that are normally no more than 5 sq. meter, spread along the narrow and dark hallway. In some extreme cases, there could be a hundred of migrants live in one such floor. The latter 
type usually makes use of the first floor space for migrants who are vendors that need space for their carts (Fig. 6.9).

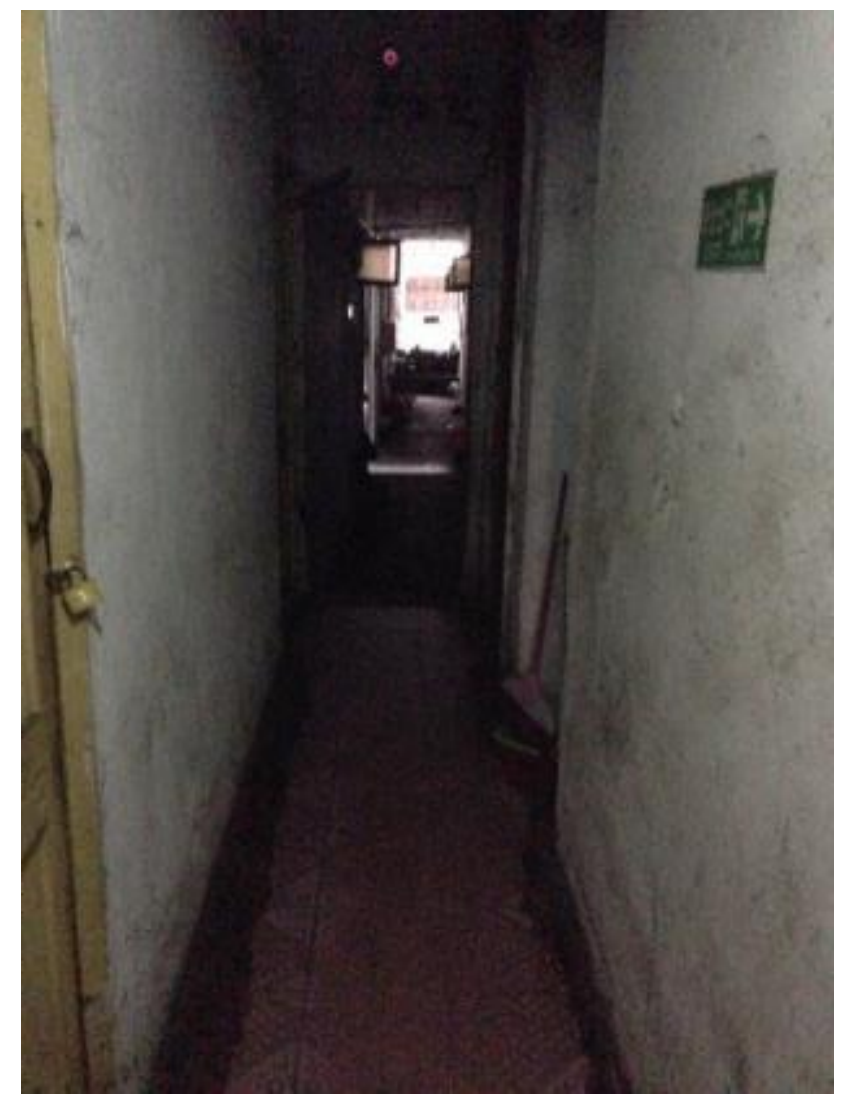

Figure 6.8 Long and dark hallway 


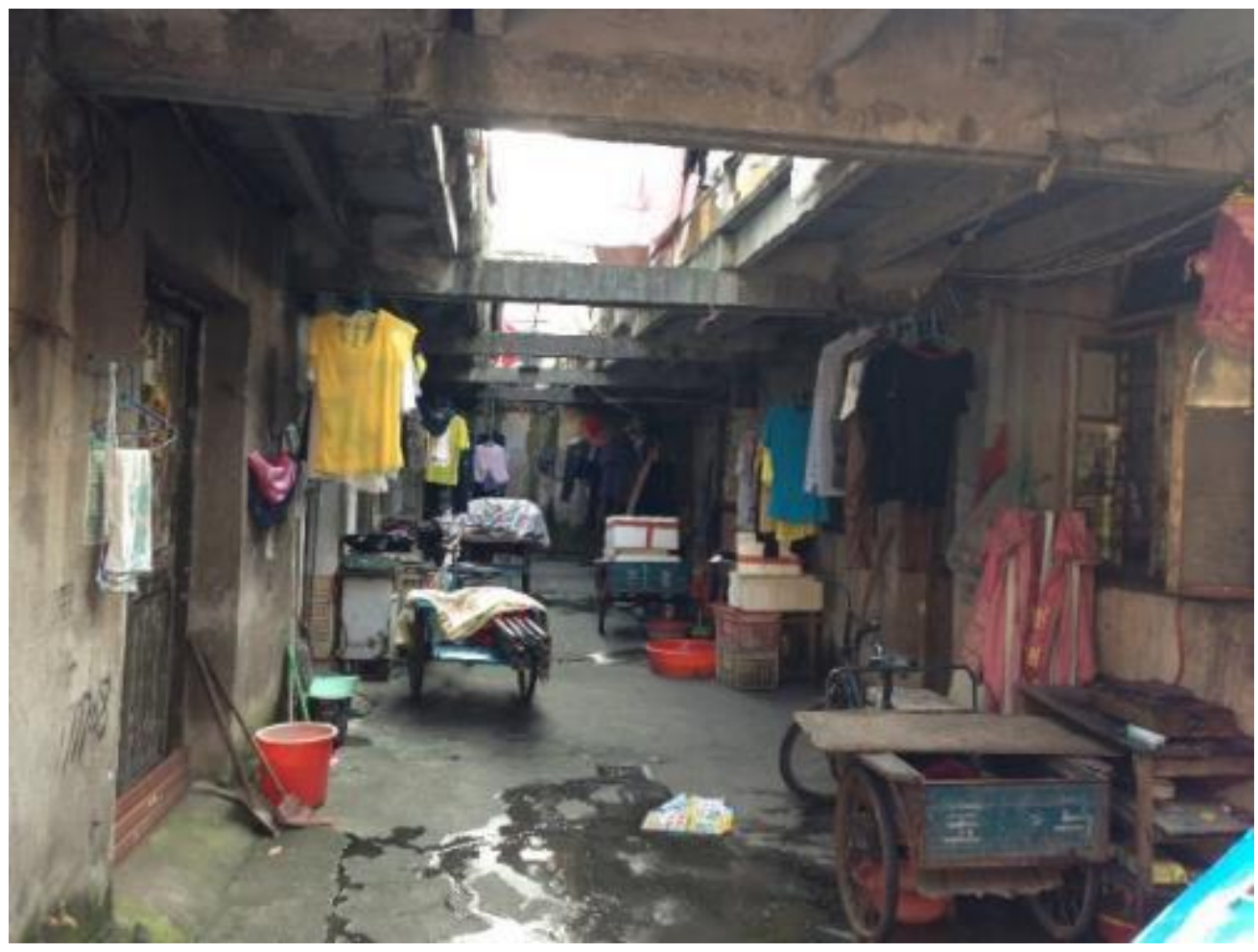

Figure 6.9 Yards full of carts of vendors

\subsubsection{Living Space}

Lots of migrants try to save money by giving up their private space to live in the dormitories, others either share a room or rent a bed-sized room from private party (Table 3). For migrants who live in the factory dormitories, 14.74 percent of them share a room with more than 5 people, 25 percent share with other 3 to 5 people, and 39.1 percent share with other 1 to 2 people. For migrants who rent private housing are also common to share an apartment with other migrants (Here the sense of "an apartment" often means a room). Most of them share a room with other 1 to 2 person, including those who live with their family. Therefore, it is common that some household have dozens of migrants, and some others even hold hundreds of migrants at the same time. 
The average living space per person is extremely small in Shuangyu. In the survey, 58.05 percent of the migrants who live in the rented housing and 62.82 percent who live in the dormitory claim that their average living space per person is less than 5 sq. meters, and a large number of migrants claim their average living space per person is about 5 to 10 sq. meters. This average living space per person is not only smaller than the standard of local residents, but also smaller than most of migrant settlements in other cities such as Shenzhen, Beijing, Shanghai, Guangzhou (Siqi Zheng, Fenjie Long, C.Cindy Fan, \& Yizhen Gu, 2009).

Table 6.3 Migrants' living space in Shuangyu

\begin{tabular}{lrr}
\hline & Dormitory (\%) & Rented housing (\%) \\
\hline Number of people share a room & & 2.25 \\
$>5$ & 14.74 & 21.72 \\
$3-5$ & 25 & 53.18 \\
$1-2$ & 39.1 & 22.85 \\
I live alone & 21.15 & 100 \\
Total & 100 & \\
Average space per person (sq.meters) & & 58.05 \\
< 5 sq meters & 62.82 & 30.34 \\
5-10 sq meters & 28.85 & 8.24 \\
10-20 sq meters & 6.41 & 3.37 \\
$>$ 20 sq meters & 1.92 & 100 \\
Total & 100 & \\
\hline
\end{tabular}




\subsubsection{Facilities and living cost}

Migrants who live in the factory dormitories do not pay rental fee but are responsible for the utilities. The dorms provided by the factories are often free and equipped with better facilities, such as air conditioners. However, the migrant workers are responsible for the utilities. Therefore only 55.13 percent of them said to enjoy air conditioning in the hot summer. 48.72 percent of them also use fan. Meanwhile, there is often no kitchen in the dorms. Migrants who want to cook by themselves have to secretly use an electric stove inside their dorm, which is often dangerous and prohibited by the factory. Eating in the dining hall in the factories and fast food stalls/restaurants close to factories is often the choice.

Facilities in VICs are inadequate and poorly maintained. Private toilets and kitchen are unavailable to most of those migrants who rent housing from private party. Only 14.61 percent of them have exclusive use of the toilet and 59.18 percent of them use the public toilet. In some extreme examples, dozens of migrant who live on the same floor have to share one bathroom. Due to the publicity of the bathroom, it is usually extremely dirty and unsanitary without regular cleaning (Fig. 6.10). I was told by a migrant who is a vender that he cannot often use the toilet, due to his rental housing being outside the courtyard where the toilet is located. When he comes back home after work at night, the door of the courtyard has been already locked. So he often has to look for public toilet nearby. 12.73 percent of migrants living in private housing have exclusive use of kitchen and 28.84 percent of them use public kitchen. It is common for migrants to cook in certain public area of the floor (Fig. 6.11). But those areas are usually inadequately ventilated. Some others put coal-fired stoves or gas cookers inside their tiny bedrooms, which could be a fire or health hazard and an uncomfortable source of heat in the very hot summer. Or those who live on the first floor often cook outside (Fig. 6.11). Most rooms 
and apartments rented to migrants are half-furnished with a bed, and tenants are expected to bring their own furniture. However, in such a tiny room, normally a bed is the only possible and necessary furniture that they could have. Fans and TVs are the only household electrical appliances that most migrants who live in the rented housing have, 41.57 percent and 33.71 percent, respectively (Fig. 6.12). They are necessary and also easy to carry when they move. Despite the hot summer in Wenzhou (the hottest days can reach to 110 F), 90.64 percent of surveyed units in VICs have no air conditioning. Refrigerators, almost seen as a necessary electric appliance for urban families, are not very popular among migrants with only 7.87 per cent of them owning one. From the survey I also noticed that radio is an outdated device that no more migrants have than they used to. Wifi is not common among migrants' homes, while a cell-phone with a limited data plan is more popular among migrants. One migrant who still keeps in touch with me often goes online to chat with me through QQ or weichat (social media in China). However, often after short time he has to go offline in order to save some data usage since a smart phone with data plan is not cheap for a migrant worker.

In spite of the poor living conditions in VICs, the low rental cost has attracted large numbers of migrants. Generally a small room in VICs rents for 150-300 RMB per month, and a relatively larger room costs 300-500 RMB per month. 

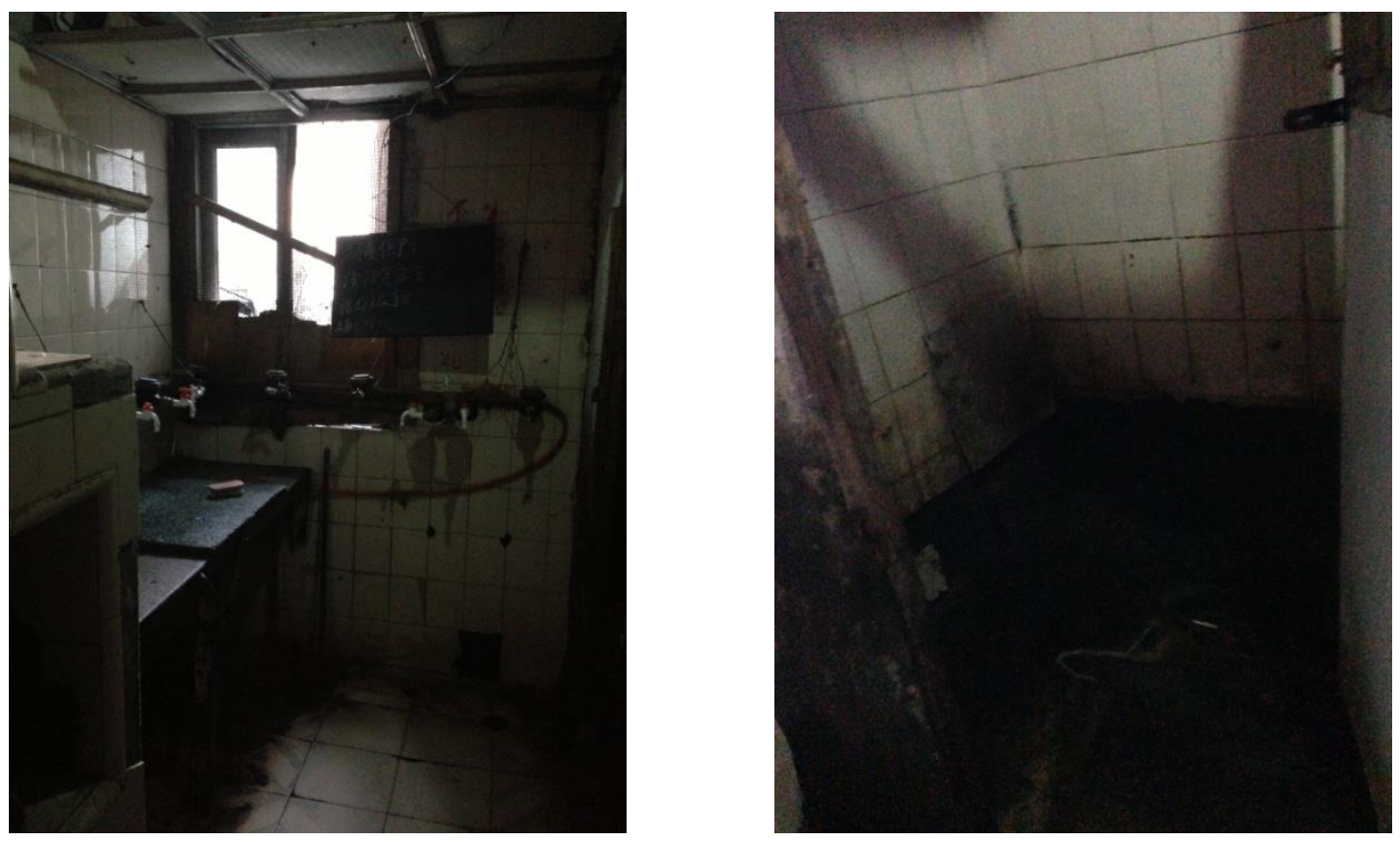

Figure 6.10 Public washing room and toilet 

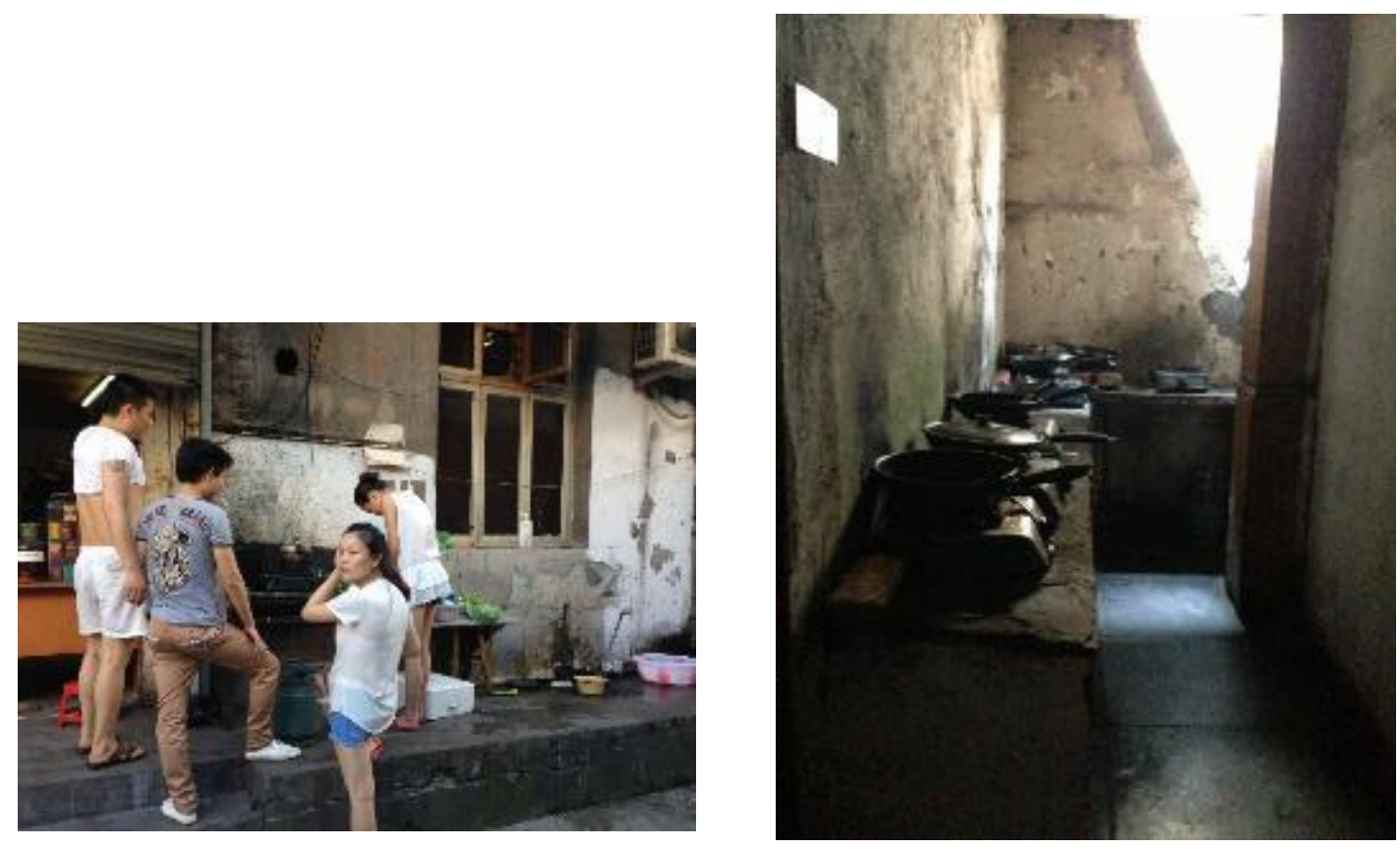

Figure 6.11 kitchen areas

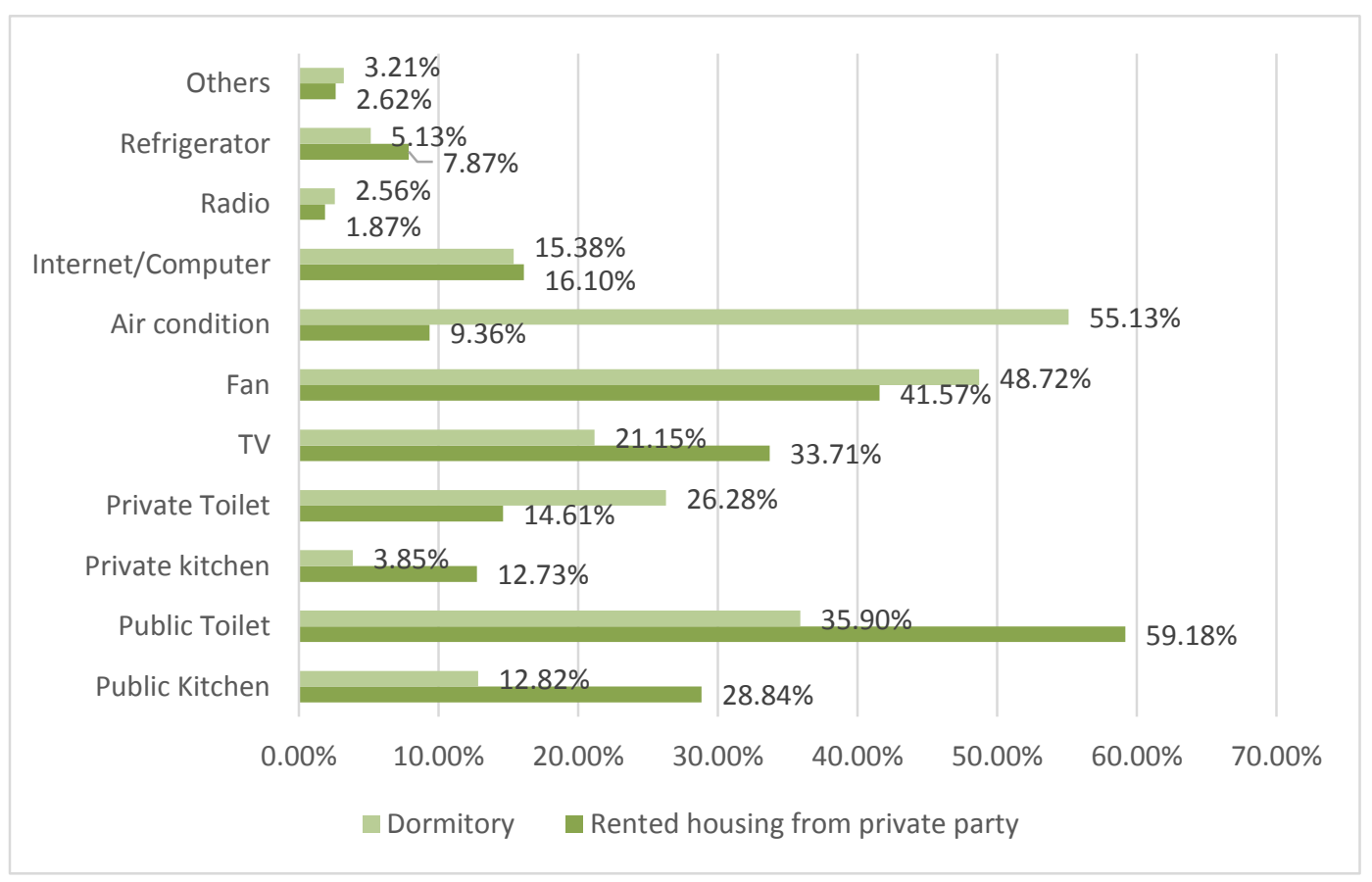

Figure 6.12 Facilities in the households 


\subsubsection{Satisfaction with living conditions}

Not surprisingly, more than half of the surveyed migrants are dissatisfied with their living condition. Only 27 percent of them are satisfied or very satisfied with the living condition. Further analysis shows that migrants who live in different housing sources have different opinions on the living condition. Generally, migrants who live in the dormitories have relatively higher satisfaction with the living condition. For the migrants who rented housing from a private party, 62.54 percent of them are not satisfy with their living conditions (Table 6.4).

Many factors have contributed to the dissatisfaction of migrants with their living conditions. Firstly, the survey results show that a dirty living environment (39.54 percent) is the top reason that migrants complain about. Due to Shuangyu's transitional location between city and countryside, it lacks strict government regulations for environmental management, such as pollution control from the factories, garbage collection from people's daily life. This problem especially severe inside the VICs. Any pond, any corner or any public space could become a garbage dump place (Fig. 13). As such, there are more migrants who live in the rented housing who complain about the dirty living environment (47.19 percent). Improving the environment is also one of the most mentioned improvements that migrants want to see in Shuangyu in the future according to the open answer question at the end of survey. Secondly, compared to the complaints of migrants who live in the rented housing, limited space is the top reason that migrants who live in the factory dormitory complain about. As mentioned about, sharing a dorm room with other migrants is often the case in most factories. Last but not the least, high cost ranks in the third place that led to dissatisfaction, especially among those who live in the rented housing. According to the interviewed migrants, although the average rental price is not high in Wenzhou compared to other large cities such as Beijing, Guangzhou, Shenzhen, both the 
average income and housing condition are lower and worse than the other cities. Other reasons such as crime and unsafety, limited facilities and public space are also important reasons that migrants feel dissatisfied with their living conditions.

Table 6.4 Satisfaction of the living condition

\begin{tabular}{lrrrr}
\hline & \multicolumn{2}{l}{ Source of housing } \\
\cline { 3 - 5 } & Total & Dormitory (\%) & \multicolumn{2}{c}{$\begin{array}{c}\text { Rented housing } \\
\text { (\%) }\end{array}$} \\
\hline Very satisfied & 7.59 & 12.18 & 4.12 \\
Satisfied & 19.54 & 27.56 & 15.36 \\
Neutral & 20.46 & 26.92 & 17.98 \\
Dissatisfied & 35.4 & 23.72 & 42.32 \\
Very dissatisfied & 17.01 & 9.62 & 20.22 \\
Total & 100 & 100 & 100 \\
\hline
\end{tabular}

Table 6.5 Reasons that migrants unsatisfied with the living environment

\begin{tabular}{lrrr}
\hline Why are you unsatisfied with the living environment? & Total (\%) & $\begin{array}{l}\text { Dormitory } \\
\text { (\%) }\end{array}$ & $\begin{array}{l}\text { Rented } \\
\text { housing (\%) }\end{array}$ \\
\hline Limited space & 35.4 & 37.18 & 34.08 \\
Dirty living environment & 39.54 & 25 & 47.19 \\
Limited public space and facilities & 22.53 & 23.08 & 22.47 \\
Crime and unsafety & 19.77 & 7.69 & 26.97 \\
High cost & 29.2 & 10.26 & 40.07 \\
others & 4.37 & 5.77 & 3.37 \\
\hline
\end{tabular}

Note: the total percentage here is not 100 percent, because this is a multiple choice questions. 

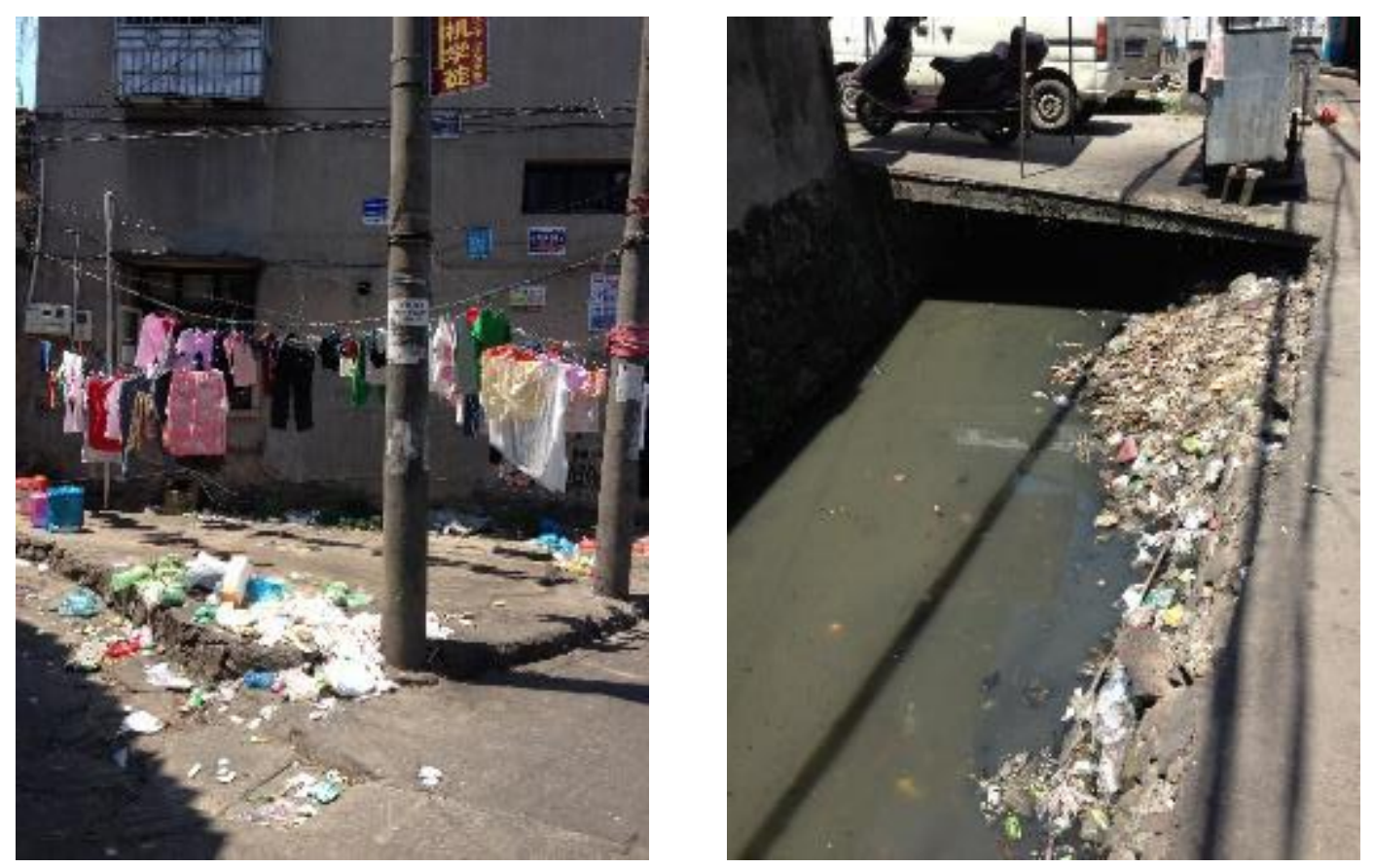

Figure 6.13 Living environment in VICs

Due to the concentration of low-income rural migrants, a lack of basic facilities and infrastructures, unsanitary environments, and high rates of crime, city managers and planners perceive VIC as an eyesore or nuisance. However, even with such informal and unregulated nature, VICs have become home to the majority of migrants. According to the survey, we have learned that migrants are willing to stay in the VICs rather than paying higher rental fees to move to a better apartment. They agree that strategies such as cleaning up the environment and tearing down some of the old houses in the VICs are a more acceptable way than simply tearing down the whole village. The survey result also implies that a demolition and redevelopment strategy might be a way to create a better living environment, but may also force migrants to leave the city. 
Table 6.6 Migrants' opinions on the redevelopment of VICs

\begin{tabular}{lrr}
\hline & $\begin{array}{c}\text { Number of } \\
\text { Response }\end{array}$ & \multicolumn{2}{c}{$\%$} \\
\hline It's ok, but better to clean up the environment & 80 & 28.07 \\
Allow villagers to expand their houses & 55 & 19.30 \\
It's good enough, doesn't need any redevelopment & 46 & 16.14 \\
Yes. It's already too crowded, better to tear down some of the & 45 & 15.79 \\
old houses. & & \\
Great! Tear down all the houses, and build new urban & 35 & 12.28 \\
apartments. & 24 & 8.42 \\
No response & & \\
\hline
\end{tabular}

\subsection{Summary}

The majority of migrants in Shuangyu either rent a room from private party (62 percent of total migrants in the survey) or live in the dormitories that are provided by their employers (36 percent). VICs, in particular, have become the major housing sources for migrants due to their low rental fees. VICs, by having the characteristics of a juridical ambiguity regarding housing, lack of settlement planning control, and an unregulated rental market, are often regarded as informal settlements. Illegal/informal constructions or division of the rooms in the VICs on the one hand provide cheap and accountable housings for migrants, on the other hand, also make a crowded and dirty living environment. Although migrants pay relatively little rental fees compare to living in other apartment, there is also lack of facilities in the VICs. More importantly, even with many complains about the dirty environment, limited space and facilities, crime and unsafety of the VICs, migrants are not willing to see the VICs get torn down and pay more rental fees for a better apartment. 


\section{CHAPTER 7}

\section{LEISURE TIME AND ACTIVITY SPACE IN MIGRANT SETTLEMENTS}

Based on the analysis in Chapter 6 , we know that most of the migrant workers live in cramped apartments and factory dorms without even basic home leisure equipment, such as TV, computers or smart phones. As such, they spend significant portions of their leisure time in public space. These spaces range from informal and transient to elaborately landscaped parks and gardens (W. Wu \& Gaubatz, 2012). Traditionally, some prominent public space could be considered as identities or landmarks of different parts of cities. The public shopping streets formed of fancy window shopfronts demarcate the prosperous commercial city centers; squares or open plazas with symbolic monuments signify the political or historical importance of this part of city. The recently mobility turn has seen these dynamic public space as 'place of movement' (Y. Fan et al., 2014; Sheller \& Urry, 2006), where certain people presence in different times of the day, doing different activities. D. Wang, Li, and Chai (2012) call these urban spaces-activity space. They argue that understand activity space is no less important than that of residential space. I agree with Wang et.al that how different social groups spend their time and use urban space indicate their social status, culture, public image or perception. Migrants with limited mobility may have a relative narrow zone for activity and have less time for recreation as well. At the same time, their different ways of interaction with the public space both spatially and temporally in turn create special images and identity of urban space that is different from others. So what are the special types of activity space in a part of city with majority of migrants? How they have impacted the urban form and brought new ways of interactions with the public space? 
This chapter considers migrant settlement as an assemblage, in which activity space as the deeper layers of this assemblage that are comprises a pattern of flows and connectivity that enables the creation, production and reproductions of ideas, goods, services and identities. It is a socio-spatial territory with some identity that formed under different relations of power, resource and knowledge. Migrants with "floating" or temporary status in the city stabilize (territorialize or reterritorialize) or destabilize (deterritorialize) their spare life interaction with the public space, creating special features and identities. The variety of formal/informal constructions and formal/informal practice within the public space.

Following the concept proposed by Wang, Li and Chai (2012), this chapter considers the activity space as a multi-dimensional concept, exploring its spatial and temporal features, as well as its users' perception. It seeks to understand the types of activity space in in parts of the city where most migrants live, and further explore how they formed and differentiated with activity space in other parts of the city. Based on the survey, this part examines several important public space that migrants may involve, which are streets, semi-public space inside VICs, square and park space, addressing their distinctive features in terms of formal/informal, static/fluid.

\subsection{Activity places}

\subsubsection{Street as activity place}

Streets serve as one of the major forms of urban activity space. They sustain a range of activities from basic circulation to any other public interactions. Street is an important element in a built environment and social life, which is indivisible from city. In China, lots of ancient 
water towns developed along the river what Chinese people call "one river, one street" or "one river, two streets". Jane Jacobs, a prominent urbanist, stresses the important role streets play in urban life, that is, the ways that interaction among the people who live and work on a particular street-"eyes on the street" - can reduce crime, encourage the exchange of ideas, and generally make the world a better place (J. Jacobs, 1992). Since the mid-nineteenth century, "shopertainment", which links shopping and entertainment, has risen in the Western countries (citation: urban geography). Shopping as entertainment has become an important part of people's daily lives. With the globalization and economic development in recent two decades, the emerging shopping malls integrated with the traditional window front shopping streets have become one of the important features of downtown Chinese cities. Those downtown commercial streets become city's name card and tourist destination, such as Beijing's Wangfujing, Shanghai's Nanjing Road, and Guangzhou's Beijing road. For local residents, those commercial streets are conceived as foci for entertainment and other public activities as well as for the buying and selling of goods (Gaubatz, 2008). Guang jie (hang out on the street) has become a significant part of people's social life.

In Wenzhou, there has been a rapid proliferation of commercial streets and pedestrian malls in the city center. Meanwhile, international companies including supermarkets such as Walmart, and international fast-food chains such as Dairy Queen and Häagen-Dazs were introduced to the commercial streets in Wenzhou. Development made on the street is fast and tremendous, while rarely under the formal plan of city government. Compared to the formal formation of street space in city centers, street space has been formed in an informal process with informal practice in migrant settlements, such as hawking, parking, and advertising. Informal governance is imposed over informal practices: informal fines, fees and bribes are paid, 
votes are bought, blind eyes are turned (Kim Dorey, 2012). Meanwhile, the use and meaning of street as activity space are subject to flows of time and space with shifting meanings of private/public and legal/illegal.

Migrant workers, who might spend most of their time working long hours for meager wages, cannot possibly afford to shop in the luxury brand and fashionable downtown commercial streets and chain restaurants. Instead of commercial streets, informal markets and farmers' market formed on the streets that are the main shopping space for migrants. In Shuangyu, three types of shopping streets serve as the same function to those commercial streets, which are market streets in VICs, temporary street market (informal market) and restaurant streets around the factories.

\section{Market Streets in urban villages}

Most villages have one or two street markets that usually composed of both temporary stalls and fixed shop fronts. They sell fresh vegetables, meat, poultry and fish, as well as specialized product and service shops, such as telephone booths, hair salons, grocery shops and electronics. Initially, the shops were run by the owners themselves. When the demand for rental increased and the owners became richer, these business spaces were rented out to migrants (Yaping Wang, Wang, \& Wu, 2009). These businesses and services provide necessities and food for migrants and villagers, yet are cheaper than those in the department stores and supermarkets. Unlike urbanites that may pay visits to supermarket about once a week, migrants usually shop daily for fresh food in the market streets. They get to know the sellers, bargaining, greeting and chatting with them. The sellers may stop the possible customers and recommend their products. In other words, activities such as shopping for groceries also serve as a part of social life for migrants. 
Market streets are usually located at the entrance of the urban village, starting from temporary stalls to fixed shop fronts. Figure 7.1 shows the entrance of Yinglouqiao village in Shuangyu. Temporary carts under the shade of big umbrellas are selling vegetables and cold drinks. When you walk inside the village, the roads become narrower with fixed shop fronts selling groceries and a variety of services. Extra carts are usually displayed in front of shops. Without "city police" patrolling on the streets, vendors are free to occupy any space on the streets. As mentioned in the previous chapter, the informal governance in urban villages allows the local villagers to add informal additions to their formal housing. One way is to attach one floor construction to the formal building at the ground level, creating shop fronts for migrants who want to run small businesses. However, this is at the cost of taking public space.

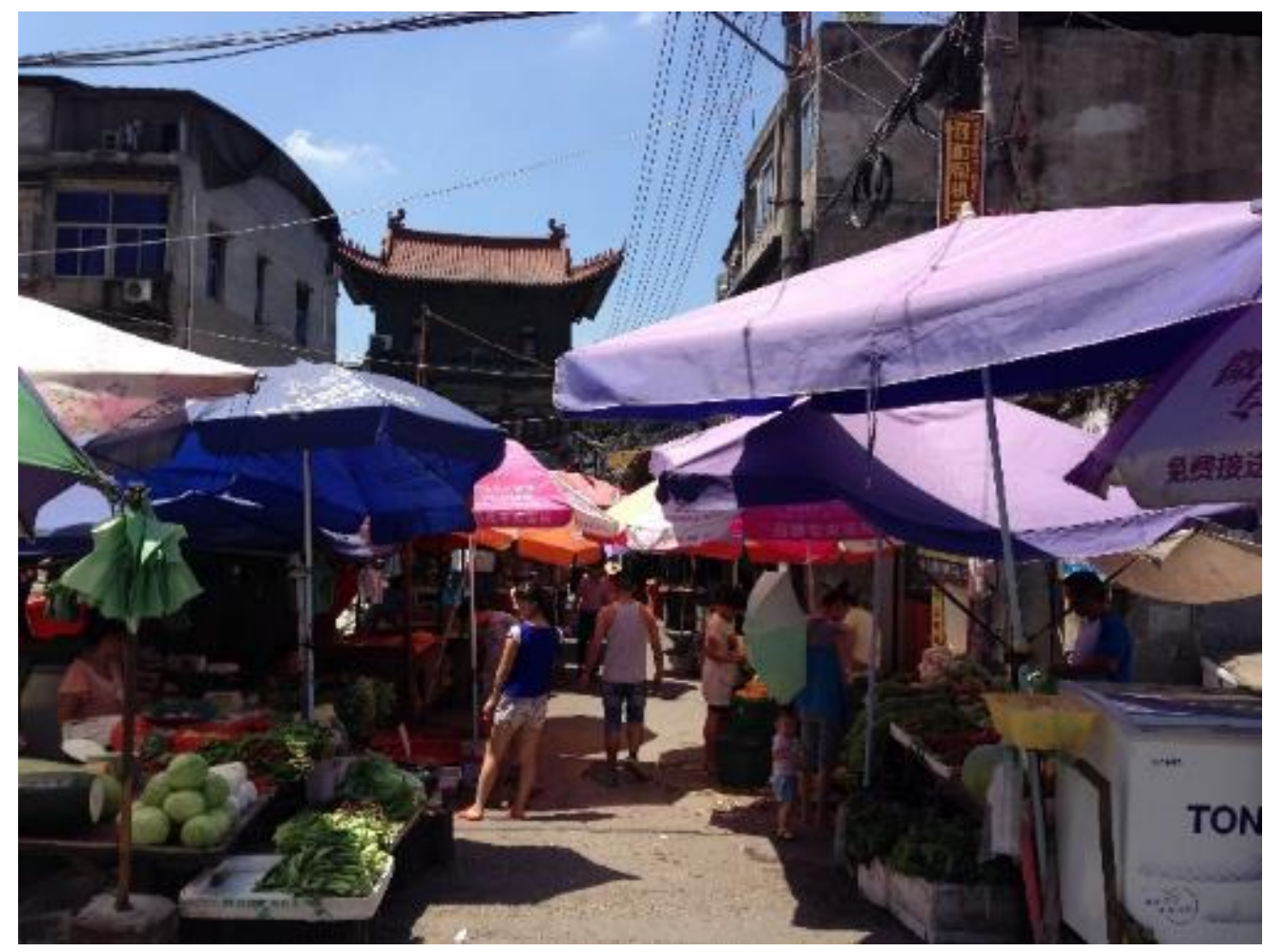

Figure 7.1 Entrance of Yinglouqiao village 

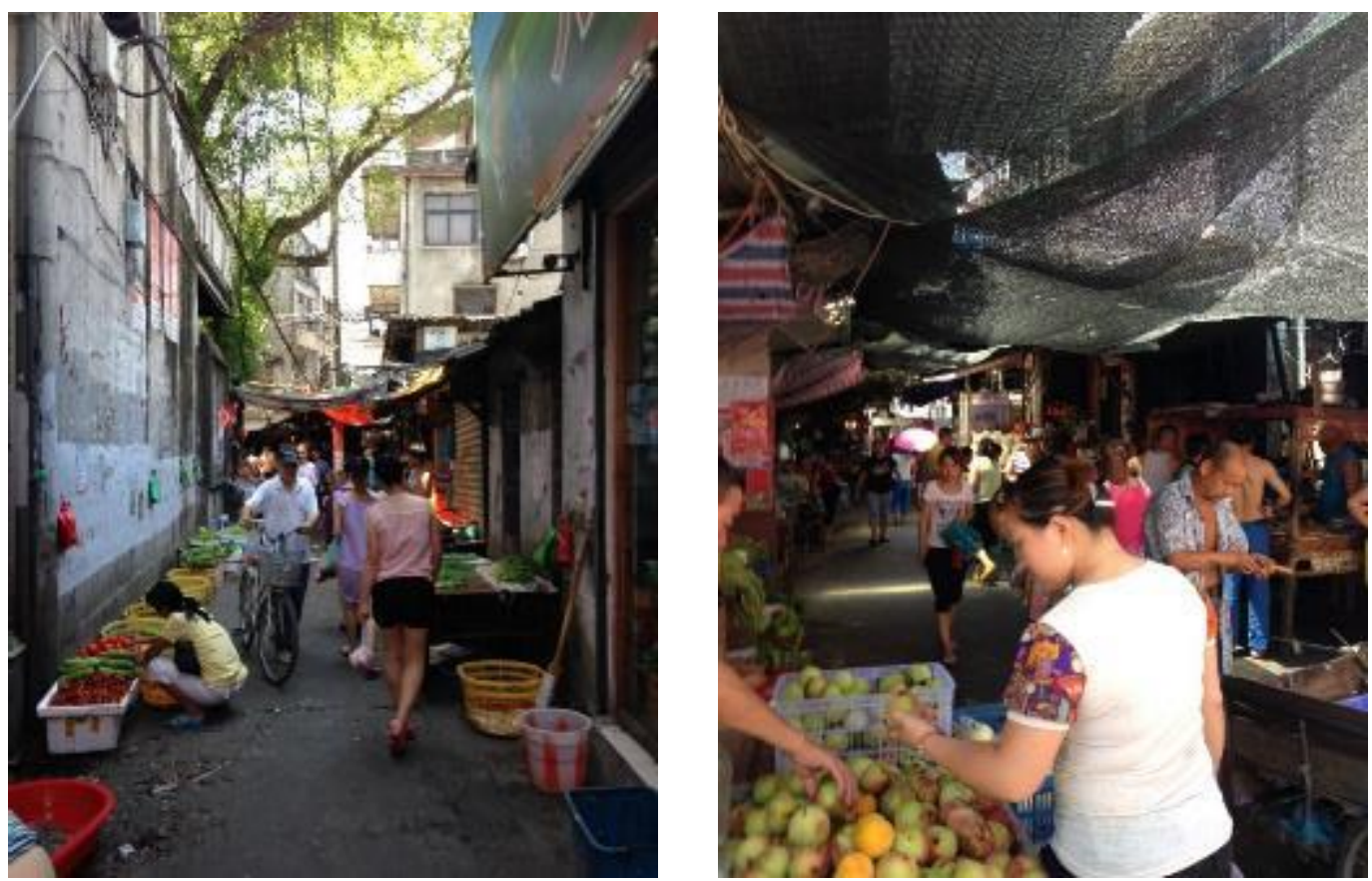

Figure 7.2 Market street in Yinglouqiao Village

\section{Night markets}

In many of China's cities, Night Markets have become an indispensable part of city life and one of the main tourist destinations, where one can experience local culture. However, the night market in marginal migrant settlements has different meanings. It primarily offers the nearby migrant residents a wide range of merchandise from all sorts of clothes and accessories, to food and snacks, to services such as cellphone repair or nail polish. It's usually invisible on the maps, but known to local residents and migrants. The key characteristics are its stability/fluidity.

Generally, the streets serve as regular space for commuting in the daytime and change to night markets after around $6 \mathrm{pm}$ during the summer time and earlier in the winter time. They become streets of temporary market stalls sheltered by umbrellas and awnings. They began to serve as useable public space, especially for migrants who live nearby to come to shop, meet 
with friends, or hang out on the street. Even though the vendors contributed to the liveliness and activeness of the public markets, they were banned in the city. Because city government believes they don't look good for the city image and hinder the development of city civilization. Therefore, the night market sometimes serves as the identity of migrant neighborhoods where city police often turn a blind eye.

Niuling night market is a long street which starts from Shuangyu farmer's $\mathrm{m}$ arket and extends to Taili Road in Lucheng Light Manufacturing Industrial Park. In the early 1990s, with the establishment of Lucheng Light Manufacturing Industrial Park, Shuangyu began to attract a large number of migrant workers. Due to lack of basic ancillary facilities and demands of shopping for necessities, vendors who sell such as food and clothes, spontaneously gathered around Sankai Road which became the rudiment of Niuling Night market. Later with the growing number of vendors and disorder, street government implemented unified regulations on the vendors. Vendors are only allowed to run the "shop" with permission in designated areas and certain time, usually from $5 \mathrm{pm}$ to $12 \mathrm{am}$.

Due to its unique location, the street is under the governance of two different authorities-Niuling community (Marked red in the Fig. 7.3) and Shuangyu street community (marked yellow in the Fig. 7.3). Niuling community, which administrates an urban villageNiuling and a new community-Qishan, is located between Shoe Capital Industrial Park (SCIP) (First phase) and Lucheng Light Manufacturing Industrial Park (LCLMIP). It is also home to Kangnai Group Co., Ltd, which is one of the biggest shoe company in Wenzhou. As such, Niuling Community hosts the largest number of migrants among all the communities in Shuangyu. In 2013, it had 34,503migrants (not including those who stay in Niuling less than six months), which is more than 23 times of local hukou residents. Due to its large migrant neighborhood, 
Niuling night market has grown into a quite big one, which is known by most of the residents who live nearby.

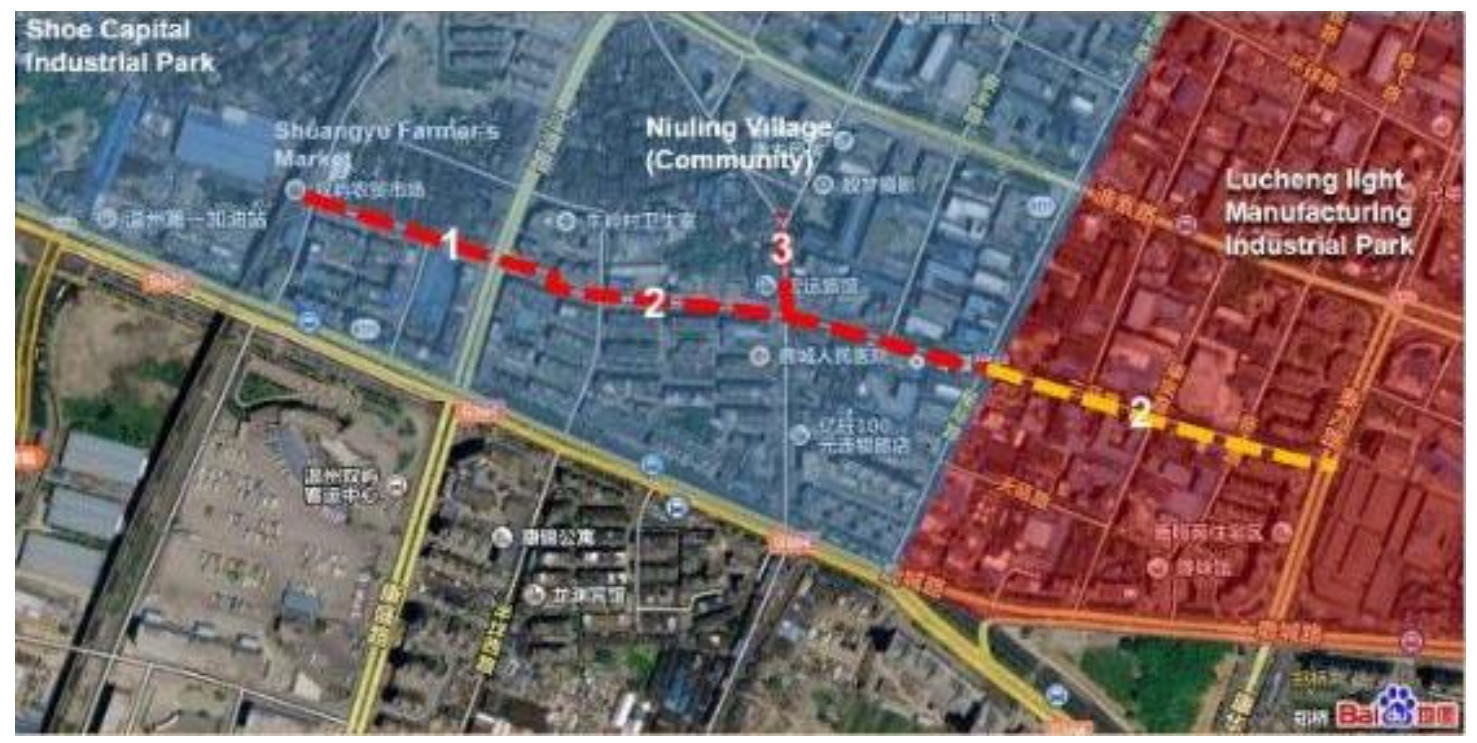

Figure 7.3 Niuling night market spatial map

The night market vendors are not squatters (or most of them to be accurate), as the street community or the village community rents out the street space when the daytime traffic dies. Because of its close location to the indoor farmer's market, the first part of the street sells most of vegetables, meats and fruits (Fig. 7.4). The indoor farmer's market opens early in the morning and close late in the night. The vendors are only allowed to start their business after 5 pm. Fees, namely for cleaning services, are collected either daily for 5 yuan (less than \$1) or monthly depending on the vendors' choices. 

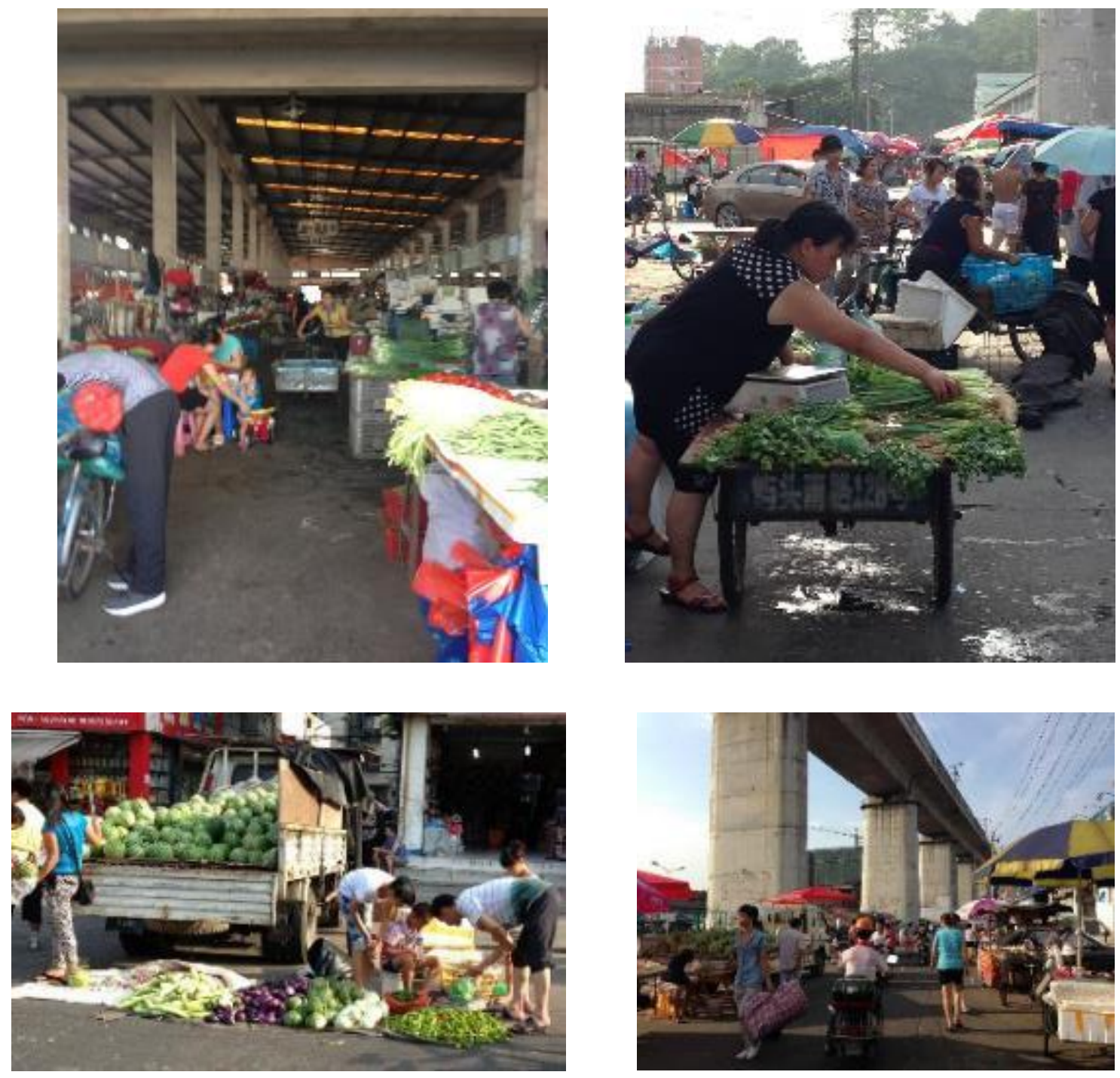

Figure 7.4 Indoor farmers' market and temporary market

Similar to the first part of the street, the second part of the street is almost quiet, serving as a commuting road during the daytime. Cars are allowed to park along the side from $12 \mathrm{am}$ to $5 \mathrm{pm}$. Then after 5:30pm, sellers come and start to pull out their stalls and display their goods, mainly clothes, shoes, as well as some services. Around 6:30pm when families finish their dinner and come out for a walk or shopping, the street becomes active public space. When it 
gets darker, more and more people come to the night market, no more cars can go through the street. The street becomes a lively social place. In the third part of the street, you can see the major stalls are snack booths. You can choose material from the carts and let them stir fry.

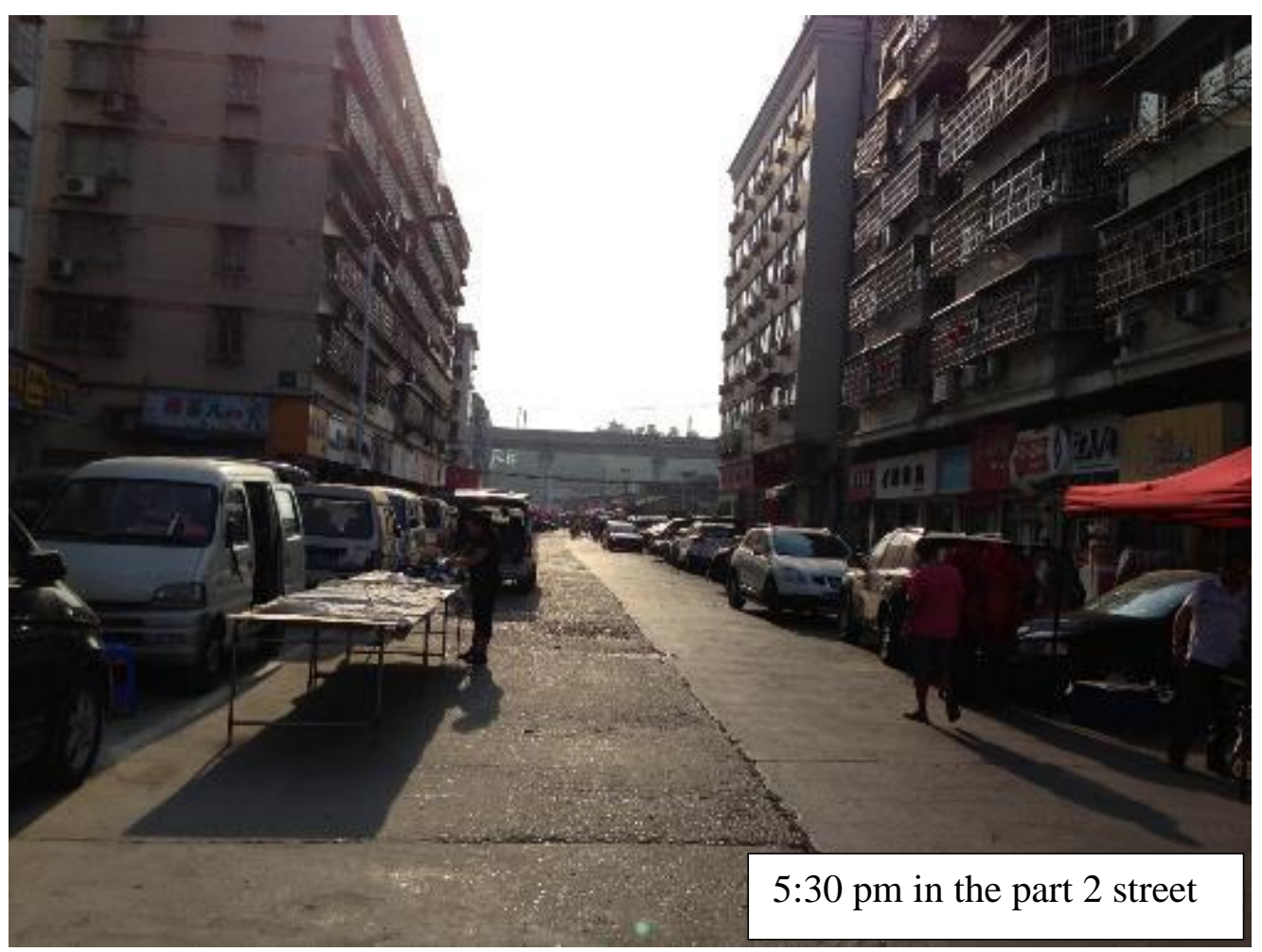



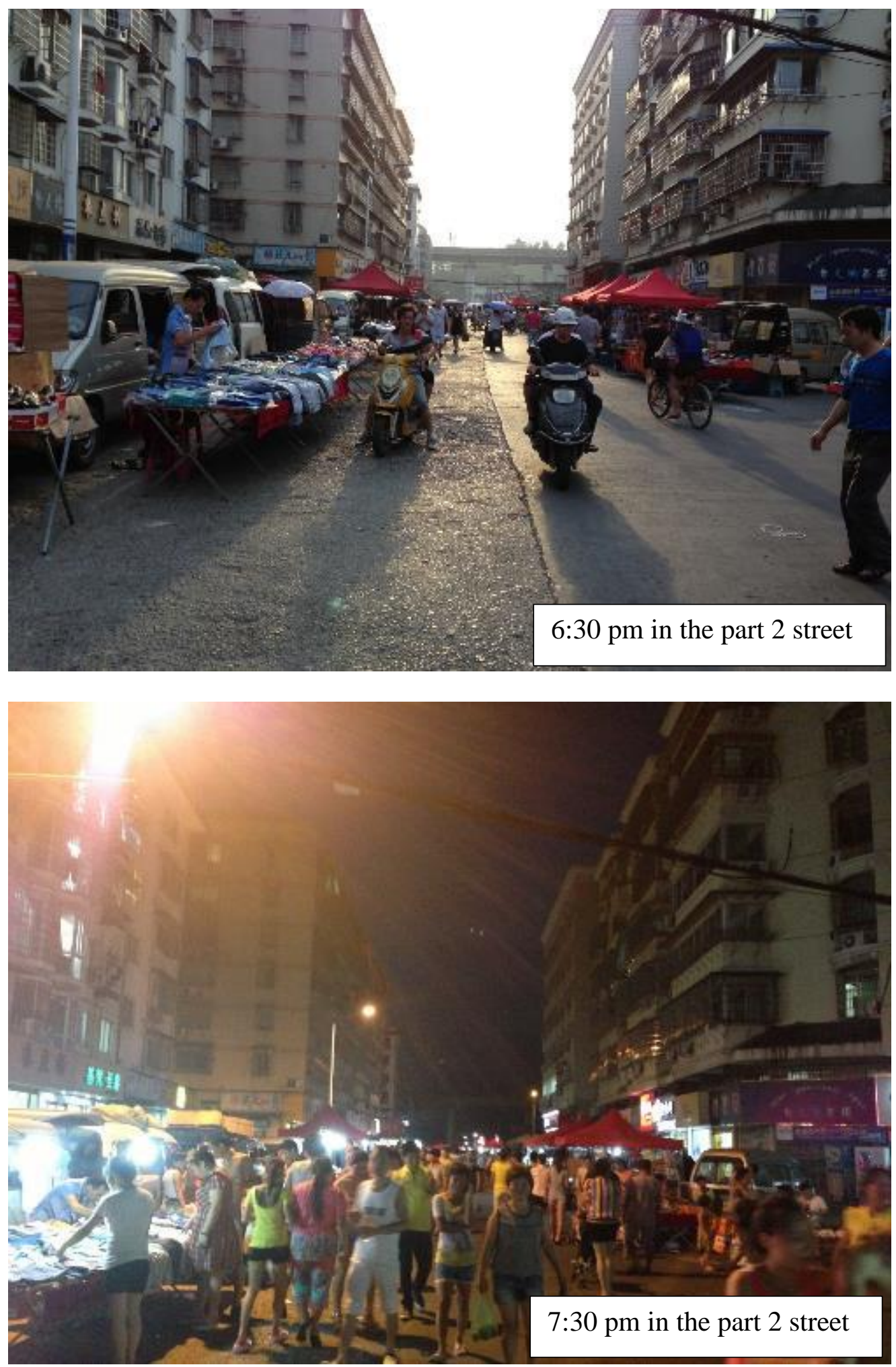


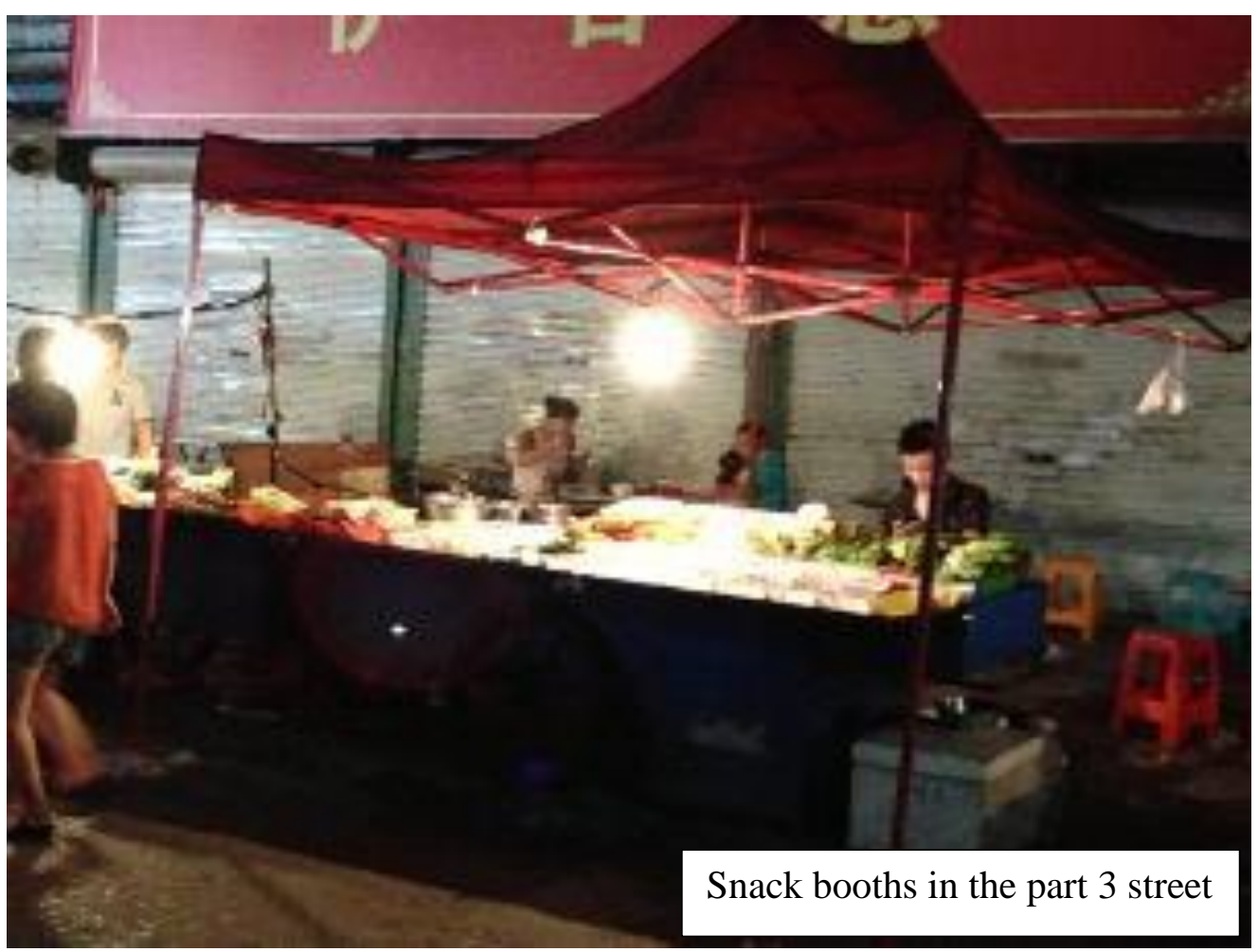

Figure 7.5 Niuling night market

Different from the market street inside the urban villages, Niuling night market is under relatively strict governance. City police patrols the street from 7 am to $12 \mathrm{am}$. They will confiscate the goods and fine those vendors who do not have a permit. The official name of "city police" is "Chengguan" in Chinese, which indicates the employees of City Urban Administrative and Law Enforcement Bureau. Established in almost every Chinese city in 2001, this local government agency is responsible to improve municipal governance by tackling the low-level crime, such as cracking down on unlicensed street vendors that usually run by rural migrants. In July 2011, with the growing number of migrant vendors in Shuangyu and streets become more crowded, the Shuangyu Subdistrict Management Enforcement Bureau established 
a group of 100 Chengguan patrolling on the streets, especially in Niuling, Jishi and Shoe Capital Industrial park where have the most number of rural migrants.

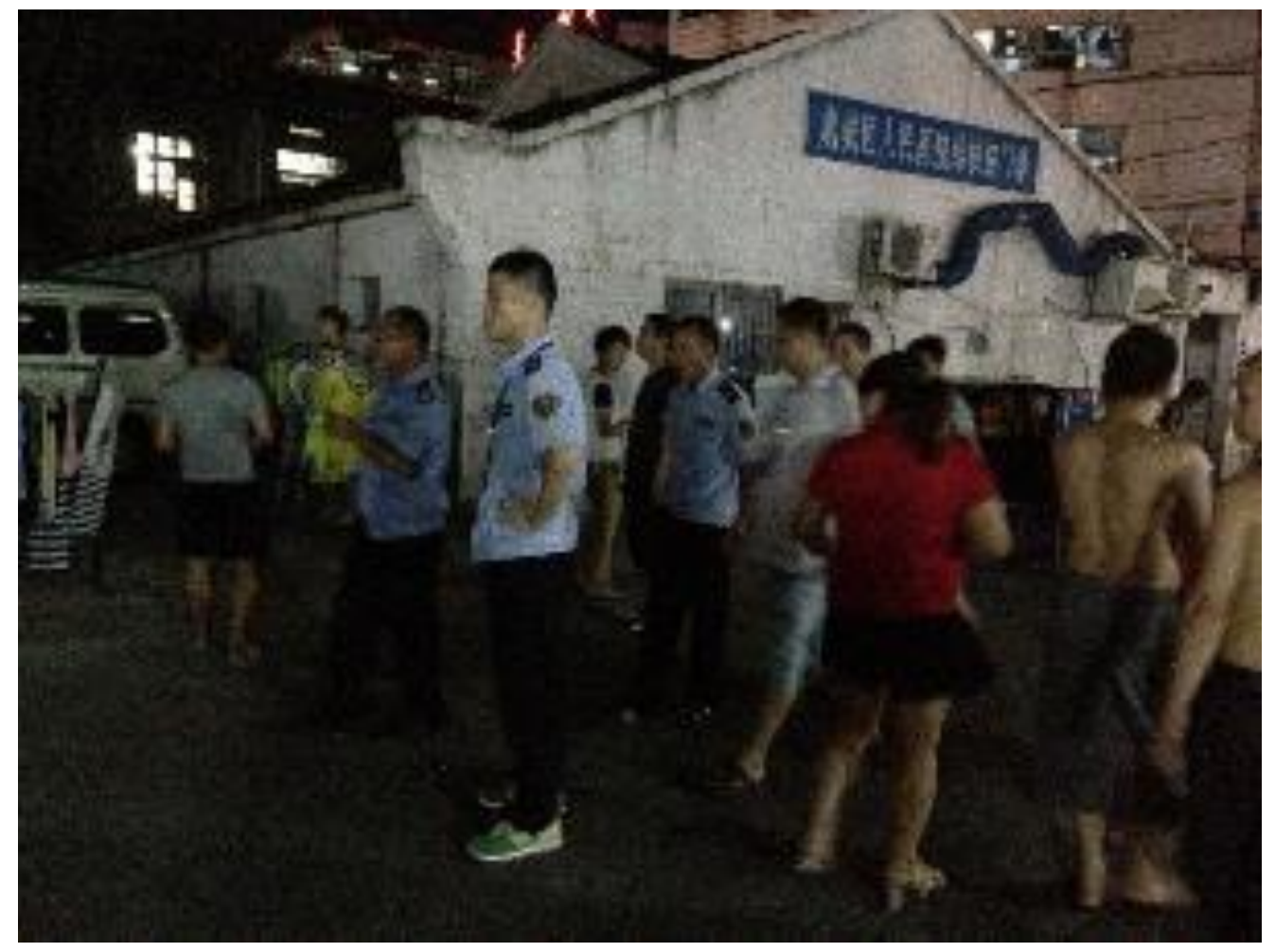

Figure 7.6 City polices are patrolling in Niuling night market

The night market shows the high fluidity of the activity place. Migrant vendors can run a business for a week and then "sell" the permit to other people if the business does not seems promising. Vendors without permission may move around to avoid arrest by the city police.

\section{Restaurant streets}

When globalization brought Western-brand restaurants into city centers in Wenzhou, rural migrants from more than ten provinces also brought different spices to those migrant settlements. Shopfronts in the urban villages and streets lined up with temporary stalls in the industrial park, which are filled up with restaurants providing all sorts of cuisines. Usually the 
restaurants are named after the sending provinces that could be easily recognized by the migrants who are looking for hometown flavor. Figure 7.7 Show a corner in Jishi village, restaurants featured cuisine from six different provinces and municipalities--Chongqing, Sichuan, Tianjin, Jiangxi, Hunan, and Guizhou. These restaurants provide cheap, fast, and diverse food for migrant workers who work nearby, also becoming a sign of migrant settlement. During the lunch and dinner time, migrant workers who wear different uniforms imprinted with companies' name, swarm into these different restaurants. Young girls come hand in hand, rushing to their often-visited restaurants, yet enjoying this short break of a long day's work.

These restaurant streets then become very active place.

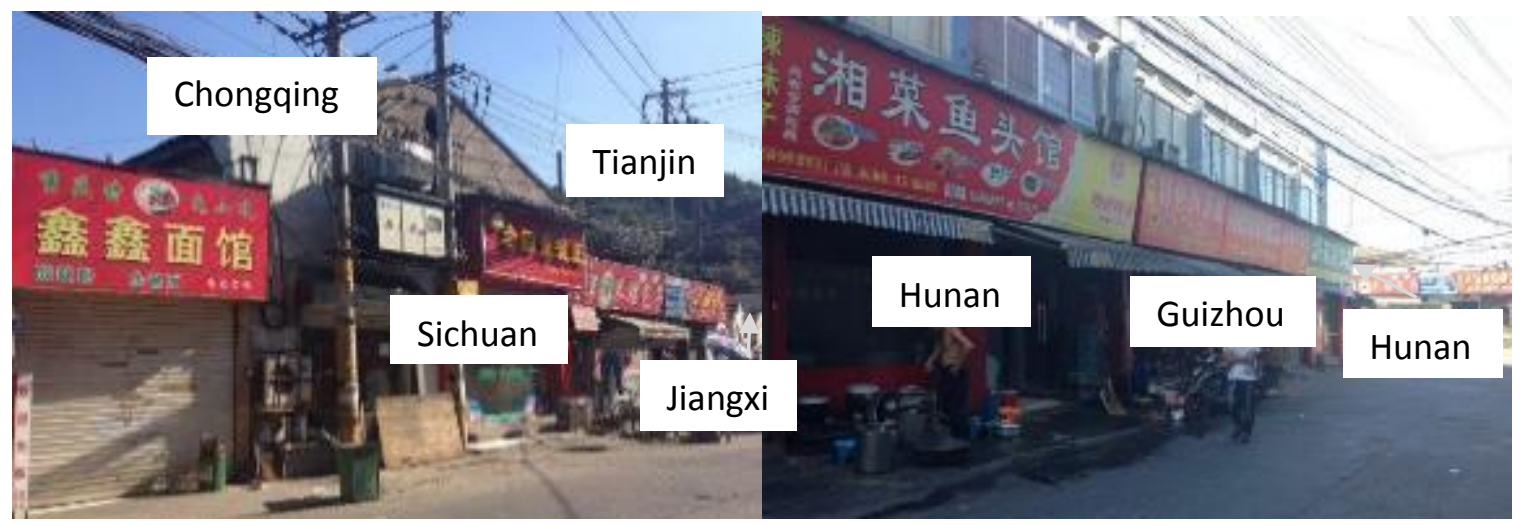

Figure 7.7 Restaurant street ${ }^{12}$ in Jishi village

${ }^{12}$ A street with restaurants that provide different flavors from the world might be normal or familiar here in the United States and Western countries. However, a street with restaurants that provide different flavor from different provinces (although they all Chinese food, but they have totally different flavors) in China is a definitely distinctive feature of migrant settlements. 


\subsubsection{Semi-public space in VICs}

Migrants' low income and long working hours suggest their limited time and narrow zone of activity space. Many migrants spend the spare time watching TV (46.67 percent of total surveyed migrants) or sleeping at home (34.48 percent of total surveyed migrants). Others often prefer to take a rest somewhere close to where they live rather than doing something for entertainment. As such, VIC serves as a big un-walled gated community for migrants. Semipublic space in VICs has become popular and distinctive space that migrants often come for rest and meet with friends. These spaces include simply the shade under an old tree or benches outside the supermarket. The left picture in Figure 7.8 shows a place outside the supermarket. With a TV put on the window and benches outside, this has become very popular place for migrants. Migrants often have to come early to get a seat and wait for the TV show. It indicates that many migrant households don't own a TV.
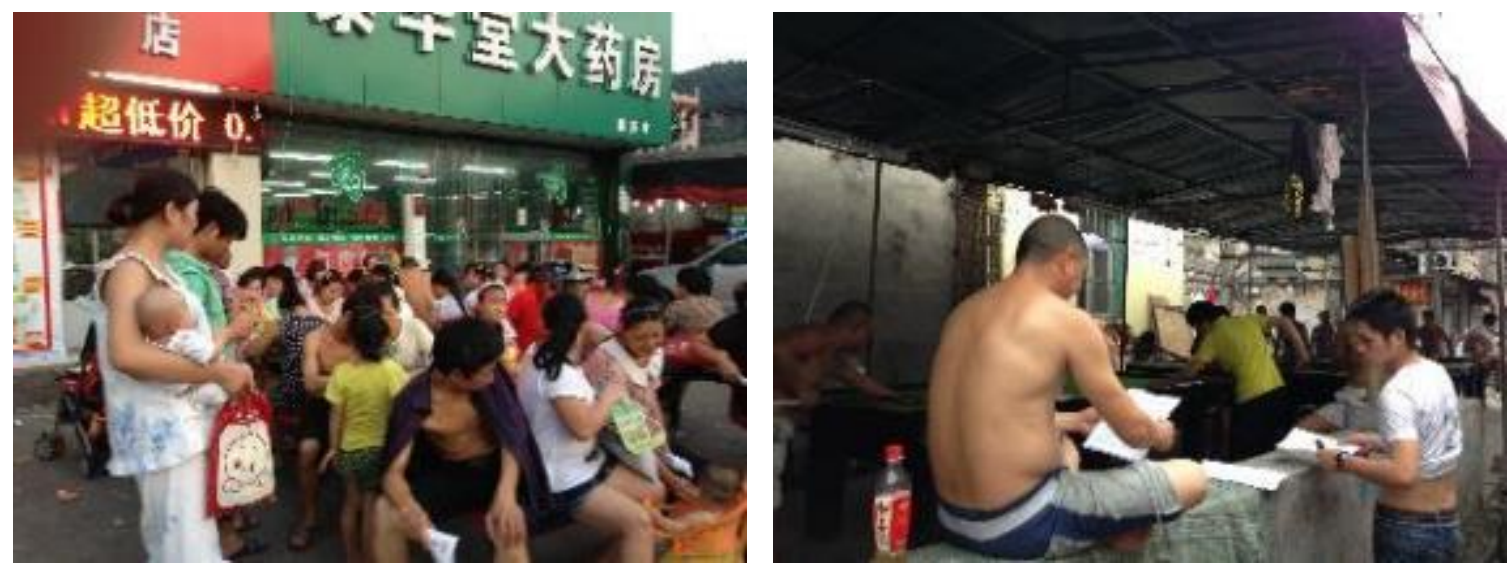

Figure 7.8 Public place in VICs

Note: The picture on the left shows that migrants are waiting outside a supermarket to watch $\mathrm{TV}$ in Jishi village. The picture on the right shows a pool place in the village. Two migrants are filling out my questionnaires. 


\subsubsection{Square}

Similar to the other parts of the city, squares serve as useable public space in Shuangyu. Especially they have become places that residents who live nearby escaping the confines of their homes on hot summer nights. Vendors who sell a wide range of services, from snacks and balloons to providing children's fun places, have attracted many migrants to the squares. In Shuangyu, due to the limited facilities and investment, Shoe Capital Cultural Square is the only public square nearby (Fig. 7.9). After 4pm, migrants gradually come and rest in the shadow of trees. When it gets darker, the square gets more active and lively. More importantly, it not only has been used as public space for people to come to rest and recreation, but also has become a place for cultural propaganda. The local government or sometimes they cooperate with the factories may hold different activities in the square, such as concert, promotional activities (Fig. 7.10). 


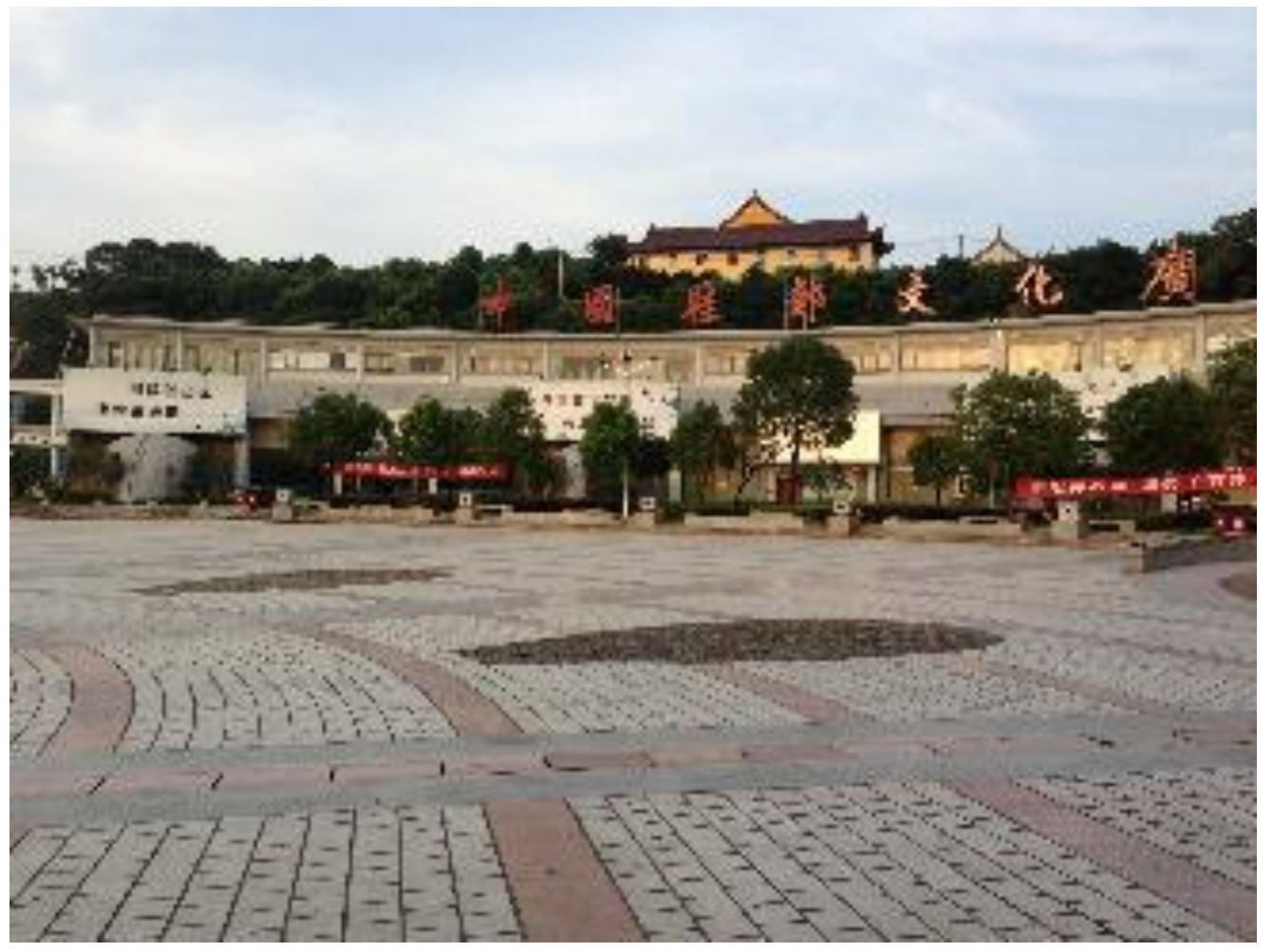

Figure 7.9 China's Shoe Capital Cultural Square 


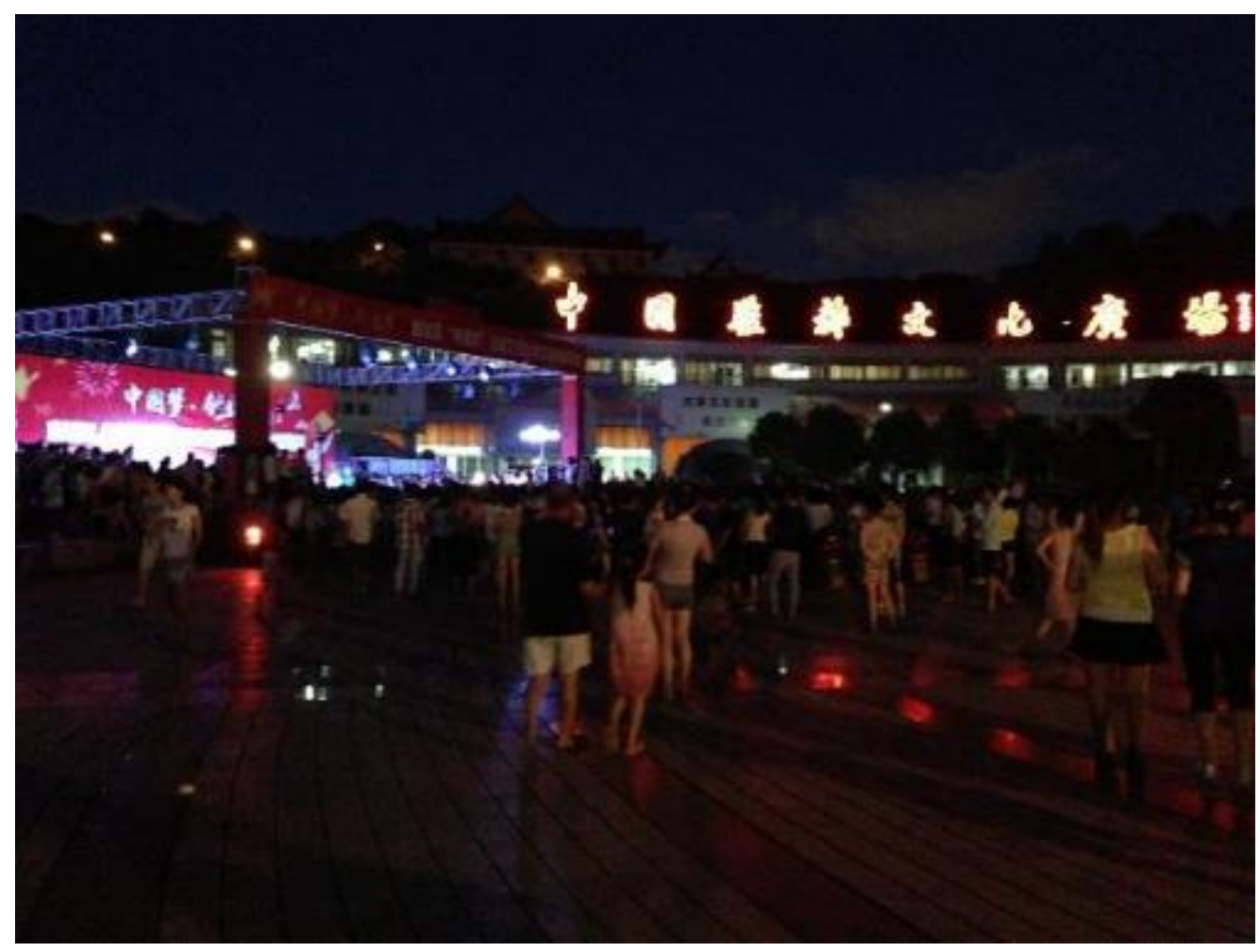

Figure 7.10 Government activity in the square

Note: The Lucheng district government and Shuangyu Subdistrict Committee are holding a show with the theme of "Chinese dream, entrepreneurial dream" in the Shoe Capital Cultural Square. In some special occasions, the Lucheng government, Shuangyu Subdistrict Committee or factories would hold some activities in the square to enrich migrants' spare time life.

\subsection{Informal activities and informal governance}

\subsubsection{Motorcycles with umbrellas}

When you approach the VICs, their main road entrance are often flanked by motorcycles awaiting for customers (Fig 7.11) The motorcycle ban policy in Wenzhou has been put into effect in June 2011. No more new motorcycle plates could be issued after that date.

Motorcycles are not allowed to drive on the main roads in the urban district area. But in 
Shuangyu, when you walk on the road, you can still see a lot of those motorcycles with umbrellas. Most of them are motorcycle taxi drivers. I was told by the motorcycle drivers, most of them attained the motorcycle's plates from Yongjia (a county close to Wenzhou urban area) and other provinces where usually the drivers came from. Most of the migrants take this job as a substitute when the factory that they are working for is not busy or off season. A lot of factories, especially those that rely on the domestic market, usually give their workers two months' vacation in June and July when their products are off-season. The drivers are aware that it is illegal to drive customers around, especially on the main roads. I was dropped off couple times unexpectedly on the road because the drivers spotted the cops ahead. If they are caught by the police, they will get a ticket for a 150 yuan fine and will have two points taken off their driver records (the total points is 12 per year). However, the temptation of making extra money drives a lot of migrants to continue to take the risk, not to mention that there is a demanding market for motorcycle taxies. The "point-to-point" fast service provides much more convenience for customers than the public bus, lower cost than taxies make them more competitive (they usually cost 5, 8 or 10 Yuan depending on how far you want to go). More importantly, they are not afraid of being picked up by the police; instead, most of times the 
authorities just ignore them or just "turn a blind eye to them" (Zheng yizhi yan, bi yizhi yan).

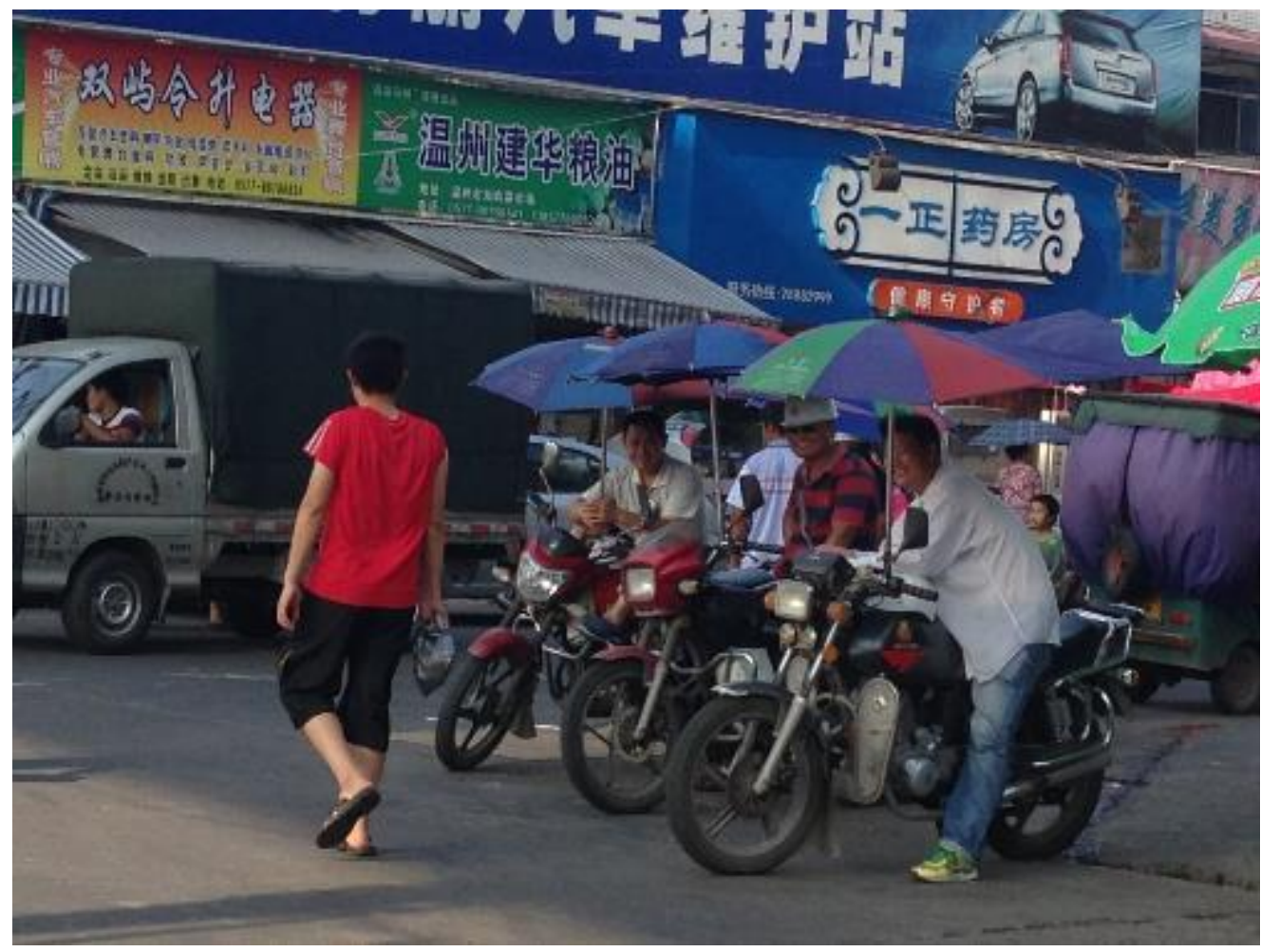

Figure 7.11 Motorcycle drivers waiting in the entrance of VIC

\subsubsection{Street vendors and peddlers}

Street vendors have become an important part of urban economies around the world.

By distributing affordable goods and services, they provide consumers with convenient and accessible retail options and form a vital part of the social and economic life of a city (Roever, 2014). Usually run by the migrants, they are everywhere in streets, sidewalks, alleyways, and public squares. However, their negative impact on the urban environment and large number of them brought great challenge to city management. Since many cities in China banned the street vendors mainly in urban districts, news about conflicts between vendors and Chengguan has never stopped. Since September 2008, Wenzhou also started to clear out the street vendors in 
the major commercial districts. In order to better deal with the vendors, the first "vendor company" run by migrant entrepreneurs has been established to manage the vendors. They take responsibility to clear out the environment and maintain order. After paying a certain amount of fees to the company, vendors who are willing to continue their business are allowed to run their business in fixed areas. However, not all the vendors, on the one hand, can fit into the limited space due to the great number of them. On the other hand, not all the vendors and peddlers can afford or are willing to pay for the cleaning and management fees. So there are still a great number of un-licensed vendors and peddlers on the street. As such, less regulated migrant settlements in the urban fringe became one of the major destinations for those vendors. Shuangyu itself along has 2,200 vendors (not included those who are not registered). Almost each urban village in Shuangyu, where migrant settlements are, includes a temporary market street for vendors and peddlers.

$\mathrm{Mr}$. Wu, who is from Chuzhou, Anhui, is an unlicensed peddler selling Taiwan-style pancakes. I met him when he came outside of Lucheng Library. He just quit his job in a clothes manufacturing factory in Cihu road Panqiao Street, Ouhai and came to Shuangyu two month ago. "It's hard to say, there is not only one reason that I quit my job and came to Shuangyu, I want to have more freedom," he paused for a thought and then continues, "I heard street vendor can earn much more money than workers, so I want to have a try". When asked if he is afraid to be caught by Chengguan because he does not have a permit, "of course" he replied resignedly. Actually he was caught once. He was told to get a license but the department in Shuangyu is not going to issue any more permits. "It's a contradiction, isn't it? They asked you to get a permit for vending on the one hand, on the other hand, they're not issuing that to us. So now I only vend in the third phase development area of the Shoe Capital (which is much further 
out to the suburb than where we are-that is-also less regulations on the street vendors)". A lot of migrants are like Mr. Wu who escape from the factories, instead they become street vendors - an occupation which is believed to have more "freedom" and higher income.

\subsubsection{One day off: informal practices of the "holiday"}

Unlike the white-collar workers who enjoy a two day-weekend after five days' work, for the majority migrants in Shuangyu, there is only one day off in a month, which is the first day of each month. In the every first day of the month, the hustle and bustle of the streets makes it very different from the quiet of the other days. It's apparently a holiday in Shuangyu. Streets are crowed with people, who are shopping, wandering around or perhaps just taking a rest on the roadside. Merchants display the products outside their shops, use the loudspeakers shouting and try to attract more customers (Like a holiday sale). Bus stations operate as busy as the rush hours-people wait for their bus to take them to the destination for fun or maybe just want to skip their working place. All the banks are full of customers waiting in lines, who are mostly migrants who just want to check their accounts to see if they got their salary this month or try to send some remittance back to their hometown. 

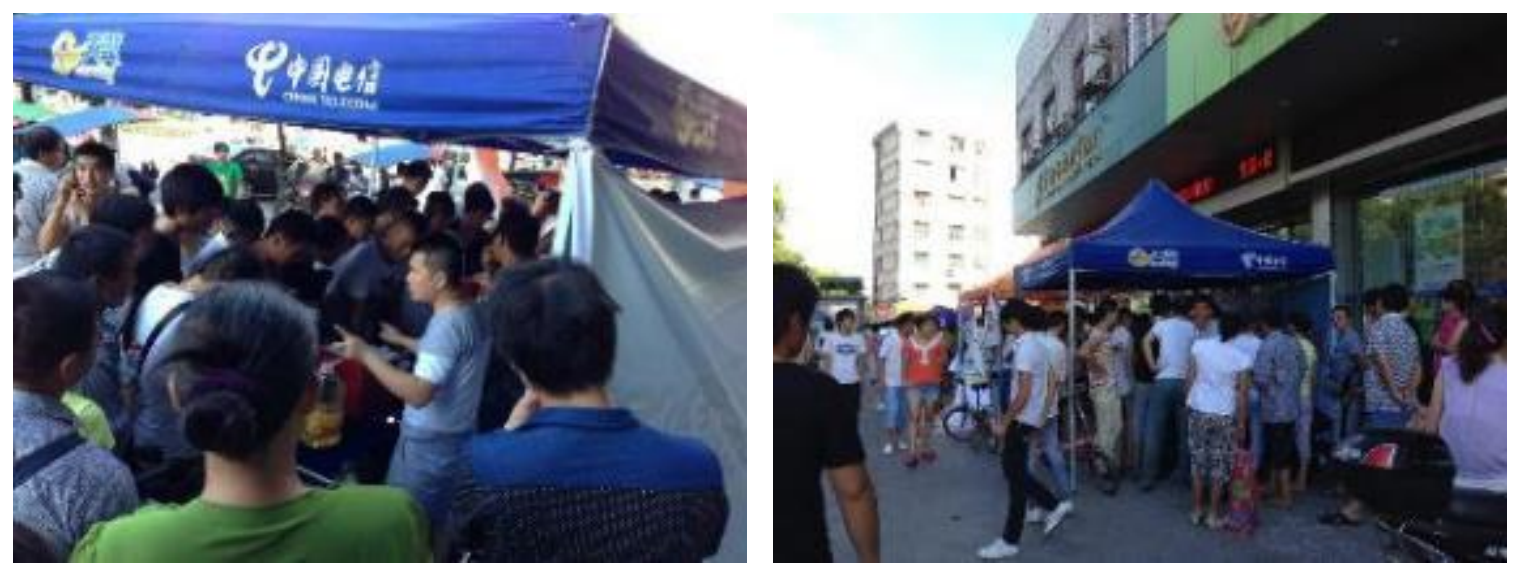

Figure 7.12 China Telecom is holding a lottery activity
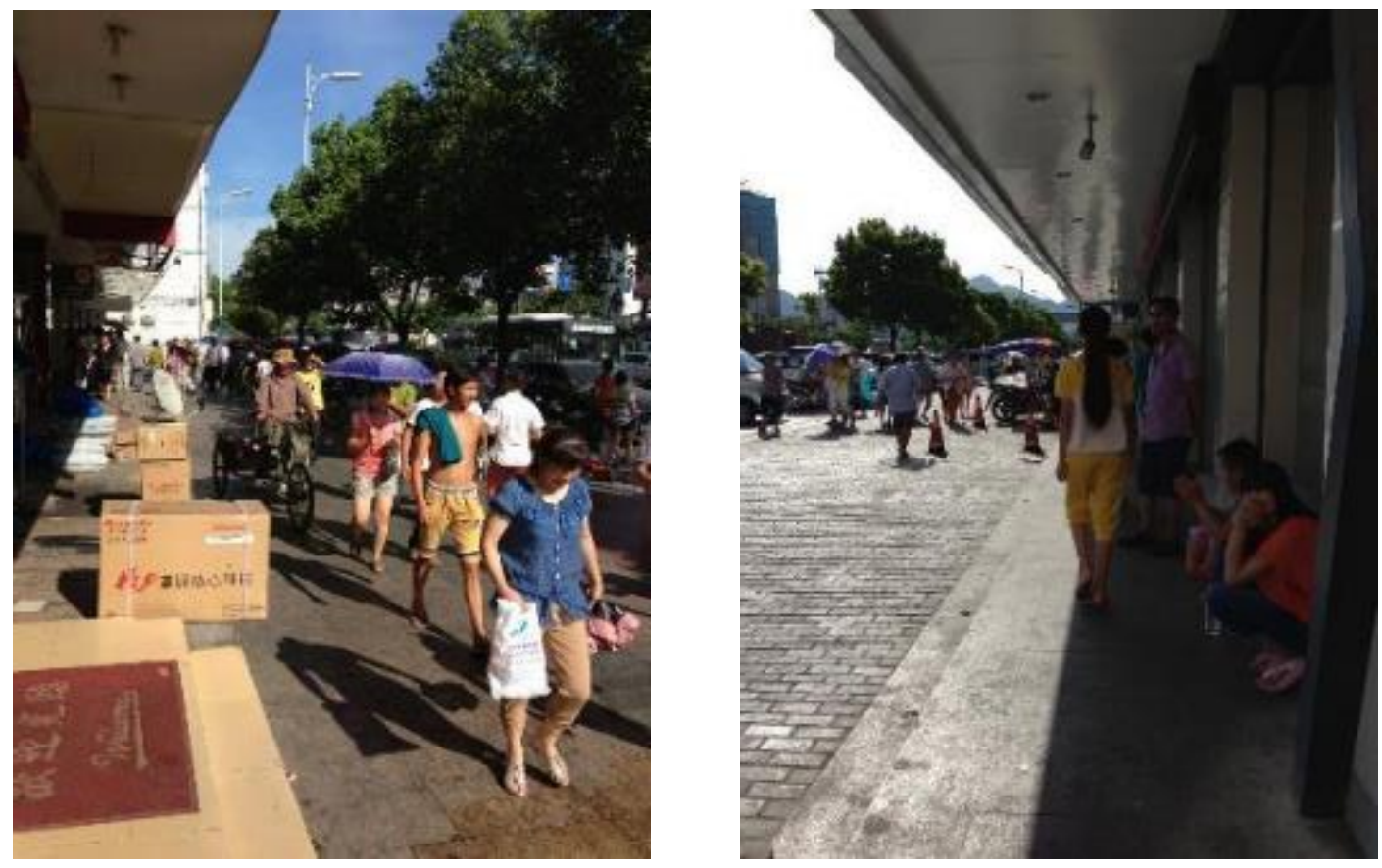

Figure 7.13 Merchants display the products outside the stores and migrants rest on the roadside 

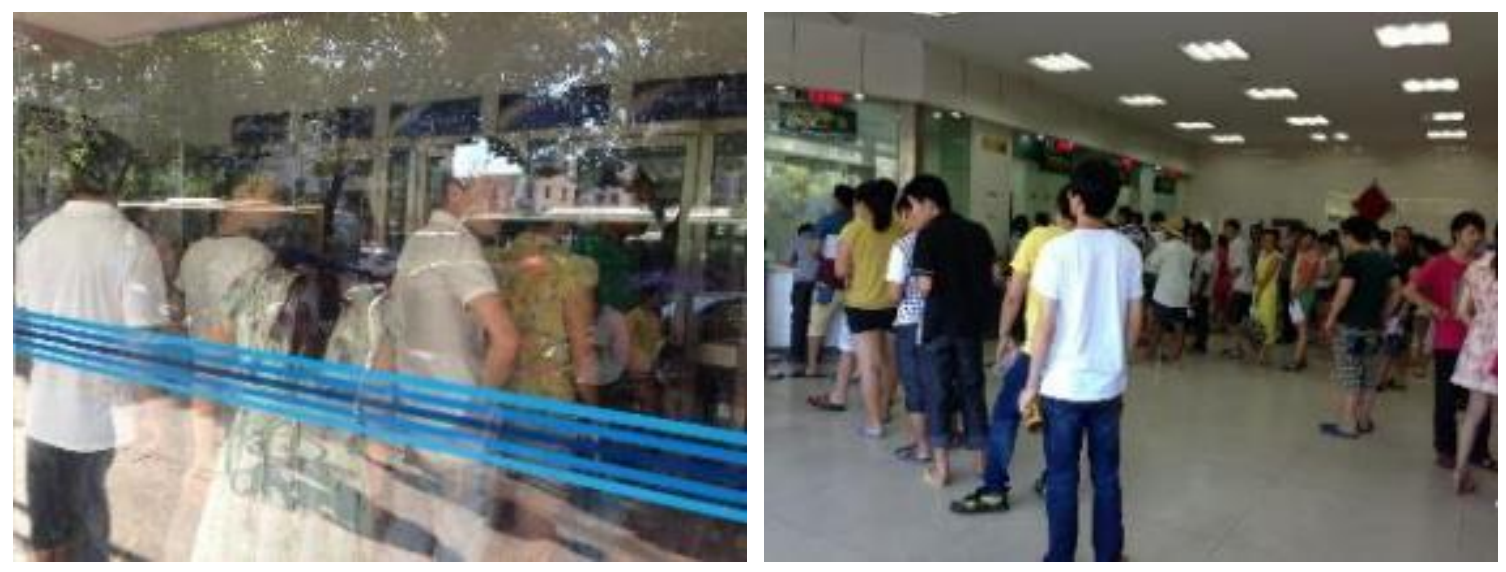

Figure 7.14 Migrants wait in lines in the bank

\subsection{Summary}

Shuangyu is becoming a typical migrant settlements featured by labor intensive migrant workers. Due to its transitional location from rural to urban area, Shuangyu lacks strict regulation and urban planning. The flourish of migrants and formation of migrant settlements have greatly impacted the streetscape and urban image. Particularly, a combination of formal and informal development have influenced the morphologies and spatial image of Shuangyu. By considering migrant settlements as a sub-assemblage, this chapter examines migrants' activity place, exploring its fluidity/static, formal/informal features.

Compare to local residents, long working hours and low-income mean that migrants have narrower zone of space and less time for entertainment. Street space, semi-public space and squares have become the major activity spaces that migrants involve most in the urban life. Compare to formal formation of activity space in city centers, activity space has been formed in an informal process with informal practice in migrant settlements, such as hawking, vending, advertising. Meanwhile, informal governance are also imposed over informal practices such as 
informal fines, fees and bribes are paid, blind eyes are turned. Although many of these informal activities have become the eyesore of the government which were mostly banned in the city center, they are becoming a distinctive and indivisible part of migrant settlements. 


\section{CHAPTER 8}

\section{SOCIAL AND SPATIAL IMPACT OF MIGRANT SETTLEMENTS ON URBAN SPATIAL FORM}

\subsection{Introduction}

The arrival of great numbers of rural to urban migrants undoubtedly imposed great influence on cities. Economically, there is growing understanding that rural migrants have brought positive impacts on urban economies through their contribution of labor in occupations shunned by local urban residents (X. Liu \& Liang, 1997). Similarly, migrants have contributed to Wenzhou's manufacturing-based economy. Many early studies of the Wenzhou model attribute its economic success to a formula of combined mass initiative, mobility, and skills in longdistance trade (A. P. L. Liu, 1992; Nolan \& Dong, 1989; K. Parris, 1993). Income earned by those out-migrants from Wenzhou who export and sell special local products has been identified as the most substantial source of initial investment in Wenzhou (A. P. L. Liu, 1992). If saying outmigration is a significant factor that contributes to Wenzhou's economic take-off during 1980 s, in-migration (mostly rural to urban migration) in recent decades is undoubtedly one of main driving forces/engines that makes Wenzhou's economy continue prospering. A study found that there is strong and positive correlation between number of floating population and GDP growth in Wenzhou (Yanlu Wang, 2009). On the one hand, the lower cost of hiring migrants compared to hiring local residents saved a significant amount of total cost for enterprises, which in turn contribute to the GDP. Migrants, on the other hand, filled the vacancies in the job markets that labor-intensive manufacturing jobs are often unwelcomed or even despised by local residents. Yet these labor-intensive manufacturing industries are the pillar of industry in Wenzhou. 
In addition to the economic impact, the influx of great number of rural to urban migrants, more importantly, has substantially impacted the social structure and spatial pattern in the urban areas. These impacts on the social and spatial structure of Wenzhou city have been neglected by the scholars. As the West gate of Wenzhou, Shuangyu seems to be physically and spatially separated from the other parts of Lucheng district by Cuiwei Ave (continues from Oujiang No.3 Bridge which connects Yongjia county and Wenzhou urban districts). Furthermore, as a local Wenzhounese myself, I have the advantage of having many local friends. When being asked about Shuangyu, most of them replied their first impression is "many, many migrants". "Migrant population" have become the name card/image of Shuangyu. In other words, Shuangyu is often perceived as a migrant settlement.

In previous chapters, we have discussed Shuangyu as an assemblage, and the informality and uniqueness of the space due to the presence of migrants. This chapter further explores the interconnectivity and flows between Shuangyu and other constituent parts of the city. Through discussing the ways that migrants use/interact with the city, the chapter further shows how the presence of the migrants, using the city in the way that they do, has had impacts on the city as a whole. Specifically, by analyzing migrants' employment patterns, housing and commute patterns, consumption patterns, and leisure patterns, this chapter reveals the spatial and social connections of migrant settlement with other parts of city, and addresses what are the policy implications to local government. 


\subsection{Spatial and social connections of migrant settlement with other parts of the city}

Generally speaking, migrants in Shuangyu have few connections with the city center. Migrants seldom visit the city center -more than 85 percent of the migrants go to the city center less than 3 times in a month, while about 55 percent of them never go to city center. This is different from local residents, who, wherever they live, go to city center very often, due to the complete amenities for all sorts of public services, shopping malls and entertainment.

\subsubsection{Employment pattern}

Like migrants in other cities, migrants who come to Wenzhou are mainly there to work or earn money. Work or employment is the first and foremost interaction that migrants have with the city. This part analyzes some unique employment patterns in Wenzhou and how they have impacted the city form. Even with the Labor Contract Law that was introduced in 2008,60 percent of migrant workers in the survey do not have official contracts with the enterprises, and mostly work on a daily or task basis. Migrants can find job information outside the factories (Fig. 8.1) and start working by simply registering their identification card in the human resource office. This system, in certain circumstances, imposes few restrictions on both migrants and employers. The fluidity of employment practices is contingent upon the volume of product demand. During the "high season" (e.g., the run-up to the Christmas Season), employers may be inflexible in their demands on workers, who may not feel free to leave at will. However during the "off-season", employers might lay-off excess labor, and employees might feel free to leave at any time to go home or seek other work. Because the arrangements between employers and 
employees are informal, migrants can leave and seek higher-paying jobs without legal

repercussions. This spontaneous approach, with the tacit agreement of both migrant workers and employers, keeps the migrant settlements simultaneously static and mobile. The survey results also indicate that the majority of migrants have changed jobs after settling down in Shuangyu. Specifically more than 60 percent of them have at least changed job once, including 32 percent who have changed twice to three times, and 18 percent who have changed more than three times.
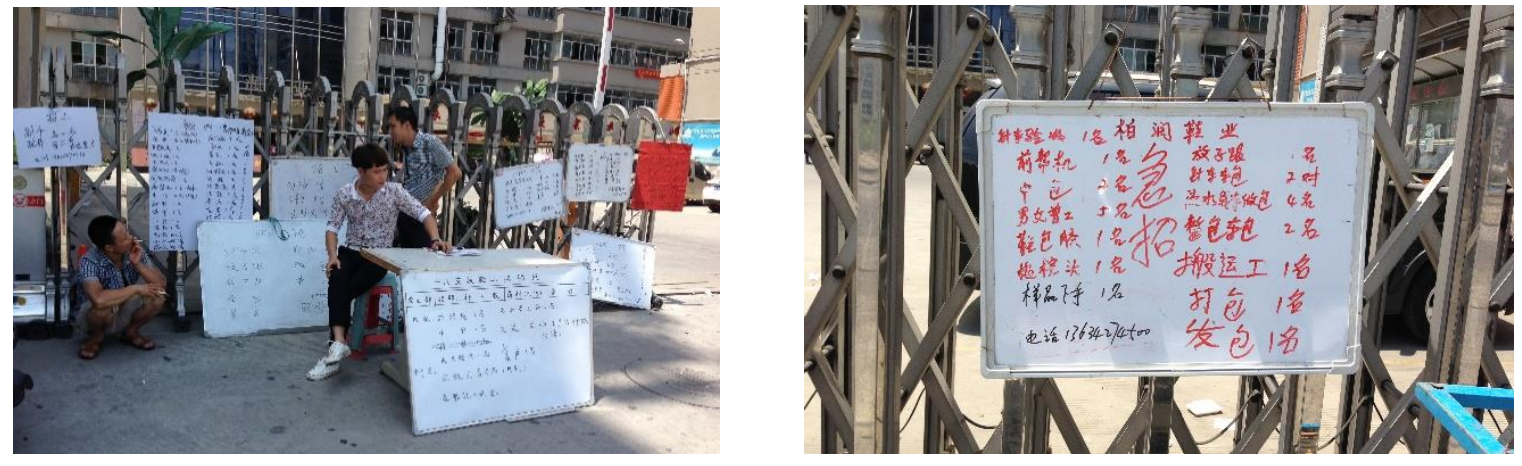

Figure 8.1 Recruiting message boards outside factories

Due to their "floating" status in the city, migrant may visit home during different times of the year; this also makes the settlements very fluid. 67.59 percent of migrants in the survey reported going back home during Spring Festival. The other 25.52 percent of them regularly visit their rural home villages during the job off-season period. This period is often in July and August, which is consistent with the global calendar of shoe manufacturing.

However, the socioeconomic status of migrants determines that most the job changes take place within the same sub-district, long distance moves and leap frogging are rare. The high frequency of job changes is usually limited to similar jobs in different factories that are in the 
same industrial park. From interviews with the migrants, I learned that a lot of them were introduced by their relatives or friends and came to Wenzhou without any knowledge about the job that they are doing now, such as the process of shoemaking. They learn the skills at the factories in the first few months. Some of them stick to labor intensive work as a common workers (pugong) $)^{13}$, others learn one or more kind of specific skills in the assembly line and become skilled workers (jigong) ${ }^{14}$. Once they have learned certain skills or are familiar with certain part of the assembly line, they don't want to change jobs that require new skills. For example, the skills learned in the shoe making assembly line may not work in the lighter-making factories. As such, there is high mobility among workers who switch jobs often but almost spatially within the same industrial cluster. This results in static relations between the industrial clusters and other parts of the city. This pattern may well be unique to Wenzhou, where industries are distributed in clusters. For the case of Shuangyu, with thousands of shoe-making factories agglomerated, it enables migrants to stay and work in the same district but also provides more mobile chances for them to change jobs.

${ }^{13}$ Common worker (Pugong): unskilled worker who can only do some simple jobs, such as wipe the sole, take off the wax paper in the shoe making assembly. They are usually paid by basic monthly salary in Wenzhou.

${ }^{14}$ Skilled worker (Jigong): is any worker who has some special skill, knowledge, or (usually acquired) ability in their work. They are usually paid by piece wage. They could get very high salary up to 8,000 to 9,000 RMB in a month or no more than basic salary about 2,000 in Shuangyu, which depends on how their skills and how much time they devoted to work. 


\subsubsection{Housing and commuting}

The spatial relationship between housing location and workplace decides their daily connections with the other parts of the city. The early research about the immigrants in American cities in the late nineteenth century found those immigrants who are mostly workingclass people had to live near their places of employment and had little contact with people outside their neighborhood. Today, the automobile and other systems of transportation and communication have weakened the connection of home to work and enlarged the geographic scale of people's active social networks (Logan, Zhang, \& Alba, 2002). Market transition and institutional changes, accompanied by economic and social changes have led to a new urban spatial structure in Chinese cities. The urban spatial structure based on homogeneous work unit compound in the period of planning economy has been gradually transferred to a more heterogeneous landscape. Urban residents are no longer tied to their places of employment (S. Li, 2004). As W. Wu and Gaubatz (2012) argue, spatially many residents now have the freedom to decide where they wish to live. As a small survey taken in one of Wenzhou's local residents' communities shows, local urbanites often travel far for work and go to the major shopping centers in the city center (Fig. 8.2). 


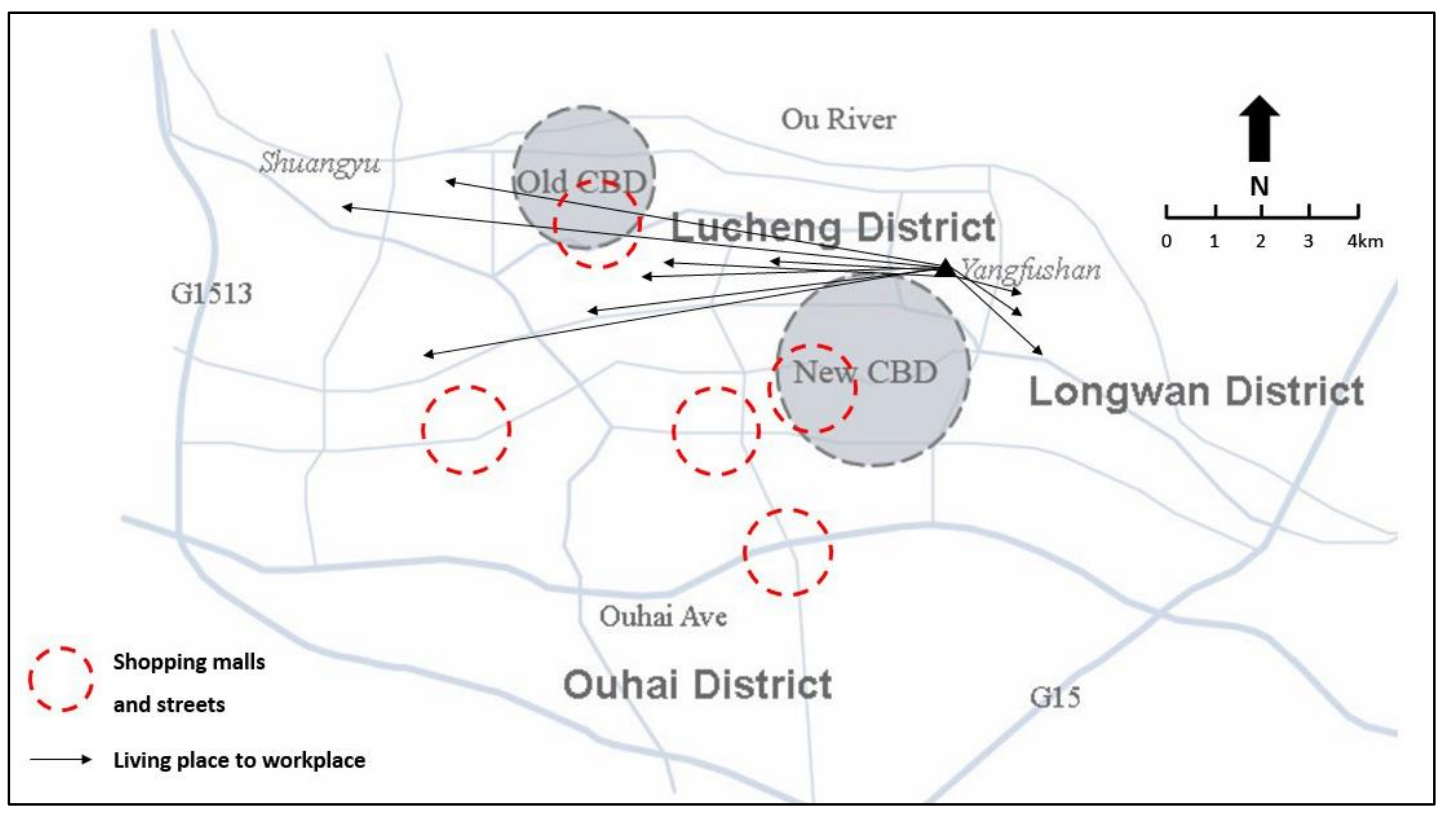

Figure 8.2 Local residents' workplace and living, shopping center

However, migrants who, without local hukou, are excluded from several types of urban housing and have very limited housing choices (W. Wu, 2004), often rent housing in the villages in the urban fringe. In Beijing for example, the limited housing choices restrict migrants to the urban fringe areas between $4^{\text {th }}$ and $5^{\text {th }}$ ring roads-where most urban villages are, despite the fact that the migrant residents often travel to different directions for work (Y. Fan et al., 2014). Pink-collar migrant workers, who usually work in wholesale and retail trade, catering services and social services, commute to the city center (inside the 3rd ring road) for work. Blue-collar migrant workers usually commute outward to the suburbs where most manual labor jobs are, such as those in manufacturing, mining, building and construction. Although not voluntary, this housing-job mismatch pattern in Beijing allows migrants to have more connections with other parts of the city, making use of and relying on public services. 
Unlike Beijing, as the primary job opportunities for migrants are from manufacturing industries in the inner suburb, Wenzhou enables migrants to live close to their workplace. The two major housing sources in Shuangyu are private rental housing in villages and dormitories that are provided by the factories. The survey result shows that the majority of the migrants live in walking distance to their workplaces (Table 8.1). And approximately 70 percent of them spend less than 10 minutes commuting to work, which is distinctively shorter than low-income groups in other cities, such as 34.95 minutes in Guangzhou (Zhou, Wu, \& Cheng, 2013). As such, the overlay of housing and job location allows migrants to have little connection with the other parts of the city and usage of public services. In this sense, Shuangyu has little connection with the other parts of the city and remains static/closed.

Table 8.1 Transportation and commute time to work

\begin{tabular}{lrr}
\hline & No. of Migrants & $\%$ \\
\hline Ways of commute to work & 284 & 63.82 \\
Walk & 51 & 11.46 \\
Bus & 46 & 10.34 \\
Bicycle & 19 & 4.27 \\
Private car & 16 & 3.59 \\
Drive motorcycle taxi and & 8 & 1.80 \\
others & 8 & 1.80 \\
Shared mini-bus/van & 6 & 1.35 \\
Motorcycle taxi & & \\
Taxi & 120 & 27.59 \\
Commute time & 182 & 41.84 \\
Less than 5 mins & 87 & 20.00 \\
5-10 mins & 37 & 8.51 \\
10-30 mins & 9 & 2.07 \\
More than 30 mins & & \\
No response & & \\
\hline
\end{tabular}


However, similar to the employment process, the flexible rental agreement between migrants and the landlords in migrant villages contributes to fluidity within migrant settlements. The rental housing available for migrants in Shuangyu is mainly constructed by the local peasants living in villages in and around two industrial parks. A spontaneous rental market has formed due to the high demand of low cost housing from migrants and local peasants' willingness to rent out rooms for profit. According to the administrative process, both landlords and tenants are required to register with local police and to complete necessary paperwork for housing rental. However, when it comes to housing rental in villages, the enactment of government regulations has often been subverted by the private provision of housing and limited state control over rural areas (L. Zhang, 2011). Most migrant housing is rented out, not according to municipal regulations, but mainly on written or more often verbal agreements between landlords and tenants. In this system, landlords can collect more rental income by renting out substandard rooms with small space that mostly do not meet the requirements of government policies. On the other hand, the tenants who sometimes do not hold legal registration in the city can also escape legal punishment. Meanwhile, short-term leases, starting at one month, allow migrants to move easily. It is also easy for migrants to make decisions to move since they usually have few possessions in the city.

\subsubsection{Consumption patterns}

Other than employment and housing, consumption is also important to understand migrants' interaction with the city. With the fast economic development in Chinese cities, the consumer lifestyles of urbanites have changed substantially, towards a higher need to fulfill successful lifestyles. However, migrants' consumption pattern which is more like rural 
consumers still remain in the level of what Maslow called "deficiency need" (including physiological, safety, love, and esteem) (Maslow, 1955). In this sense, the lives of migrants diverge from Chinese mainstream urban residents. According to the survey carried out by the New Residents Administrative Bureau in Lucheng district in Wenzhou, migrants' major consumption is food, clothes and daily supplies, if housing and utilities expense are excluded. Therefore, tracing their spatial consumption pattern for food, cloth and daily supplies is the key to understand their general consumption pattern and daily routine.

Spatial proximity to their living area is the most important factor in migrants' consumption choices. Table 8.2 reveals the migrants' choices of places for grocery shopping and special purchases. The most commonly-mentioned shopping places are nearby shops and stores. Migrants are often unable to shop far from their residences. Limited spare time, low income and little knowledge about the city are three major reasons that constrain migrants' consumption areas to the places that close to their living areas. But in the meantime, this consumption pattern of migrants also indicates that the stores and services in migrant settlements enable migrants to have little connection with the other parts of city. Shuangyu as a migrant settlement thus remains isolated from other parts of the city. 
Table 8.2 Migrants' consumption pattern

\begin{tabular}{lrr}
\hline & No. of Migrants & \multicolumn{1}{c}{$\%$} \\
\hline Places for grocery shopping & 293 & 67.36 \\
Local small grocery shops and small supermarket nearby & 69 & 15.86 \\
Farmer's market in the village & 59 & 13.56 \\
Vendors and temporary stalls nearby & 55 & 12.64 \\
Big supermarket such as Walmart not very close by & & \\
Places for special purchases, such as clothes, gift & 153 & 35.17 \\
Shops and stores nearby & 112 & 25.75 \\
Night market & 105 & 24.14 \\
Commercial street in Shuangyu district & 79 & 18.16 \\
Whole sale market & 36 & 8.28 \\
Shopping malls & 9 & 2.07 \\
No response & & \\
\hline
\end{tabular}

Only eight percent of the migrants in the survey prefer to shop in the large shopping centers in the city center. Large shopping centers are new space that emerged in Chinese cities after the reform in the 1980 s. Those shopping centers serve as places for both the buying and selling of goods, and for entertainment, have become very popular among urbanites. In Wenzhou, modern shopping malls and large shopping centers were gradually built since the end of 1990s. For example, Kaitai shopping mall was the first shopping mall introduced to Wenzhou (1998), along with the renewed Wuma shopping street, Intime department store (2006) and Lizi huadu fashion shopping square (2005) became popular shopping centers for local residents.

They offer a great range of things from cosmetics to food, to clothes and entertainment services such as cinema and a game center. However, migrants seldom go to those places. Even though more than half of the migrants have stayed in the city for more than five years (Fig. 3), many of them have never been to any of these popular shopping malls and commercial streets in Wenzhou (Table 3). Only Wuma Street, which has some historical significance, has been visited 
by a great number of migrants, usually more due to its function as a place of interest rather than as a shopping place.

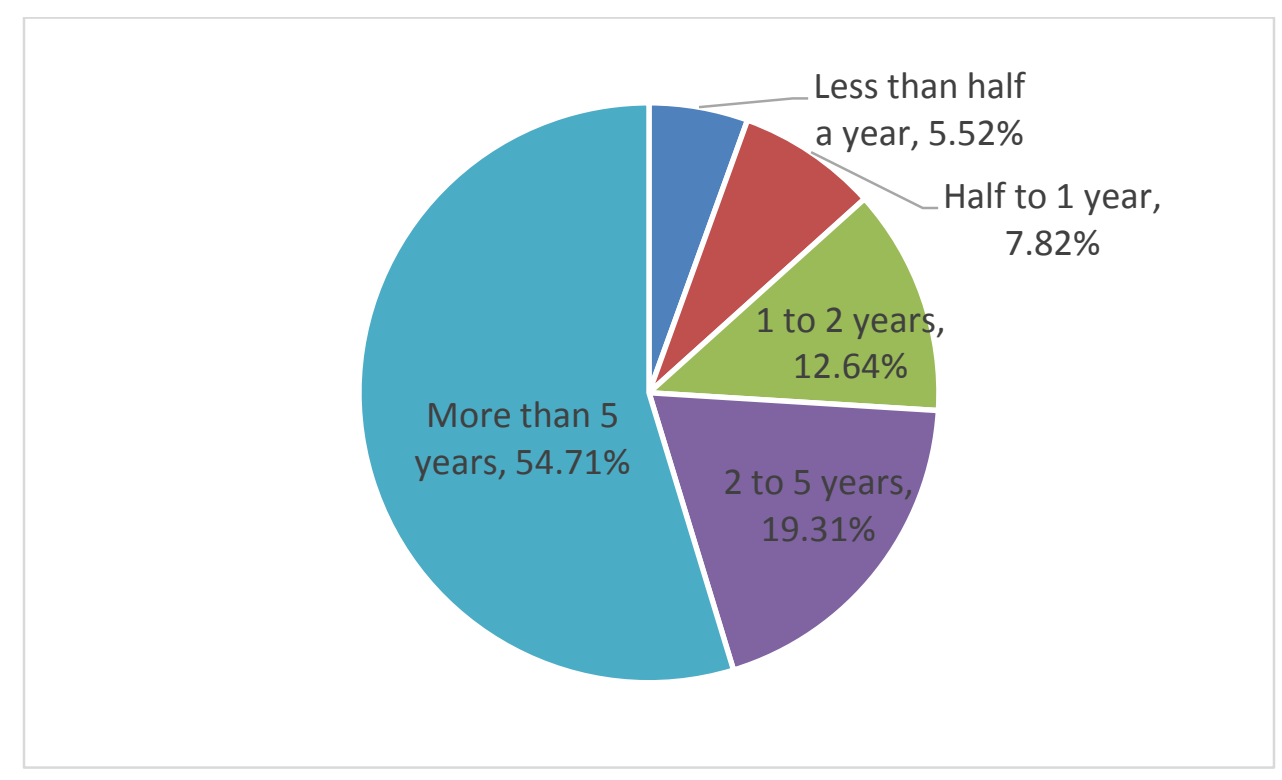

Figure 8.3 Migrants' years of stay in Wenzhou

Table 8.3 Popular shopping malls and commercial streets in Wenzhou

\begin{tabular}{lrr}
\hline & NO. of migrants & \\
\hline Wuma street & 263 & 60.46 \\
Kaitai department store & 91 & 20.92 \\
Time square shopping center & 69 & 15.86 \\
Shamaohe lady street & 52 & 11.95 \\
Intime department store & 48 & 11.03 \\
Others & 26 & 5.98 \\
Danlu shopping square & 16 & 3.68 \\
\hline
\end{tabular}

Note: the total percentage is not 100 percent. Since this is a multiple choice question (could choose more than one answer), the percentage is calculated out of total number of migrants (which may less than total number of answers) 
Rather than shopping in the department stores and malls, migrants prefer shopping at informal/temporary markets such as farmers' markets and night markets in the villages (Table 2). The formation of these markets involves both formal and informal processes, with significant daytime/nighttime variation in both goods and services offered and customers. Night markets, for example, are usually operated on the public street which serve as regular space for commuting in the daytime and changes to a market place in the evening. Vendors and hawkers with formal licenses are allowed to sell goods and services in the fixed area of the street. Additionally, a significant number of vendors who do not have permits to sell often move place to place to avoid the urban police. As such, the informality of these markets also implies a lack of formal control over planning, design and governance. In the migrant settlements, the urban police may turn a blind eye on these informal practices. The existence of these market places not only provide goods and services for migrants' daily life consumption, but also create diverse and fluid spaces.

\subsubsection{Leisure pattern and social network}

The ways that migrants use their spare time are also important to understand how they interact with the city. The survey shows that the leisure activities of the migrants tend to be simpler and spatially limited within the neighborhood range. When it comes to leisure activities, they prefer to simply rest by watching TV at home (46.67 percent) or sleep (34.48 percent) (Table 8.4). This indicates that the perimeter of leisure space for migrants is very limited within their home range. Also, "no time" and "the city center is too far away" are the two most mentioned reasons that migrants used to explain not going to the city center for leisure. As I mentioned before, these labor migrants often work overtime. In order to earn more money, 
migrants usually sacrifice their leisure time to work. As such, it is reasonable for migrants to mention "no time" as an excuse for not going to the city center. However, Shuangyu is less than 3 miles away from the city center. Thus, the perception of "close" or "far" indicates their limited mobility across space. Differential mobility empowerments reflect social structures and hierarchies of power and position between different groups of people. People with better knowledge of the city, higher-income, and more spare time may have the higher capacity to move. While migrants are the group of people that possess less power of mobility.

Table 8.4 Migrants' leisure activities

\begin{tabular}{lrr}
\hline & No. of migrants & $\%$ \\
\hline Watch TV & 203 & 46.67 \\
Sleep & 150 & 34.48 \\
Surf on line & 83 & 19.08 \\
Shopping & 78 & 17.93 \\
Walk or work out in the parks nearby & 74 & 17.01 \\
Not too much spare time & 68 & 15.63 \\
Play chess, Mahjong and poker with friends & 63 & 14.48 \\
Go to the library nearby & 26 & 5.98 \\
Rest and enjoy the sunshine outside & 12 & 2.76 \\
Work at a second job & 11 & 2.53 \\
Others & 2 & 0.46 \\
\hline
\end{tabular}

The survey results also indicate social segregation between migrants and local residents. Many studies have suggested that kinship and friendship ties are important, as migrants often use them as social institutions in making settlement choices and overcoming mobility barriers (Gaubatz, 1998; W. Wu, 2006). Interviews with migrants also show introduction by people from the same origin (laoxiang), relatives and people they knew before are the initial reasons that migrants came to Shuangyu. Not surprisingly, people from the same place of origin and relatives have become important social network for migrants, who they often keep connections with 
(Table 8.5). The majority of the migrants in the survey do not know any local residents (Table 8.5). Renting a room in a local peasant's house is the first and may be the only linkage between them and the local residents.

However, unlike those homogeneous migrant villages discussed in case studies of "Zhejiang village", "Xinjiang village" and "Henan village" in Beijing (Gu \& Shen, 2003b; H. Liu \& Gu, 1999; Ma \& Xiang, 1998), there are no such migrant enclaves in Shuangyu which either have dominant number of migrants who run the same business or come from the same origin. Take one shoe manufacturing firm for example, there are many workers who came from Jiangxi province (27 percentage), but no such phenomenon showing that a dominant share of migrants came from the same province. Different from what has been found in early studies that factories are willing to hire people come from the same origin, there is a changing trend in hiring migrant workers in nowadays. The clerk from one of the factory's Human Resource department told me that they still prefer to employ the workers from the same origin that have been introduced by their employees since they know them well. However, considering migrants from the same origin may take sides and divide into factions which often bring problems to the factory, the factory employers try to balance the number of workers from different origins. Also, they may purposely divide them into different assembly lines/workshops, just in case if they are not satisfied with the job and quit at the same time which would impede the production process.

Meanwhile, migrant associations such as business association, townsmen association that are usually organized by the people from the same origin are not popular among migrants in Wenzhou. Instead, migrants often participate in the activities that are held by the factories, such as karaoke competition, fun games, and sports competition. Most of the connections they 
make are through work. This indicates that migrants' concentration in Shuangyu is more a result of the same job and housing choices than their economic, social and cultural connections.

Migrants in this type of settlements are usually less connected both in cultural life and economic activities, possessing little social capital and power (X. Wu, 2003). And their connections outside Shuangyu are very rare.

Table 8.5 Migrants' social network

\begin{tabular}{lrr}
\hline & No. of Migrants & $\%$ \\
\hline Work mates & 222 & 51.03 \\
People from the same place of origin & 193 & 44.37 \\
Relatives & 135 & 31.03 \\
Employee & 57 & 13.10 \\
Old classmates & 47 & 10.80 \\
Don't usually hang out with anyone & 30 & 6.90 \\
Local residents & 23 & 5.29 \\
Boss & 13 & 2.99 \\
Others & 7 & 1.61 \\
Landlord & 6 & 1.38 \\
\hline
\end{tabular}

\subsubsection{Summary}

For local urbanites, their mainstream society is commonly composed of their residential space where they live, a larger living space for work, consumption and leisure, and the largest space for social activities (Fig. 8.4). From the above analysis, we can see that migrants' social space is independent from the mainstream society. Rather than embedding inside the mainstream society, the migrants' social space is in the marginal region of the city (Fig. 8.4). Marginalization can be perceived as a process of formation of migrant settlements in the city. Furthermore, the living space of migrants is relatively confined in a small space which is close to 
the same space of the residential space. Their social network is also trapped in a small circle, in an involution status, namely growth without development.
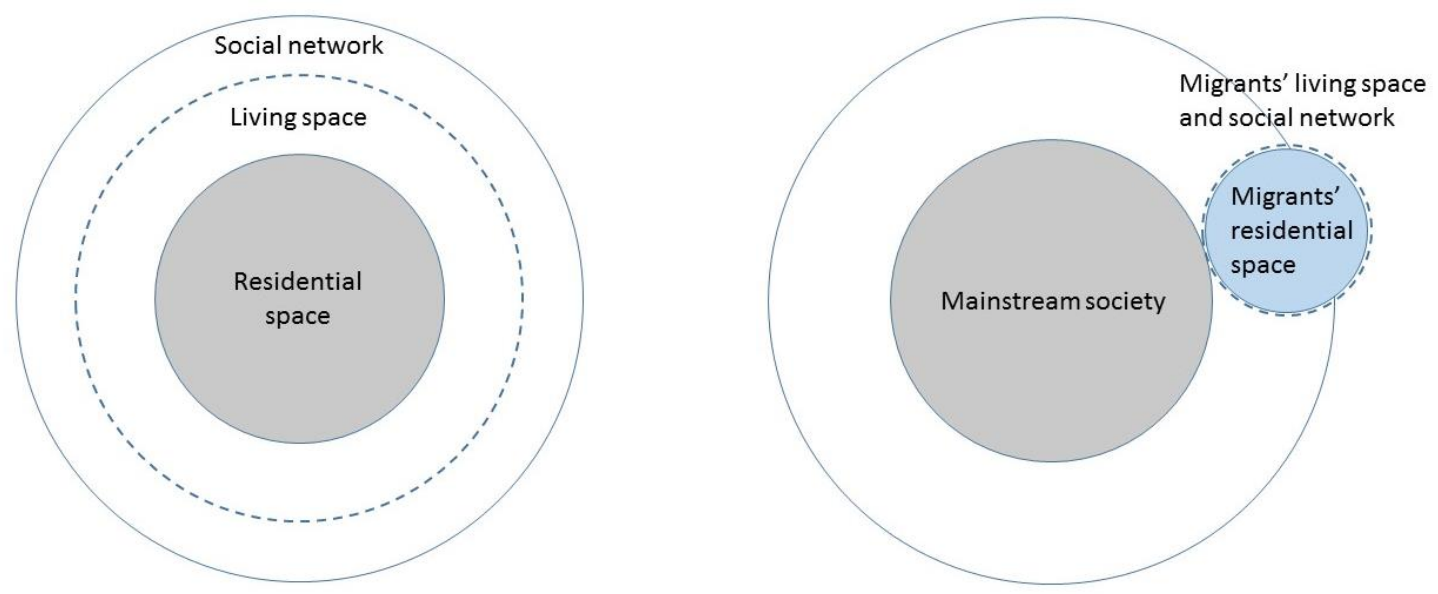

Figure 8.4 Mainstream society space and migrants' social space

\subsection{Summary}

By thinking city as an assemblage and is formed from the interconnectivity and flows between constituent parts, this chapter explores migrant settlement as a sub-assemblage/part of the city and further analyzes its connections with other parts of the city. With data drawn from both statistical and survey sources, my analyses reveal migrants' living and work patterns in the sub-district scale.

Although spatially aggregated in the similar part of the city-urban fringe, the migrant settlement in Wenzhou has been found to have different connections with other parts of the city in comparison to some megacities. Firstly, the co-location of housing and employment within Shuangyu restricts migrants to spend most time within Shuangyu. It is different from some findings about Beijing, where migrants who usually live in the villages between $4^{\text {th }}$ and $5^{\text {th }}$ 
ring roads while commute to either city center for service jobs or outer suburbs for manufacturing jobs. These daily connections makes migrant settlements more fluid and have more impacts on urban public services such as transportation. Secondly, the perimeter of migrants' daily life is limited within Shuangyu based on their consumption preference and leisure activities. They usually do not spend much money on shopping but if they have to, they prefer going shopping in some places near where they live rather than shopping centers in the city center. Their leisure activities are also very simple mostly take place inside the apartment by watching TV or sleep or within the neighborhood. Last but not the least, The survey also reveals migrants' social network and its spatial perimeter are pretty much limited to migrants in Shuangyu, who are mostly work mates, people from the same origin and relatives. Little connection has been built up between migrants and local residents. In conclusion, migrant settlements and service structures in Shuangyu have been developed which enable the migrants to have relatively little contact with the central city businesses and remain closed and static in relation to the other parts of city. Shuangyu can be considered as an independent subassemblage within a larger city assemblage or "city within the city" ${ }^{15}$, rather than a part of urban assemblage.

However, Shuangyu as a whole is rather fluid and mobile. For example, the loose/informal regulations on the job and housing markets allow migrants to change jobs and move easily. Most of those migrant workers in Wenzhou do not have official contracts with the factories. This system, in certain circumstances, imposes few restrictions on both migrants and employers. Migrants can leave and seek higher-paying jobs without legal repercussions.

15 "City within the city" is a new term that firstly put forward by the author. 
Employers can also let the migrant workers go when their products are in the off-season. This spontaneous approach keeps the migrant settlements simultaneously mobile, while also static since most of migrants usually just switch jobs to a different factory in Shuangyu due to their limited skills and mobility. To conclude, spatially close while socially distinct and segregated, Shuangyu as a migrant settlement could be considered closed/open, static/mobile, formal/informal at the same time in reference to their relationships to the other parts of city. Clearly, this "city within the city" urban form is resulted from the limited mobility of migrants. As Sheller and Urry (2006) argued "mobility is a resource to which not everyone has an equal relationship". 


\section{CHAPTER 9}

\section{CONCLUSIONS}

\subsection{Major findings}

The unabated migration trend from the rural areas to large cities during the last two decades is a major influence on urban spatial development in China, as exemplified in many megacities such as Beijing and Guangzhou. Substantial research has been done on the patterns of migrant settlement in these well-known Chinese cities, while less attention has been paid to the second or third-tier large cities that are also favored destinations for the rural migrants. More importantly, they primary focus on either the lives of migrants or migrant settlements, and while neglect how the process of migration and settlements has impacted on city's spatial structure as a whole. This dissertation uses Wenzhou, a third tier large city of more than 9 million people on China's southeast coast, to analyze how the process of migration and settlement changes the spatial structure of Chinese cities.

As recent urban assemblage theory argues, "city" is never fixed or stable, but always in a process of making or unmaking (Anderson \& McFarlane, 2011; J. M. Jacobs, 2012; McFarlane, 2011a, 2011b). The process of migration and settlement is no doubt one of the defining features of this place making process. In this dissertation, I consider the migrant settlement as a sub-level assemblage-an emergent entity that can further combine with others to produce an ever larger assemblage. Based on this perception, I approach this study in two different scales: (1) city-scale analysis considers Wenzhou as a whole, and addresses the spatial distribution patterns of migrant settlements. (2) sub-district scale survey to understand the process and formation of 
migrant settlement with an emphasis of their fluid/static status in relation to the other parts of the city, and further discuss its impact on urban form.

With reference to research questions raised in Chapter 1, major findings of this dissertation are summarized as follows:

\section{City scale analysis}

Question (1): What are the distinctive characteristics of migrants and the process of migrant settlement formation in Wenzhou in comparison to Beijing and Guangzhou?

Question (2): How are migrants spatially distributed in the city? In particular, how has the metropolitan form/spatial pattern changed from 2000 to 2010 ?

\section{Question (3) How is the spatial distribution of migrant settlements in the city similar} to or different from the patterns in Beijing and Guangzhou?

Although migrants make up a similar share of the population in Beijing (36 percent), Guangzhou (37 percent) and Wenzhou (35.5 percent), the social and spatial characteristic of Wenzhou's migrant population are quite different. Unlike Beijing and Guangzhou's migrants, many of whom are successful migrant business-people, or well-educated college graduates, the majority of the migrants in Wenzhou are manufacturing workers (approximately 90 percent of total migrants) with low educational attainment. Their long working hours and low incomes favor their living close to the factories. As such, their housing of choice is usually a shared room in villages located near the factories, or factory dormitories. The concentration of migrant settlements in different parts of a city may derive from a variety of different factors. Housing availability (concentrate in the village-held land) or social network (concentrate in the places where already have many migrants come from the same place of origin) are important factors that influence the formation of migrant comminutes in Beijing and Guangzhou. In contrast, 
Wenzhou's migrant settlements, which are dominated by manufacturing workers, are spatially linked to patterns of industrial development. Thus the city's industrial development strategies have had a direct influence on the location, formation, and characteristics of migrant settlements. The county-level analysis indicates that the majority of the migrants concentrate in the urban districts and two county-level cities, which also count for the determinant portion of industrial product output. By looking at the urban districts alone, we can see that with the manufacturing industries' successive movement from the city center to the inner ring, and to the urban fringe, the migrant settlements also relocated with the industries.

Furthermore, I also make use of the classic "concentric zone model" of urban spatial organization as a baseline for understanding the differing dynamics of migrant settlements in contemporary Chinese cities. Migrant settlements in Beijing, which were first primarily located in the zone of urban periphery, now has become an inner ring zone surrounding the city center. Migrants who live this zone either travel to the city center for service jobs, or travel to urban fringe for construction and secondary industry work. Meanwhile, wealthy people's zone has been gradually developed in the urban fringe. Different from Beijing, Guangzhou's migrant settlements except concentrating in the inner ring, also have a significant concentration in the city center. These migrant settlements have been evolved around the villages in the city center, and have gradually become sub-centers of Guangzhou city. In comparison with the patterns of "migrant settlements in the city periphery" in Beijing and "villages in the city" in Guangzhou, migration and migrant settlements contribute to Wenzhou's emerging urban form in a manner which diverges from the two models. The migrant settlement in Wenzhou represents a third type, that is-migrant settlements are not only located in inner ring and urban fringe zone, but also in the rural regions which have evolved around "single-industry clusters". 


\section{Sub-district level analysis}

Question (4): What are the distinctive features of migrant settlements in terms of migrant housing, living environment, activity places, as well as governance?

Question (5): What is the spatial and social relationship of migrant settlements to the city center? Are they strongly connected to other parts of the city, or do they generate distinct urban spaces such as "cities within the city" or "two parallel cities"?

For the detailed case study in this dissertation, the Shuangyu sub-district, which is located in the west part of the old city center, is selected to be the investigation area. By having both Wenzhou's biggest shoe manufacturing industrial park and the Lucheng light manufacturing industrial park, Shuangyu has attracted more than 231,068 migrants from other provinces, which is about 6 times number of local people $(39,461)$. With a mix of traditional industry clusters and migrant neighborhoods, Shuangyu offers a rich environment for this microanalysis. Due to its transitional location from rural to urban area, Shuangyu has experienced a combination of both formal and informal development, which have greatly influenced the morphologies and spatial image of Shuangyu.

On the one hand, within Shuangyu, migrant settlements show different spatial features in terms of migrant housing and activity space. The majority of migrants rent room from private party in VICs. The demand of cheap housing from the migrants and motivation of higher income from the housing rent impelled the illegal/informal constructions or division of the rooms in the VICs. Due to a juridical ambiguity regarding housing, lack of settlement planning control, and an unregulated rental market, VICs are often regarded as informal settlements. The informality of 
VICs are often considered as eyesore in urban governance. However, they also have become distinctive migrant settlements that migrants are not willing to see them to get torn down. Compare to local residents, migrants are usually have a narrower zone of activity space, which mostly within the neighborhood. Informal practices such as temporary market, vending, motorcycle taxi have become distinctive features of migrant settlements. Meanwhile, informal governance are also imposed over informal practices such as informal fines, fees and bribes are paid, blind eyes are turned.

On the other hand, although spatially aggregated in the similar part of the city-urban fringe, Shuangyu as migrant settlement in Wenzhou has been found to have different connections with other parts of the city in comparison to some megacities. Firstly, the colocation of housing and employment within Shuangyu restricts migrants to spend most time within Shuangyu. It is different from some findings about Beijing, where migrants who usually live in the villages between 4th and 5th ring roads while commute to either city center for service jobs or outer suburbs for manufacturing jobs. These daily connections makes migrant settlements more fluid and have more impacts on urban public services such as transportation. Secondly, the perimeter of migrants' daily life is limited within Shuangyu based on their consumption preference and leisure activities. They usually do not spend much money on shopping but if they have to, they prefer going shopping in some places near where they live rather than shopping centers in the city center. Their leisure activities are also very simple mostly take place inside the apartment by watching TV or sleep or within the neighborhood. Last but not the least, The survey also reveals migrants' social network and its spatial perimeter are pretty much limited to migrants in Shuangyu, who are mostly work mates, people from the 
same origin and relatives. Little connection has been built up between migrants and local residents.

In conclusion, migrant settlements and service structures in Shuangyu have been developed which enable the migrants to have relatively little contact with the central city businesses and remain closed and static in relation to the other parts of city. Shuangyu can be considered as an independent sub-assemblage within a larger city assemblage or "city within the city", rather than a part of urban assemblage. Also, we can see that rather than imbedding inside the mainstream society, the migrants' social space is in the marginal region of the city.

However, Shuangyu as a whole is rather fluid and mobile. For example, the loose/informal regulations on the job and housing markets allow migrants to change jobs and move easily. Most of those migrant workers in Wenzhou do not have official contracts with the factories. This system, in certain circumstances, imposes few restrictions on both migrants and employers. Migrants can leave and seek higher-paying jobs without legal repercussions.

Employers can also let the migrant workers go when their products are in the off-season. This spontaneous approach keep the migrant settlements simultaneously mobile, while also static since most of migrants usually just switch jobs to a different factory in Shuangyu due to their limited skills and mobility. To conclude, spatially close while socially distinct and segregated, Shuangyu as a migrant settlement could be considered closed/open, static/mobile, formal/informal at the same time in reference to their relationships to the other parts of city.

\subsection{Policy implications}

This dissertation has some implications for policy makers. Firstly, as we all know, due to the concentration of low-income residents, a lack of basic facilities and infrastructures, 
unsanitary environments, and high rates of crime, city managers and planners perceive VIC as an eyesore or nuisance. They attempt to eliminate this informality or "non-state space" to create more governable spaces through formal land and infrastructure development. Therefore, the 'demolish and redevelop' approach to VIC has become a common strategy to build a so-called 'civilized and harmonized' urban space in Chinese cities. However, this study reveals that VIC provides inexpensive housing which enabled low-income migrants to overcome rural-urban biased housing policy and settle in cities. Even with many complains about the dirty environment, limited space and facilities, crime and unsafety of the VICs, migrants are not willing to see the VICs get torn down and pay more rental fees for a better apartment. In fact, due to the existence of these informal housing, the government does not need to take the responsibility for migrants' housing, while allow them to take advantage of cheap and flexible rural labor. As such, government's current strategy for migrant settlements--"demolish and redevelop" may result in either increasing cost to accommodate/relocate the rural migrants or forcing migrants to leave the city. As such, the government may need to be careful about the impact of VIC redevelopment policy. Rather than "demolish and redevelop", the government may think about making efforts to legalize and upgrade the existing informal migrant settlements by improving the environment, providing more resources and better services.

Secondly, dismantling the "two-tier class system" or reform of the hukou system has been one of the state's priorities. Many scholars and publics also blame the hukou system as the main reason creating the disparity between rural migrants and local urbanites. However, while having an urban hukou might be important for those migrants, such as young graduates, skilled workers who are willing to settle down in the city; the laborers who are the majority among the migrants in China care more about the income they can get in the city. As the dissertation 
reveals the migrant settlements in Wenzhou have resulted in a "city within the city" spatial structure, which is mostly due to the social mobility of migrants. Their purpose for being in the city is for economic reasons rather than becoming urbanites. Therefore, work or how much they could earn is more important than whether they are accessible to urban housing or even the welfare system. For these type of migrant settlements, it is more important to improve their working environment and create a fair salary system for them rather than granting them a local hukou.

\subsection{Limitations of the study and suggestions for future research}

This dissertation uses Wenzhou as a case study, attempting to understand how migration and migrant settlement patterns in a third-tier city might be distinct from those in megacities. However, just as I argued at the beginning, "...the persistence of significant urban and regional contrasts ensure that certain phenomena [such as migrant settlements] are not generalizable across cities" in China. Wenzhou with its distinctive historical development pattern, may have little representativeness of all the third-tier cities. As such, this study is rather used as an example to encourage more people to study cities of different scales, which is important and have the potential to enrich studies of migrant settlement. Meanwhile, in order to narrow the scope of the dissertation, I limit this comparison to Beijing and Guangzhou as exemplars of different patterns of migrant settlement. In future work, it would also be useful to place Shanghai and Shenzhen within this comparison.

Another limitation is the data availability of Wenzhou city. Compare to conducting research on the well-known megacities, one of the difficulties is to obtain accountable data sets. When discussing the relation of migration and Wenzhou's spatial development, this dissertation 
only uses census data of the migrant population without mentioning the changing pattern of local residents. The failure of providing the data about the local residents may result in lacking the big picture of population movement.

Last but not the least, given that many factors have influenced the spatial structure of the city, such as land use, industry structure, infrastructure, this study only focuses on migration as the major influence on the urban form. In the future research, I will study how these factors have impacted on the migration process and the formation of urban spatial structure. 


\begin{abstract}
APPENDIX I
QUESTIONNAIRE SURVEY IN MIGRANT SETTLEMENTS IN SHUANGYU, WENZHOU (ENGLISH

VERSION)
\end{abstract}

Gender

Origin

(County/City/Province)

\title{
SECTION A: Background Information
}

A1 How old are you?
1. $<16$
2. $16-25$
3. 26-35
4. $36-45 \quad 5.46-60$
6. $>60$

A2 What is your hukou status (Household registration system)

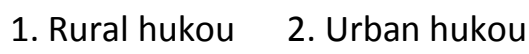

A3 What is your current marital status?

1. Single 2. Married 3. Divorced, Widow or widower

A4 If you're married, did your spouse also come to Wenzhou?

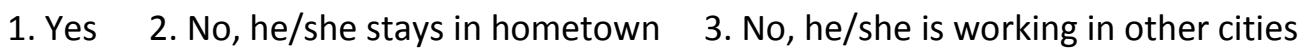
A5 Did you bring your children to Wenzhou, if applicable?

1. Yes, they go to school in Wenzhou 2.Yes, but they're too young for school. 3. Yes, they are working in Wenzhou 4. No, they go to school/stay at home in hometown 5. No, they go to work in hometown $\quad 6$. No, they go to work in other cities

A6 What is your highest education level?
1. College and Up
2. Post-secondary school
3. Senior high school or technical

school
4. Middle school
5. Primary and under

A7 How long have you been staying in Wenzhou?

1. Less than half a year 2. Half a year to one year 3 . One to two years 4 . Two to five

years 5. More than five years

A8 Do you plan to stay in Wenzhou in the future

1. Yes 2. No, if there is any good job opportunity, l'll move back to my hometown 3 . No, I plan to find a job in other cities 4. Haven't thought about it 
A9 Have you returned to your hometown since you came to Wenzhou?

1. Yes, a couple times when the job here is not busy $\quad$ 2. Yes, during the Chinese New Year 3. Never

A10 What are the most important things you are concerned about in Wenzhou? (choose any if apply)
1. Salary
2. Living cost
3. Job opportunities
4. Leisure
5. Safety
6. Living

environment 7. Children's education

8. Health and social welfare

9. Other

A11 Are there lots of migrants from your hometown in Wenzhou?

$\begin{array}{lll}\text { 1. Yes, a lot } & \text { 2. No, not too many } \quad 3 \text {. Not sure about it }\end{array}$

\section{SECTION B: Information about Work and Living Conditions in Wenzhou}

B1 What is your current job?

1. Factory worker 2. Self-employed or business owner, such owning a restaurant, grocery shops 3. Taxi or Moto driver 4. Construction worker 5. Manager level worker in the factories and company $\quad 6$. Work in service sectors such as baby sitter, house cleaner and waiter 7. Vendor, or owning a stall in the night market 8 . Unemployed 9. Other:

B2 How do you go to work every day?

1. Bus 2. Shared mini-bus/van 3. Bicycle 4. Walk 5. Taxi 6. Private car 7. Motorcycle 8.0ther

B3 How long does it take to travel to your work place?

1. Less than 5 mins $\quad 2.5-10$ mins $\quad 3.10-30$ mins 4 . More than 30 mins

B4 What is your current wage per month on average? (By RMB)

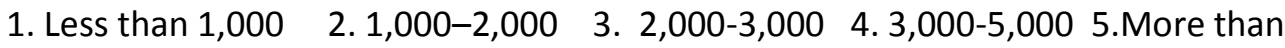
5,000

B5 Do you have a long-term contract with a company or do you work on a daily basis?

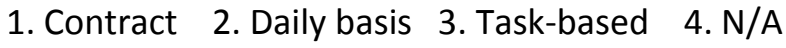

B6 How long do you usually work per day? 

1. Less than 6 hours
2. 6-8 hours
3. 8-10 hours
4. More than 10 hours

B7 If you have had other jobs in Wenzhou before, about how many?
1. More than 3
2. $2-3$
3. 1
4. None

B8 Where do you stay in Wenzhou?

1. Apartment I bought 2. A rented apartment, alone 3 . Sharing a rented apartment with others 4. Company dormitory 5. Other

B9 How many people are sharing your room?
1. More than 5
2. 3-5
3. 1- 2
4. I live alone

B10 How big is it?
1. $<5$ sq meters
2. 5-10 sq meters
3. $10-20$ sq meters
4.More than $20 \mathrm{sq}$

meters

B11 How much rent do you share per month? (By RMB)
1. free, provided by companies
2.Less than 150
2. $150-300$
3. $300-500$
4. More than 500

B12 What basic facilities do you have in your apartment?

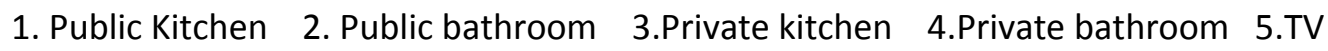

\section{Fan 7. Air-conditioner 8. Computer/Internet 9. Radio}

B13 On a scale of 1-5 with 1 being "very unsatisfied", how satisfied are you with current living condition ? (Check the number)

1. 2. 3. 4. 5.

B14 If not satisfied, why?

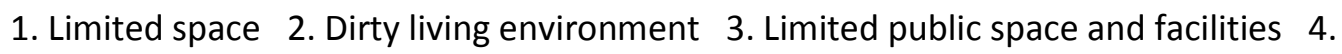
Crime and unsafe 5. High cost 6. Other:

B15 What do you think about redevelopment of urban villages?

1. Great! Tear down all the houses, and build new urban apartments. 2. Yes. It's already too crowded, better to tear down some of the old houses. 3. It's Ok, but better to 
clean up the environment $\quad$ 4. Allow villagers to expand their houses 5. It's good enough, doesn't need any redevelopment

B16 If the urban village where you live gets torn down for redevelopment, where will you move to?

1. Will try to find another urban village nearby because it's close to your working place 2. Find some other apartment in city even if it is expensive. 3. Move to further place to same money 4.Other:

\section{SECTION C: Connections to the other parts of Wenzhou}

C1 What do you usually do in your spare time?

1. Play chess, Mahjong and poker with friends $\quad 2$. Watch TV at home 3 . Sleep 4. Walk or work out in the parks nearby 5 . Shopping 6 . Surf on line 7 . Rest and enjoy the sunshine outside 8 . Not too much spare time 9 . Work at a second job 10 . Go to the library nearby 10.. Other:

C2 Who do you usually connect with?

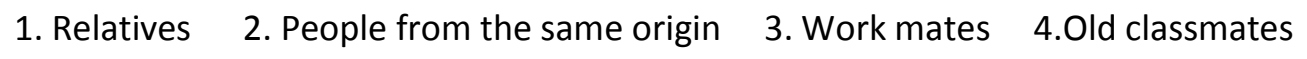

5. Local people 6. Landlords $\quad$ 7. Boss $\quad$ 8.Emloyees 9. Don't usually hang out with anyone

C3 Do you ever go to other migrant settlements? If so, what do you do there?

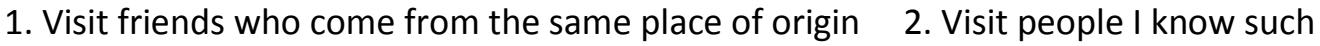
as work mates 3. Just for a walk 4. Shopping, restaurants or other activities 5 . Seldom go C4 Where do you usually go shopping for daily items, such as food

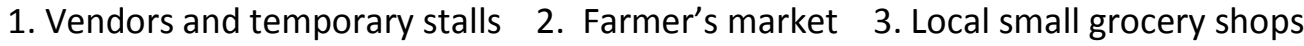
and small supermarket nearby $\quad$ 4. Big supermarket such as Walmart not very close by 5 . Others

C5 Where do you usually go shopping for special things, such as clothes, shoes, mobile phone, gifts for friends and family, etc

1. Night market or stalls 2 . Shops and stores nearby 3 . Whole sales centers near train station 4. Commercial streets 5. Fancy shopping malls 6. Others 
C6 Which of the following places have you been to for shopping? (choose any if apply)

1. Wuma street

2. Shamao He street

3. Kaitai

4. Yintai

5. Times Square shopping center 6 Danlu Square in Ouzhou Cheng

7. Other:

C7 Where do you usually go to if you get sick?

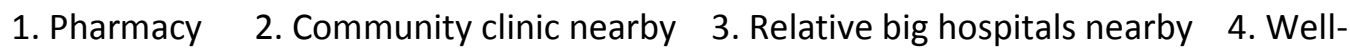
known hospitals in the city center because they're more reliable 4. Haven't been sick in Wenzhou

C8 How many times do you go to city center in a month?
1. Almost none
2. Less than 3 times
3. 3-5 times
4. More than 5 times

C9 How do you usually get there?
1. Bus
2. Mini-bus
3. Taxi
4. Drive private car
5. Motorcycle 6 .

Others

C10 What do you usually do when you go to city center?

1. Shopping 2. For entertainment, such as sing Karaoke, go to movie, hang out with friends 3. Go to see doctor in hospital 4. Administrative business, such as get a temporary living certificate 5 . Shopping goods for their business, such as grocery shop

C11 Which of the following places have you been to? (Choose any if apply)

1. Jiangxin Island

2. Wenzhou Amusement Park

3. Jinshan Forest Park

4. Zhongshan Park

5. Wuma historical Site

6. Binjiang Park

7. Bailu or other Cinemas

8. $21^{\text {st }}$ Century Park

9. Wenzhou's Library

10. Science Museum

11. KTV 12. Others

C12 What are the biggest changes in Shuangyu during the past feel years?? 
C13. What do you think Shuangyu as a living and working place still need to approve? 


\begin{abstract}
APPENDIX II
QUESTIONNAIRE SURVEY IN MIGRANT SETTLEMENTS IN SHUANGYU, WENZHOU (CHINESE

VERSION)

访谈问卷（新居民版本）

（本问卷为匿名形式，个人信息绝对保密）

性别

户籍

（县/市/省）

\section{$\mathrm{A}$ 新居民基本情况}

A1 您的年龄?
1. $<18$
2. $18-25$
3. 26-35
4. $36-45$
5. $46-60$
6. $>60$

A2 您的户口是?

1. 农村户口 2. 城市居民户口

A3 您的婚姻状况是?

1. 未婚 2. 已婚 3. 离异、丧偶

A4 假如您结婚了, 您的妻子/丈夫也在温州么?

1. 是的, 一起在温州 2. 不是, 他/她在老家 3. 不是, 他/她在别的城市

A5 假如您结婚了并有孩子的话，孩子也在温州么？

1. 是的, 他们在温州上学 2. 是的, 他们在温州, 但还小没上学

3. 是的, 他们在温州工作 4. 没有, 他们在老家上学/家里 5. 没有, 他们在老家工作

6. 没有, 他们在其他城市上学/打工

A6 您的文化程度?

1. 小学及以下 2 . 初中 3 . 高中、中专 4 . 大专 5 . 大学本科及以上

A7 您在温州多久了?

1. 不到半年 2. 半年到1年 $3.1-2$ 年 $\quad 4.2-5$ 年 5.5 年以上

A8 准备一直在温州待下去么?

1. 是的 2 . 不是, 有机会就回老家找工作 3 . 不是, 有机会就去其他地方找工作

4. 不清楚

A9 您来温州后, 回过老家么?

1. 从来没回过 2 . 过年的时候就回 3. 不忙没活的时候就回老家 
A10 您最关注以下哪些问题?

1. 工资待遇 2. 生活成本 3. 就业情况 4. 业余生活 5. 治安状况 6. 居住环境 7. 子女入学 8. 医疗和社会保障 9. 居住地落户 10 . 其他

A11 据您所知, 有很多老乡在温州工作么?
1. 是的, 很多
2. 没有很多
3. 不太清楚

\section{$\mathrm{B}$ 新居民工作和生活在温州}

B1 您目前从事什么工作？（如果您同时有以下不同职业的话，请都勾选）

1. 工厂打工 2. 个体户老板, 如开餐馆、商店等 3. 开摩的或者出租车
4. 建筑工人
5. 工厂中层干部、管理人员
6. 保姆、清洁工、服务员等服务人员

7. 摆摊子, 如夜市等

8. 待业

9. 其他

B2 您每天上下班的主要交通方式?
1. 公交
2. 工厂的班车
3. 自行车
4. 步行
5. 打车
6. 私家车
7. 坐摩的

8. 其他

B3 到达工作地点大概所需要的时间是?
1.5分钟以内
2. 5-10分钟
3. 小于 30 分钟
4. 大于 30 分钟

B4 您的月工资收入大概有多少?
1. $<1000$
2. $1000-2000$
3. $2000-3000$
4. $3000-5000$
5. $>5000$

B5 您是否有签用劳动合同?
1. 有正式合同
2. 没有，按天算
3. 计件
4. 给自己打工

B6 您一天工作多长时间?
1.6小时以下
2. $6-8$ 小时
3. 8-10小时
4. 10 小时以辺

B7您第一次来到双屿后有换过工作么?（包括换厂）
1. $>3$ 个
2. $2-3$ 个
3. 1 个
4. 从来没有

B8 您现在住的房子是自己买的还是租的?
1. 自己买的
2. 单独租的
3. 与他人合租的
4. 单位宿舍
5. 其他

B9 您住的房子几个人住?
1. $>5$
2. $3-5$ 个
3. 1-2个
4. 就我一个人住

B10 您住的房子大概有多大? 

1. 〈5平方米 2.5-10平方米
3. 10-20平方米
4. $>20$ 平方米

B11 平均每人一个月的租金是多少元?
1. 单位免费提供
2. $<150$
3. $150-300$
4. $300-500$
5. $>500$

B12 您居住房子的基本设施有
1. 公共暦房
2. 公共卫生间
3. 独立厨房
4. 独立卫生间
5. 电视
6. 电风扇

7. 空调

8. 网络/电脑

9. 广播收音机

10. 冰箱 11 . 其他

$\mathrm{B} 13$ 您是对目前的居住状况满意吗? 用15 来打分, 1 表示非常满意, 5 表示非常不满意
1. 非常满意
2. 满意
3. 比较满意
4. 不太满意
5. 非常不满意

B14 如果觉得不太满意, 主要是哪些原因:

1. 居住空间太小 2. 脏, 垃圾随意堆放, 污水横流

3. 周围公共服务设施太少, 如缺少公园 4. 不安全 5. 房租太贵

6. 其他

B15 您对城中村改造怎么看?

1. 现在挺好, 不用改造 2 . 允许村民多建房, 有更多房子可以出租 3. 控制或者减少建筑量, 现在房子太密了 4. 现有基础上改善环境为主 5. 推倒，建成城市公寓

B16 如果您所在的城中村被拆除, 改为城市公寓, 那么对您的生活

1. 仍然设法住在工作附近，搬到附近其他的城中村

2. 在城里找民宅住, 租金贵些无所谓 3. 打算搬到更远的地方住, 省钱最重要 4. 其他

\section{C 新居民与城市的空间关系}

C1 您平时休息的主要方式和场所

1. 下棋、麻将、打牌等 2. 在家看电视 3. 睡觉 4. 去附近的公园散步或锻炼
5. 逛街
6. 上网
7. 纳凉、晒太阳
8. 基本没有休息时间
9. 打第二份工

10. 去附近的图书馆看书 11. 其他

C2 您平时都和谁交往? 

1. 基本不和别人交往
2. 亲戚
3. 同乡
4. 工友
5. 同学
6. 本地人 7. 房东

8. 上司 9. 员工 10 . 其他

C3 您平时去其他村么?

1. 几乎不走动 2. 是的, 去找老乡玩 3. 是的, 去找工作伙伴玩

4. 是的, 随意溜达溜达 5. 去逛街、买东西

C4 您一般都去哪里买日用品？

1. 去推车、夜市买 2. 集市、农贸市场 3. 附近的小商店和超市

4. 宁可去远点的大型超市 5. 其他

C5 您一般都去哪里购物, 像是买衣服, 给家人的礼物之类的东西?

1. 夜市 2. 附近的商店 3. 去批发中心, 比如火车站附近 4. 商业街, 如五马街 5. 大型的购物商场，开太，银泰之类的 6. 其他

C6 您去过以下的这些地方购物么? 去买过东西的请打勾

1. 五马街 2. 纱帽河 3. 开太百货

4 . 银泰百货 5 . 时代广场 6 . 欧洲城的丹璐广场

7 . 其他

C7 假如您生病的话您会去哪里看病?

1. 就直接去药店买药 2. 附近社区的诊所 3. 附近稍大点的医院

4. 一定要去市中心的大医院 5. 在温州几乎没生病, 基本没去过

C8 您每个月大概会去几次市中心?

1. 基本不去 $2 .<3$ 次 3.3 - 5 次 $4 .>5$ 次

C9 您一般都是怎么去的?
1. 公交
2. 公司班车
3. 打的
4. 自驾车
5. 摩的
6. 其他

C10 您一般去市中心都是做什么?

1. 逛街购物 2. 娱乐消遣, 比如唱 $\mathrm{k}$, 看朋友 3. 医院看病

4. 行政事务, 比如办证 5 . 进货 6 . 其他

C11 您去过下面的哪些地方? (勾选所有去过的)

1. 江心屿

2. 温州乐园 3 景山公园 
4. 中山公园 5. 五马街

6. 滨江公园

7. 白鹭等其他电影院

8. 新政府大楼 21 世纪公园

9. 温州图书馆 10. 科技馆

11. 任何KTV

12. 其他

C12 您觉得双屿这边近几年来最大的变化是什么?

C13

您觉得双屿最需要改进的地方是什么? 


\section{APPENDIX III \\ IN-DEPTH INTERVIEW QUESTIONS (ENGLISH VERSION)}

Interviews will consist of open-ended questions (in addition to the basic questionnaire)

1. Tell me something about yourself (Where are you from? What is your job? Where do you live? etc.)

2. Why did you come to Wenzhou rather than another city?

3. How did you find a place to live when you first came to Wenzhou? Are you still living in the same place?

4. What do you usually do in your spare time?

5. Do you think the infrastructure, public services, and urban amenities around this place are enough to support a comfortable life? If not, why? What need to be improved?

6. Have you ever travelled to the other parts of Wenzhou? What do you usually do there?

7. What do you know about Wenzhou? Do you know how may urban districts in Wenzhou city? Where's the location of the city government building?

8. Which is your favorite place in Wenzhou?

9. How do you like Wenzhou in terms of work and living? Why?

10. Do you have any friends who are NOT migrants? Do you feel like Wenzhou is your home now? Have you ever thought about owning an apartment in Wenzhou?

11. Compare to your hometown with Wenzhou, what is the biggest difference you could think?

12. Have you ever joined any association or organization? Such as Townsmen Association (Tongxianghui) 
13. Have you ever participated in any activities that were held by the community? What were they? Do you think those activities enrich your life?

14. If you could change one thing in Wenzhou, what would it be?

15. Do you think Wenzhou's changing? How?

16. Where do you expect to be living/working five years from now? 


\section{APPENDIX IV}

\section{IN-DEPTH INTERVIEW QUESTIONS (CHINESE VERSION)}

\section{访谈调查问题}

访谈除了要填写问卷外, 还有一些开放性的问题组成, 如下:

1. 请简单介绍下你的情况, 比如你来自哪里, 做什么工作, 住在哪里等等

2. 你为什么选择来温州工作而不是其他城市?

3. 你第一次来温州的时候是怎么找到住的地方的？现在还住在老地方么?

4. 不上班闲的时候你一般都去哪里做些什么?

5. 你觉得你现在住的地方周边的公共服务设施足够么? 比如说公园啊, 医院啊, 公交车等。如果不够的话, 你觉得什么地方还需要改进?

6. 你有去过温州的其他地方么? 去那里一般都是做什么?

7. 你觉得你对了解温州么? 比如你知道温州有几个区么? 市政府在哪个区呢?

8. 在温州去过的地方里面, 你最喜欢什么地方?

9. 你喜欢你在温州的工作和生活么? 为什么?

10. 你认识任何的本地人么? 你觉得在温州有归属感么? 有把温州当成第二个家 么? 你有想过在温州买房, 成为温州人么?

11. 跟你老家相比, 你觉得温州最大的不一样是什么?

12. 你有参加过任何组织么? 比如老乡会、同乡会、工会等等。你认为这些组织怎 么样?

13. 你有参加过任何社区或者工厂组织的活动么? 都是些什么活动? 你认为这些 活动怎样?

14. 你觉得温州有什么变化么? 主要体现在哪些方面。 
15. 如果你可以改变温州的一点, 你会选择改变什么?

16. 5 年以后，你希望你能够在哪里生活? 


\section{BIBLIOGRAPHY}

Amin, A., \& Thrift, N. (2002). Cities: Reimagining the Urban. Oxford: Wiley-Blackwell.

Anderson, B., \& McFarlane, C. (2011). Assemblage and Geography. Area, 43(2), 124-127.

Bhattachary, P. C. (1993). Rural-urban Migration in Economic Development. Journal of Economic Surveys, 7(3), 39.

BJMBS. (2011). The Sixth National Population Census of Beijing. Beijing: Beijing Statistical Information Net Retrieved from

http://www.bjstats.gov.cn/rkpc_6/pcsj/201105/t20110506_201580.htm.

Bolt, G., Burgers, J., \& Kempen, R. v. (1998). On the Social Significance of Spatial Location; Spatial Segregation and Social Inclusion. Journal of Housing and the Built Environment, 13(1), 83-95.

Brenner, N., Madden, D. J., \& Wachsmuth, D. (2011). Assemblage urbanism and the challenges of critical urban theory. City, 15(2), 225-240. doi: 10.1080/13604813.2011.568717

Brown, J. C. (1972). Patterns of Intraurban Settlement in Mexico City: An Examination of Turner Theory. Dissertation series, Cornell University.

Burgess, E. W. (1924). The growth of the City: An Introduction to a Research Project. Publications of the American Sociological Society, 18, 85-97.

C.Beauchemin, \& P.Bocquier. (2004). Migration and Urbanization in Francophone West Africa. Urban Studies, 41(11), 2245-2272.

Castells, M. (1996). The Rise of the Network Society Oxford, UK \& Malden, MA, USA: WileyBlackwell.

Chan, K. W. (2011). China, Internal Migration. In I. Ness \& P. Bellwood (Eds.), The Encyclopedia of Global Migration: Blackwell publishing.

Chan, K. W., \& Zhang, L. (1999). The Hukou System and Rural-Urban Migration in China: Processes and Changes. The China Quarterly(160), 818-855.

Chang, L. T. (2009). Factory Girls: From Village to City in a Changing China. New York: The Random House, Inc.

Chen, S., \& Ma, B. (2007). Wenzhou Business Association: the Analysis of Its Autonomy-Case Study of Wenzhou Apparel Business Association, 2013

CITYRE. (2013). The Top List of Cities in Real Estate Price 2013, from http://www.cityre.cn/ 
Conway, D., \& Brown, J. (1980). Intraurban Relocation and Structure: Low-Income Migrants in Latin America and the Caribbean. Latin American Research Review, 15(3), 95-125. doi: $10.2307 / 2502993$

DeLanda, M. (2006). A New Philosophy of Society: Assemblage Theory and Social Complexity. New York: Continuum.

Deleuze, G., \& Guattari, F. (1987). A Thousand Plateaus. Minneapolis: University of Minnesota Press.

Dovey, K. (2012). Informal urbanism and complex adaptive assemblage. International Development Planning Review, 34(4), 349-368. doi: 10.3828/idpr.2012.23

Edensor, T., \& Jayne, M. (Eds.). (2011). Urban Theory Beyond the West: A World of Cities. London: Routledge.

Fainstein, S., \& Gorden, I. (1992). Divided Cities: New York and London in the Contemporary World. Oxford, UK: Blackwell.

Fan, C. (2003). Rural-Urban Migration and Gender Division of Labor in Transitional China. International Journal of Urban and Regional Research, 27(1), 24-47.

Fan, C. (2008). China on the Move: Migration, the State and the Household. London and New York: Routledge.

Fan, Y., Allen, R., \& Sun, T. (2014). Spatial mismatch in Beijing, China: Implications of job accessibility for Chinese low-wage workers. Habitat International, 44(0), 202-210. doi: http://dx.doi.org/10.1016/j.habitatint.2014.06.002

Feng, W., Zuo, X., \& Ruan, D. (2002). Rural Migrants in Shanghai: Living under the Shadow of Socialism. International Migration Review, 36(2), 520-545. doi: 10.2307/4149463

Ford, L. R. (1996). A New and Improved Model of Latin American City Structure. Geographical Review, 86(3), 437-440. doi: 10.2307/215506

Forster, K. (1990). The Wenzhou Model for Economic Development: Impressions. China Information, 5(3), 53-64.

Gaubatz, P. (1998). Understanding Chinese Urban Form: Contexts for Interpreting Continuity and Change. Built Environment, 24, 251-269.

Goodkind, D. (2002). China's Floating Population: Definitions, Data and Recent Findings Urban Studies, 39(12), 2237-2250.

Gu, C., \& Shen, J. (2003a). Transformation of Urban Socio-Spatial Structure in Socialist Market Economics: the Case of Beijing. Habitat International, 27(1), 107-122. 
Gu, C., \& Shen, J. (2003b). Transformation of urban socio-spatial structure in socialist market economies: the case of Beijing. Habitat International, 27(1), 107-122. doi: http://dx.doi.org/10.1016/S0197-3975(02)00038-3

GZMBS. (2011). The Sixth National Population Census of Guangzhou. Guangzhou: Guangzhou Municipal Government.

Harvey, D. (1990). Between Space and Time: Reflections on the Geographical Imagination1. Annals of the Association of American Geographers, 80(3), 418-434. doi: 10.1111/j.14678306.1990.tb00305.x

Hay, I. (Ed.). (2010). Qualitative Research Methods in Human Geography (Third ed.). Canada: Oxford University Press

He, S. (2014). Consuming Urban Living in 'Villages in the City': Studentification in Guangzhou, China. Urban Studies.

Holm, A., \& Kuhn, A. (2011). Squatting and Urban Renewal: The Interaction of Squatter Movements and Strategies of Urban Restructuring in Berlin. International Journal of Urban and Regional Research, 35(3), 644-658. doi: 10.1111/j.1468-2427.2010.001009.x

Hu, Z. (1987). The Characterristics and Geographical Background of Wenzhou Model. [Wenzhou Moshi de Tezheng yu Dili Beijing]. Economic Geography, 7(1), 5.

Huchzermeyer, M. (2003). A legacy of control? The capital subsidy for housing, and informal settlement intervention in South Africa. International Journal of Urban and Regional Research, 27(3), 591-612. doi: 10.1111/1468-2427.00468

Jacobs, A. (2010). China's Army of Graduates Struggles for Jobs, The New York Times.

Jacobs, J. (1992). The Death and Life of Great American Cities. New York: Vintage.

Jacobs, J. M. (2012). Urban Geographies I: Still Thinking Cities Relationally. Progress in Human Geography, 36(3), 412-422.

Jiang, L., \& Wu, F. (2014). Guangzhou Non-registered Population Spatial Distribution and Impact on Poloycentricity Spatial Structure. [2000-2010 nian guangzhou wailai renkou kongjian fenbu biandong yu dui duo zhongxin chengshi kongjian jiegou yingxiang yanjiu]. Modern Urban Research, 5.

Kirsch, S. (1995). The incredible shrinking world? Technology and the production of space. Environment and Planning D: Society and Space, 13(5), 529-555.

Knight, J., Deng, Q., \& Li, S. (2011). The puzzle of migrant labour shortage and rural labour surplus in China. China Economic Review, 22(4), 585-600. doi:

10.1016/j.chieco.2011.01.006 
Lefebvre, H. (2003 [1970]). The Urban Revolution. Minnesota: University of Minnesota Press.

Li, P. (2002). Tremendous Changes: The End of Villages-A Study of Villages in the Center of Guangzhou City. [Jubian: Cunluo de zhongjie--Dushili de cunzhuang yanjiu]. Social Sciences in China(01), 168-179.

Li, S. (2004). Residential Mobility and Urban Change in China. In L. J. C. Ma \& F. Wu (Eds.), Restructuring the Chinese City: Changing Society, Economy and Space (pp. 157-170). New York: Routledge.

Lian, S. (2009). Ant Tribe. Guangxi, China: Guangxi Normal Univeristy.

Liao, B., \& Wong, D. W. (2014). Changing urban residential patterns of Chinese migrants: Shanghai, 2000-2010. Urban Geography, 1-18. doi: 10.1080/02723638.2014.988058

Lin, Y., De Meulder, B., Cai, X., Hu, H., \& Lai, Y. (2014). Linking social housing provision for rural migrants with the redevelopment of 'villages in the city': A case study of Beijing. Cities, 40, Part A(0), 111-119. doi: http://dx.doi.org/10.1016/j.cities.2014.03.011

Liu, A. P. L. (1992). The "Wenzhou Model" of Development and China's Modernization. Asian Survey, 32, 696-711.

Liu, H., \& Gu, C. (1999). Beijing liudong renkou juluo de xingtai,jiegou yu gongneng. [The Floating Population Concentration Areas in Beijing: Patterns, Structure and Functions]. Scientia Geographica Sinica, 19(6), 497-503.

Liu, T., Qi, Y., Cao, G., \& Liu, H. (2015). Spatial patterns, driving forces, and urbanization effects of China's internal migration: County-level analysis based on the 2000 and 2010 censuses. Journal of Geographical Sciences, 25(2), 236-256. doi: 10.1007/s11442-015$1165-z$

Liu, X., \& Liang, W. (1997). Zhejiangcun: social and spatial implications of informal urbanization on the periphery of Beijing. Cities, 14(2), 95-108. doi: http://dx.doi.org/10.1016/S02642751(96)00047-9

Liu, Y., He, S., Wu, F., \& Webster, C. (2010). Urban villages under China's rapid urbanization: Unregulated assets and transitional neighbourhoods. Habitat International, 34(2), 135144. doi: http://dx.doi.org/10.1016/j.habitatint.2009.08.003

Liu, Y., Li, Z., \& Breitung, W. (2012). The social networks of new-generation migrants in China's urbanized villages: A case study of Guangzhou. Habitat International, 36(1), 192-200. doi: http://dx.doi.org/10.1016/j.habitatint.2011.08.008

Liu, Y., Li, Z., Liu, Y., \& Chen, H. (2014). Growth of rural migrant enclaves in Guangzhou, China: Agency, everyday practice and social mobility. Urban Studies. doi: $10.1177 / 0042098014553752$ 
Logan, J. R., Zhang, W., \& Alba, R. D. (2002). Immigrant Enclaves and Ethnic Communities in New York and Los Angeles. American Sociological Review, 67(2), 299-322. doi:

$10.2307 / 3088897$

Longhurst, R. (2010). Semi-structured Interviews and Focus Groups. London: SAGE.

Lu, J. (2008). The Experimental Field of Private Economy: Wenzhou. Beijing, China: China Youth Publishing Group.

Ma, L. J. C., \& Xiang, B. (1998). Native Place, Migration and the Emergence of Peasant Enclaves in Beijing. The China Quarterly(155), 546-581. doi: 10.2307/655950

Marcuse, P., \& Kempen, R. v. (Eds.). (2002). Of States and Cities: The Partitioning of Urban Space. Oxford: Oxford University Press.

Marukawa, T. (2009). The Emergence of Industrial Clusters in Wenzhou, China Asian Industrial Clusters, Global Competitiveness and New Policy Initiatives (pp. 213-237). Singapore: World Scientific.

Marx, K. (1973). Grundisse. London: Penguin Group.

Maslow, A. (1955). Deficiency motivation and growth motivation Nebraska symposium on motivation: 1955 (pp. 1-30). Lincoln, NE, US: University of Nebraska Press.

McFarlane, C. (2011a). Assemblage and critical urbanism. City, 15(2), 204-224. doi: $10.1080 / 13604813.2011 .568715$

McFarlane, C. (2011b). The city as assemblage: dwelling and urban space. Environment and Planning D: Society and Space, 29(4), 649-671.

McFarlane, C., \& Anderson, B. (2011). Thinking with assemblage. Area, 43(2), 162-164. doi: 10.1111/j.1475-4762.2011.01012.x

McGee, T. (1979). Conservation and Dissolution in the Third World City: The 'Shanty Town' as an Element of Conservation. Development and Change, 10(1), 1-22. doi: 10.1111/j.14677660.1979.tb00028.x

McGee, T. G. (1967). The Southeast Asian City: A Social Geography of the Primate Cities of Southeast Asia. London: Bell.

Meyerson, F. A. B., Merino, L., \& Durand, J. (2007). Migration and Environment in the Context of Globalization. Frontiers in Ecology and the Environment, 5(4), 182-190.

Minnery, J., Argo, T., Winarso, H., Hau, D., Veneracion, C. C., Forbes, D., \& Childs, I. (2013). Slum upgrading and urban governance: Case studies in three South East Asian cities. Habitat International, 39(0), 162-169. doi: http://dx.doi.org/10.1016/j.habitatint.2012.12.002 
Mirror, T. G. (2007). Notes on the Geography of China: Wenzhou Retrieved July 28th, 2015

Mobrand, E. (2006). Politics of Cityward Migration: An Overview of China in Comparative Perspective. Habitat International, 30, 261-274.

Mollenkopf, J. H., \& Castells, M. (1992). Dual City: Restructuring New York. New York: Russell Sage Foundation.

NBSC. (2013). Statistical Communiqué of the People's Republic of China on the 2012 National Economic and Social Development. (1). Beijing: National Bureau of Statistics Retrieved from http://www.stats.gov.cn/english/newsandcomingevents/t20130222_402874607.htm.

Nolan, P., \& Dong, F. R. (Eds.). (1989). Market Forces in China: Competition and Small BusinessThe Wenzhou Debate. London: Zed Books.

Office, L. C. E. C. (Ed.). (2011). Lucheng Nianjian. Beijing: Fangzhi.

Parris, K. (1993). Local Initiative and National Reform. China Quaterly, 134, 242-263.

Parris, K. (1993). Local Initiative and National Reform: The Wenzhou Model of Development. The China Quarterly, 134, 242-263. doi: doi:10.1017/S0305741000029672

Portes, A., \& Bach, R. L. (1985). Latin journey: Cuban and Mexican immigrants in the United States. Berkeley: University of California Press.

Qian, Q., \& Chen, Y. (2003). Study Over Transient Population Settlement In Megapolis With Zhejiang Village Of Beijing and Shipai Area Of Guangzhou As Cases (woguo Dachengshi Liudong Renkou Jujuqu Chubu Yanjiu--Yi Beijing "ZhejiangCun" he Guangzhou Shipai Diqu Weili). Urban Population, 27(11), 60-66.

R.Skeldon. (1990). Population Mobility in Developing Countries. London: Belhaven Press.

Roberts, K. (2007). The Changing Profile of Chinese Labor Migration. In Z. Zhao \& F. Guo (Eds.), Transition and Challenge: China's population at the Beginning of the 21st Century (pp. 233-250). New York: Oxford University Press.

Roever, S. (2014). IEMS Sector Report: Street Vendors. Women in Informal Employment: Globalizing and Organizing.

Sauners, D. (2011). Arrival City: How the Largest Migration in History is Reshaping our world: Pantheon.

Sheller, M., \& Urry, J. (2006). The new mobilities paradigm. Environment and Planning A, 38(2), 207-226. 
Smith, D. (2002). Patterns and Processes of 'Studentification' in Leeds. Regional Reviews, 11, 1719.

Sonobe, T., Hu, D., \& Otsuka, K. (2004). From inferior to superior products: an inquiry into the Wenzhou model of industrial development in China. Journal of Comparative Economics, 32(3), 542-563. doi: 10.1016/j.jce.2004.05.001

Swanton, D. (2011). Assemblage and Critical Urban Praxis-Part Four. City: Analysis of Urban Trends, Culture, Theory, Policy, Action, 15(627-730).

Tasan-Kok, T., Kempen, R. v., Raco, M., \& Bolt, G. (2014). Towards Hyper-Diversified European Cities: A Critical Literature Review (F. o. Geosciences, Trans.). Utrecht: Utrecht University.

Teng, J. (2012). Social Networks and the Migration Decision: Evidence from China Retrieved Aug. 31, 2012, from http://www.eale.nl/conference2012/program/Papers\%20parallel\%20E/E07_Teng.pdf

Tomba, L. (1999). Explorting the "Wenzhou Model" to Beijing and Florence: Suggestions for A Comparative Perspective on Labour and Economic Organization in Two Migrant Communites. In F. N.Pieke \& H. Mallee (Eds.), Internal and International Migration: Chinese Perspectives. Richmond Surrey (London): Curzon Press.

Turner, J. (1968). Housing Priorities, Settlement Patterns and Urban Development in Modernizing Countries. Journal of American Institute of Planners, 24, 354-363.

UNDEA. (2013). Population Facts: The Number of International Migrants Worldwide reaches 232 million (D. o. E. a. S. A. P. Division, Trans.).

UNDEA, \& OECD. (2013). World Migration in Figures (D. o. E. a. S. A. P. Division \& O. f. E. C.-o. a. Development, Trans.).

UNDP. (2013). China Human Development Report. 2013: Sustainable and Liveable Cities: Toward Ecological Urbanisation:

English. Beijing: China Transition and Publishing Corporation.

Ureta, S. (2013). The Shelter that Wasn't There: On the Politics of Co-ordinating Multiple Urban Assemblages in Santiago, Chile. Urban Studies.

Venn, C. (2006). The City as Assemblage. Diasporic Cultures, Postmodern Spaces, and Bipolitics. In H. Berking, S. Frank, L. Frers, M. Low, L. Meier, S. Steets \& S. Stoetzer (Eds.), Negotiating Urban Confilits: Interaction, Space and Control (pp. 41-52): Transcript Verlag.

Wang, D., Li, F., \& Chai, Y. (2012). Activity Spaces and Sociospatial Segregation in Beijing. Urban Geography, 33(2), 256-277. doi: 10.2747/0272-3638.33.2.256 
Wang, Y. (2009). Wailai laodongli yu waizi dui Wenzhou jingji fazhan de youli yingxiang. [The Beneficial Influence of Floating Population and Foreign Investment on Wenzhou's Economic Development]. Rural Economic(10), 76-80.

Wang, Y., Wang, Y., \& Wu, J. (2009). Urbanization and Informal Development in China: Urban Villages in Shenzhen. International Journal of Urban and Regional Research, 33(4), 957973.

Wei, Y. (2007). Restructuring Industrial Districts, Scaling up Regional Development: A Study of the Wenzhou Model, China. Economic Geography, 83(4), 421-444.

Wei, Y. (2009). China's Shoe Manufacturing and the Wenzhou Model: Perspectives on the World's Leading Producer and Exporter of Footwear. Eurasian Geography and Economics, 50(6), 720-739. doi: 10.2747/1539-7216.50.6.720

Wei, Y. (2011). Beyong The GPN--New Regionalism Divide in China: Restructuring the Clothing Industry, Remaking the Wenzhou Model. Geografiska Annaler: Series B, Human Geography, 93(3), 237-251. doi: 10.1111/j.1468-0467.2011.00375.x

Willis, K. D. (2009). Squatter Settlements Retrieved 8/17, 2015, from https://pure.royalholloway.ac.uk/portal/files/1892862/Squatter_settlements.pdf

Willmore, L., Cao, G.-Y., \& Xin, L.-J. (2012). Determinants of off-farm work and temporary migration in China. Population \& Environment, 33(2), 161-185. doi: 10.1007/s11111011-0135-3

WMBS (Ed.). (2011). Wenzhou Statistical Yearbook: China Statistics Press.

Wu, F., Zhang, F., \& Webster, C. (2012). Informality and the Development and Demolition of Urban Villages in the Chinese Peri-urban Area. [10.1177/0042098012466600]. Urban Studies.

Wu, W. (2002). Migrant Housing in Urban China: Choices and Constraints. Urban Affairs Review, 38(1), 90-119.

Wu, W. (2004). Sources of Migrant Housing Disadvantage in Urban China. Environmental and Planning A, 36, 1285-1304.

Wu, W. (2005). Migrant Residential Distribution and Metropolitan Spatial Development in Shanghai. In L. J.C.Ma \& F. L. Wu (Eds.), Restructuring the Chinese City: Changing Society, Economy and Space (pp. 200-217). New York: Routledge.

Wu, W. (2006). Migrant Intra-urban Residential Mobility in Urban China. Housing Studies, 21(5), 745-765. doi: 10.1080/02673030600807506

Wu, W. (2008). Migrant Settlement and Spatial Distribution in Metropolitan Shanghai. The Professional Geographer, 60(1), 101-120. doi: 10.1080/00330120701724210 
Wu, W., \& Gaubatz, P. (2012). The Chinese City. London: Routledge.

Wu, W. P. (2002a). Temporary Migrants in Shanghai: Housing and Settlement Patterns. In J. R. Logan (Ed.), The New Chinese City: Globalization and Market Reform (pp. 212-226). New York: Blackwell.

Wu, X. (2003). "Bianyuan shequ" tainsuo. [An Investigation into Margoinal Community]. Planning Studies, 27(7), 40-45.

WZMPCO. (2013). Tabulation on the 2010 population census of Wenzhou municipality. Wenzhou: Wenzhou Municipal Population Census Office.

Xiang, B. (2005). Transcending Boundaries: Zhejiangcun: The Story of a Migrant Village in Beijing (J. Weldon, Trans.). Boston: Brill Academic Pub.

Xue, D., \& Huang, G. (2008). Regulation beyond formal regulation: Spatial gathering and surviving situation of the informal sectors in urban village case study in Xiadu Village of Guangzhou City. Geographical Research, 06.

Ye, X. Y., \& Wei, D. Y. H. (2005). Geospatial Analysis of Regional Development in China. Eurasian Geography and Ecnomics, 46, 445-446.

Yuan, Y., \& Xu, X. (2008). Residential Segregation of Floating Population and Driving Forces in Guangzhou City. [Guangzhoushi wailai renkou juzhu geli ji yingxiang yinsu]. Human Geography, 5(103), 1003-2398.

Zhang, L. (2001). Strangers in the City: Reconfigurations of Space, Power, and Social Networks. Stanford, CA: Stanford University Press.

Zhang, L. (2011). The political economy of informal settlements in post-socialist China: The case of chengzhongcun(s). Geoforum, 42(4), 473-483. doi: http://dx.doi.org/10.1016/j.geoforum.2011.03.003

Zhang, L., Zhao, S. X. B., \& Tian, J. P. (2003). Self-help in Housing and Chengzhongcun in China's Urbanization. International Journal of Urban and Regional Research, 27(4), 912-937.

Zhang, R. (1994). The Wenzhou Model. Zhejiang Xuekang [Journal of Zhejiang], 3, 21-28.

Zhang, Z. (1989). Wenzhou chao. [Peking] :: Wen hua yi shu chu ban she : Xin hua shu dian Beijing fa xing suo jing xiao.

Zhao, M. (2009). Analysis on the Features of Wenzhou City's Urban Morphology Evolution. Master of Science, Zhejiang University, Hangzhou.

Zhao, Y. (1999). Leaving the Countryside: Rural-To-Urban Migration Decisions in China. The American Economic Review, 89(2), 281-286. 
Zheng, S., Long, F., Fan, C. C., \& Gu, Y. (2009). Urban Villages in China: A 2008 Survey of Migrant Settlements in Beijing. Eurasian Geography and Ecnomic, 50(4), 425-446.

Zheng, S., Long, F., Fan, C. C., \& Gu, Y. (2009). Urban Villages in China: A 2008 Survey of Migrant Settlements in Beijing. Eurasian Geography and Economics,, 50(4), 425-446.

Zheng, Y. (2007). De facto Federalism in China: Reforms and Dynamics of Central-local Relations. Singapore: World Scientific Publishing.

Zhou, S., Wu, Z., \& Cheng, L. (2013). The Impact of Spatial Mismatch on Residents in Low-income Housing Neighbourhoods: A Study of the Guangzhou Metropolis, China. Urban Studies, 50(9), 1817-1835. doi: 10.1177/0042098012465906

Zhu, N., Luo, X., \& Zou, H.-f. (2012). Migration, Urbanization and City Growth in China, 2012, from http://down.aefweb.net/WorkingPapers/w545.pdf 